\title{
Integration Technologies for Rare-Earth Ion Doped Gain Materials on Glass
}

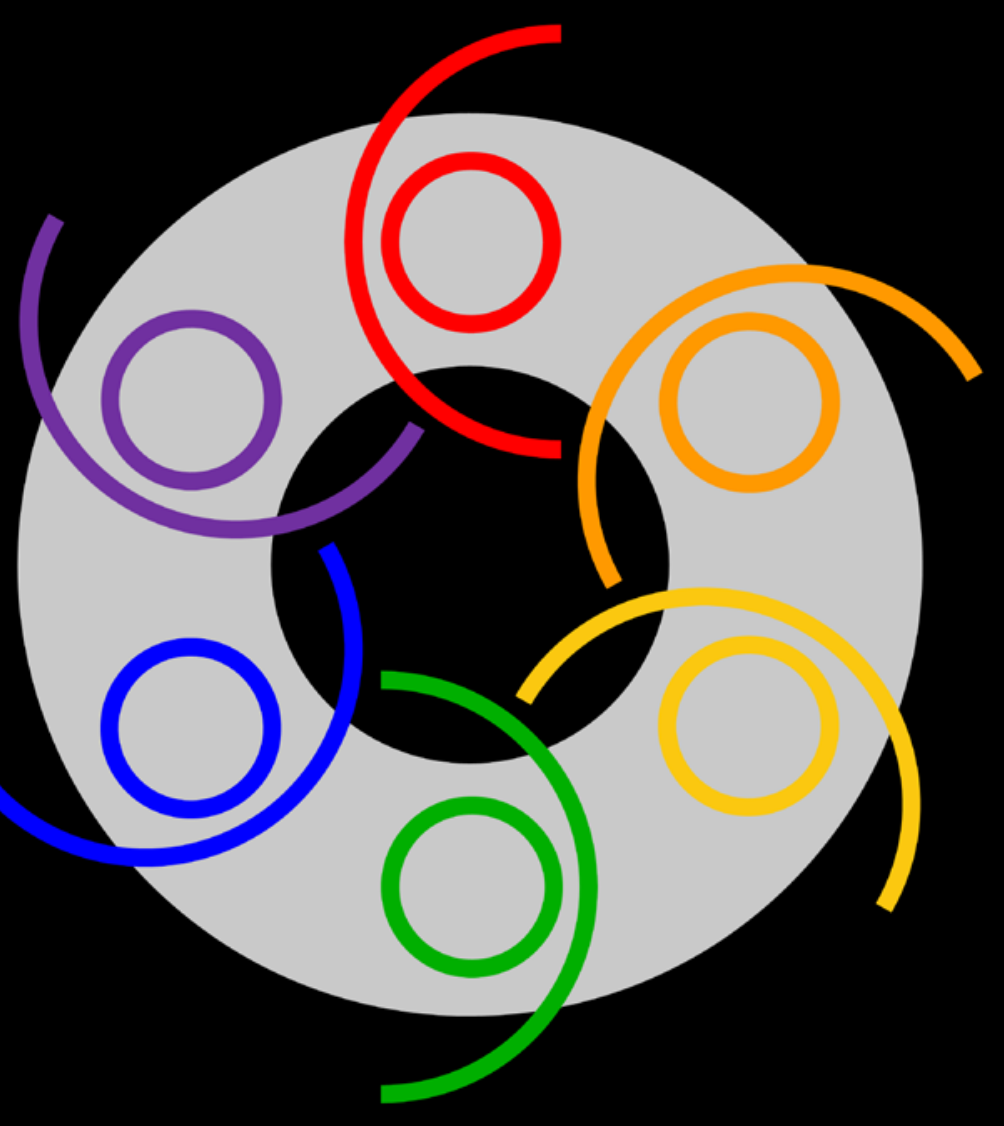

Carlijn Iris van Emmerik 



\section{INTEGRATION TECHNOLOGIES FOR RARE-EARTH ION DOPED GAIN MATERIALS ON GLASS}

Carlijn Iris van Emmerik 


\section{Graduation Committee:}

Chairman / secretary

Prof. dr. J.L. Herek

\section{Supervisor:}

Prof. dr. S.M. García Blanco

\section{Committee Members:}

Prof. dr. J.E. Broquin

Prof. dr. D. Marris-Morini

Prof. dr. L.K. Nanver

Prof. dr. A.J.H.M. Rijnders

Assoc. Prof. dr. A.Y. Kovalgin

Assoc. Prof. dr. H.L. Offerhaus
University of Twente

University of Twente

Grenoble Institute of Technology - Minatec

Université Paris Sud- Université Paris Saclay

Delft University of Technology

University of Twente

University of Twente

University of Twente

The research described in this thesis was carried out at the Optical Sciences (OS) group, Faculty of Science and Technology and MESA+ Institute for Nanotechnology, University of Twente. P.O. Box 217, 7500 AE Enschede, The Netherlands.

This project has received funding from the European Research Council (ERC) under the European Union's Horizon 2020 research and innovation program (No. 648978RENOS).

Cover $\quad$ : Art impression of different rare-earth ion doped ring lasers on a polishing disk. The bended bus waveguides represent the swirl of the suspension during lapping and polishing.

Printed by : Gildeprint

ISBN : 978-90-365-4877-9

(C) 2019 Carlijn Iris van Emmerik, The Netherlands

All rights reserved. No parts of this thesis may be reproduced, stored in a retrieval system or transmitted in any form or by any means without permission of the author. 


\title{
INTEGRATION TECHNOLOGIES FOR RARE-EARTH ION DOPED GAIN MATERIALS ON GLASS
}

\author{
DISSERTATION \\ to obtain \\ the degree of doctor at the Universiteit Twente, \\ on the authority of the rector magnificus, \\ Prof. dr. T.T.M. Palstra, \\ on account of the decision of the graduation committee \\ to be publicly defended \\ on Friday the $6^{\text {th }}$ of December 2019 at 10.45
}

by

\section{Carlijn Iris van Emmerik}

born on the $14^{\text {th }}$ of March 1991

in Hengelo, The Netherlands 
This dissertation has been approved by:

Prof. dr. S.M. García Blanco (Promotor) 


\section{Table of Contents}

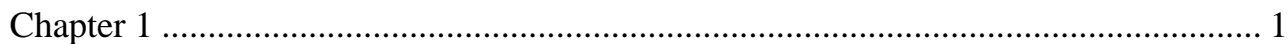

Integration of rare-earth ion doped gain materials on glass............................................. 1

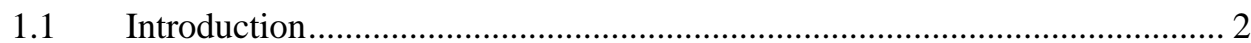

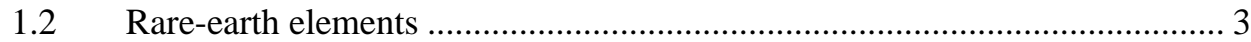

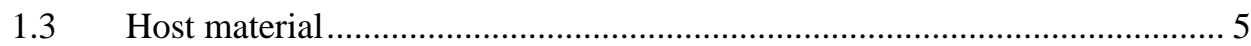

$1.4 \quad$ Host materials used in this work …........................................................... 7

1.5 State of the art integrated $\mathrm{KY}\left(\mathrm{WO}_{4}\right)_{2}$ lasers and amplifiers........................... 8

1.6 State of the art integrated $\mathrm{Al}_{2} \mathrm{O}_{3}$ lasers and amplifiers................................. 10

1.7 Specifications for the integration of rare-earth ion doped $\mathrm{KY}\left(\mathrm{WO}_{4}\right)_{2}$ and single-layer active-passive $\mathrm{Al}_{2} \mathrm{O}_{3}$ on glass................................................. 12

1.8 Outline of the thesis ..................................................................................... 13

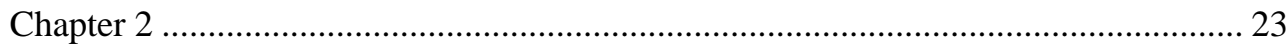

Heterogeneous integration of $\mathrm{KY}\left(\mathrm{WO}_{4}\right)_{2}$-on-glass: a bonding study ........................... 23

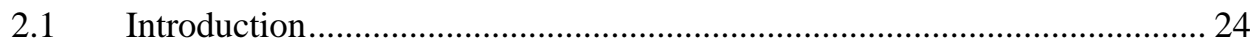

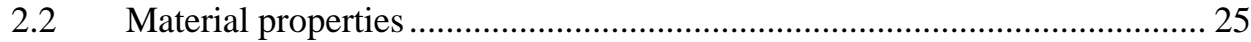

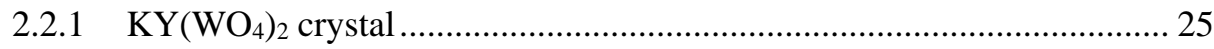

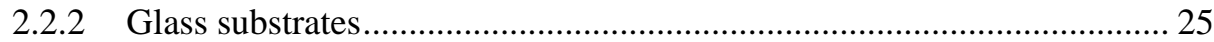

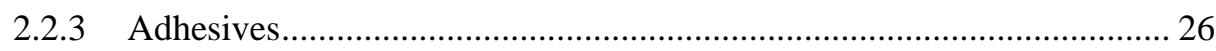

$2.3 \quad$ Bonding methodology .......................................................................... 27

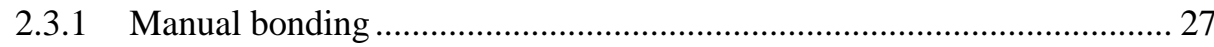

2.3.2 Bonding using a flip-chip bonder ........................................................... 28

2.3.3 Bonding using a flip-chip bonder and a substrate with pre-etched pillars 29

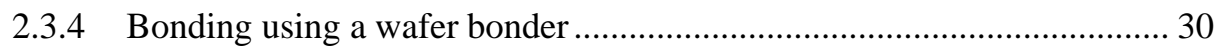

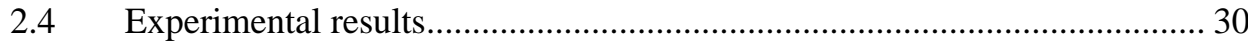

2.4.1 Bonding using low temperature adhesive .................................................. 30

2.4.2 Bonding using high temperature adhesive ................................................. 31

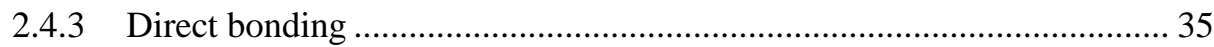

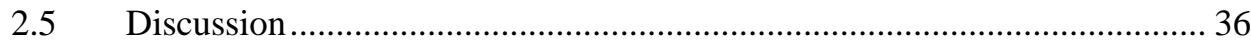




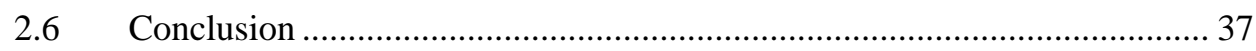

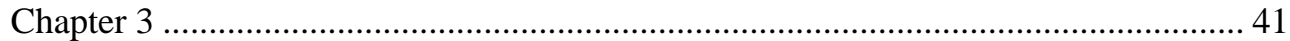

Lapping and polishing of crystalline $\mathrm{KY}\left(\mathrm{WO}_{4}\right)_{2}$ : toward high refractive index

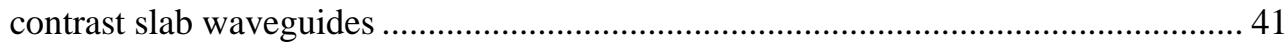

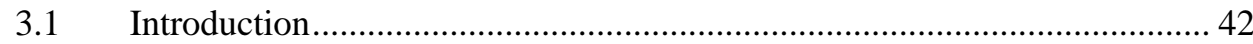

3.2 Preparation of $\mathrm{KY}\left(\mathrm{WO}_{4}\right)_{2}$-on-glass assemblies ....................................... 43

3.2.1 Three-grade beveled $\mathrm{KY}\left(\mathrm{WO}_{4}\right)_{2}$ edges....................................................... 43

3.2.2 Preparation of $\mathrm{KY}\left(\mathrm{WO}_{4}\right)_{2}$ assemblies..................................................... 46

3.3 Lapping and polishing equipment and consumables..................................... 47

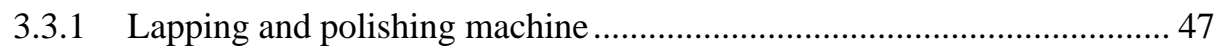

3.3.2 Lapping and polishing materials ................................................................ 49

3.3.3 Conditioning of cast iron and polyurethane disks..................................... 49

3.3.4 Overall lapping and polishing process description .................................... 52

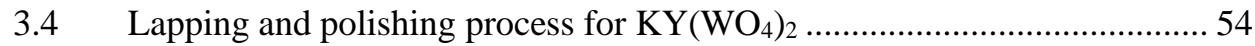

3.4.1 Lapping process for $\mathrm{KY}\left(\mathrm{WO}_{4}\right)_{2}$ layers ................................................... 54

3.4.2 Polishing process for $\mathrm{KY}\left(\mathrm{WO}_{4}\right)_{2}$ layers................................................. 55

$3.5 \quad$ Lapping towards thin layers ....................................................................... 59

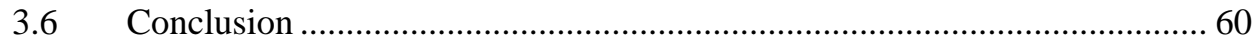

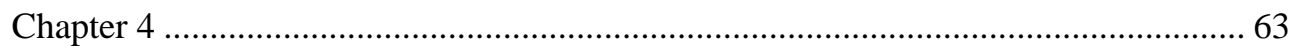

The influence of oxygen flow on the optical and material characteristics of RF

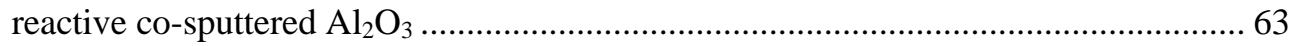

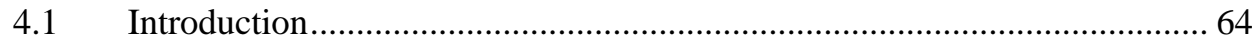

4.2 Hysteresis during reactive magnetron sputtering ....................................... 65

$4.3 \quad \mathrm{RF}$ reactive co-sputtering of $\mathrm{Al}_{2} \mathrm{O}_{3}$ layers: general description .................... 68

$4.4 \quad$ Influence of target erosion on process parameters .......................................... 70

4.5 Characterization of the sputtered $\mathrm{Al}_{2} \mathrm{O}_{3}$ films.............................................. 73

4.6 Effect of oxygen flow on the optical and morphological properties of the

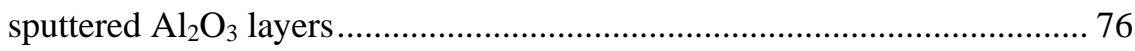

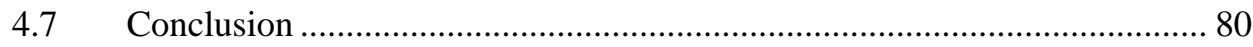


Chapter 5

Integration technologies for single-layer active-passive $\mathrm{Al}_{2} \mathrm{O}_{3}$

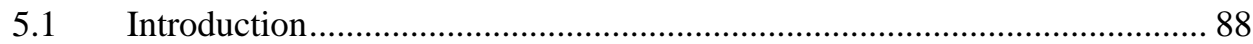

5.2 CMP assisted fabrication of single-layer active-passive $\mathrm{Al}_{2} \mathrm{O}_{3} \ldots \ldots \ldots \ldots . . . . . . . . .89$

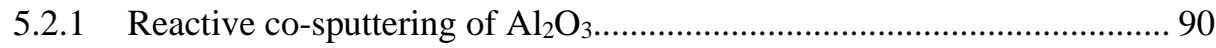

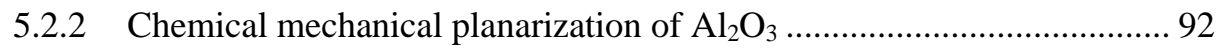

5.2.3 Demonstration of single-layer active-passive $\mathrm{Al}_{2} \mathrm{O}_{3}$............................. 93

5.3 Shadow mask assisted fabrication of single-layer active-passive $\mathrm{Al}_{2} \mathrm{O}_{3}$..... 94

5.3.1 Reactive co-sputtering using two shadow masks...................................... 95

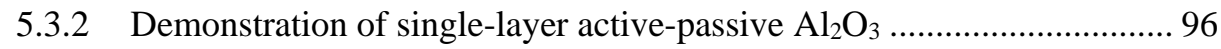

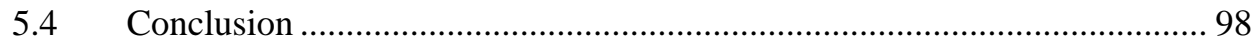

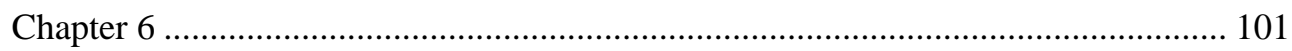

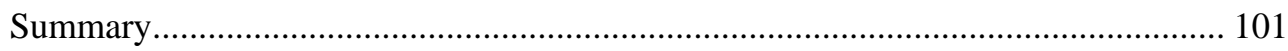

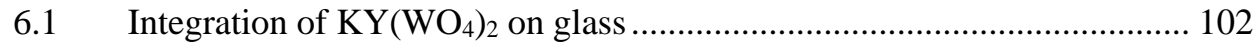

6.2 Integration of single-layer active-passive $\mathrm{Al}_{2} \mathrm{O}_{3}$ on glass .......................... 103

6.3 Recommendations for the heterogeneous integration of

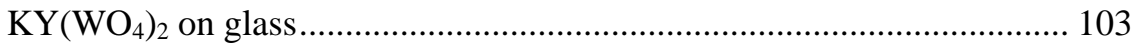

6.4 Recommendations for the integration of single-layer active-passive $\mathrm{Al}_{2} \mathrm{O}_{3}$ on glass .............................................................. 104

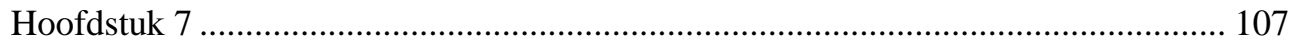

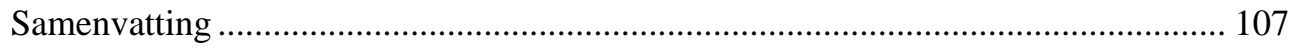

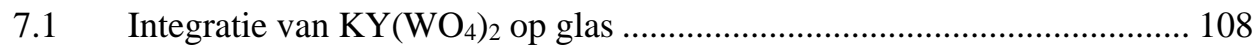

7.2 Integratie van enkele-laag actief-passief $\mathrm{Al}_{2} \mathrm{O}_{3}$ op glas ............................. 109

7.3 Aanbevelingen voor de heterogene integratie van $\mathrm{KY}\left(\mathrm{WO}_{4}\right)_{2}$ op glas ...... 109

7.4 Aanbevelingen voor de integratie van enkele-laag actief-passief

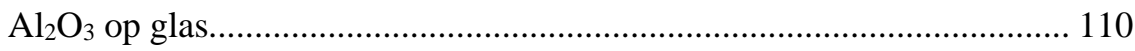

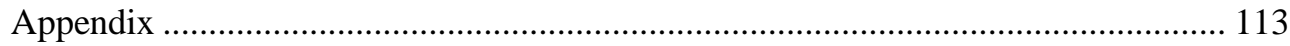

A. Influence of the deposition height on the uniformity of the $\mathrm{Al}_{2} \mathrm{O}_{3}$ layer ... 114

B. Planarization efficiency of $\mathrm{Al}_{2} \mathrm{O}_{3}$ regions for single-layer active-passive

$\mathrm{Al}_{2} \mathrm{O}_{3}$ integration 
C. Effect of wafer temperature on the optical properties of reactive co-sputtered $\mathrm{Al}_{2} \mathrm{O}_{3}$ layers.......................................................................... 117

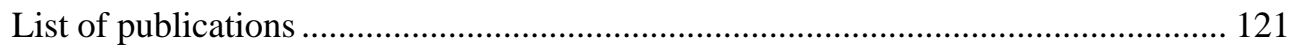

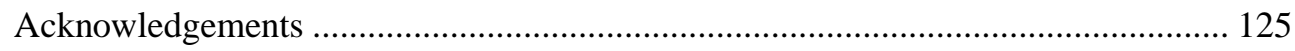




\section{Chapter 1}

\section{Integration of rare-earth ion doped gain materials on glass}

In this chapter, the interest in rare-earth ion doped gain materials for integrated photonics is described. Rare-earth ions are introduced and the influence of the host material on their luminescence properties is given, justifying the choice for crystalline $\mathrm{KY}\left(\mathrm{WO}_{4}\right)_{2}$ and amorphous $\mathrm{Al}_{2} \mathrm{O}_{3}$ as host materials in this work. An overview of the state of the art in the development of integrated lasers and amplifiers in both materials is given. Finally, the outline of the thesis is presented. 


\subsection{Introduction}

The field of integrated optics is mainly driven by the increasing demand on data traffic, speed and storage [1]. The data processing chips used in data centers and the devices that we use in our everyday life (i.e., computers, smartphones) still rely on electronic circuits, which soon will not be able to handle the ever increasing demands in bandwidth and speed in an power efficient manner [2,3] and photonic circuits can overcome those shortcomings $[4,5]$. The idea to route photons through an optical system in a way similar to the routing of electrons in an electronic system originates from 1969 [6]. Many research activities have been dedicated thereafter to develop compact, efficient, on-chip lasers, amplifiers, waveguides, modulators and detectors with a small footprint $[4,5]$ to realize and optimize this idea.

The well-defined emission wavelengths and long lifetimes of rare-earth ions are of great interest for telecommunications. The most widely applied device utilizing rareearth ions is the erbium-doped fiber amplifier (EDFA), established in 1987 [7,8]. This fiber became the workhorse in long-haul optical communications $[9,10]$. Afterwards fiber based Q-switched [11], mode-locked [12] and tunable lasers [13] were demonstrated.

Subsequently, researches were driven to convert the promising results obtained in fiber optics to integrated optics, which has the advantage of more compact devices and the ability to process many devices in a single substrate [14]. Examples of rare-earth ion doped integrated devices include waveguide amplifiers [15-19], lasers [20-22], modelocked lasers $[23,24]$ and Q-switched lasers $[25,26]$. Furthermore, the broadening of the emission band of rare-earth ions when doped in an amorphous host were used to further develop on-chip tunable lasers for, amongst others, sensing (i.e., gas [27,28] and biomolecules [29,30]) and spectroscopic [31] measurements.

Rare-earth ions exhibit narrow homogeneous linewidths and maintain long coherence times for both optical [32] and spin [33] transitions when doped in a crystalline hosts. Long storage time can be achieved with rare-earth ion doped materials [34,35]. These characteristics explain the extensive investigation into rare-earth ion doped crystals for classical information storage and processing based on atomic frequency combs [36] and quantum memories [37-39]. Furthermore, narrow linewidth lasing has been achieved in both amorphous (i.e., linewidth of $3 \mathrm{kHz}$ and $1.7 \mathrm{kHz}$ for respectively, erbium/ytterbium co-doped phosphate glass [40] and $\mathrm{Er}^{3+}: \mathrm{Al}_{2} \mathrm{O}_{3}$ [41] DFB lasers) and crystalline (i.e. linewidth of $37 \mathrm{~Hz}$ in $\mathrm{Er}^{3+}: \mathrm{Y}_{2} \mathrm{SiO}_{5}$ [33]) rare-earth ion doped materials. Recent work has demonstrated that heavily rare-earth ion doped potassium double tungstate (i.e., $\left.\mathrm{KRE}\left(\mathrm{WO}_{4}\right)_{2}, \mathrm{RE}=\mathrm{Yb}, \mathrm{Gd}, \mathrm{Lu}\right)$ can achieve large modal gain of $\sim 800$ $1000 \mathrm{~dB} / \mathrm{cm}[42,43]$, which is comparable to state of the art semiconductor devices. 
The complex devices necessary for applications (e.g., sensing, spectroscopy) should not be made solely out of rare-earth ion doped material because this will lead to low efficiency due to high reabsorption losses. Those devices have to be made out of an active (rare-earth ion doped) gain section and passive (undoped) guiding sections (e.g., $\mathrm{Si}, \mathrm{Si}_{3} \mathrm{~N}_{4}$ ) to reduce the pump power requirements to invert the gain section and to let the devices work at their full potential. An example is the integration of rare-earth ion doped aluminum oxide $\left(\mathrm{RE}^{3+}: \mathrm{Al}_{2} \mathrm{O}_{3}\right)$ with silicon nitride $\left(\mathrm{Si}_{3} \mathrm{~N}_{4}\right)$ [22,44-46]

This thesis focusses on the integration of rare-earth ion doped materials, in particular potassium yttrium double tungstate $\left(\mathrm{KY}\left(\mathrm{WO}_{4}\right)_{2}\right)$, and amorphous aluminum oxide $\left(\mathrm{Al}_{2} \mathrm{O}_{3}\right)$, on glasses. The research is performed in the Integrated Optical Sciences (IOS) group at the University of Twente. Devices with high gain [42,43,47], wide tunability $[48,49]$ and promising efficiency [50] in both materials were demonstrated in IOS and the former Integrated Optical Mirosystem (IOMS) Group. All fabrication stages are performed in the MESA+ Nanolab at the University of Twente.

\subsection{Rare-earth elements}

Rare-earth elements are listed in the periodic table with element number 21, 37 and 5771 (i.e., lanthanides) as shown in Fig. 1.1(a) [51]. The neutral lanthanides have a common electron configuration of $[\mathrm{Xe}] 4 \mathrm{f}^{\mathrm{n}} 6 \mathrm{~s}^{2}$ or $[\mathrm{Xe}] 4 \mathrm{f}^{\mathrm{n}-1} 5 \mathrm{~d}^{1} 6 \mathrm{~s}^{2}$, where [Xe] represents a Xenon core and $n$ the number of electrons in the $4 \mathrm{f}$ shell of the lanthanides (i.e., lanthanum $n=0$ to lutetium $n=14$ ). The ions occur mostly in the trivalent state, $R^{3+}$, in the host material (i.e., crystal, ceramic, glass) by giving up two loosely bond electrons from the outer 6 s shell and one electron from either the $5 \mathrm{~d}$ or $4 \mathrm{f}$ shell [52].

The trivalent ytterbium ion $\left(\mathrm{Yb}^{3+}\right)$ has 13 electrons in its $4 \mathrm{f}$ shell and has a simple energy level scheme. The energy levels in this scheme can be represented by the RussellSaunders notation ${ }^{2 \mathrm{~S}+1} \mathrm{LJ}$, where $\mathrm{S}$ is the total spin quantum number, $\mathrm{J}$ is the total angular momentum quantum number, and $\mathrm{L}$ is the orbital quantum number [53]. Following this notation, the upper state and the ground state manifold of $\mathrm{Yb}^{3+}$ can be presented by ${ }^{2} \mathrm{~F}_{5 / 2}$ and ${ }^{2} \mathrm{~F}_{7 / 2}$ respectively. The two energy states are split in, respectively, three and four Stark sub-levels (i.e., number of Stark levels is determined by $(2 \mathrm{~J}+1) / 2)$ due to the crystal field of the host material. Figure 1.1(b) shows the two-level energy diagram of $\mathrm{Yb}^{3+}$ when doped in a $\mathrm{KY}\left(\mathrm{WO}_{4}\right)_{2}$ crystal with its Stark levels. A possible energy transition is also illustrated in this figure. When the ytterbium ion absorbs the energy from a photon with a wavelength of $980 \mathrm{~nm}$, the ion promotes from the ground state ${ }^{2} \mathrm{~F}_{5 / 2}$ to the first, (0'), Stark sub-level of the upper ${ }^{2} \mathrm{~F}_{7 / 2}$ state, due to the fact that the energy of the photon at least equals the energy difference between those two levels. When the ion relaxes back from this state to the (2) Stark sub-level it emits a photon with a wavelength of $1025 \mathrm{~nm}$. 
The electrons in the $4 \mathrm{f}$ shell do not take part in the bonding of the rare-earth ion with the host material and they are well shielded by their optically passive outer, $5 \mathrm{~s}^{2}$ and $5 \mathrm{p}^{6}$, shells. The energy levels rare-earth ions are therefore largely insensitive to the host material in which they are placed [54-56].

The variety of rare-earth ions allows the emission from the ultra violet (UV) to infrared (IR) regime [52,54]. Table 1.1 shows a selection of emission wavelengths for rare-earth ions utilized for laser and amplifier applications.

(a)

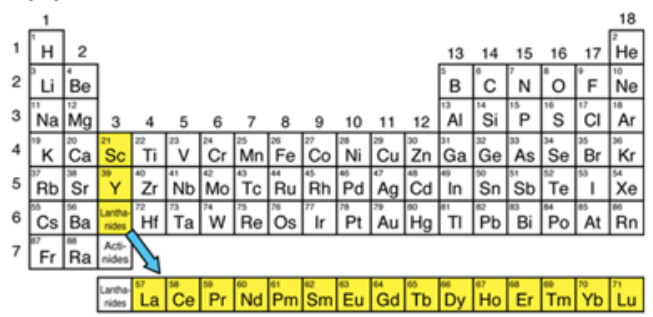

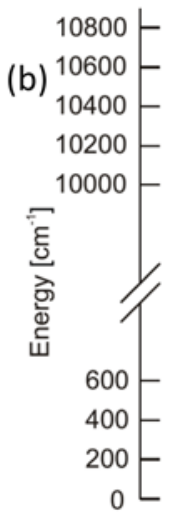

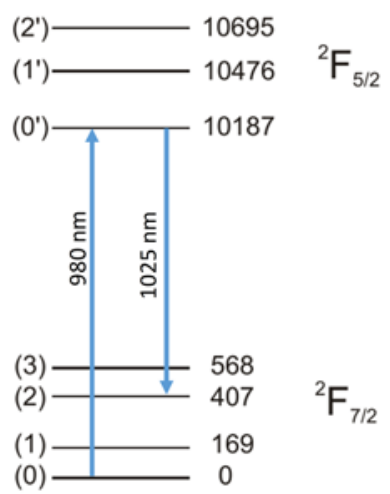

Fig. 1.1 (a) Periodic table indicating the rare-earth elements [57]. (b) Energy levels of $\mathrm{Yb}^{3+}$ ions in $\mathrm{Yb}^{3+}: \mathrm{KY}\left(\mathrm{WO}_{4}\right)_{2}$, and the usual pump and laser transitions [58]

Table 1.1 Selection of emission wavelengths of rare-earth ions in various host materials used for laser and amplifier devices.

\begin{tabular}{|l|l|l|}
\hline Ion & Emission wavelength $\mathbf{( \mu \mathbf { m } )}$ & References \\
\hline Erbium $\left(\mathbf{E r}^{3+}\right)$ & $1.5-1.6$ & {$[47,49,59-61]$} \\
\hline Ytterbium $\left(\mathbf{Y b}^{3+}\right)$ & $1.0-1.1$ & {$[43,48,62]$} \\
\hline Neodymium $\left.\mathbf{( N d}{ }^{3+}\right)$ & $0.88,1.06-1.10,1.33$ & {$[63-66]$} \\
\hline Thulium $\left(\mathbf{T m}^{3+}\right)$ & $1.8-2.0$ & {$[50,67-71]$} \\
\hline Holmium $\left.\mathbf{( \mathbf { H o } ^ { 3 + }}\right)$ & $2.0-2.1$ & {$[24,45,72-74]$} \\
\hline
\end{tabular}




\subsection{Host material}

Rare-earth ions can be hosted in different solid materials (i.e., polymer, glass, crystal). The type of host material is important to take into account during the design phase of onchip optical devices because the lattice of the material has influence on the spectral bandwidth and emission and absorption cross-sections of the relevant optical transitions (Table 1.2).

Rare-earth ions exhibit limited solubility. Beyond a critical concentration, rare-earth ions tend to form clusters of rare-earth ions [55]. Clustering of rare-earth ions is likely to occur in glasses and polymers due to their amorphous nature. Co-doping of silica glass with aluminum or phosphor act as a solvation shell for rare-earth ions and decreases the amount of rare-earth ion clusters in this material $[75,76]$.

Closely spaced or clustered ions tend to interact by transferring energy. This constitutes a loss mechanism as it allows for a non-radiative decay of the energy to the host lattice or a radiative decay at an undesired wavelength. Energy transfer, however, can be beneficial in pumping schemes in which a material is doped with different rareearth ions. The excitation of one type of ion is transferred to the other type, allowing a wider selection of pump sources to be used or a more efficient absorption of the pump. This mechanism is used, for example, in $\mathrm{Yb} / \mathrm{Er}[77,78]$ and Tm/Ho [74,79] co-doped host materials. Other examples of beneficial use of energy transfer process include the excited state absorption (ESA) in erbium doped materials, in which energy transfer from two photon absorption will populate the ${ }^{2} \mathrm{H}_{11 / 2}$ or ${ }^{4} \mathrm{~S}_{3 / 2}$ level of erbium for emission in the visible wavelength range [80], and the cross-relaxation process in thulium gain material, which leads to on-chip lasers with slope efficiencies of $80 \%$ [50]

Whereas clustering of rare-earth ions limits the operational concentration in glasses and polymers, it is often the mismatch in ionic radii between the rare-earth ion and the ion that will be replaced in the crystalline lattice that limits the maximum concentration in crystalline host materials [81]. This lattice mismatch causes stress in the crystal resulting in defects in the layer. Nevertheless, lasing operation in $100 \%$ doped $\mathrm{Yb}^{3+}: \mathrm{YAG}$ and $\mathrm{Yb}^{3+}: \mathrm{KY}\left(\mathrm{WO}_{4}\right)_{2}$ crystals has been demonstrated with a slope efficiency of $27 \%$ and $44 \%$, respectively [82,83]. The performance of those heavily doped crystals is limited due to heat generating processes caused by the energy-transfer processes from $\mathrm{Tm}^{3+}, \mathrm{Er}^{3+}, \mathrm{Ho}^{3+}$ impurities [84]. Short pump-pulse operation was needed to minimize the thermal effects in the $\mathrm{KYb}\left(\mathrm{WO}_{4}\right)_{2}$ crystal [83].

The emission spectrum of the rare-earth ions is affected by the splitting and shifting of the energy levels due to the presence of an electric field in the host material, the so called Stark splitting (i.e., homogeneous broadening). Stark splitting is the main broadening system in crystalline hosts, which leads to sharp emission lines (Fig. 
1.2(a)) [85,86]. Broad emission spectra are obtained in rare-earth ion doped glasses (Fig. 1.2(b)) and polymers due to homogeneous and inhomogeneous broadening of the energy levels [49,87].

The narrow emission lines of rare-earth ion doped crystalline material, in combination with their high emission and absorption cross-sections for rare-earth ions doped in the crystal (i.e. roughly a magnitude higher than for rare-earth ions doped in amorphous host materials (Fig. 1.2(a,b)), are an advantage for high stability, narrowband amplification [43] and lasing [21,63,88] applications while the broad smooth emission spectrum in doped amorphous materials affords relatively flat gain, which is advantageous for tunable laser applications [89] and broadband amplifiers [49,90].
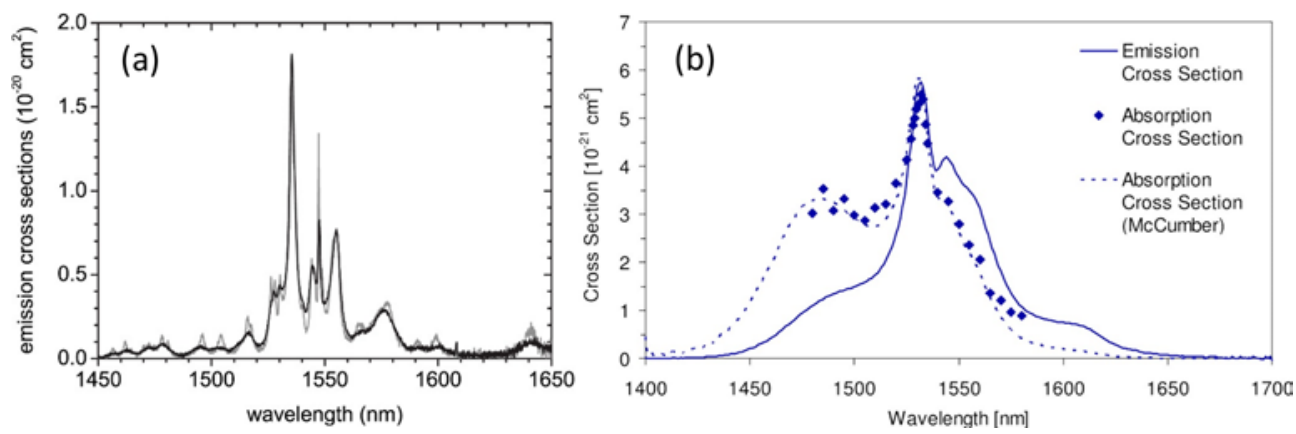

Fig. 1.2 (a) Emission cross-sections of crystalline Er:(Gd,Lu) ${ }_{2} \mathrm{O}_{3}$ film (black curve) and an Er: $\mathrm{Y}_{2} \mathrm{O}_{3}$ bulk crystal (gray curve) [86]. (b) Emission and absorption cross-section of amorphous $\mathrm{Er} \mathrm{Al}_{2} \mathrm{O}_{3}$ thin film [49].

Laser and amplifier devices based on polymers are often fabricated using spincoating [20,64]. This fabrication method leads to low fabrication costs. One of the main concerns in the laser performance of polymer lasers is the degradation or even damage induced by photo-oxidation effects and temperature increase in the gain section during pumping [20,90]. These disadvantages are avoided by using glasses as host material. They have often a higher thermal stability and they can be deposited on a wide range of substrates at the wafer level. An advantage of crystalline materials over glasses is their high thermal conductivity [91,92], which makes them suitable for efficient high power lasers. A drawback for dielectric laser crystals in integrated optical systems is that they have to be epitaxially grown on a lattice matched substrate, which result in low index contrast between the waveguide core and cladding $\left(\Delta \mathrm{n} \sim 10^{-2}\right.$ [75] [93-96]). 
Table 1.2 Integrated optical host materials for rare-earth ions [18]

\begin{tabular}{|c|c|c|c|c|}
\hline Host type & Category & Examples & Advantage & Disadvantage \\
\hline \multirow[t]{2}{*}{ Amorphous } & Glass & $\begin{array}{l}\text { a- } \mathrm{Al}_{2} \mathrm{O}_{3} \\
\text { Bismuthate glass } \\
\text { Fluoride glass } \\
\text { Phosphate glass } \\
\text { Silicate glass }\end{array}$ & $\begin{array}{l}\text { Broad emission spectrum; } \\
\text { High stability; } \\
\text { Deposition on a variety of } \\
\text { substrates; } \\
\text { Optically isotropic }\end{array}$ & $\begin{array}{l}\text { Low refractive index } \\
\text { contrast }\end{array}$ \\
\hline & Polymer & $\begin{array}{l}\text { Fluorinated- } \\
\text { dianhydride/epoxy } \\
\text { PMMA } \\
\text { PPMA }\end{array}$ & $\begin{array}{l}\text { Broad emission spectrum; } \\
\text { Low cost; } \\
\text { Deposition on a variety of } \\
\text { substrates }\end{array}$ & $\begin{array}{l}\text { Thermal instability; } \\
\text { Color centers }\end{array}$ \\
\hline Crystalline & Dielectric & $\begin{array}{l}(\mathrm{Gd}, \mathrm{Lu})_{2} \mathrm{O}_{3} \\
\mathrm{KY}\left(\mathrm{WO}_{4}\right)_{2} \\
\mathrm{LiNbO}_{3} \\
\mathrm{Y}_{3} \mathrm{Al}_{5} \mathrm{O}_{12} \\
\mathrm{YAlO}_{3} \\
\mathrm{Y}_{2} \mathrm{O}_{3} \\
\mathrm{Er}_{3}\left(\mathrm{SiO}_{4}\right)_{2} \mathrm{Cl}\end{array}$ & $\begin{array}{l}\text { High emission and } \\
\text { absorption cross-sections; } \\
\text { Highly stable output } \\
\text { (lasers); } \\
\text { High thermal conductivity }\end{array}$ & $\begin{array}{l}\text { Narrow wavelength } \\
\text { range (for amplifiers or } \\
\text { tunable lasers); } \\
\text { Epitaxial growth on } \\
\text { specific substrates } \\
\text { required }\end{array}$ \\
\hline
\end{tabular}

\subsection{Host materials used in this work}

The goal of this project is to integrate rare-earth ion doped gain materials on glass substrates, where the glass substrate mimics the integration on wafers with a buffer layer of glass (e.g., SOI, $\mathrm{SiN}_{\mathrm{x}}$, silica on silicon), to enable small, (power) efficient, tunable lasers and amplifiers. Both a crystalline host material, $\mathrm{KY}\left(\mathrm{WO}_{4}\right)_{2}$, as well as an amorphous host material, $\mathrm{a}-\mathrm{Al}_{2} \mathrm{O}_{3}$, were investigated.

Monolithic, rare-earth ion doped potassium yttrium double tungstate, $\mathrm{RE}^{3+}: \mathrm{KY}\left(\mathrm{WO}_{4}\right)_{2}$, is a promising candidate for active on-chip devices. The crystal has a high refractive index of $\mathrm{n} \sim 2$ at $1550 \mathrm{~nm}$ and a wide transparency window (350$5400 \mathrm{~nm}$ ) [97,98]. Its gain bandwidth is relatively large compared to doped YAG crystals [99] and $\mathrm{KY}\left(\mathrm{WO}_{4}\right)_{2}$ can compete with glass lasers in terms of tunability $[48,49]$. $\mathrm{KY}\left(\mathrm{WO}_{4}\right)_{2}$ has the advantage of a high emission and absorption cross-section $\left(\sigma_{\mathrm{em}} \sim 1.3 \times 10^{-19} \mathrm{~cm}^{2}[100]\right)$ for rare-earth ions doped into the material, compared to glasses (e.g., $\sigma_{\mathrm{em}} \sim 5-8 \times 10^{-21} \mathrm{~cm}^{2}$ for $\mathrm{Al}_{2} \mathrm{O}_{3}$ and phosphate glasses [49,101]). This crystal has a conductivity of $\kappa \sim 3.3 \mathrm{~W} / \mathrm{mK}$ [92], which is comparable to other laser crystals (i.e., $\kappa \sim 5-11 \mathrm{~W} / \mathrm{mK}$ for YLF, LuAG, YAG [102]) and fairly large compared to the conductivity of different glass types (i.e., $\kappa \sim 10^{-2} \mathrm{~W} / \mathrm{mK}$ for fluoride, chalcogenide and silicate glasses [91]) used for laser applications.

Aluminum oxide, $\mathrm{Al}_{2} \mathrm{O}_{3}$, is chosen as amorphous host material for rare-earth ions. $\mathrm{Al}_{2} \mathrm{O}_{3}$ has a higher refractive index ( $\mathrm{n} \sim 1.65$ at $633 \mathrm{~nm}[103,104]$ ), compared to other glasses ( $\mathrm{n} \sim 1.45$ for silica glasses) leading to greater integration density. It also exhibits 
a wide transparency window (150-5500 nm [105]). This material is an excellent host due to the many bonding sites available for the trivalent rare-earth ions [18]. Amorphous $\mathrm{Al}_{2} \mathrm{O}_{3}$ has the ability to be doped with high concentrations of rare-earth ions in comparison to $\mathrm{Si}$ and $\mathrm{Si}_{3} \mathrm{~N}_{4}$ [106,107] and other silica based glasses [55]. Only moderate luminescence quenching is observed for amorphous $\mathrm{Al}_{2} \mathrm{O}_{3}$ with high concentrations of rare-earth ions $\left(\sim 2 \times 10^{20} \mathrm{~cm}^{3} \mathrm{Er}^{3+}: \mathrm{Al}_{2} \mathrm{O}_{3}\right) \quad[19,108]$. The material can be fabricated with low planar waveguide losses (i.e., $0.12 \pm 0.02 \mathrm{~dB} / \mathrm{cm}$ at $1523 \mathrm{~nm}[109,110]$ and $0.04 \pm 0.02 \mathrm{~dB} / \mathrm{cm}$ [111] fabricated with $\mathrm{RF}$ reactive sputtering and atomic layer deposition, respectively) and low waveguide losses (i.e., $0.60 \pm 0.04 \mathrm{~dB} / \mathrm{cm}$ for rib waveguides at $1550 \mathrm{~nm}$ [29]). Those material and fabrication properties make amorphous $\mathrm{Al}_{2} \mathrm{O}_{3}$ an attractive material for UV, visible, near- and mid-IR on-chip active devices $[65,112,113]$.

\subsection{State of the art integrated $\mathrm{KY}\left(\mathrm{WO}_{4}\right)_{2}$ lasers and amplifiers}

The refractive index contrast between the waveguide core and the surrounding cladding plays an important role in the reduction of the waveguide cross-section. Small waveguides contribute to a better overlap between the pump and signal wavelength and they will enable the development of compact, power efficient, active micro devices. This section gives an overview of different fabrication methods for waveguides structures in $\mathrm{KY}\left(\mathrm{WO}_{4}\right)_{2}$ that have been developed over the past two decades.

Type II femtosecond laser written waveguide devices (i.e., decreased refractive index in the irradiated regions [114]) have been demonstrated in $\mathrm{KY}\left(\mathrm{WO}_{4}\right)_{2}$ and $\mathrm{KGd}\left(\mathrm{WO}_{4}\right)_{2}$ [115-117]. The mode field diameter for single mode guiding is in the order of a couple of tens of micrometers, for light with a wavelength around $\sim 1 \mu \mathrm{m}$. The large mode field diameter is caused by the low refractive index contrast $\Delta \mathrm{n} \sim 10^{-3}$ [117]. Waveguide losses of $\sim 2 \mathrm{~dB} / \mathrm{cm}$ at $\sim 1 \mu \mathrm{m}[115,117]$ and $1.8 \mathrm{~dB} / \mathrm{cm}$ at $1.6 \mu \mathrm{m}$ [116] have been demonstrated in these devices.

Another way to create a refractive index contrast is the growth of a doped $\mathrm{KY}\left(\mathrm{WO}_{4}\right)_{2}$ layer onto an undoped seed crystal using liquid phase epitaxy (LPE). Lattice engineering is required to obtain defect free doped $\mathrm{KY}\left(\mathrm{WO}_{4}\right)_{2}$ layers $[93,94]$ lattice matched to the undoped substrate and with the desired refractive index and rare-earth ion doping concentration. The waveguide structures are defined by $\mathrm{Ar}^{+}$beam etching in the doped layers (Fig. 1.3(a)) and they are overgrown with an undoped $\mathrm{KY}\left(\mathrm{WO}_{4}\right)_{2}$ layer. This type of devices have a refractive index contrast of $\Delta \mathrm{n} \sim 10^{-2}$ [93,94]. Rib waveguides with cross-sections of several micrometers in horizontal and vertical direction are made in those layers, as shown in Fig. 1.3(b). Low losses of $<0.34 \mathrm{~dB} / \mathrm{cm}$ at $1023 \mathrm{~nm}$ were 
obtained from the structure shown in Fig 1.3(a) [118] when overgrown with an undoped $\mathrm{KY}\left(\mathrm{WO}_{4}\right)_{2}$ layer. Waveguide lasers with high slope efficiency and high output power (i.e., $\eta \sim 80 \%$, $\mathrm{P}_{\text {out }} \sim 1.6 \mathrm{~W}$ ) at a wavelength of $1.84 \mu \mathrm{m}$ [50] as well as widely tunable (i.e., $65 \mathrm{~nm}$ ) lasers at $\sim 1 \mu \mathrm{m}$ wavelength $[48,118]$ have been demonstrated. And a similar slope efficiency (i.e., $~ 82.6 \%$ ) have been demonstrated at a wavelength of $1.84 \mu \mathrm{m}$ for waveguides fabricated in doped $\mathrm{KY}\left(\mathrm{WO}_{4}\right)_{2}$ layers, grown by LPE, with precise diamond blade dicing [119]. Exploiting the high solubility of rare-earth ions in $\mathrm{KY}\left(\mathrm{WO}_{4}\right)_{2}$ without clustering together with the two level energy scheme of $\mathrm{Yb}^{3+}$, resulted in the demonstration of very high optical gain $(\sim 800-1000 \mathrm{~dB} / \mathrm{cm})$ at $1 \mu \mathrm{m}$ of wavelength in highly doped $\mathrm{Yb}^{3+}: \mathrm{KY}\left(\mathrm{WO}_{4}\right)_{2}$ waveguide amplifiers [42,43].

(a)

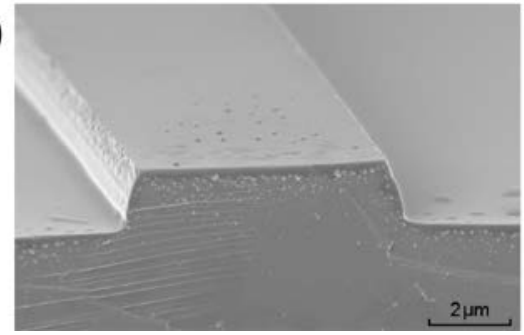

Fig. $\quad 1.3 \quad$ (a) Scanning electron (b)

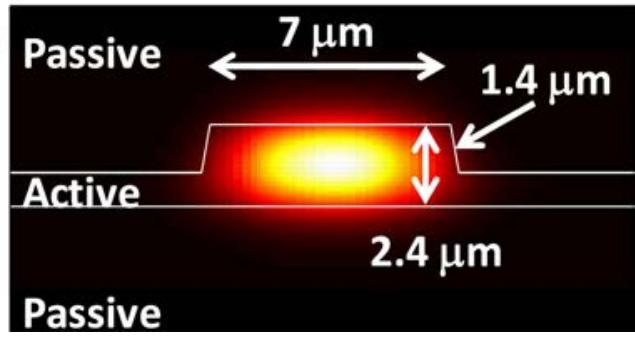

microscope (SEM) image of a $\mathrm{KY}_{0.40} \mathrm{Gd}_{0.433} \mathrm{Lu}_{0.150} \mathrm{Yb}_{0.017}\left(\mathrm{WO}_{4}\right)_{2}$ layer grown by LPE and etched with $\mathrm{Ar}^{+}$beam etching without overgrowth [118]. (b) Optical TE mode profile for such a waveguide made for operation at a wavelength of $981 \mathrm{~nm}$ [21].

Carbon swift heavy ion irradiation is another method to obtain even higher refractive index contrast in a $\mathrm{KY}\left(\mathrm{WO}_{4}\right)_{2}$ layer. Carbon ions are accelerated with an energy of $9 \mathrm{MeV}$ and a fluence of $3 \cdot 10^{14}$ ions $/ \mathrm{cm}^{2}$ towards the $\mathrm{KY}\left(\mathrm{WO}_{4}\right)_{2}$ surface to induce damage in the crystal. This damage is caused by ionization effects and ballistic interaction of the high energy ions with the material. The electron and ballistic damage cause amorphization in the crystal when the energy deposited by the irradiation surpasses the ionization threshold of $\mathrm{KY}\left(\mathrm{WO}_{4}\right)_{2}$ [120]. The crystal structure at the surface of the crystal is then partially repaired by annealing (i.e., at $350{ }^{\circ} \mathrm{C}$ for 3 hours), which sharpens the refractive index boundary and reduces the propagation losses. The final slab layer is $\sim 1 \mu \mathrm{m}$ thick and it has a refractive index contrast of $\sim 0.15$ with respect to the amorphous region. Optical slab propagation losses below $1.5 \mathrm{~dB} / \mathrm{cm}$ at $1550 \mathrm{~nm}$ have been measured [121]. This type of $\mathrm{KY}\left(\mathrm{WO}_{4}\right)_{2}$ irradiated layers have, thereafter, been used for the fabrication of high-refractive index pedestal structures [122].

A different approach to attain high-contrast $\mathrm{KY}\left(\mathrm{WO}_{4}\right)_{2}$ waveguide devices is demonstrated by Medina et al. [123] and Sefunç et al. [124]. The $\mathrm{KY}\left(\mathrm{WO}_{4}\right)_{2}$, or $\mathrm{KLu}\left(\mathrm{WO}_{4}\right)_{2}$ for the first study, crystals were heterogeneously integrated on a $\mathrm{SiO}_{2}$ substrate with an optical adhesive to create an high refractive index contrast between the 
crystal and substrate (i.e., $\Delta \mathrm{n} \sim 0.4$ ). The first study demonstrated tapered waveguides made by ultraprecise dicing and reactive ion etching (RIE) as thinning step. Those tapers with a total length of $8 \mathrm{~mm}$ had a waveguide width and height of respectively, $20 \mu \mathrm{m}$ and $0.8 \mu \mathrm{m}$ and are used for optical sensing applications [125]. The latter study developed an extensive lapping and polishing process to thin the original layer $\left(10 \times 10 \times 1 \mathrm{~mm}^{3}\right)$ down to $\sim 2.4 \mu \mathrm{m}$ where after waveguides, with a total length of 200$300 \mu \mathrm{m}$, were fabricated using focus ion beam milling (FIB). The final waveguide dimensions are shown in Fig. 1.4(a). The high refractive index contrast between the $\mathrm{KY}\left(\mathrm{WO}_{4}\right)_{2}$ and air of $\sim 0.45$, makes small waveguide dimension possible. The high mode confinement for the fundamental TE mode in the waveguide cross-section at $1550 \mathrm{~nm}$ is shown in Fig. 1.4(b). The channel waveguide losses are characterized to be $<1.5 \mathrm{~dB} / \mathrm{cm}$ at $1550 \mathrm{~nm}$.

(a)

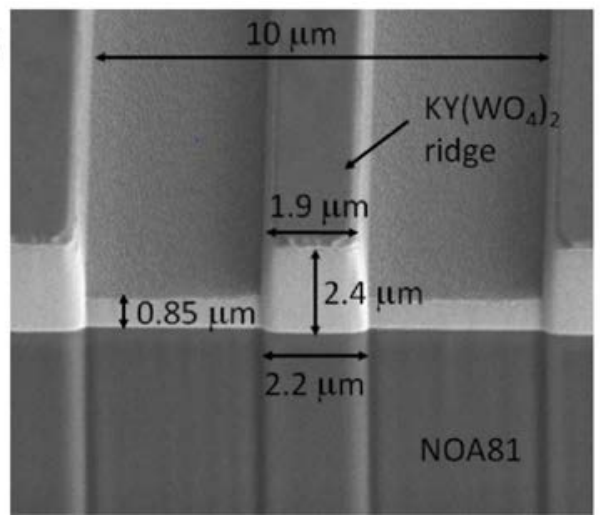

(b)

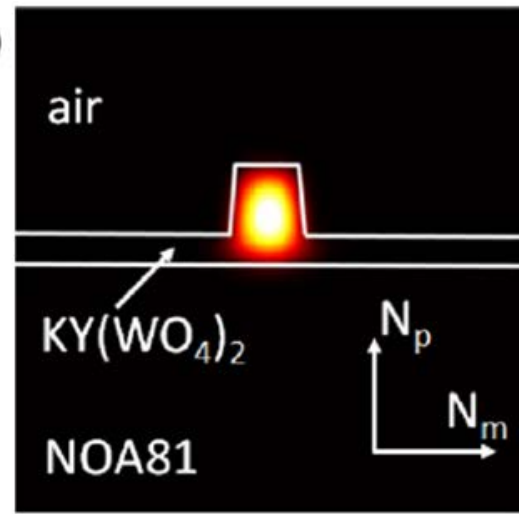

Fig. 1.4 (a) SEM image of the cross-section of a FIB milled $\mathrm{KY}\left(\mathrm{WO}_{4}\right)_{2}$ rib waveguide.

(b) Optical TE mode profile at the at a wavelength of $1550 \mathrm{~nm}$ [124].

\subsection{State of the art integrated $\mathrm{Al}_{2} \mathrm{O}_{3}$ lasers and amplifiers}

Rare-earth ion doped $\mathrm{Al}_{2} \mathrm{O}_{3}$ waveguide amplifiers with a wide gain bandwidth [49] and high net gain [19] have been demonstrated over the past years. Peak gains of $1.57 \mathrm{~dB} / \mathrm{cm}$ at $880 \mathrm{~nm}$ (i.e. $\mathrm{Nd}^{3+}: \mathrm{Al}_{2} \mathrm{O}_{3}$ [65]) and $2.0 \mathrm{~dB} / \mathrm{cm}$ at $1533 \mathrm{~nm}$ (i.e. $\mathrm{Er}^{3+}: \mathrm{Al}_{2} \mathrm{O}_{3}$ [49]) are demonstrated for straight $\mathrm{Al}_{2} \mathrm{O}_{3}$ waveguide amplifiers deposited by radio frequency (RF) reactive co-sputtering [109]. Internal net gain of $20 \mathrm{~dB}$ is shown for $12.9 \mathrm{~cm}$ and $24.4 \mathrm{~cm}$ long spiral $\mathrm{Er}^{3+}: \mathrm{Al}_{2} \mathrm{O}_{3}$ waveguides with concentrations of $1.92 \times 10^{-20} \mathrm{~cm}^{-3}$ and $0.95 \times 10^{-20} \mathrm{~cm}^{-3}$, respectively [19]. A terrific net modal gain of $20.1 \pm 7.31 \mathrm{~dB} / \mathrm{cm}$ is achieved in $\mathrm{Er}^{3+}: \mathrm{Al}_{2} \mathrm{O}_{3}$ hybrid slot waveguides of $250 \mu \mathrm{m}$ length [126]. The rare-earth ion doped layer is deposited with atomic layer deposition in this research, which allows 
precise control over the rare-earth ion concentration (i.e., $\mathrm{Er}^{3+}$ concentration of $\sim 0.49 \times 10^{20} \mathrm{~cm}^{-3}$ ). However, the overall net gain was only $1.40 \mathrm{~dB}$ due to the short waveguide length. Furthermore, ALD are limited by their low growth rate for wafer scale $\mathrm{Al}_{2} \mathrm{O}_{3}$ layers [111,127] whereas $\mathrm{RF}$ reactive magnetron sputtering is suitable for wafer scale deposition.

Several type of lasers have been demonstrated using $\mathrm{RE}^{3+}: \mathrm{Al}_{2} \mathrm{O}_{3}$ as gain material. Channel $\mathrm{RE}^{3+}: \mathrm{Al}_{2} \mathrm{O}_{3}$ distributed feedback (DFB) lasers [128] and distributed Bragg reflector (DBR) lasers $[129,130]$ are an example of them. These type of lasers are also demonstrated by integration of a $\mathrm{RE}^{3+}: \mathrm{Al}_{2} \mathrm{O}_{3}$ layer on top of $\mathrm{Si}_{3} \mathrm{~N}_{4}$ structures (Fig. 1.5(a)) (DFB lasers [45,113,131], DBR lasers [132-135]). The light in those devices is guided through the passive $\mathrm{Si}_{3} \mathrm{~N}_{4}$ waveguides and is evanescently coupled to the gain section on top (Fig. 1.5(b)). Rare-earth ion doped $\mathrm{Al}_{2} \mathrm{O}_{3}$ can also potentially be integrated with ion exchanged glass waveguides [136-138] for laser and amplifier applications.

(a)

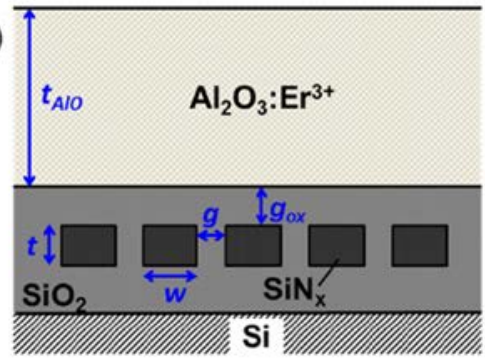

(b)

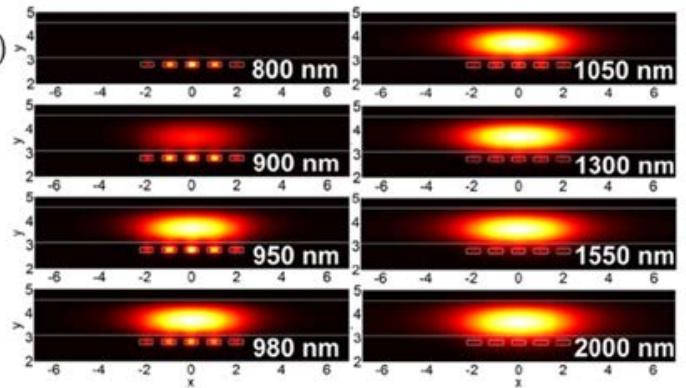

Fig. 1.5 (a) Schematic of wavelength-insensitive laser waveguide design by multisegmented $\mathrm{SiN}_{\mathrm{x}}$ structure. (b) Mode-solver calculation of the intensity distribution for various near infrared wavelengths in the multi-segmented waveguide design [113].

Ring lasers with $\mathrm{RE}^{3+}: \mathrm{Al}_{2} \mathrm{O}_{3}$ gain sections have been fabricated by a damascene process above $\mathrm{Si}_{3} \mathrm{~N}_{4}$ ring resonator $[22,68,89,139]$ or as cladding on top of a $\mathrm{Si}$ ring resonator [140]. In this process, doped $\mathrm{Al}_{2} \mathrm{O}_{3}$ material is deposited in a trench etched in the $\mathrm{SiO}_{2}$ substrate (Fig. 1.6(a)). The light is, in this example, guided through the passive $\mathrm{Si}_{3} \mathrm{~N}_{4}$ waveguide structure and evanescently coupled to the $\mathrm{RE}^{3+}: \mathrm{Al}_{2} \mathrm{O}_{3}$ gain section.

Alternatively, devices with subsequently active and passive waveguides have been developed. The light is coupled back and forwards between the passive and active waveguide through adiabatic taper transitions (Fig. 1.6(b)) [46,141]. The damascene process and the adiabatic transition between passive $\mathrm{Si}_{3} \mathrm{~N}_{4}$ Vernier structures and active $\mathrm{Er}^{3+}: \mathrm{Al}_{2} \mathrm{O}_{3}$ gain section are used to demonstrate CMOS-compatible widely tunable lasers on a silicon photonics platform [89]. 

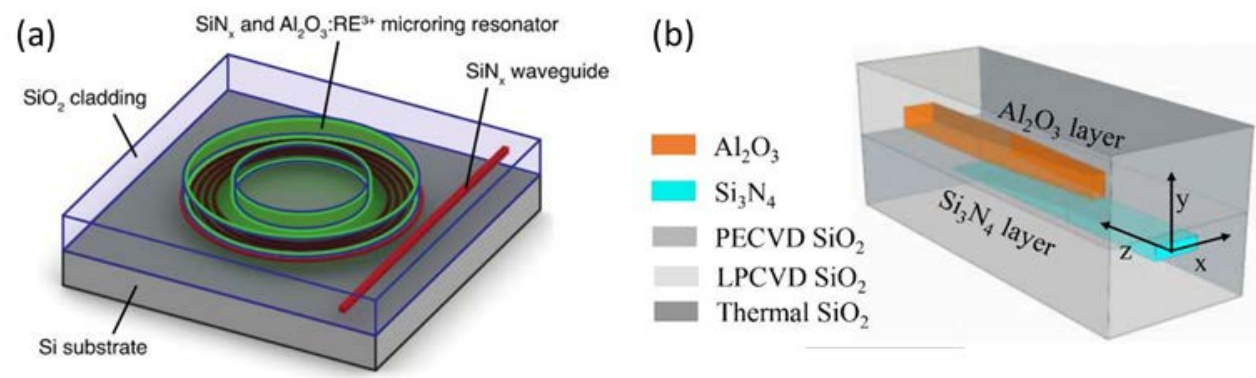

Fig. 1.6 (a) Illustration of the resulting monolithic rare-earth ion doped microring laser structure [22], (b) 3D schematic of the coupling section of the double-layer $\mathrm{Al}_{2} \mathrm{O}_{3}$ and $\mathrm{Si}_{3} \mathrm{~N}_{4}$ photonic platform [141].

Furthermore, $\mathrm{Al}_{2} \mathrm{O}_{3}$ has been doped with various rare-earth ions and lasing at many different wavelengths has been shown, including $\sim 0.88$, $\sim 1.06$ and $\sim 1.33 \mu \mathrm{m}$ (i.e., $\mathrm{Nd}^{3+}: \mathrm{Al}_{2} \mathrm{O}_{3}$ ) [65], $\quad \sim 1.03 \mu \mathrm{m}$ (i.e., $\mathrm{Yb}^{3+}: \mathrm{Al}_{2} \mathrm{O}_{3}$ ) [22], $\quad \sim 1.55 \mu \mathrm{m}$ (i.e., $\left.\mathrm{Er}^{3+}: \mathrm{Al}_{2} \mathrm{O}_{3}\right)[22,44,89,142], ~ 1.8-1.9 \mu \mathrm{m}\left(\mathrm{Tm}^{3+}: \mathrm{Al}_{2} \mathrm{O}_{3}\right)[68,143,144]$ and $\sim 2 \mu \mathrm{m}$ $\left(\mathrm{Ho}^{3+}: \mathrm{Al}_{2} \mathrm{O}_{3}\right)[45]$.

\subsection{Specifications for the integration of rare-earth ion doped $\mathrm{KY}\left(\mathrm{WO}_{4}\right)_{2}$ and single-layer active-passive $\mathrm{Al}_{2} \mathrm{O}_{3}$ on glass}

The work in this thesis focusses on the integration of rare-earth ion doped $\mathrm{KY}\left(\mathrm{WO}_{4}\right)_{2}$ and single-layer active-passive $\mathrm{Al}_{2} \mathrm{O}_{3}$ regions in a reliable manner. The integration procedures have to fulfill certain specifications in order to enable fabrication of laser and amplifier devices at the wafer level with standard lithography and etching processes.

Although, high refractive index contrast waveguide were demonstrated by Sefünç et al. [124], a reliable integration flow is missing together with a good understanding of the process. In order to fabricate high refractive index contrast $\mathrm{KY}\left(\mathrm{WO}_{4}\right)_{2}$ waveguides, a defect free $\mathrm{KY}\left(\mathrm{WO}_{4}\right)_{2}$ layer with thickness between $0.90 \mu \mathrm{m}$ to $1.60 \mu \mathrm{m}$, depending on the application, with a maximum deviation of $\pm 0.02 \mu \mathrm{m}$ across the whole $10 \times 10 \mathrm{~mm}^{2}$ sample surface is required.

Active and passive functionalities on the same chip without misalignment in the coupling section can be realized by a single-layer active-passive $\mathrm{Al}_{2} \mathrm{O}_{3}$ integration where the waveguides can be fabricated with a single lithography and etching step. Therefore, low loss active and passive $\mathrm{Al}_{2} \mathrm{O}_{3}$ regions with an adiabatic active-passive transition are required. Furthermore, the mechanical properties of both regions should be comparable and the topology on the layer should be small (i.e. thickness $\pm 50 \mathrm{~nm}$ from the average layer thickness) to ensure that waveguide etches with similar depths in both regions. 
Insight into the effect of different deposition parameters on the optical and mechanical characteristics of undoped and rare-earth ion doped $\mathrm{Al}_{2} \mathrm{O}_{3}$ has to be gained to enable the technology for robust integration of single-layer active-passive $\mathrm{Al}_{2} \mathrm{O}_{3}$.

\subsection{Outline of the thesis}

Chapter 1 describes the optical characteristics of rare-earth ions and an overview of different host materials is given together with their advantages and disadvantages. An overview of the state of the art in $\mathrm{KY}\left(\mathrm{WO}_{4}\right)_{2}$ and $\mathrm{Al}_{2} \mathrm{O}_{3}$ integrated lasers and amplifiers is given and the missing niches for both materials are identified.

Chapter 2 details the bonding study performed for the heterogeneous integration of $\mathrm{KY}\left(\mathrm{WO}_{4}\right)_{2}$-on-glass. A summary of the important material properties for $\mathrm{KY}\left(\mathrm{WO}_{4}\right)_{2}$ sample, multiple glass substrates and several types of adhesives is given. This is followed by an overview of the used bonding methodologies. The experimental findings of integration experiments using low and high temperature curable adhesives and direct bonding are described thereafter. The results are published in the OSA Continuum journal, in a paper entitled "Heterogeneous integration of $\mathrm{KY}\left(\mathrm{WO}_{4}\right)_{2}$-on-glass: a bonding study" [145].

The development of a lapping and polishing process of $\mathrm{KY}\left(\mathrm{WO}_{4}\right)_{2}$ towards high refractive index contrast slab waveguides is detailed in Chapter 3. First, the preparation of the $\mathrm{KY}\left(\mathrm{WO}_{4}\right)_{2}$-on-glass assemblies is described for this extensive process. Followed by an elaborated explanation of the lapping and polishing consumables (i.e., lapping slurry, polishing suspension) and equipment (i.e., machine, lapping and polishing disks). And a detailed description of the maintenance of the equipment and the general process is given. Lapping and polishing processes are developed on thick $(>300 \mu \mathrm{m}) \mathrm{KY}\left(\mathrm{WO}_{4}\right)_{2}$ samples and the lapping process, with the intention to lap a $\mathrm{KY}\left(\mathrm{WO}_{4}\right)_{2}$ sample from $1 \mathrm{~mm}$ down to $1-2 \mu \mathrm{m}$, is described afterwards. The results are published in Micromachines "Lapping and polishing of crystalline $\mathrm{KY}\left(\mathrm{WO}_{4}\right)_{2}$ : toward high refractive index contrast slab waveguides" [146].

Chapter 4 studies the influence of the oxygen flow on the optical and material characteristics of the deposited $\mathrm{Al}_{2} \mathrm{O}_{3}$ in a radio frequency (RF) reactive co-sputtering process. The deposition of $\mathrm{Al}_{2} \mathrm{O}_{3}$ relies on the reaction of sputtered aluminum and oxygen ions and the relationship between the oxygen flow during the process and the final composition of the deposited layer is normally very non-linear and highly complex. Furthermore, the process often has hysteresis effects and parameters and the operating point will drift due to erosion on the aluminum target. Therefore, a method is proposed to quantify the relative oxidation state, $\eta_{\mathrm{ox}}$, of the aluminum target during deposition of the layers to determine the correct operating settings to achieve optical guiding layers. 
The influence of this relative oxidation state on the refractive index and optical guidance for undoped (i.e., passive) $\mathrm{Al}_{2} \mathrm{O}_{3}$ layers is investigated. The nature (i.e., amorphous, polycrystalline, crystalline) of a selection of layers is identified using transmission electron microscopy (TEM) and X-ray diffraction (XRD). The manuscript "Relative oxidation state of the target as guideline for depositing optical quality RF reactive magnetron sputtered $\mathrm{Al}_{2} \mathrm{O}_{3}$ " has been submitted for publication.

Chapter 5 gives a proof of principle demonstration of single-layer active-passive $\mathrm{Al}_{2} \mathrm{O}_{3}$ devices fabricated using two different integration schemes. One is based on a shadow mask to deposit active $\mathrm{Al}_{2} \mathrm{O}_{3}$ regions and chemical mechanical polishing (CMP) to achieve a planar layer. The second integration scheme is based on the deposition of active and passive regions through a two-step shadow mask process that improves the reproducibility and ease of fabrication. The results of the CMP assisted integration are published under the title "Single-layer active-passive $\mathrm{Al}_{2} \mathrm{O}_{3}$ photonic integration platform” in Optical Material Express [147].

The thesis is concluded with a summary of the work presented in the chapters together with an outlook to future work in Chapter 6. 


\section{References}

[1] "Cisco Visual Networking Index: Forecast and Trends, 2017-2022," https://www.cisco.com/c/en/us/solutions/collateral/service-provider/visual-networking-indexvni/white-paper-c11-741490.pdf

[2] D. A. B. Miller and H. M. Ozaktas, "Limit to the Bit-Rate Capacity of Electrical Interconnects from the Aspect Ratio of the System Architecture," J. Parallel Distrib. Comput. 41, 42-52 (1997)

[3] L. B. Kish, "End of Moore’s law: thermal (noise) death of integration in micro and nano electronics," Phys. Lett. A 305, 144-149 (2002)

[4] D. Thomson, A. Zilkie, J. E. Bowers, T. Komljenovic, G. T. Reed, L. Vivien, D. Marris-Morini, E. Cassan, L. Virot, J.-M. Fédéli, J.-M. Hartmann, J. H. Schmid, D.-X. Xu, F. Boeuf, P. O’Brien, G. Z. Mashanovich, and M. Nedeljkovic, "Roadmap on silicon photonics," J. Opt. 18, 073003 (2016)

[5] M. Glick, L. C. Kimmerling, and R. C. Pfahl, "A Roadmap for Integrated Photonics," Opt. Photonics News 29, 36 (2018)

[6] S. E. Miller, "Integrated Optics: An Introduction," Bell Syst. Tech. J. 48, 2059-2069 (1969)

[7] E. Desurvire, J. R. Simpson, and P. C. Becker, "High-gain erbium-doped traveling-wave fiber amplifier," Opt. Lett. 12, 888 (1987)

[8] R. J. Mears, L. Reekie, I. M. Jauncey, and D. N. Payne, "Low-noise erbium-doped fibre amplifier operating at $1.54 \mu \mathrm{m}, "$ Electron. Lett. 23, 1026 (1987)

[9] O. Leclerc, B. Lavigne, E. Balmefrezol, P. Brindel, L. Pierre, D. Rouvillain, and F. Seguineau, "Optical regeneration at $40 \mathrm{~Gb} / \mathrm{s}$ and beyond," J. Light. Technol. 21, 2779-2790 (2003)

[10] R. G. H. van Uden, R. A. Correa, E. A. Lopez, F. M. Huijskens, C. Xia, G. Li, A. Schülzgen, H. de Waardt, A. M. J. Koonen, and C. M. Okonkwo, "Ultra-high-density spatial division multiplexing with a few-mode multicore fibre," Nat. Photonics 8, 865-870 (2014)

[11] R. J. Mears, L. Reekie, S. B. Poole, and D. N. Payne, "Low-threshold tunable CW and Q-switched fibre laser operating at $1.55 \mu \mathrm{m}$," Electron. Lett. 22, 159 (1986)

[12] D. J. Richardson, R. I. Laming, D. N. Payne, M. W. Phillips, and V. J. Matsas, "320 fs soliton generation with passively mode-locked erbium fibre laser," Electron. Lett. 27, 730 (1991)

[13] D. Hudson, E. Magi, L. Gomes, and S. D. Jackson, "1 W diode-pumped tunable $\mathrm{Ho}^{3+}, \mathrm{Pr}^{3+}$-doped fluoride glass fibre laser," Electron. Lett. 47, 985 (2011)

[14] E. Lallier, "Rare-earth-doped glass and $\mathrm{LiNbO}_{3}$ waveguide lasers and optical amplifiers," Appl. Opt. 31, 5276 (1992)

[15] T. Kitagawa, K. Hattori, K. Shuto, M. Yasu, M. Kobayashi, and M. Horiguchi, "Amplification in erbium-doped silica-based planar lightwave circuits," Electron. Lett. 28, 1818 (1992)

[16] T. Ohtsuki, N. Peyghambarian, S. Honkanen, and S. I. Najafi, "Gain characteristics of a high concentration $\mathrm{Er}^{3+}$-doped phosphate glass waveguide," J. Appl. Phys. 78, 3617-3621 (1995)

[17] Y. C. Yan, A. J. Faber, H. de Waal, P. G. Kik, and A. Polman, "Erbium-doped phosphate glass waveguide on silicon with $4.1 \mathrm{~dB} / \mathrm{cm}$ gain at 1.535 m," Appl. Phys. Lett. 71, 2922-2924 (1997)

[18] J. D. B. Bradley and M. Pollnau, "Erbium-doped integrated waveguide amplifiers and lasers," Laser Photon. Rev. 5, 368-403 (2011)

[19] S. A. Vázquez-Córdova, M. Dijkstra, E. H. Bernhardi, F. Ay, K. Wörhoff, J. L. Herek, S. M. García-Blanco, and M. Pollnau, "Erbium-doped spiral amplifiers with $20 \mathrm{~dB}$ of net gain on silicon," Opt. Express 22, 25993 (2014)

[20] J. Yang, M. B. J. Diemeer, C. Grivas, G. Sengo, A. Driessen, and M. Pollnau, "Steady-state lasing in a solid polymer," Laser Phys. Lett. 7, 650-656 (2010)

[21] D. Geskus, E. H. Bernhardi, K. van Dalfsen, S. Aravazhi, and M. Pollnau, "Highly efficient $\mathrm{Yb}^{3+}$ doped channel waveguide laser at 981 nm.," Opt. Express 21, 13773-8 (2013) 
[22] J. D. B. Bradley, E. S. Hosseini, Z. Su, T. N. Adam, G. Leake, D. Coolbaugh, and M. R. Watts, "Monolithic erbium- and ytterbium-doped microring lasers on silicon chips," Opt. Express 22, 12226 (2014)

[23] F. Wang, A. G. Rozhin, V. Scardaci, Z. Sun, F. Hennrich, I. H. White, W. I. Milne, and A. C. Ferrari, "Wideband-tuneable, nanotube mode-locked, fibre laser," Nat. Nanotechnol. 3, 738-742 (2008)

[24] A. A. Lagatsky, F. Fusari, S. Calvez, J. A. Gupta, V. E. Kisel, N. V. Kuleshov, C. T. A. Brown, M. D. Dawson, and W. Sibbett, "Passive mode locking of a Tm,Ho:KY(WO 4$)_{2}$ laser around 2 $\mu \mathrm{m}$," Opt. Lett. 34, 2587 (2009)

[25] J. W. Kim, S. Young Choi, S. Aravazhi, M. Pollnau, U. Griebner, V. Petrov, S. Bae, K. Jun Ahn, D.-I. Yeom, and F. Rotermund, "Graphene $Q$-switched Yb:KYW planar waveguide laser," AIP Adv. 5, 017110 (2015)

[26] J. W. Kim, S. Y. Choi, J. E. Bae, M. H. Kim, Y. U. Jeong, E. Kifle, X. Mateos, M. Aguiló, F. Díaz, U. Griebner, V. Petrov, G.-H. Kim, and F. Rotermund, "Comparative study of Yb:KYW planar waveguide lasers Q-switched by direct- and evanescent-field interaction with carbon nanotubes," Opt. Express 27, 1488 (2019)

[27] T. Arakawa, H. Kurachi, and J. Shiokawa, "Physicochemical properties of rare earth perovskite oxides used as gas sensor material," J. Mater. Sci. 20, 1207-1210 (1985)

[28] X. Niu, W. Du, and W. Du, "Preparation, characterization and gas-sensing properties of rare earth mixed oxides," Sensors Actuators B Chem. 99, 399-404 (2004)

[29] M. de Goede, M. Dijkstra, R. Obregón, J. Ramón-Azcón, E. Martínez, L. Padilla, F. Mitjans, and S. M. Garcia-Blanco, " $\mathrm{Al}_{2} \mathrm{O}_{3}$ microring resonators for the detection of a cancer biomarker in undiluted urine," Opt. Express 27, 18508 (2019)

[30] E. H. Bernhardi, K. O. van der Werf, A. J. F. Hollink, K. Wörhoff, R. M. de Ridder, V. Subramaniam, and M. Pollnau, "Intra-laser-cavity microparticle sensing with a dual-wavelength distributed-feedback laser," Laser Photon. Rev. 7, 589-598 (2013)

[31] R. Wang, S. Sprengel, A. Vasiliev, G. Boehm, J. Van Campenhout, G. Lepage, P. Verheyen, R. Baets, M.-C. Amann, and G. Roelkens, "Widely tunable $2.3 \mu \mathrm{m}$ III-V-on-silicon Vernier lasers for broadband spectroscopic sensing," Photonics Res. 6, 858 (2018)

[32] J. J. Longdell, E. Fraval, M. J. Sellars, and N. B. Manson, "Stopped Light with Storage Times Greater than One Second Using Electromagnetically Induced Transparency in a Solid," Phys. Rev. Lett. 95, 063601 (2005)

[33] T. Böttger, C. W. Thiel, R. L. Cone, and Y. Sun, "Effects of magnetic field orientation on optical decoherence in $\mathrm{Er}^{3+}: \mathrm{Y}_{2} \mathrm{SiO}_{5}, "$ Phys. Rev. B 79, 115104 (2009)

[34] M. P. Hedges, J. J. Longdell, Y. Li, and M. J. Sellars, "Efficient quantum memory for light," Nature 465, 1052-1056 (2010)

[35] K. Heshami, D. G. England, P. C. Humphreys, P. J. Bustard, V. M. Acosta, J. Nunn, and B. J. Sussman, "Quantum memories: emerging applications and recent advances," J. Mod. Opt. 63, 2005-2028 (2016)

[36] M. Afzelius, C. Simon, H. de Riedmatten, and N. Gisin, "Multimode quantum memory based on atomic frequency combs," Phys. Rev. A 79, 052329 (2009)

[37] H. de Riedmatten, M. Afzelius, M. U. Staudt, C. Simon, and N. Gisin, "A solid-state light-matter interface at the single-photon level," Nature 456, 773-777 (2008)

[38] A. Amari, A. Walther, M. Sabooni, M. Huang, S. Kröll, M. Afzelius, I. Usmani, B. Lauritzen, N. Sangouard, H. de Riedmatten, and N. Gisin, "Towards an efficient atomic frequency comb quantum memory," J. Lumin. 130, 1579-1585 (2010)

[39] C. W. Thiel, T. Böttger, and R. L. Cone, "Rare-earth-doped materials for applications in quantum information storage and signal processing," J. Lumin. 131, 353-361 (2011)

[40] L. Bastard, S. Blaize, and J.-E. Broquin, "Glass integrated optics ultranarrow linewidth distributed 
feedback laser matrix for dense wavelength division multiplexing applications," Opt. Eng. 42, 2800 (2003)

[41] E. H. Bernhardi, H. A. G. M. van Wolferen, L. Agazzi, M. R. H. Khan, C. G. H. Roeloffzen, K. Wörhoff, M. Pollnau, and R. M. de Ridder, "Ultra-narrow-linewidth, single-frequency distributed feedback waveguide laser in $\mathrm{Al}_{2} \mathrm{O}_{3}: \mathrm{Er}^{3+}$ on silicon," Opt. Lett. 35, 2394 (2010)

[42] D. Geskus, S. Aravazhi, S. M. García-Blanco, and M. Pollnau, "Giant optical gain in a rare-earthion-doped microstructure," Adv. Mater. 24, 22-25 (2012)

[43] Y.-S. Yong, S. Aravazhi, S. A. Vázquez-Córdova, J. L. Herek, S. M. García-Blanco, and M. Pollnau, "Gain dynamics in a highly ytterbium-doped potassium double tungstate epitaxial layer," J. Opt. Soc. Am. B 35, 2176 (2018)

[44] J. D. Bradley, R. Stoffer, L. Agazzi, F. Ay, K. Wörhoff, and M. Pollnau, "Integrated $\mathrm{Al}_{2} \mathrm{O}_{3}: \mathrm{Er}^{3+}$ ring lasers on silicon with wide wavelength selectivity," Opt. Lett. 35, 73 (2010)

[45] N. Li, E. S. Magden, Z. Su, N. Singh, A. Ruocco, M. Xin, M. Byrd, P. T. Callahan, J. D. B. Bradley, C. Baiocco, D. Vermeulen, and M. R. Watts, "Broadband 2- $\mu$ m emission on silicon chips: monolithically integrated Holmium lasers," Opt. Express 26, 2220 (2018)

[46] J. Mu, M. Dijkstra, Y. S. Yong, M. de Goede, L. Chang, and S. M. Garcia Blanco, "Monolithic Integration of and towards Double-layer Active-passive Platform," IEEE J. Sel. Top. Quantum Electron. 1-1 (2019)

[47] S. A. Vázquez-Córdova, S. Aravazhi, C. Grivas, Y.-S. Yong, S. M. García-Blanco, J. L. Herek, and M. Pollnau, "High optical gain in erbium-doped potassium double tungstate channel waveguide amplifiers," Opt. Express 26, 6260 (2018)

[48] D. Geskus, S. Aravazhi, K. Wörhoff, and M. Pollnau, "High-power, broadly tunable, and lowquantum-defect $\mathrm{KGd}_{1-\mathrm{x}} \mathrm{Lu}_{\mathrm{x}}\left(\mathrm{WO}_{4}\right)_{2}: \mathrm{Yb}^{3+}$ channel waveguide lasers.," Opt. Express 18, 26107-12 (2010)

[49] J. D. B. Bradley, L. Agazzi, D. Geskus, F. Ay, K. Wörhoff, and M. Pollnau, "Gain bandwidth of $80 \mathrm{~nm}$ and $2 \mathrm{~dB} / \mathrm{cm}$ peak gain in $\mathrm{Al}_{2} \mathrm{O}_{3}: \mathrm{Er}^{3+}$ optical amplifiers on silicon," J. Opt. Soc. Am. B 27, 187 (2010)

[50] K. van Dalfsen, S. Aravazhi, C. Grivas, S. M. García-Blanco, and M. Pollnau, "Thulium channel waveguide laser with $1.6 \mathrm{~W}$ of output power and $\sim 80 \%$ slope efficiency," Opt. Lett. 39, 4380 (2014)

[51] J. H. L. Voncken, The Rare Earth Elements An Introduction (Springer, n.d.)

[52] Y. Dwivedi and S. C. Zilio, "Advances in Rare Earth Spectroscopy and Applications," J. Nanosci. Nanotechnol. 14, 1578-1596 (2014)

[53] O. Svelto, Principles of Lasers (Springer, 2010)

[54] Z. Luo, Y. Huang, and X. Chen, Spectroscopy of Solid-State Laser and Luminescent Materials (Nova Science Publishers, 2007)

[55] A. J. Kenyon, "Recent developments in rare-earth doped materials for optoelectronics," Prog. Quantum Electron. 26, 225-284 (2002)

[56] X. Chen, Y. Liu, and D. Tu, Lanthanide-Doped Luminescent Nanomaterials (Springer, 2014)

[57] K. Toeda, "Do Bacteria and DNA Adsorb Rare Earth Elements? Opening the Door to Application from Atomic-Level Viewpoint," http://www.spring8.or.jp/en/news_publications/research_highlights/no_56/

[58] N. V. Kuleshov, A. A. Lagatsky, A. V. Podlipensky, V. P. Mikhailov, and G. Huber, "Pulsed laser operation of Yb-doped KY(WO 4$)_{2}$ and KGd(WO4)2," Opt. Lett. 22, 1317 (1997)

[59] G. N. Van Den Hoven, R. J. I. M. Koper, and A. Polman, "Net optical gain at $1.53 \mathrm{~m}$ in Er-doped $\mathrm{Al}_{2} \mathrm{O}_{3}$ waveguides on silicon," Appl. Phys. Lett. 68 68, 1886-1888 (1996)

[60] V. Fromzel, N. Ter-Gabrielyan, and M. Dubinskii, "Efficient resonantly-clad-pumped laser based on a Er:YAG-core planar waveguide," Opt. Express 26, 3932 (2018) 
[61] J. a. Frantz, L. B. Shaw, J. S. Sanghera, and I. D. Aggarwal, "Waveguide amplifiers in sputtered films of $\mathrm{Er}^{3+}$-doped gallium lanthanum sulfide glass," Opt. Express 14, 1797-1803 (2006)

[62] T. Calmano, M. Ams, P. Dekker, M. J. Withford, and C. Kränkel, "2 W single-longitudinal-mode Yb:YAG distributed-feedback waveguide laser," Opt. Lett. 42, 2734 (2017)

[63] S. H. Waeselmann, C. E. Rüter, D. Kip, C. Kränkel, and G. Huber, "Nd:sapphire channel waveguide laser," Opt. Mater. Express 7, 2361 (2017)

[64] J. Yang, M. B. J. Diemeer, D. Geskus, G. Sengo, M. Pollnau, and A. Driessen, "Neodymiumcomplex-doped photodefined polymer channel waveguide amplifiers," Opt. Lett. 34, 473 (2009)

[65] J. Yang, K. van Dalfsen, K. Wörhoff, F. Ay, and M. Pollnau, "High-gain $\mathrm{Al}_{2} \mathrm{O}_{3}: \mathrm{Nd}^{3+}$ channel waveguide amplifiers at 880 nm, 1060 nm, and 1330 nm," Appl. Phys. B 101, 119-127 (2010)

[66] J. W. Ang, Y. C. Hen, T. Z. Hou, D. W. Ang, T. Ong, X. W. Ang, Q. G. Ao, and C. T. Ang, "944 $\mathrm{mJ} \mathrm{Nd}$ : YAG planar waveguide laser amplifier with the optical to optical efficiency of $52 \%, " 24$, 14612-14617 (2016)

[67] M. S. Gaponenko, P. A. Loiko, N. V. Gusakova, K. V. Yumashev, N. V. Kuleshov, and A. A. Pavlyuk, "Thermal lensing and microchip laser performance of $\mathrm{N}$ g-cut $\mathrm{Tm}^{3+}: \mathrm{KY}\left(\mathrm{WO}_{4}\right)_{2}$ crystal," Appl. Phys. B 108, 603-607 (2012)

[68] J. D. B. Bradley, Z. Su, E. S. Magden, N. Li, M. Byrd, P. Purnawirman, T. N. Adam, G. Leake, D. Coolbaugh, and M. R. Watts, "1.8- $\mu$ m thulium microlasers integrated on silicon," in Proc. SPIE 9744, Optical Components and Materials XIII, S. Jiang and M. J. F. Digonnet, eds. (International Society for Optics and Photonics, 2016), Vol. 9744, p. 97440U

[69] L. Li, W. Nie, Z. Li, C. Romero, R. I. Rodriguez-Beltrán, J. R. Vázquez de Aldana, and F. Chen, "Laser-writing of ring-shaped waveguides in BGO crystal for telecommunication band," Opt. Express 25, 24236 (2017)

[70] Z. Li, A. M. Heidt, J. M. O. Daniel, Y. Jung, S. U. Alam, and D. J. Richardson, "Thulium-doped fiber amplifier for optical communications at $2 \mu \mathrm{m}$," Opt. Express 21, 9289 (2013)

[71] P. A. Loiko, J. M. Serres, X. Mateos, M. P. Demesh, A. S. Yasukevich, K. V. Yumashev, V. Petrov, U. Griebner, M. Aguiló, and F. Díaz, "Spectroscopic and laser characterization of Yb,Tm:KLu(WO4)2 crystal," Opt. Mater. (Amst). 51, 223-231 (2016)

[72] X. Mateos, P. Loiko, S. Lamrini, K. Scholle, P. Fuhrberg, S. Vatnik, I. Vedin, M. Aguiló, F. Díaz, U. Griebner, and V. Petrov, "Thermo-optic effects in Ho:KY(WO$)_{2}$ thin-disk lasers," Opt. Mater. Express 8, 684 (2018)

[73] V. Jambunathan, X. Mateos, M. C. Pujol, J. J. Carvajal, F. Díaz, M. Aguiló, U. Griebner, and V. Petrov, "Continuous-wave laser generation at 2.1 $\mu \mathrm{m}$ in $\mathrm{Ho:KRE}\left(\mathrm{WO}_{4}\right)_{2}(\mathrm{RE}=\mathrm{Y}, \mathrm{Gd}, \mathrm{Lu})$ crystals: a comparative study," Opt. Express 19, 25279 (2011)

[74] P. Loiko, R. Soulard, G. Brasse, J.-L. Doulan, A. Braud, A. Tyazhev, A. Hideur, and P. Camy, "Tm,Ho:LiYF4 planar waveguide laser at $2.05 \mu \mathrm{m}$," Opt. Lett. 43, 4341 (2018)

[75] K. Arai, H. Namikawa, K. Kumata, T. Honda, Y. Ishii, and T. Handa, "Aluminum or phosphorus co-doping effects on the fluorescence and structural properties of neodymium-doped silica glass," J. Appl. Phys. 59, 3430-3436 (1986)

[76] R. Sen, N. N. G. Boetti, M. Hokka, and L. Petit, "Optical, structural and luminescence properties of oxyfluoride phosphate glasses and glass-ceramics doped with $\mathrm{Yb}^{3+}$," J. Non-Crystalline Solids X 1, 100003 (2019)

[77] B.-C. Hwang, S. Jiang, T. Luo, J. Watson, G. Sorbello, and N. Peyghambarian, "Cooperative upconversion and energy transfer of new high $\mathrm{Er}^{3+}$ - and $\mathrm{Yb}^{3+}-\mathrm{Er}^{3+}$-doped phosphate glasses," J. Opt. Soc. Am. B 17, 833 (2000)

[78] J. Martinez de Mendivil, G. Lifante, C. J. Berrospe, W. Bolaños, J. J. Carvajal, X. Mateos, M. Aguiló, F. Díaz, and E. Cantelar, "Waveguide laser modelling of Erbium/Ytterbium activated monoclinic double tungstates," Opt. Quantum Electron. 45, 349-356 (2012) 
F. Díaz, "Tm,Ho:KY(WO4)2 planar waveguide laser," Laser Phys. Lett. 13, 095801 (2016)

[80] H. Lin, G. Meredith, S. Jiang, X. Peng, T. Luo, N. Peyghambarian, and E. Y.-B. Pun, "Optical transitions and visible upconversion in $\mathrm{Er}^{3+}$ doped niobic tellurite glass," J. Appl. Phys. 93, 186191 (2003)

[81] X. Zhang, W. He, Y. Yue, and Y. Zhang, "Influence of neodymium-doping on structure and properties of yttrium aluminium garnet," CrystEngComm 15, 8029 (2013)

[82] F. D. Patel, E. C. Honea, J. Speth, S. A. Payne, R. Hutcheson, and R. Equall, "Laser demonstration of $\mathrm{Yb}_{3} \mathrm{Al}_{5} \mathrm{O}_{12}$ (YbAG) and materials properties of highly doped $\mathrm{Yb}: \mathrm{YAG}$," IEEE J. Quantum Electron. 37, 135-144 (2001)

[83] P. Klopp, U. Griebner, V. Petrov, X. Mateos, M. A. Bursukova, M. C. Pujol, R. Sole, J. Gavalda, M. Aguilo, F. Güell, J. Massons, T. Kirilov, and F. Diaz, "Laser operation of the new stoichiometric crystal $\mathrm{KYb}\left(\mathrm{WO}_{4}\right)_{2}$," Appl. Phys. B Lasers Opt. 74, 185-189 (2002)

[84] H. Yin, P. Deng, and F. Gan, "Defects in YAG:Yb crystals," J. Appl. Phys. 83, 3825-3828 (1998)

[85] F. Auzel, "On the maximum splitting of the $\left({ }^{2} \mathrm{~F}_{7 / 2}\right)$ ground state in $\mathrm{Yb}^{3+}$-doped solid state laser materials," J. Lumin. 93, 129-135 (2001)

[86] A. Kahn, H. Kühn, S. Heinrich, K. Petermann, J. D. B. Bradley, K. Wörhoff, M. Pollnau, Y. Kuzminykh, and G. Huber, "Amplification in epitaxially grown Er:(Gd,Lu $)_{2} \mathrm{O}_{3}$ waveguides for active integrated optical devices," J. Opt. Soc. Am. B 25, 1850 (2008)

[87] A. Jha, B. Richards, G. Jose, T. Teddy-Fernandez, P. Joshi, X. Jiang, and J. Lousteau, "Rare-earth ion doped $\mathrm{TeO}_{2}$ and $\mathrm{GeO}_{2}$ glasses as laser materials," Prog. Mater. Sci. 57, 1426-1491 (2012)

[88] D. Geskus, S. Aravazhi, E. Bernhardi, C. Grivas, S. Harkema, K. Hametner, D. Günther, K. Wörhoff, and M. Pollnau, "Low-threshold, highly efficient $\mathrm{Gd}^{3+}, \mathrm{Lu}^{3+}$ co-doped $\mathrm{KY}\left(\mathrm{WO}_{4}\right)_{2}: \mathrm{Yb}^{3+}$ planar waveguide lasers," Laser Phys. Lett. 6, 800-805 (2009)

[89] N. Li, D. Vermeulen, Z. Su, E. S. Magden, M. Xin, N. Singh, A. Ruocco, J. Notaros, C. V. Poulton, E. Timurdogan, C. Baiocco, and M. R. Watts, "Monolithically integrated erbium-doped tunable laser on a CMOS-compatible silicon photonics platform," Opt. Express 26, 16200 (2018)

[90] C. Grivas and M. Pollnau, "Organic solid-state integrated amplifiers and lasers," Laser Photon. Rev. 6, 419-462 (2012)

[91] S. M. Lima, J. A. Sampaio, T. Catunda, A. C. Bento, L. C. M. Miranda, and M. L. Baesso, "Modemismatched thermal lens spectrometry for thermo-optical properties measurement in optical glasses: a review," J. Non. Cryst. Solids 273, 215-227 (2000)

[92] K. Petermann, D. Fagundes-Peters, J. Johannsen, M. Mond, V. Peters, J. J. Romero, S. Kutovoi, J. Speiser, and A. Giesen, "Highly Yb-doped oxides for thin-disc lasers," J. Cryst. Growth 275, 135140 (2005)

[93] Y. Romanyuk, "liquid-phase epitaxy of doped $\mathrm{KY}\left(\mathrm{WO}_{4}\right)_{2}$ layers for waveguide lasers," Fédérale de Lausanne (2005)

[94] S. Aravazhi, D. Geskus, K. van Dalfsen, S. A. Vázquez-Córdova, C. Grivas, U. Griebner, S. M. García-Blanco, and M. Pollnau, "Engineering lattice matching, doping level, and optical properties of $\mathrm{KY}\left(\mathrm{WO}_{4}\right)_{2}$ : Gd, $\mathrm{Lu}, \mathrm{Yb}$ layers for a cladding-side-pumped channel waveguide laser," Appl. Phys. B 111, 433-446 (2013)

[95] S. H. Waeselmann, S. Heinrich, C. Kränkel, and G. Huber, "Lasing of $\mathrm{Nd}^{3+}$ in sapphire," Laser Photon. Rev. 10, 510-516 (2016)

[96] T. O. Kääriäinen and D. C. Cameron, "Plasma-Assisted Atomic Layer Deposition of $\mathrm{Al}_{2} \mathrm{O}_{3}$ at Room Temperature," Plasma Process. Polym. 6, S237-S241 (2009)

[97] A. A. Kaminskii, A. F. Konstantinova, V. P. Orekhova, A. V Butashin, R. F. Klevtsova, and A. A. Pavlyuk, "Optical and nonlinear laser properties of the $\chi^{(3)}$-active monoclinic $\alpha-K Y\left(\mathrm{WO}_{4}\right)_{2}$ crystals," Crystallogr. Reports 46, 665-672 (2001)

[98] X. Mateos, R. Solé, J. Gavaldà, M. Aguiló, J. Massons, and F. Díaz, "Crystal growth, optical and 
spectroscopic characterisation of monoclinic $\mathrm{KY}\left(\mathrm{WO}_{4}\right)_{2}$ co-doped with $\mathrm{Er}^{3+}$ and $\mathrm{Yb}^{3+}$," Opt. Mater. (Amst). 28, 423-431 (2006)

[99] J. Koerner, C. Vorholt, H. Liebetrau, M. Kahle, D. Kloepfel, R. Seifert, J. Hein, and M. C. Kaluza, "Measurement of temperature-dependent absorption and emission spectra of Yb:YAG, Yb:LuAG, and $\mathrm{Yb}: \mathrm{CaF}_{2}$ between $20^{\circ} \mathrm{C}$ and $200{ }^{\circ} \mathrm{C}$ and predictions on their influence on laser performance," J. Opt. Soc. Am. B 29, 2493 (2012)

[100] Y.-S. Yong, S. Aravazhi, S. A. Vázquez-Córdova, J. J. Carjaval, F. Díaz, J. L. Herek, S. M. García-Blanco, and M. Pollnau, "Temperature-dependent absorption and emission of potassium double tungstates with high ytterbium content.," Opt. Express 24, 26825-26837 (2016)

[101] W. J. Miniscalco, "Erbium-doped glasses for fiber amplifiers at 1500 nm," J. Light. Technol. 9, 234-250 (1991)

[102] R. L. Aggarwal, D. J. Ripin, J. R. Ochoa, and T. Y. Fan, "Measurement of thermo-optic properties of $\mathrm{Y}_{3} \mathrm{Al}_{5} \mathrm{O}_{12}, \mathrm{Lu}_{3} \mathrm{Al}_{5} \mathrm{O}_{12}, \mathrm{YAIO}_{3}, \mathrm{LiYF}_{4}, \mathrm{LiLuF}_{4}, \mathrm{BaY}_{2} \mathrm{~F}_{8}, \mathrm{KGd}\left(\mathrm{WO}_{4}\right)_{2}$, and KY(W," J. Appl. Phys. 98, 103514 (2005)

[103] K. Worhoff, F. Ay, and M. Pollnau, "Optimization of Low-Loss $\mathrm{Al}_{2} \mathrm{O}_{3}$ Waveguide Fabrication for Application in Active Integrated Optical Devices," in ECS Transactions (ECS, 2006), Vol. 3, pp. 17-26

[104] P. Loiko, N. Ismail, J. D. B. Bradley, M. Götelid, and M. Pollnau, "Refractive-index variation with rare-earth incorporation in amorphous $\mathrm{Al}_{2} \mathrm{O}_{3}$ thin films," J. Non. Cryst. Solids 476, 95-99 (2017)

[105] E. R. Dobrovinskaya, L. A. Lytvynov, and V. Pishchik, Sapphire Material, Manufacturing, Applications (Springer, 2009)

[106] P. G. Kik and A. Polman, "Erbium-Doped Optical-Waveguide Amplifiers on Silicon," MRS Bull. 23, 48-54 (1998)

[107] P. Xing, G. F. R. Chen, X. Zhao, D. K. T. Ng, M. C. Tan, and D. T. H. Tan, "Silicon rich nitride ring resonators for rare - earth doped telecommunications-band amplifiers pumped at the O-band," Sci. Rep. 7, 9101 (2017)

[108] L. Agazzi, K. Wörhoff, and M. Pollnau, "Energy-Transfer-Upconversion Models, Their Applicability and Breakdown in the Presence of Spectroscopically Distinct Ion Classes: A Case Study in Amorphous $\mathrm{Al}_{2} \mathrm{O}_{3}: \mathrm{Er}^{3+}, "$ J. Phys. Chem. C 117, 6759-6776 (2013)

[109] K. Wörhoff, J. D. B. Bradley, F. Ay, D. Geskus, T. P. Blauwendraat, and M. Pollnau, "Reliable Low-Cost Fabrication of Low-Loss $\mathrm{Al}_{2} \mathrm{O}_{3}: \mathrm{Er}^{3+}$ Waveguides With 5.4-dB Optical Gain," IEEE J. Quantum Electron. 45, 454-461 (2009)

[110] J. D. B. Bradley, F. Ay, K. Wörhoff, and M. Pollnau, "Fabrication of low-loss channel waveguides in $\mathrm{Al}_{2} \mathrm{O}_{3}$ and $\mathrm{Y}_{2} \mathrm{O}_{3}$ layers by inductively coupled plasma reactive ion etching," Appl. Phys. B 89, 311-318 (2007)

[111] M. Demirtas, C. Odaci, N. K. Perkgoz, C. Sevik, and F. Ay, "Low Loss Atomic Layer Deposited $\mathrm{Al}_{2} \mathrm{O}_{3}$ Waveguides for Applications in On-Chip Optical Amplifiers," IEEE J. Sel. Top. Quantum Electron. 24, 1-8 (2018)

[112] T. Ishizaka and Y. Kurokawa, "Optical properties of rare-earth ion $\left(\mathrm{Gd}^{3+}, \mathrm{Ho}^{3+}, \mathrm{Pr}^{3+}, \mathrm{Sm}^{3+}, \mathrm{Dy}^{3+}\right.$ and $\mathrm{Tm}^{3+}$ ) -doped alumina films prepared by the sol-gel method," J. Lumin. 92, 57-63 (2000)

[113] Purnawirman, N. Li, E. S. Magden, G. Singh, N. Singh, A. Baldycheva, E. S. Hosseini, J. Sun, M. Moresco, T. N. Adam, G. Leake, D. Coolbaugh, J. D. B. Bradley, and M. R. Watts, "Ultra-narrowlinewidth $\mathrm{Al}_{2} \mathrm{O}_{3}: \mathrm{Er}^{3+}$ lasers with a wavelength-insensitive waveguide design on a wafer-scale silicon nitride platform," Opt. Express 25, 13705 (2017)

[114] F. Chen and J. R. V. de Aldana, "Optical waveguides in crystalline dielectric materials produced by femtosecond-laser micromachining," Laser Photon. Rev. 8, 251-275 (2014)

[115] C. N. Borca, V. Apostolopoulos, F. Gardillou, H. G. Limberger, M. Pollnau, and R.-P. Salathé, "Buried channel waveguides in $\mathrm{Yb}$-doped $\mathrm{KY}\left(\mathrm{WO}_{4}\right)_{2}$ crystals fabricated by femtosecond laser 
irradiation," Appl. Surf. Sci. 253, 8300-8303 (2007)

[116] S. M. Eaton, C. A. Merchant, R. Iyer, A. J. Zilkie, A. S. Helmy, J. S. Aitchison, P. R. Herman, D. Kraemer, R. J. D. Miller, C. Hnatovsky, and R. S. Taylor, "Raman gain from waveguides inscribed in $\mathrm{KGd}\left(\mathrm{WO}_{4}\right)_{2}$ by high repetition rate femtosecond laser," Appl. Phys. Lett. 92, 081105 (2008)

[117] F. M. Bain, A. A. Lagatsky, R. R. Thomson, N. D. Psaila, N. V. Kuleshov, A. K. Kar, W. Sibbett, and C. T. A. Brown, "Ultrafast laser inscribed $\mathrm{Yb}: \mathrm{KGd}\left(\mathrm{WO}_{4}\right)_{2}$ and $\mathrm{Yb}: \mathrm{KY}\left(\mathrm{WO}_{4}\right)_{2}$ channel waveguide lasers," Opt. Express 17, 22417 (2009)

[118] D. Geskus, S. Aravazhi, C. Grivas, K. Wörhoff, and M. Pollnau, "Microstructured $\mathrm{KY}\left(\mathrm{WO}_{4}\right)_{2}: \mathrm{Gd}^{3+}, \mathrm{Lu}^{3+}, \mathrm{Yb}^{3+}$ channel waveguide laser," Opt. Express 18, 22417-22422 (2010)

[119] E. Kifle, P. Loiko, U. Griebner, V. Petrov, P. Camy, A. Braud, M. Aguiló, F. Díaz, and X. Mateos, "Diamond saw dicing of thulium channel waveguide lasers in monoclinic crystalline films," Opt. Lett. 44, 1596 (2019)

[120] R. Frentrop, I. Subbotin, S. Frans;, R. Keim, V. Tormo, J. Olivares, K. ; Shcherbachev, S. Yakunin, I. Makhotkin, and S. M. . Garcia-Blanco, "In-depth structural analysis of swift heavy ion irradiation in $\mathrm{KY}\left(\mathrm{WO}_{4}\right)_{2}$ for the fabrication of planar optical waveguides," Opt. Mater. Express in production (2019)

[121] R. Frentrop, J. Olivares, V. Tormo-Márquez, and S. M. García-Blanco, "High-contrast slab waveguide fabrication in $\mathrm{KY}\left(\mathrm{WO}_{4}\right)_{2}$ by swift heavy ion irradiation," in Integrated Optics: Devices, Materials, and Technologies XXII (SPIE, 2018), Vol. 10535

[122] S. M. Martinussen, R. N. Frentrop, M. Dijkstra, F. Segerink, V. Tormo-Márquez, J. Olivares, and S. M. Garcia-Blanco, "Pedestal microdisks in potassium yttrium double tungstate," Opt. Mater. Express 9, 3371 (2019)

[123] M. Medina, C. E. Rüter, M. C. Pujol, D. Kip, J. Masons, A. Ródenas, M. Aguiló, and F. Díaz, "KLu(WO$)_{2} / \mathrm{SiO}_{2}$ Tapered Waveguide Platform for Sensing Applications," Micromachines 10, 454 (2019)

[124] M. A. Sefunc, F. B. Segerink, and S. M. García-Blanco, "High index contrast passive potassium double tungstate waveguides," Opt. Mater. Express 8, 629 (2018)

[125] M. Medina, C. E. Rüter, M. C. Pujol, D. Kip, J. Masons, A. Ródenas, M. Aguiló, F. Díaz, M. Medina, C. E. Rüter, M. C. Pujol, D. Kip, J. Masons, A. Ródenas, M. Aguiló, and F. Díaz, "KLu( $\left(\mathrm{WO}_{4}\right)_{2} / \mathrm{SiO}_{2}$ Tapered Waveguide Platform for Sensing Applications," Micromachines 10, 454 (2019)

[126] J. Rönn, W. Zhang, A. Autere, X. Leroux, L. Pakarinen, C. Alonso-Ramos, A. Säynätjoki, H. Lipsanen, L. Vivien, E. Cassan, and Z. Sun, "Ultra-high on-chip optical gain in erbium-based hybrid slot waveguides," Nat. Commun. 10, 432 (2019)

[127] A. Suárez-García, J. Gonzalo, and C. N. Afonso, "Low-loss $\mathrm{Al}_{2} \mathrm{O}_{3}$ waveguides produced by pulsed laser deposition at room temperature," Appl. Phys. A Mater. Sci. Process. 77, 779-783 (2003)

[128] C. C. Kores, N. Ismail, D. Geskus, M. Dijkstra, E. H. Bernhardi, and M. Pollnau, "Temperature dependence of the spectral characteristics of distributed-feedback resonators," Opt. Express 26, 4892 (2018)

[129] E. H. Bernhardi, H. A. G. M. van Wolferen, K. Wörhoff, R. M. de Ridder, and M. Pollnau, "Highly efficient, low-threshold monolithic distributed-Bragg-reflector channel waveguide laser in $\mathrm{Al}_{2} \mathrm{O}_{3}: \mathrm{Yb}^{3+}$," Opt. Lett. 36, 603 (2011)

[130] E. H. Bernhardi, Q. Lu, H. A. G. M. van Wolferen, K. Wörhoff, R. M. de Ridder, and M. Pollnau, "Monolithic distributed Bragg reflector cavities in Al2O3 with quality factors exceeding $10^{6}$," Photonics Nanostructures - Fundam. Appl. 9, 225-234 (2011)

[131] E. S. Hosseini, J. D. B. Bradley, J. Sun, G. Leake, T. N. Adam, D. D. Coolbaugh, and M. R. Watts, "CMOS-compatible 75 mW erbium-doped distributed feedback laser," Opt. Lett. 39, 3106 (2014) 
[132] M. Belt, T. Huffman, M. L. Davenport, W. Li, J. S. Barton, and D. J. Blumenthal, "Arrayed narrow linewidth erbium-doped waveguide-distributed feedback lasers on an ultra-low-loss silicon-nitride platform," Opt. Lett. 38, 4825 (2013)

[133] M. Belt and D. J. Blumenthal, "Erbium-doped waveguide DBR and DFB laser arrays integrated within an ultra-low-loss $\mathrm{Si}_{3} \mathrm{~N}_{4}$ platform," Opt. Express 22, 10655 (2014)

[134] H. Ichikawa, K. Yamaguchi, T. Katsumata, I. Shoji, 4 R Zhou, E. Li, H. Li, P. Wang, and J. Yao, "High-power and highly efficient composite laser with an anti-reflection coated layer between a laser crystal and a diamond heat spreader fabricated by room-temperature bonding," Opt. Express 25, 22797-22804 (2017)

[135] Purnawirman, J. Sun, T. N. Adam, G. Leake, D. Coolbaugh, J. D. B. Bradley, E. S. Hosseini, and M. R. Watts, "C- and L-band erbium-doped waveguide lasers with wafer-scale silicon nitride cavities," Opt. Lett. 38, 1760 (2013)

[136] F. Gardillou, L. Bastard, and J.-E. Broquin, "4.25dB gain in a hybrid silicate/phosphate glasses optical amplifier made by wafer bonding and ion-exchange techniques," Appl. Phys. Lett. 85, 5176-5178 (2004)

[137] S. Blaize, L. Bastard, C. Cassagnetes, and J. E. Broquin, "Multiwavelengths DFB waveguide laser arrays in Yb-Er codoped phosphate glass substrate," IEEE Photonics Technol. Lett. 15, 516-518 (2003)

[138] N. Arab, L. Bastard, J. Poëtte, J.-E. Broquin, and B. Cabon, "Thermal coupling impact on an MMW carrier generated using two free-running DFB lasers on glass," Opt. Lett. 43, 5500 (2018)

[139] Z. Su, N. Li, H. C. Frankis, E. S. Magden, T. N. Adam, G. Leake, D. Coolbaugh, J. D. B. Bradley, and M. R. Watts, "High-Q-factor $\mathrm{Al}_{2} \mathrm{O}_{3}$ micro-trench cavities integrated with silicon nitride waveguides on silicon," Opt. Express 26, 11161 (2018)

[140] P. F. Jarschel and N. C. Frateschi, "Resonant amplification via Er-doped clad Si photonic molecules: Towards compact low-loss/high-Q Si photonic devices," Solid. State. Electron. 155, 144-149 (2019)

[141] J. Mu, M. Dijkstra, and S. M. Garcia-Blanco, "Resonant Coupling for Active-passive Monolithic Integration of $\mathrm{Al}_{2} \mathrm{O}_{3}$ and $\mathrm{Si}_{3} \mathrm{~N}_{4}$," IEEE Photonics Technol. Lett. 1-1 (2019)

[142] E. Salih Magden, G. Singh, N. Singh, A. Baldycheva, E. Shah Hosseini, J. Sun, M. Moresco, T. N. Adam, G. Leake, D. Coolbaugh, J. D. B Bradley, and M. R. Watts, "Ultra-narrow-linewidth $\mathrm{Al}_{2} \mathrm{O}_{3}: \mathrm{Er}^{3+}$ lasers with a wavelength-insensitive waveguide design on a wafer-scale silicon nitride platform “Silicon photonic hybrid ring-filter external cavity wavelength tunable lasers,”" Opt. Express 14014, 57-62 (2003)

[143] Z. Su, N. Li, E. Salih Magden, M. Byrd, J. D. B. Purnawirman, T. N. Adam, G. Leake, D. Coolbaugh, J. D. B. Bradley, and M. R. Watts, "Ultra-compact and low-threshold thulium microcavity laser monolithically integrated on silicon," Opt. Lett. 41, 5708 (2016)

[144] N. Li, C. Purnawirman, Z. Su, E. Salih Magden, P. T. Callahan, K. Shtyrkova, M. Xin, A. Ruocco, C. Baiocco, E. P. Ippen, F. X. Kärtner, J. D. B. Bradley, D. Vermeulen, and M. R. Watts, "Highpower thulium lasers on a silicon photonics platform," Opt. Lett. 42, 1181 (2017)

[145] C. I. van Emmerik, R. Frentrop, M. Dijkstra, F. Segerink, R. Kooijman, M. Muneeb, G. Roelkens, E. Ghibaudo, J.-E. Broquin, and S. M. Garcia-Blanco, "Heterogeneous integration of $\mathrm{KY}_{\left(\mathrm{WO}_{4}\right)_{2}-}$ on-glass: a bonding study," OSA Contin. 2, 2065-2076 (2019)

[146] C. I. van Emmerik, R. Kooijman, M. Dijkstra, and S. M. Garcia-Blanco, "Lapping and Polishing of Crystalline KY(WO4)2: Toward High Refractive Index Contrast Slab Waveguides," Micromachines 2019, Vol. 10, Page 674 10, 674 (2019)

[147] C. I. van Emmerik, M. Dijkstra, M. de Goede, L. Chang, J. Mu, and S. M. Garcia-Blanco, "Singlelayer active-passive $\mathrm{Al}_{2} \mathrm{O}_{3}$ photonic integration platform," Opt. Mater. Express 8, 3049 (2018) 


\section{Chapter 2}

\section{Heterogeneous integration of $\mathrm{KY}\left(\mathrm{WO}_{4}\right)_{2}$-on-glass: a bonding study}

Rare-earth ion doped potassium yttrium double tungstate, $R E: K Y\left(W_{4}\right)_{2}$, is a promising candidate for small, power-efficient, on-chip lasers and amplifiers. There are two major bottlenecks that complicate the realization of such devices. Firstly, the anisotropic thermal expansion coefficient of $\mathrm{KY}\left(\mathrm{WO}_{4}\right)_{2}$ makes it challenging to integrate the crystal on glass substrates. Secondly, the crystal layer has to be, for example, $<1 \mu \mathrm{m}$ to obtain single mode, high refractive index contrast waveguides operating at $1550 \mathrm{~nm}$. In this work, different adhesives and bonding techniques in combination with several types of glass substrates are investigated. An optimal bonding process will enable further processing towards the manufacturing of integrated active optical $\mathrm{KY}\left(\mathrm{WO}_{4}\right)_{2}$ devices.

This chapter is published as:

C.I. van Emmerik, R. Frentrop, F. Segerink, R. Kooijman, M. Muneeb, G. Roelkens, E. Ghibaudo, J-E. Broquin, and S.M. Garcia-Blanco, "Heterogeneous integration of $\mathrm{KY}\left(\mathrm{WO}_{4}\right)_{2}$-on-glass: a bonding study", OSA Continuum, 2(6), 2065-2076 (2019) 


\subsection{Introduction}

Potassium yttrium double tungstate $\left(\mathrm{KY}\left(\mathrm{WO}_{4}\right)_{2}\right)$ is a promising candidate for on-chip lasers and amplifiers. Its relatively high refractive index $(n \approx 2$ at $1550 \mathrm{~nm}[1,2])$ makes it suitable for the fabrication of devices with a small footprint. The crystal provides large emission and absorption cross-sections for rare-earth ions doped into the material [3]. Furthermore, large concentrations of rare-earth ions can be introduced into the crystal matrix without undesirable quenching effects, thanks to the long interionic distances between the atoms $(\langle d\rangle \approx 0.4 \mathrm{~nm}[4])$.

Its crystalline structure is also advantageous to achieve excellent gain characteristics when doped with rare-earth ions, which is needed for the realization of lasers and amplifiers. However, the integration of $\mathrm{KY}\left(\mathrm{WO}_{4}\right)_{2}$ on glass substrates is challenging. Firstly, $\mathrm{KY}\left(\mathrm{WO}_{4}\right)_{2}$ has to be grown on a lattice matched substrate, i.e., growth of slightly doped $\mathrm{KY}\left(\mathrm{WO}_{4}\right)_{2}$ on an undoped $\mathrm{KY}\left(\mathrm{WO}_{4}\right)_{2}$ seed substrate by liquid phase epitaxy (LPE) $[5,6]$, which makes this method not suitable for the integration of the material on amorphous substrates. Secondly, the $\mathrm{KY}\left(\mathrm{WO}_{4}\right)_{2}$ sample has a large ( 250-650\%) thermal expansion coefficient (CTE) mismatch with the glass substrate, which gives restrictions on the thermal budget that can be used during the integration process.

Previous studies have demonstrated waveguide lasers with high efficiency and high output power at a wavelength of $2 \mu \mathrm{m}$ [7] and lasers at $\sim 1 \mu \mathrm{m}$ wavelength with large tuning bandwidth [8,9], fabricated using LPE [6]. Those devices have a comparable performances as waveguide lasers made by laser writing in various glasses (i.e., ZBLAN [10], bismuthate glass [11]) and crystals (i.e., GdVO 4 [12], YAG [13,14]) but with lower lasing threshold. Both fabrication methods result in relatively large structures due to the low refractive index contrast between core and cladding (i.e., $\Delta \mathrm{n} \sim 0.02$ [6] with LPE, $\Delta \mathrm{n} \sim 0.003$ [15] with laser writing). High refractive index contrast rib $\mathrm{KY}\left(\mathrm{WO}_{4}\right)_{2}$ waveguides have been demonstrated by Sefünç et al. [16], where a bulk crystal of $10 \times 10 \mathrm{~mm}^{2}$ and $1 \mathrm{~mm}$ thickness has been bonded with a UV-curable optical adhesive to a $\mathrm{SiO}_{2}$ substrate and thinned to $\sim 2.4 \mu \mathrm{m}$. Optical waveguides were patterned using focused ion beam (FIB) milling. This method is, however, not suitable for the realization of long devices (i.e., several millimeters) and it doesn't allow for scalability. Therefore, we aim at a comparable integration method where the devices can be made with standard UV-lithography and reactive ion etching to enable scalability.

There are a few requirements that have to be met for the fabrication of optical $\mathrm{KY}\left(\mathrm{WO}_{4}\right)_{2}$-on-glass devices. Firstly, the bond has to be free of defects at the interface between the $\mathrm{KY}\left(\mathrm{WO}_{4}\right)_{2}$ sample and the glass substrate because interfacial defects increase scattering losses, which harms the performance of optical devices. Defects at the interface can also induce cracking of the samples in the later thinning and polishing 
step. Secondly, the bond needs to have a high strength to survive the thinning procedure. Additionally, the bond line should be uniform within tens of nanometers such that the optical devices patterned on the surface of the chip have similar thickness and therefore similar performance. Finally, the materials used for the integration should be CMOS compatible for future integration with passive platforms (such as $\mathrm{Si}$ or $\mathrm{Si}_{3} \mathrm{~N}_{4}$ ).

This work focusses on the integration method of a bulk $\mathrm{KY}\left(\mathrm{WO}_{4}\right)_{2}$ crystal onto a glass substrate. Different bonding methods, in combination with various adhesives, are tested. The advantages and disadvantages of each method are discussed to satisfy the requirements for the fabrication of high refractive index contrast optical waveguides.

\subsection{Material properties}

\subsection{1 $\mathrm{KY}\left(\mathrm{WO}_{4}\right)_{2}$ crystal}

$\mathrm{KY}\left(\mathrm{WO}_{4}\right)_{2}$ is a monolithic, birefringent crystal with three crystalline axes $\left(\mathbf{a}^{*}, \mathbf{-} \mathbf{b}^{*}, \mathbf{c}^{*}\right.$ in I2/c space group and $\mathbf{a}, \mathbf{b}, \mathbf{c}$ in the $\mathrm{C} 2 / \mathrm{c}$ space group), three optical axes $\left(\mathrm{N}_{\mathrm{g}}>\mathrm{N}_{\mathrm{m}}>\mathrm{N}_{\mathrm{p}}\right.$ [1]) and three CTE tensors $\left(X_{3}^{\prime}>X_{1}^{\prime}>X_{2}^{\prime}\right)$. The position of the optical axes with respect to both crystal space groups is shown in Fig. 2.1(a) and the thermal axes are shown in Fig. 2.1(b). The maximum and minimum of the CTE tensor, $X_{3}^{\prime}$ $\left(\sim 21.0 \mathrm{ppm} /{ }^{\circ} \mathrm{C}\right)$ and $X_{1}^{\prime}\left(\sim 7.2 \mathrm{ppm} /{ }^{\circ} \mathrm{C}\right)$, are close to the $\mathbf{c}^{*}$ and $\mathbf{a}^{*}$-axis, respectively (Fig. 2.1(b)). The difference in CTE between the crystalline axes does not cause any problem when the crystal is heated while not attached to a substrate. However, bonding of a $\mathrm{KY}\left(\mathrm{WO}_{4}\right)_{2}$ crystal at elevated temperatures to, for example, a silicon wafer with a layer of thermal oxide $\left(\mathrm{CTE}_{\mathrm{TEOS}} \approx 3.3 \mathrm{ppm} /{ }^{\circ} \mathrm{C}\right)$ induces stress in the layers after cooling, which leads to cracks in either the sample or substrate.

\subsubsection{Glass substrates}

The CTE anisotropy in $\mathrm{KY}\left(\mathrm{WO}_{4}\right)_{2}$ can induce stress/strain when bonded to a glass substrate at elevated $\left(>150^{\circ} \mathrm{C}\right)$ temperatures. The CTE in the $\mathbf{a}^{*}$-c* crystalline plane of $\mathrm{KY}\left(\mathrm{WO}_{4}\right)_{2}$ is respectively 8.5-19.7 $\mathrm{ppm} /{ }^{\circ} \mathrm{C}[17]$.

Two different glass types have been studied to minimize the CTE mismatch between the glass substrate and the $\mathbf{a}^{*}-\mathrm{c}^{*}$ crystalline plane of $\mathrm{KY}\left(\mathrm{WO}_{4}\right)_{2}$. MEMpax (SCHOTT AG, MEMpax ${ }^{\circledR}$, DE), a borosilicate glass, has a CTE of $3.3 \mathrm{ppm} /{ }^{\circ} \mathrm{C}[18]$, which corresponds to that of silicon and mimics the thermal oxide grown on a silicon wafer. There is a large CTE mismatch between MEMpax and the two in-plane $\mathrm{KY}\left(\mathrm{WO}_{4}\right)_{2}$ axes, which makes it unsuitable for bonding purposes where elevated temperatures are involved. Soda-lime glass has a CTE between $9.1-9.4 \mathrm{ppm} /{ }^{\circ} \mathrm{C}[19,20]$. This value is 
close to that of $\mathrm{KY}\left(\mathrm{WO}_{4}\right)_{2}$ and therefore soda-lime substrates are used when elevated temperatures $\left(>150^{\circ} \mathrm{C}\right)$ are required.
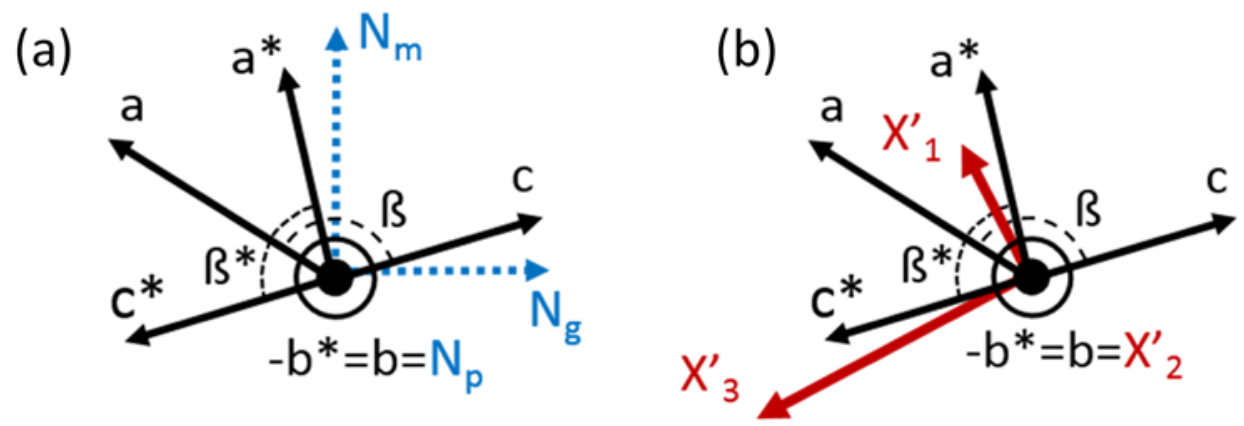

Fig. 2.1 Crystalline axes (black) with structure according to I2/c space group with $\mathbf{a}^{*}=1.063 \mathrm{~nm}, \quad-\mathbf{b}^{*}=1.034 \mathrm{~nm}, \quad \mathbf{c}^{*}=0.755 \mathrm{~nm}, \quad \mathbf{B}^{*}=94.3^{\circ} \quad$ and $\quad \mathbf{a}=0.807 \mathrm{~nm}$, $\mathbf{b}=1.034 \mathrm{~nm}, \mathbf{c}=0.755 \mathrm{~nm}, \mathbf{B}=130.7^{\circ}$ from the $\mathrm{C} 2 / \mathrm{c}$ space group together with (a) the optical axes (blue); (b) the principle thermal axes (red) [17].

\subsubsection{Adhesives}

The bonding process and adhesive that are used are important to successfully bond a $\mathrm{KY}\left(\mathrm{WO}_{4}\right)_{2}$ sample on a glass substrate. UV-curable adhesives are optimal for room temperature bonding. Bohle low viscosity 740 (Verifix ${ }^{\circledR}$ LV 740, Bohle BV) and Norland Optical Adhesive 81 (NOA81, Norland Products Inc.) were selected because of their low viscosity and large strength in comparison to other optical adhesives. Two epoxy based adhesives, Epotek 353ND and 377 (Epoxy Technology Inc.), were selected to test bonding at $150^{\circ} \mathrm{C}$. And finally divinylsiloxane-bis-benzocyclobutene (DVS-BCB, Cyclotene ${ }^{\circledR} 3022-35$, Dow Chemical), further referred to as BCB [21,22], and $\mathrm{O}_{2}$ activated direct bonding $[23,24]$ were selected because of the accuracy in the achievable bond line. A disadvantage of the latter methods is the curing/annealing temperature, which is around $250{ }^{\circ} \mathrm{C}$ for an optimal strong bond. The curing/annealing can be performed at lower temperatures $\left(\sim 150^{\circ} \mathrm{C}\right)$, leading to longer process times (> 10 hours) and often to weaker bonds [25]. The specifications of the mentioned adhesives are shown in Table 2.1. 
Heterogeneous integration of $\mathrm{KY}\left(\mathrm{WO}_{4}\right)_{2}$-on-glass: a bonding study

Table 2.1 Specifications of the different adhesives used.

\begin{tabular}{|c|c|c|c|c|c|c|c|c|c|}
\hline $\begin{array}{l}\text { Adhesive } \rightarrow \\
\text { Cure setting } \\
\& \\
\text { Properties } \\
\text { Name } \downarrow\end{array}$ & $\begin{array}{l}\text { Cure } \\
\text { type }\end{array}$ & $\begin{array}{l}\text { Cure } \\
\text { dose }\end{array}$ & $\begin{array}{l}\text { DV at } \\
25^{\circ} \mathrm{C} \\
\text { (cps) }\end{array}$ & $\begin{array}{l}\text { TS } \\
\text { (MPa) }\end{array}$ & $\begin{array}{l}\text { SM } \\
\text { (MPa) }\end{array}$ & $\begin{array}{l}\text { CTE } \\
<90{ }^{\circ} \mathrm{C} \\
(\mathbf{p p m} / \\
\left.{ }^{\circ} \mathrm{C}\right)\end{array}$ & $\begin{array}{l}\mathbf{T}_{\text {degrade }} \\
\left({ }^{\circ} \mathrm{C}\right)\end{array}$ & $\begin{array}{l}\mathrm{n}(\lambda \\
\approx \\
\mathbf{6 0 0} \\
\mathrm{nm})\end{array}$ & Ref \\
\hline $\begin{array}{l}\text { Bohle } \\
\text { LV } 740\end{array}$ & $365 \mathrm{~nm}$ & $1 \mathrm{~J} / \mathrm{cm}^{2}$ & 100 & -- & 17.0 & -- & 120 & 1.50 & [26] \\
\hline NOA 81 & $365 \mathrm{~nm}$ & $2 \mathrm{~J} / \mathrm{cm}^{2}$ & 300 & 1.4 & -- & 200 & 125 & 1.56 & [27] \\
\hline $\begin{array}{l}\text { Epotek } \\
\text { 353ND }\end{array}$ & $150^{\circ} \mathrm{C}$ & 1 hour & $\begin{array}{l}3000- \\
5000\end{array}$ & -- & $>13.8$ & 54 & 250 & 1.57 & [28] \\
\hline $\begin{array}{l}\text { Epotek } \\
377\end{array}$ & $150^{\circ} \mathrm{C}$ & 1 hour & $\begin{array}{l}150- \\
300\end{array}$ & -- & 10.0 & 57 & 300 & 1.52 & [29] \\
\hline BCB & $\begin{array}{l}160- \\
250^{\circ} \mathrm{C}\end{array}$ & $\begin{array}{l}10-1 \\
\text { hours }\end{array}$ & -- & 2.9 & -- & 42 & 350 & 1.55 & [30] \\
\hline $\begin{array}{l}\text { Direct } \\
\text { bonding }\end{array}$ & $150^{\circ} \mathrm{C}$ & $72 \mathrm{~h}$ & $\mathrm{NaN}$ & -- & -- & $\mathrm{NaN}$ & -- & $\mathrm{NaN}$ & [25] \\
\hline
\end{tabular}

$\mathrm{DV}=$ dynamic viscosity, $\mathrm{TS}=$ tensile strength, $\mathrm{SM}=$ shear modulus, $\mathrm{T}_{\text {degrade }}=$ degradation temperature of the adhesive, $\mathrm{n}=$ refractive index

\subsection{Bonding methodology}

Multiple bonding techniques have been investigated to integrate $\mathrm{KY}\left(\mathrm{WO}_{4}\right)_{2}$ samples onto glass substrates. In the following sections, the different bonding techniques are described, namely manual bonding, bonding using a flip-chip bonder and bonding using a wafer bonder instrument.

\subsubsection{Manual bonding}

For stability during the thinning process, three $\mathrm{KY}\left(\mathrm{WO}_{4}\right)_{2}$-on-glass assemblies need to be mounted on an ultra-parallel glass plate ( $\varnothing 83 \mathrm{~mm}$, thickness $6 \mathrm{~mm}$, Logitech, UK) as shown in Fig. 2.2(a). This imposes stringent requirements on the thickness and uniformity of the different layers in each of the three stacks, namely the glass substrates, the $\mathrm{KY}\left(\mathrm{WO}_{4}\right)_{2}$ samples and the adhesive layers in between, since it determines the final uniformity of the thin $\mathrm{KY}\left(\mathrm{WO}_{4}\right)_{2}$ slabs.

The first step in the bonding protocol is to ensure that all the glass substrates have identical thickness. To that aim, both the top and bottom surfaces are grinded on a cast iron disk using a $800 \mathrm{SiC}$ slurry. This step also permits enhancing the adhesion with the substrate. The thickness of the substrates is measured at the center and at the four corners of the substrate with a thickness measurement system equipped with an inductive probe with an accuracy of $0.2 \mu \mathrm{m}$ (Milimar C1208 and P1300, Mahr, GmbH, DE). If the height at those five points is not within the accuracy of the measurement system (i.e., $0.2 \mu \mathrm{m}$ ), 
additional grinding is done exerting higher pressure on the areas where the layer is thicker than the rest of the substrates. This process is repeated until all samples are parallel and have identical thickness (i.e., $\pm 0.4 \mu \mathrm{m}$ due to repeatability, hysteresis and error limit of the measurement system). With the same measurement technique, three identical $\mathrm{KY}\left(\mathrm{WO}_{4}\right)_{2}$ samples (Altechna, $\mathrm{LT}$ ) are selected from the batch of samples.

In order to verify that the glass substrates and $\mathrm{KY}\left(\mathrm{WO}_{4}\right)_{2}$ samples form an identical stack, they are positioned on top of the ultra-parallel plate. An optical flat is then placed on top of this configuration and illuminated with monochromatic light (Kemet, UK, Sodium line $\lambda=598 \mathrm{~nm}$ ) to inspect the Newton rings on the top layer. The position of the layer stacks is adjusted until less than 10 bright and dark fringes are visible (Fig. 2.2(b)). The $\mathrm{KY}\left(\mathrm{WO}_{4}\right)_{2}$ samples are then removed and a drop $(\sim 10 \mu \mathrm{L})$ of low-viscosity $\mathrm{UV}$-curable adhesive is applied on top of the substrate. The $\mathrm{KY}\left(\mathrm{WO}_{4}\right)_{2}$ samples are then carefully placed on top in the same position as before. The planarity of the stack is checked by looking at the Newton rings before curing. Finally, the adhesive is cured with the optical flat on top as load $\left(\sim 0.2 \mathrm{~N} / \mathrm{cm}^{2}\right)$.
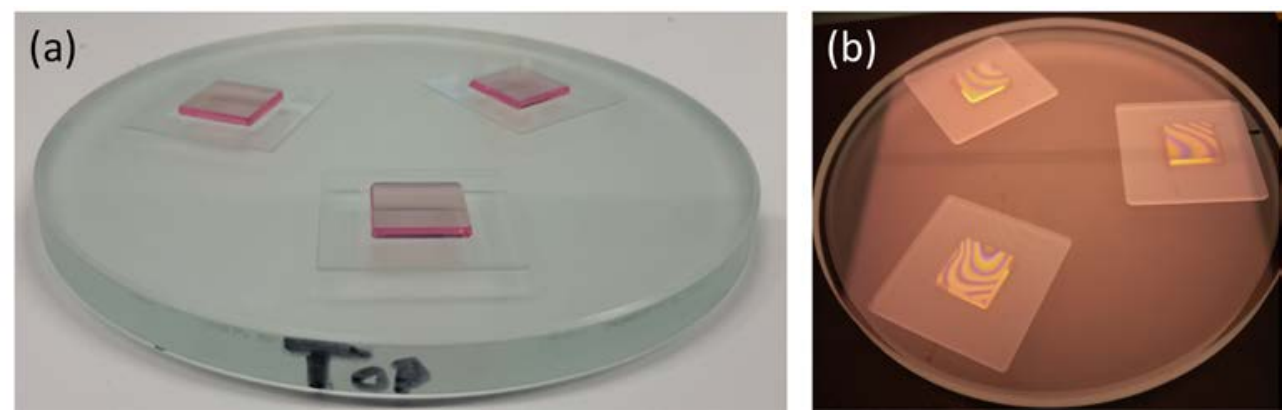

Fig. 2.2 Photographs of (a) three stacks consisting of $\mathrm{KY}\left(\mathrm{WO}_{4}\right)_{2}$ sample bonded with UV-curable adhesive onto MEMpax substrates and wax mounted on an ultra-parallel supporting glass for thinning and polishing. (b) Three stacks consisting of $\mathrm{KY}\left(\mathrm{WO}_{4}\right)_{2}$ samples on grinded soda-lime substrates with Newton rings, visible on the $\mathrm{KY}\left(\mathrm{WO}_{4}\right)_{2}-$ optical flat interface, to check the planarity of the stacks.

\subsubsection{Bonding using a flip-chip bonder}

A flip-chip bonder (Finetech GmbH, Lambda, DE) is used for precision bonding. The bonder has an in-plane alignment accuracy of $\pm 0.5 \mu \mathrm{m}$ and it can apply a uniform force ranging from 0.1 till $400.0 \mathrm{~N}$ on a sample. The optimal bonding force was found to be between 100 and $150 \mathrm{~N}$ to ensure a bond line of $\sim 1 \pm 0.5 \mu \mathrm{m}$ across the whole sample without defects and/or air traps induced by the bonding force [31]. Prior to bonding, both the sample and the substrate are cleaned for 15 minutes in an ultrasonic bath with DI water to remove particles on the surface followed by a chemical cleaning step in a $99 \%$ 
$\mathrm{HNO}_{3}$ bath for 10 minutes. Subsequently, both substrate and sample were treated with oxygen plasma (50 sccm $\mathrm{O}_{2}, 100 \mathrm{~W}, 5$ minutes) to activate the surfaces.

A gimbal tool was utilized in the flip-chip bonder to ensure perfect planarity between the $\mathrm{KY}\left(\mathrm{WO}_{4}\right)_{2}$ sample and the substrate. The gimbal was initialized by applying $400 \mathrm{~N}$ on a dummy $\mathrm{KY}\left(\mathrm{WO}_{4}\right)_{2}$ sample placed on top of a dummy substrate. The real sample and substrate were then mounted on the top and bottom of the bonder, respectively, and a drop of specified adhesive will be applied on the substrate. The $\mathrm{KY}\left(\mathrm{WO}_{4}\right)_{2}$ sample will be put in contact with the substrate by lowering the arm tool of the bonder. The bonding force and curing protocols for the bonding are then applied as required.

\subsubsection{Bonding using a flip-chip bonder and a substrate with pre-etched pillars}

To control the thickness and uniformity of the bond line, a structure of pillars ( $\varnothing 6 \mu \mathrm{m}$, spacing 100,250 or $500 \mu \mathrm{m}$, height $\sim 3 \mu \mathrm{m}$ ) was designed in a recessed region of dimensions $12 \times 12 \mathrm{~mm}^{2}$ to mimic a micro-bead filled adhesive, with which a planarity determined by the tolerance of the bead diameter can be achieved [32]. The pillar structures are microfabricated in the glass substrate (i.e., MEMpax or soda-lime glass) using standard lithography and fluorine based reactive ion etching [33]. An optical microscope image of a section of the fabricated structures on a MEMpax substrate is shown in Fig. 2.3(a). Figure 2.3(b) shows a schematic of a $\mathrm{KY}\left(\mathrm{WO}_{4}\right)_{2}$ sample bonded onto a structured substrate. The pillars determine the bonding height and the adhesive in the recessed region creates a strong bond between the substrate and the $\mathrm{KY}\left(\mathrm{WO}_{4}\right)_{2}$ sample. A small number of bubbles can be trapped in the adhesive due to the presence of the pillars, which should be minimized by proper surface activation of both the substrate and the sample by oxygen plasma. The pillars were designed so that the optical devices can be placed around the pillars, avoiding changes in the propagation characteristics of the final devices caused by addition of scattering points. 


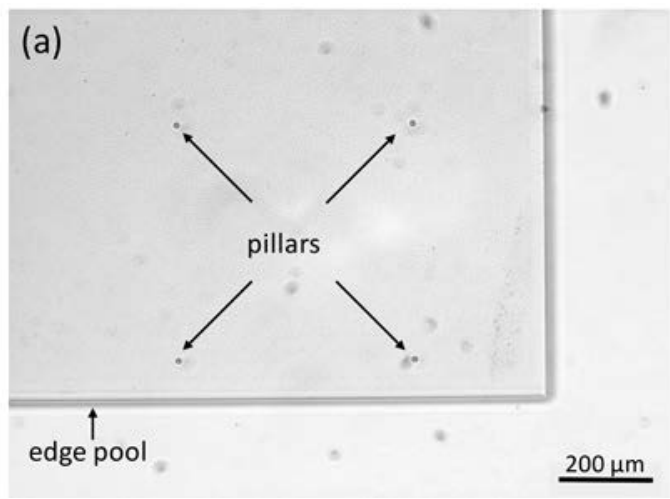

(b)

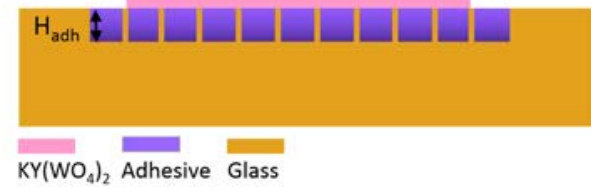

Fig. 2.3 (a) Top view of an optical microscope image with a corner section of the recessed region (i.e., pool). Inside the recessed region, pillars with a diameter of $6 \mu \mathrm{m}$ and a spacing of $500 \mu \mathrm{m}$ are visible. (b) Schematic representation of a $\mathrm{KY}\left(\mathrm{WO}_{4}\right)_{2}$ sample bonded on a MEMpax glass substrate with pillars of $\sim 2.8 \mu \mathrm{m}$ etched in the substrate.

\subsubsection{Bonding using a wafer bonder}

A wafer bonder, Suss MicroTec ELAN CB6L, was utilized in the bonding tests of $\mathrm{KY}\left(\mathrm{WO}_{4}\right)_{2}$ to glass using $\mathrm{BCB}$. Since this instrument is designed for the bonding of full wafers, the sample and substrate were clamped between two Pyrex wafers with a graphite sheet between the sample and the top wafer to equalize the bonding pressure. The temperature and pressure protocols for the bonding are then applied as required.

\subsection{Experimental results}

\subsubsection{Bonding using low temperature adhesive}

UV-curable adhesives allow bonding at room temperature. Two UV-curable adhesives, Bohle LV740 and NOA81 (Table 2.1) were investigated in this study.

Manual bonding was utilized to bond $\mathrm{KY}\left(\mathrm{WO}_{4}\right)_{2}$ samples onto a $20 \times 20 \mathrm{~mm}^{2}$ soda-lime substrate using Bohle LV740. The manual bonding process flow described in Section 2.3.1 was followed. The adhesive was cured with UV-light with a fluence of $1 \mathrm{~J} / \mathrm{cm}^{2}$. The process resulted in a mean bond line of $2.7 \mu \mathrm{m}$ with $\pm 1.0 \mu \mathrm{m}$ variation along the $8 \mathrm{~mm}$ length of the sample. A thinner more uniform bond line with a planarity in the tens of nanometer range is required to realize optical devices. To reduce the achievable bond line a larger load is needed. However, a heavier UV-transparent optical flat was not available. Therefore, it is concluded that manual bonding, with the available materials, is not suitable for the envisioned application. 
A $\mathrm{KY}\left(\mathrm{WO}_{4}\right)_{2}$ sample was bonded onto a $20 \times 20 \mathrm{~mm}^{2}$ MEMpax substrate using NOA81 and the flip-chip bonder method described in Section 2.3.2. A drop of $\sim 30 \mu \mathrm{L}$ of NOA81 was applied on the substrate before the sample and substrate where placed in contact. The applied force was built-up with a ramp of $5 \mathrm{~N} / \mathrm{s}$ until a total force of $100 \mathrm{~N}$ was reached. The arm tool stayed down for $\sim 40$ seconds. During this time, the adhesive is pre-cured by applying UV-irradiation with a handheld UV-gun (peak wavelength of $365 \mathrm{~nm}$ ). After bonding, the stack is fully cured with a total dose of $2 \mathrm{~J} / \mathrm{cm}^{2}$ in a UV-oven (Spectrolinker, XL-1500 UV crosslinker). The mean bond line with this procedure was $0.6 \mu \mathrm{m}$ with a variation of $\pm 0.4 \mu \mathrm{m}$ along the $8 \mathrm{~mm}$ length of the sample, which is not yet sufficient to fabricate thin $\mathrm{KY}\left(\mathrm{WO}_{4}\right)_{2}$ layers with tens of nanometers of maximum variation in thickness.

To increase the bond line uniformity, the method of using a substrate with pre-etched pillars acting as spacers is utilized. Bonding is carried out using NOA81 and the flipchip bonding procedure onto a MEMpax substrate with microfabricated pillars. The measured bond line was $2.7 \mu \mathrm{m}$ across the whole sample, which corresponds with the pillar height (i.e., measured height of the pillars was $2.8 \pm 0.2 \mu \mathrm{m}$ ). The thickness of the bond line can be accurately controlled by varying the reactive ion etching procedure of the pillars.

\subsubsection{Bonding using high temperature adhesive}

Epoxy based adhesives, with curing temperatures of $\sim 150{ }^{\circ} \mathrm{C}$ as well as BCB, with curing temperatures ranging from $165-250{ }^{\circ} \mathrm{C}$, were investigated. These adhesives increase the thermal budget in future processes (i.e., $\mathrm{T}_{\text {max_Uv }} \approx 120^{\circ} \mathrm{C}$ and $\mathrm{T}_{\text {max_epoxy }} \approx 250^{\circ} \mathrm{C}$ ), such as the deposition of a polishing stop [33] or the integration with a passive photonic platform. Increase of the thermal budget will also ensure a higher reliability during the use and lifetime of the devices. Cracking of the samples occurred due to the combination of the high bonding temperatures and the high CTE mismatch between the sample and the substrate. Trenches oriented along the crystalline direction of lower CTE (i.e., close to the $\mathbf{a}^{*}$-axis) succeeded in protecting the interface, resulting in a crack and defect free interface, where the optical devices will be fabricated (see Section 2.4.2.3).

\subsubsection{Bonding using high temperature epoxy}

Epoxy based adhesives are typically cured at elevated temperatures $\left(\sim 150{ }^{\circ} \mathrm{C}\right)$ to get maximal bonding strength. To obtain the highest planarity of the bond, a $\mathrm{KY}\left(\mathrm{WO}_{4}\right)_{2}$ sample was bonded on a MEMpax substrate with pillars, as described in Section 2.3.3, using a flip-chip bonder. 
Prior to bonding, both the substrate and sample had the same cleaning and surface activation process as described in Section 2.3.2. After cleaning and activation, both the sample and substrate were transferred to the flip-chip bonder. Five drops, with a total volume of $\sim 30 \mu \mathrm{L}$, of Epotek 353ND where placed at the center of the substrate. The curing protocol is as follow: first the temperature is raised to $70^{\circ} \mathrm{C}$ for 120 seconds to allow the adhesive to reflow. During the last 30 seconds of this stage, the arm with the sample was lowered and the force was built on the sample with a ramp of $5 \mathrm{~N} / \mathrm{s}$ up to $150 \mathrm{~N}$ where it stayed for 10 minutes. After the reflow step, the temperature was raised to $150{ }^{\circ} \mathrm{C}$ for 1 hour to fully cure the adhesive and finally the sample was cooled down to room temperature by natural convection. The first 20 minutes of the curing curve are shown in Fig. 2.4(a).

The sample cracked during the cooling step when reaching the temperature of $80^{\circ} \mathrm{C}$, which indicates that the stress in the layer was too big due to the CTE mismatch between the $\mathrm{KY}\left(\mathrm{WO}_{4}\right)_{2}$ sample and the MEMpax substrate. The cracks are mainly along the $\mathbf{a}^{*}$ axis, as shown in Fig. 2.4(b), which can be explained by the fact that the highest thermal expansion is close to the $\mathbf{c}^{*}$-axis. The $\mathbf{c}^{*}$-axis is almost perpendicular to the $\mathbf{a}^{*}$-axis (i.e., angle between $\mathbf{a}^{*}$-c* axis is $\sim 94^{\circ}$ ), which has the lowest CTE in the $\mathbf{a}^{*}$-c* plane of the crystal. When the crystal cools down, it will be compressed along the $\mathbf{a}^{*}$-axis and it is most likely to crack in this direction. A few cracks along the a-axis of the crystal were also observed. Those cracks cannot directly be explained by the crystalline structure and they are also seen during the growth of lattice and refractive index engineered $\mathrm{KY}\left(\mathrm{WO}_{4}\right)_{2}: \mathrm{Gd}, \mathrm{Lu}, \mathrm{Yb}$ layers on undoped substrates using liquid phase epitaxy [6].

(a)

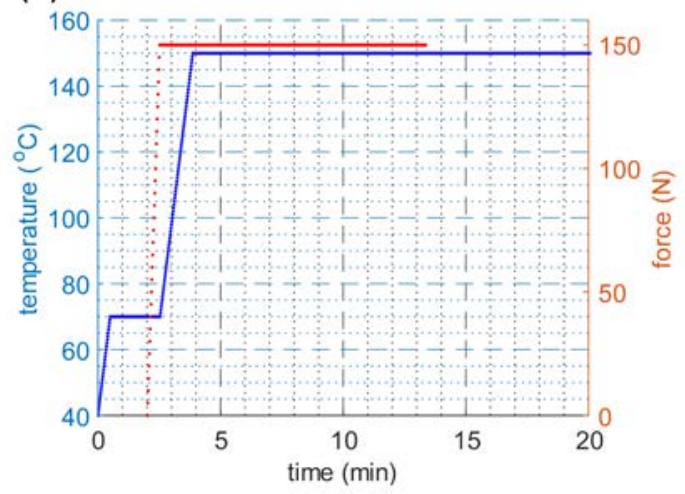

(b)

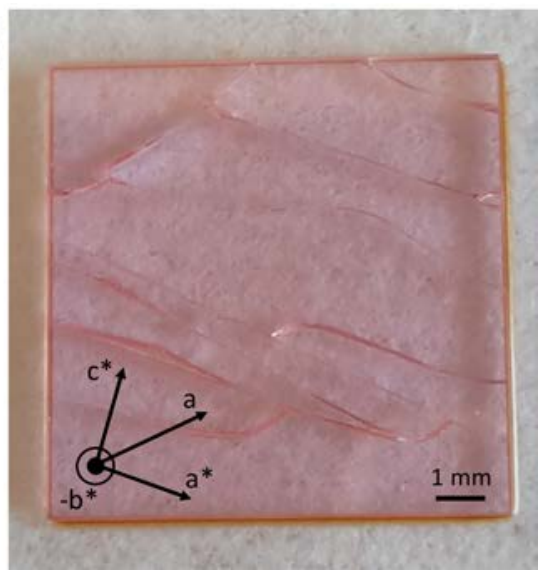

Fig. 2.4 (a) First 20 minutes of the flip-chip bonding temperature and force profiles. The sample stays at $150{ }^{\circ} \mathrm{C}$ for 1 hour before it is cooled by natural convection. (b) Photograph of a $\mathrm{KY}\left(\mathrm{WO}_{4}\right)_{2}$ sample bonded on a MEMpax substrate at $150^{\circ} \mathrm{C}$, where cracks mainly occur along the $\mathbf{a}^{*}$-axis. 


\subsubsection{Bonding using BCB}

Benzocyclobutene (BCB) has been reported to provide very uniform, thin, strong bond lines [21], which is ideal for our applications. Therefore, tests were performed to bond a $\mathrm{KY}\left(\mathrm{WO}_{4}\right)_{2}$ sample to a soda-lime substrate (to minimize the CTE mismatch) using a $500 \mathrm{~nm}$ thick BCB layer. This adhesive is commonly cured at temperatures above $250{ }^{\circ} \mathrm{C}$ to obtain the strongest possible bond [30]. In this study, three bonding tests were performed at $230{ }^{\circ} \mathrm{C}, 190^{\circ} \mathrm{C}$ and $165^{\circ} \mathrm{C}$ respectively. The corresponding curing times are $\sim 2,10$ and 36 hours, respectively.

Prior to bonding, the sample and substrate were cleaned for 15 minutes in an ultrasonic bath with DI water to remove particles on the surface followed by a chemical cleaning step in a $99 \% \mathrm{HNO}_{3}$ bath for 10 minutes. A mixture of 1:2 = BCB : mesitylene was spincoated at $3000 \mathrm{rpm}$ for 40 seconds on the soda-lime substrate to obtain a $500 \mathrm{~nm}$ thick adhesive layer. The sample and substrate are then mounted in the wafer bonder as described in Section 2.3.4. The curing curve is as follows: first, the temperature is raised, with a ramp of $\sim 1.7^{\circ} \mathrm{C} / \mathrm{min}$ to $150{ }^{\circ} \mathrm{C}$ to pre-cure the adhesive for 20 minutes. After precuring, the temperature is raised again, with a ramp of $\sim 1.0^{\circ} \mathrm{C} / \mathrm{min}$, to the final curing temperature. A bonding force of $165 \mathrm{~N}$ is applied on the 4 inch Pyrex wafer during the time of pre-curing and temperature raise. Finally, the sample is cooled by natural convection to roughly $40^{\circ} \mathrm{C}$ before unloading. The first part of the bonding procedure is shown in Fig. 2.5(a). Again, the samples cracked along the $\mathbf{a}^{*}$-axis as shown in Fig. 2.5(b). This indicates that the CTE mismatch between the $\mathrm{KY}\left(\mathrm{WO}_{4}\right)_{2}$ sample and soda-lime substrate is still too large.

(a)

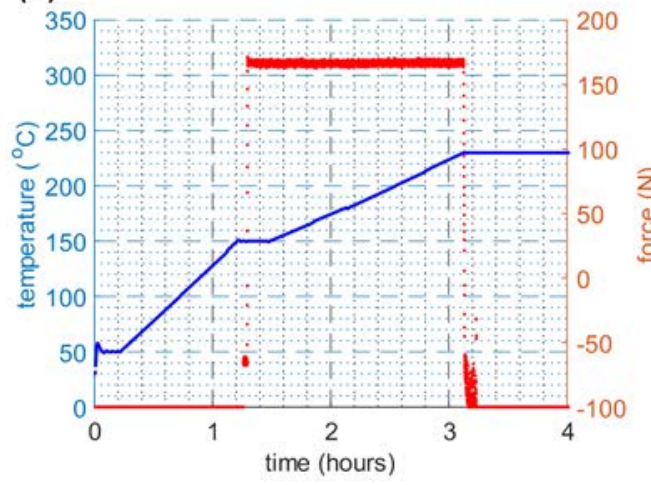

(b)

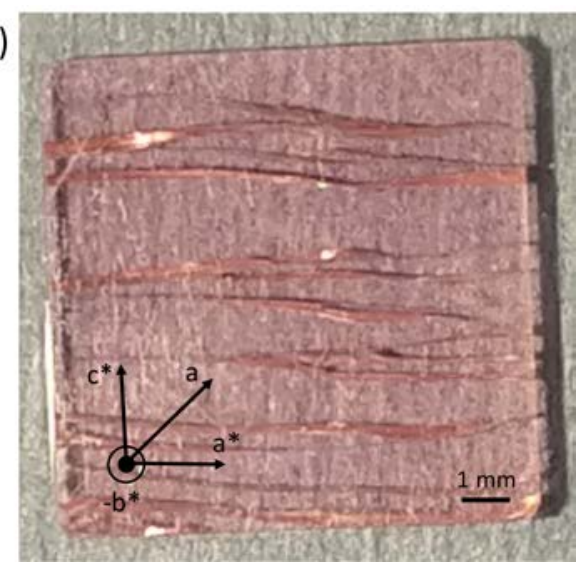

Fig. 2.5 (a) First 4 hours of bonding temperature and force profile. (b) Photograph of a $\mathrm{KY}\left(\mathrm{WO}_{4}\right)_{2}$ sample bonded at $250{ }^{\circ} \mathrm{C}$ to a soda-lime substrate, cracks mainly occur along the $\mathbf{a}^{*}$-axis. 


\subsubsection{Stress relief trenches in sample}

All bonding tests at curing temperatures above $150{ }^{\circ} \mathrm{C}$ had cracks mainly along the $\mathbf{a}^{*}$ axis. In order to bond at elevated temperatures without cracks at the interface between the sample and the substrate, trenches were diced on the surface of the $\mathrm{KY}\left(\mathrm{WO}_{4}\right)_{2}$ sample along the $\mathbf{a}^{*}$-axis to release stress at the interface and guide the cracks to the top surface (i.e., non-bonding surface) of the sample. The trenches are $50 \mu \mathrm{m}$ wide and $250 \mu \mathrm{m}$ deep with a heart-to-heart distance of $550 \mu \mathrm{m}$ along the $\mathbf{a}^{*}$-axis of the crystal, as can be seen in Fig. 2.6(a) and (b).

A $\mathrm{KY}\left(\mathrm{WO}_{4}\right)_{2}$ sample with trenches was bonded onto a soda-lime substrate (i.e., to have the lowest CTE mismatch between the sample and substrate) using the flip-chip bonder method described in Section 2.3.2. Prior to bonding, the substrate was cleaned for 15 minutes in an ultrasonic bath with DI water to remove particles on the surface followed by a chemical cleaning step in a $99 \% \mathrm{HNO}_{3}$ bath for 10 minutes and functionalized with a $1 \%$ saline solution because the oxygen plasma treatment was not sufficient to obtain the correct surface energy match between the substrate and the adhesive. After this step, Epotek 377 was spin-coated at $6000 \mathrm{rpm}$ for 45 seconds and was reflown at $80^{\circ} \mathrm{C}$ for 5 minutes on the heating plate of the flip-chip bonder. After reflow, the $\mathrm{KY}\left(\mathrm{WO}_{4}\right)_{2}$ sample was placed in contact with the soda-lime substrate by lowering the arm tool of the flip-chip bonder and the force was built up to $10 \mathrm{~N}$, to prevent that the adhesive bulge up more than $2 \mu \mathrm{m}$. The adhesive was finally cured for 1 hour at $150{ }^{\circ} \mathrm{C}$, and afterwards it cooled down by convection.

Again cracks occurred in the layer, as shown in Fig. 2.6(a), but now they originate from the most inner part of the trench and propagate to the top surface of the crystal. This leaves a defect free interface between the sample and substrate, which potentially can be used for optical devices after the bulk layer is thinned down to the required thickness.

The bonding process with stress relief trenches was repeated using a $1 \mu \mathrm{m}$ thick BCB layer in the wafer bonder (Section 2.3.4). The process is similar to the one described in Section 2.4.2.2 and the adhesive was cured at $210{ }^{\circ} \mathrm{C}$ for 8 hours. In this case the stress was relieved mainly from the trenches (along the $\mathbf{a}^{*}$-axis) as shown in Fig. 2.6(b). Some of the cracks propagate in a diagonal from one trench to another along the a-axis. As mentioned before, those types of cracks were also reported during the growth of lattice and refractive index engineered $\mathrm{KY}\left(\mathrm{WO}_{4}\right)_{2}: \mathrm{Gd}$, $\mathrm{Lu}, \mathrm{Yb}$ layers on undoped $\mathrm{KY}\left(\mathrm{WO}_{4}\right)_{2}$ substrates using liquid phase epitaxy [6]. 
(a)

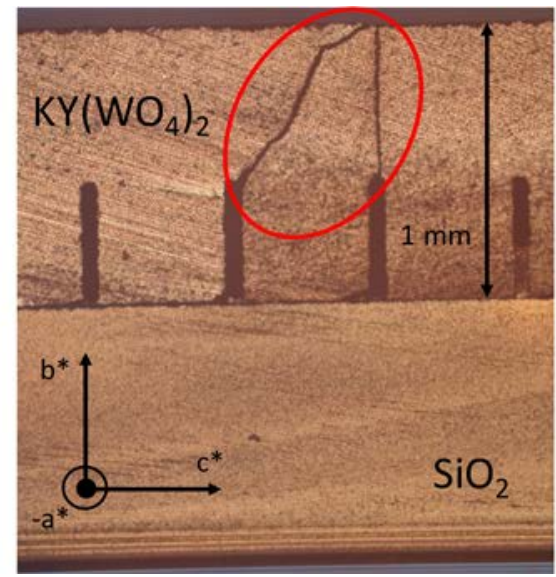

(b)

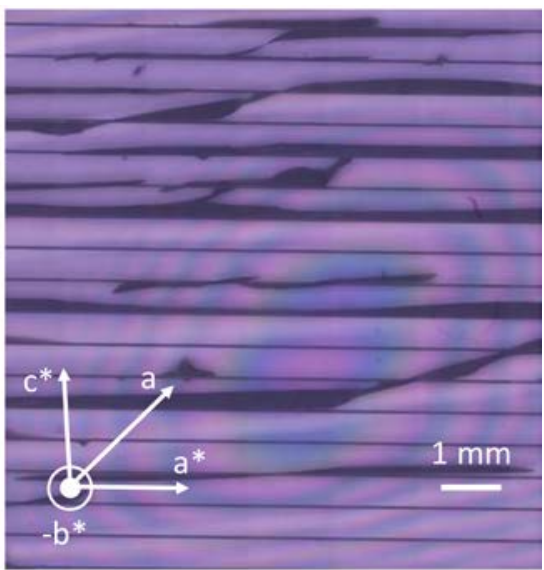

Fig. 2.6 (a) Side view microscope image of a $\mathrm{KY}\left(\mathrm{WO}_{4}\right)_{2}$ sample with trenches bonded with Epotek 377 onto a soda-lime substrate where cracks originate from the top of the trench and propagate towards the top surface of the crystal, indicated with red circle. (b) Photograph in top view of a $\mathrm{KY}\left(\mathrm{WO}_{4}\right)_{2}$ sample with trenches bonded with $\mathrm{BCB}$ on soda-lime glass. The cracks propagate to the top surface and are mainly along the a*-axis.

\subsubsection{Direct bonding}

A KY $\left(\mathrm{WO}_{4}\right)_{2}$ sample has been bonded onto a custom-made $\mathrm{GO} 14^{\circledR}$ silicate glass using the direct wafer bonding technique [34]. Direct wafer bonding requires no adhesives and consists of a direct wafer-to-wafer contact between two hydrophilic surfaces. The process induces a surface reorganization based on three mechanisms: spontaneous adhesion based on Van der Walls forces and $\mathrm{OH}$ groups, slow fracture effect and consolidation by thermal annealing resulting in the creation of covalent bonds between the two surfaces. Its quality depends on the number of hydroxyl groups at both surfaces and it is therefore strongly dependent upon the cleanness and the activation of the wafers. The process that has been used here is directly derived from the SOI one as described by [34]. The only difference is that the temperature of the thermal annealing has been lowered from above $800{ }^{\circ} \mathrm{C}$ to $150^{\circ} \mathrm{C}$ in order to prevent melting of the glass. This change entailed an increase of the annealing time to 72 hours in order to provide enough energy to create the covalent bonds. A previous study [25] showed that, with such a process, a surface energy, $\gamma$, greater than $1 \mathrm{~J} / \mathrm{m}^{2}$ is achieved, which allows the bond to withstand standard mechanical processes such as dicing and polishing. After the molecular bonding, both surfaces are crack free, as shown in Fig. 2.7. With this procedure there is no bond line, which is very promising for future processing and fabrication of optical devices. 


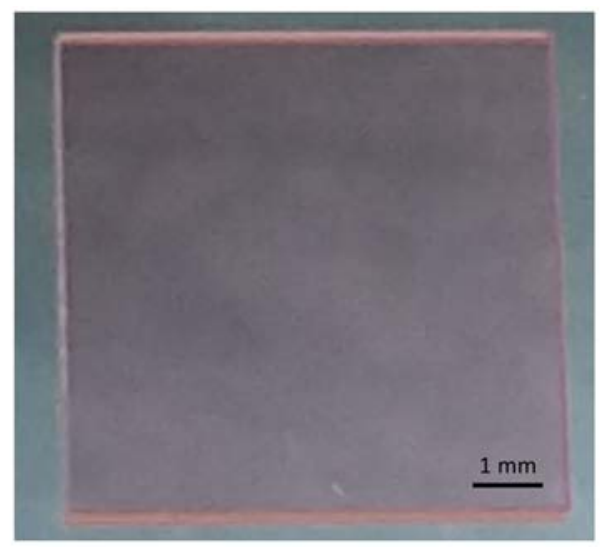

Fig. 2.7. Photograph of direct bonded $\mathrm{KY}\left(\mathrm{WO}_{4}\right)_{2}$ onto GO14 silicate glass.

\subsection{Discussion}

In the previous sections, different bonding processes are discussed to integrate $\mathrm{KY}\left(\mathrm{WO}_{4}\right)_{2}$ crystals onto glass substrates. Low and high curing temperature adhesives as well as direct bonding have been investigated. All of those methods, together with their associated bonding procedures, have their own advantages and disadvantages.

UV-curable adhesives have as advantage that there is no temperature increase during the bonding process and therefore the CTE mismatch between sample and substrate does not play a role. A substrate mimicking a microbead filled epoxy was developed to fulfill the specifications for the thickness and uniformity of the bond line (i.e., maximum deviation of tens of nanometers across the whole sample). $\mathrm{KY}\left(\mathrm{WO}_{4}\right)_{2}$ samples were bonded using a flip-chip bonder with a gimbal tool with UV-curable adhesive (NOA81) to these engineered substrates to achieve a perfectly planar bond across the sample with the desired thickness (i.e., given by the height of the microfabricated pillars in the substrate).

However, in the future integration of the laser crystals to a passive integrated photonics platform, the thermal budget of the adhesive comes into play. The room temperature adhesives used in this study degrade if they are exposed for a long time to a temperature above $120^{\circ} \mathrm{C}$. Therefore, high temperature adhesives are studied to increase the thermal budget. However, the high temperature adhesives require curing temperatures above $150{ }^{\circ} \mathrm{C}$. Such high temperatures increase stress due to the large CTE mismatch between the sample and the substrate. Even with a low temperature ramp of $<1^{\circ} \mathrm{C} / \mathrm{min}$, the sample cracks during cooling. We demonstrate that trenches diced along the $\mathbf{a}^{*}$-axis of the crystal guide the cracks from the bottom of the trench to the top surface of the sample, leaving a defect free interface between the $\mathrm{KY}\left(\mathrm{WO}_{4}\right)_{2}$ sample and the 
glass substrate. Those trenches, in combination with even smaller BCB bond lines, can pave the way to future integration to other passive platforms.

The most planar bond is achieved using low temperature direct bonding, which is preferential for future integration. This bonding method, however, had the longest annealing time ( 72 hours) and need ultra-smooth surfaces (RMS roughness $<1.5 \mathrm{~nm}$ [35]). Therefore, additional polishing can be necessary to achieve a void free bonding surface.

\subsection{Conclusion}

A perfectly planar bond was achieved with a flip-chip bonder using a room temperature curable adhesive and a substrate that mimics a micro bead filled adhesive. For adhesives requiring a curing temperature above $150^{\circ} \mathrm{C}$, cracks appeared upon cooling due to the CTE mismatch between sample and substrate. Stress-relief trenches diced along the $\mathbf{a}^{*}$ axis made it possible to guide the cracks to the top surface of the crystal. This resulted in a defect-free interface between the crystal sample and glass substrate for the majority of the surface. Finally, a $\mathrm{KY}\left(\mathrm{WO}_{4}\right)_{2}$ sample was bonded, for the first time to our knowledge, crack-free to a glass substrate using low temperature direct wafer bonding.

The bonding techniques developed in this work pave the way towards the development of $\mathrm{KY}\left(\mathrm{WO}_{4}\right)_{2}$-on-glass devices integrated onto passive technology platforms. 


\section{References}

[1] A. A. Kaminskii, A. F. Konstantinova, V. P. Orekhova, A. V Butashin, R. F. Klevtsova, and A. A. Pavlyuk, "Optical and nonlinear laser properties of the $\chi^{(3)}$-active monoclinic $\alpha-\mathrm{KY}\left(\mathrm{WO}_{4}\right)_{2}$ crystals," Crystallogr. Reports 46, 665-672 (2001)

[2] X. Mateos, R. Solé, J. Gavaldà, M. Aguiló, J. Massons, and F. Díaz, "Crystal growth, optical and spectroscopic characterisation of monoclinic $\mathrm{KY}\left(\mathrm{WO}_{4}\right)_{2}$ co-doped with $\mathrm{Er}^{3+}$ and $\mathrm{Yb}^{3+}$," Opt. Mater. (Amst). 28, 423-431 (2006)

[3] Y.-S. Yong, S. Aravazhi, S. A. Vázquez-Córdova, J. J. Carjaval, F. Díaz, J. L. Herek, S. M. García-Blanco, and M. Pollnau, "Temperature-dependent absorption and emission of potassium double tungstates with high ytterbium content.," Opt. Express 24, 26825-26837 (2016)

[4] I. M. Krygin, A. D. Prokhorov, V. P. D’yakonov, M. T. Borowiec, and H. Szymczak, "Spin-spin interaction of Dy ${ }^{3+}$ ions in KY(WO4)2," Phys. Solid State 44, 1587-1596 (2002)

[5] W. Bolaños, J. J. Carvajal, X. Mateos, G. S. Murugan, A. Z. Subramanian, J. S. Wilkinson, E. Cantelar, D. Jaque, G. Lifante, M. Aguiló, and F. Díaz, "Mirrorless buried waveguide laser in monoclinic double tungstates fabricated by a novel combination of ion milling and liquid phase epitaxy," Opt. Express 18, 26937 (2010)

[6] S. Aravazhi, D. Geskus, K. van Dalfsen, S. A. Vázquez-Córdova, C. Grivas, U. Griebner, S. M. García-Blanco, and M. Pollnau, "Engineering lattice matching, doping level, and optical properties of $\mathrm{KY}\left(\mathrm{WO}_{4}\right)_{2}: \mathrm{Gd}, \mathrm{Lu}, \mathrm{Yb}$ layers for a cladding-side-pumped channel waveguide laser," Appl. Phys. B 111, 433-446 (2013)

[7] K. van Dalfsen, S. Aravazhi, C. Grivas, S. M. García-Blanco, and M. Pollnau, "Thulium channel waveguide laser with $1.6 \mathrm{~W}$ of output power and $\sim 80 \%$ slope efficiency," Opt. Lett. 39, 4380 (2014)

[8] D. Geskus, S. Aravazhi, K. Wörhoff, and M. Pollnau, "High-power, broadly tunable, and lowquantum-defect $\mathrm{KGd}_{1-\mathrm{x}} \mathrm{Lu}_{\mathrm{x}}\left(\mathrm{WO}_{4}\right)_{2}: \mathrm{Yb}^{3+}$ channel waveguide lasers.," Opt. Express 18, 26107-12 (2010)

[9] D. Geskus, S. Aravazhi, C. Grivas, K. Wörhoff, and M. Pollnau, "Microstructured $\mathrm{KY}\left(\mathrm{WO}_{4}\right)_{2}: \mathrm{Gd}^{3+}, \mathrm{Lu}^{3+}, \mathrm{Yb}^{3+}$ channel waveguide laser," Opt. Express 18, 22417-22422 (2010)

[10] F. Piantedosi, G. Y. Chen, T. M. Monro, and D. G. Lancaster, "Widely tunable, high slope efficiency waveguide lasers in a Yb-doped glass chip operating at $1 \mu \mathrm{m}$," Opt. Lett. 43, 1902 (2018)

[11] R. Mary, S. J. Beecher, G. Brown, R. R. Thomson, D. Jaque, S. Ohara, and A. K. Kar, "Compact, highly efficient ytterbium doped bismuthate glass waveguide laser," Opt. Lett. 37, 1691 (2012)

[12] Y. Tan, A. Rodenas, F. Chen, R. R. Thomson, A. K. Kar, D. Jaque, and Q. Lu, "70\% slope efficiency from an ultrafast laser-written $\mathrm{Nd}: \mathrm{GdVO}_{4}$ channel waveguide laser," Opt. Express 18, 24994 (2010)

[13] T. Calmano, A.-G. Paschke, S. Müller, C. Kränkel, and G. Huber, "Curved Yb:YAG waveguide lasers, fabricated by femtosecond laser inscription," Opt. Express 21, 25501 (2013)

[14] J. Siebenmorgen, T. Calmano, K. Petermann, and G. Huber, "Highly efficient Yb:YAG channel waveguide laser written with a femtosecond-laser," Opt. Express 18, 16035 (2010)

[15] F. Chen and J. R. V. de Aldana, "Optical waveguides in crystalline dielectric materials produced by femtosecond-laser micromachining," Laser Photon. Rev. 8, 251-275 (2014)

[16] M. A. Sefunc, F. B. Segerink, and S. M. García-Blanco, "High index contrast passive potassium double tungstate waveguides," Opt. Mater. Express 8, 629 (2018)

[17] P. A. Loiko, K. V. Yumashev, N. V. Kuleshov, G. E. Rachkovskaya, and A. A. Pavlyuk, "Detailed characterization of thermal expansion tensor in monoclinic $\mathrm{KRe}\left(\mathrm{WO}_{4}\right)_{2}$ (where $\mathrm{Re}=\mathrm{Gd}, \mathrm{Y}, \mathrm{Lu}$, Yb)," Opt. Mater. (Amst). 34, 23-26 (2011)

[18] SCHOTT, "MEMpax $\quad$ S Ultra-Thin Borosilicate Glass," 
http://www.schott.com/advanced_optics/english/products/optical-materials/thinglass/mempax/index.html

[19] "ThermoFisher Scientific: Typical values of Microslides (Soda Lime Glass)," 8983 (n.d.)

[20] Schott, "MICROCROWN Microscopy Glass,"

https://www.schott.com/advanced_optics/english/products/optical-materials/thinglass/microscopy-glass-microcrown/index.html

[21] S. Keyvaninia, M. Muneeb, S. Stankovic, P. J. Van Veldhoven, D. Van Thourhout, and G. Roelkens, "Ultra-thin DVS-BCB adhesive bonding of III-V wafers, dies and multiple dies to a patterned silicon-on-insulator substrate," Opt. Mater. Express 3, 35-46 (2013)

[22] S. Stanković, R. Jones, J. Heck, M. Sysak, D. Van Thourhout, and G. Roelkens, "Die-to-Die Adhesive Bonding Procedure for Evanescently-Coupled Photonic Devices," Electrochem. SolidState Lett. 14, H326 (2011)

[23] W. P. Maszara, G. Goetz, A. Caviglia, and J. B. McKitterick, "Bonding of silicon wafers for silicon-on-insulator," J. Appl. Phys. 64, 4943-4950 (1988)

[24] G. Kissinger and W. Kissinger, "Void-free silicon-wafer-bond strengthening in the $200-400{ }^{\circ} \mathrm{C}$ range," Sensors Actuators A Phys. 36, 149-156 (1993)

[25] T. Allenet, D. Bucci, F. Geoffray, F. Canto, L. Couston, E. Jardinier, and J.-E. Broquin, "Packaged integrated opto-fluidic solution for harmful fluid analysis," in J.-E. Broquin and G. Nunzi Conti, eds. (International Society for Optics and Photonics, 2016), Vol. 9750, p. 975011

[26] Bohle, "UV-Klebstoff Verifix LV 740," 1-2 (n.d.)

[27] NORLAND PRODUCTS INCORPORATED, "Norland Optical Adhesive 81," 1-2 (1966)

[28] Epoxy Technology, "EPO-TEK 353ND," 1-2 (2014)

[29] Epoxy Technology, "EPO-TEK 377," 1-2 (2015)

[30] Dow Chemical Company, "CYCLOTENE TM 3000 Series Advanced Electronics Resins," 1-10 (2012)

[31] M. A. Sefunc, "New architectures for integrated optics: low-loss tight bends and on-chip highindex-contrast potassium double tungstate waveguides," University of Twente (2016)

[32] S. Park, J. H. Park, S. Hwang, and J. Kwak, "Bench-top fabrication and electrochemical applications of a micro-gap electrode using a microbead spacer," Electrochem. commun. 68, 7680 (2016)

[33] C. I. van Emmerik, S. M. Martinussen, J. Mu, M. Dijkstra, R. Kooijman, S. M. S. M. GarcíaBlanco, J. Mu, and R. Kooijman, "A novel polishing stop for accurate integration of potassium yttrium double tungstate on a silicon dioxide platform," Proc. IEEE Phot. Soc. Benelux 10535, 184-187 (2017)

[34] U. Tong, Q.-Y.; Gösele, Semiconductor Wafer Bonding: Science and Technology (John Willey \& sons, inc, 1999)

[35] K. Tanabe, K. Watanabe, and Y. Arakawa, "III-V/Si hybrid photonic devices by direct fusion bonding," Sci. Rep. 2, 1-6 (2012) 


\section{Chapter 3}

\section{Lapping and polishing of crystalline $\mathrm{KY}\left(\mathrm{WO}_{4}\right)_{2}$ : toward high refractive index contrast slab waveguides}

Rare-earth ion doped potassium yttrium double tungstate, $R E: K Y\left(W O_{4}\right)_{2}$, is a promising candidate for small, power-efficient, on-chip lasers and amplifiers. Thin $\mathrm{KY}\left(\mathrm{WO}_{4}\right)_{2}$-on-glass layers with thicknesses ranging between $0.9 \mu \mathrm{m}$ and $1.6 \mu \mathrm{m}$ are required to realize on-chip lasers based on high refractive index contrast waveguides operating between $1.55 \mu \mathrm{m}$ and $3.00 \mu \mathrm{m}$. The crystalline nature of $\mathrm{KY}\left(\mathrm{WO}_{4}\right)_{2}$ makes growth of thin, defect free layers on amorphous glass substrates impossible. Heterogeneous integration is one of the promising approaches to achieve thin $\mathrm{KY}\left(\mathrm{WO}_{4}\right)_{2}$-on-glass layers. In this process, crystal samples, with a thickness of $1 \mathrm{~mm}$, are bonded onto a glass substrate and thinned down with an extensive lapping and polishing procedure to the desired final thickness. In this work, a lapping and polishing process for $\mathrm{KY}\left(\mathrm{WO}_{4}\right)_{2}$ is developed towards the realization of integrated active optical devices in this material.

This chapter is published as:

C.I. van Emmerik, R. Kooijman, M, M. Dijkstra and S.M. García-Blanco, "Lapping and polishing of crystalline $\mathrm{KY}\left(\mathrm{WO}_{4}\right)_{2}$ : toward high refractive index contrast slab waveguides” Micromachines, 10(10), 674 (2019) 


\subsection{Introduction}

Potassium double tungstate (i.e., $\left.\mathrm{KY}\left(\mathrm{WO}_{4}\right)_{2}, \mathrm{KGd}\left(\mathrm{WO}_{4}\right)_{2}, \mathrm{KLu}\left(\mathrm{WO}_{4}\right)_{2}\right)$ is used for decades as active material for high power ultra-short pulsed lasers [1,2], thin disk lasers [3,4] and Raman lasers [5-7]. The large interionic distance $(\langle d\rangle \approx 0.4 \mathrm{~nm}[8])$ of $\mathrm{KY}\left(\mathrm{WO}_{4}\right)_{2}$ allows to dope it with high concentrations of rare-earth ions [9-11] without experiencing quenching effects. The crystal provides high emission and absorption cross-section for rare-earth ions doped in it [11]. These properties in combination with its relatively high refractive index ( $n \approx 2$ at $1550 \mathrm{~nm}[12])$ makes $\mathrm{KY}\left(\mathrm{WO}_{4}\right)_{2}$ an interesting material for the realization of small, high-contrast, low threshold, powerefficient on-chip lasers and amplifiers.

Waveguide amplifiers [10] and lasers [13-15] fabricated in low refractive index contrast waveguides have been experimentally demonstrated in $\mathrm{KY}\left(\mathrm{WO}_{4}\right)_{2}$ over the past decade. Those devices were fabricated using liquid phase epitaxy (LPE) to grow an optical quality, lattice matched, refractive index engineered, doped layer onto an undoped seed crystal [16,17]. A refractive index contrast $\Delta n \sim 0.02[16,17]$ could be achieved using this technique. Excellent optical performance has been demonstrated in such devices, including a highly efficient thulium laser with a maximum output power of $1.6 \mathrm{~W}$ and slope efficiency of $\sim 80 \%$ [13] and devices lasing at $\sim 1 \mu \mathrm{m}$ with wide tunability $[14,15]$ and high optical gain [18].

Increasing the refractive index contrast between the core layer and the cladding will increase the efficiency of the fabricated devices by increasing the field intensity on the doped material. Swift heavy ion irradiation (12 MeV carbon ions) has been used to fabricate planar waveguides by introducing a buried layer with a lower refractive index approximately $\sim 1 \mu \mathrm{m}$ below the surface of the substrate [19]. The lower refractive index layer results from the amorphization of the crystalline $\mathrm{KY}\left(\mathrm{WO}_{4}\right)_{2}$ material by the energy deposited by the incident ions via electronic interactions. After an annealing step, to repair residual damage in the waveguide core, a refractive index contrast of $\sim 0.15$ was obtained with optical slab propagation losses below $1.5 \mathrm{~dB} / \mathrm{cm}$ at $1550 \mathrm{~nm}$ [19]. A refractive index contrast ranging from 0.4 to 0.6 can be achieved by the integration of $\mathrm{KY}\left(\mathrm{WO}_{4}\right)_{2}$ onto a glass substrate. Sefünç et al. have demonstrated the integration of $\mathrm{KY}\left(\mathrm{WO}_{4}\right)_{2}$ on a glass substrate using room temperature curable adhesive (NOA81) and an extensive lapping and polishing procedure to thin a bulk crystal from $1 \mathrm{~mm}$ down to $2.4 \mu \mathrm{m}$ [20]. Waveguides with a maximum length of $300 \mu \mathrm{m}$ were fabricated using focused ion beam (FIB) milling. Optical losses below $1.5 \mathrm{~dB} / \mathrm{cm}$ were measured for rib waveguides at $1550 \mathrm{~nm}$. FIB milling of waveguides is time consuming and stitching errors will occur during fabrication of millimeter long devices. Standard lithography and reactive ion etching can be used to fabricate millimeters long waveguides in a 
reproducible manner. A defect free $\mathrm{KY}\left(\mathrm{WO}_{4}\right)_{2}$ layer with a layer thickness between $0.90 \mu \mathrm{m}$ to $1.60 \mu \mathrm{m}$, depending on the application, and with a maximum deviation of $\pm 0.02 \mu \mathrm{m}$ across the whole $10 \times 10 \mathrm{~mm}^{2}$ sample surface is required to enable this fabrication process.

In this work, we present the development of a lapping and polishing process made on thick $(>300 \mu \mathrm{m}) \mathrm{KY}\left(\mathrm{WO}_{4}\right)_{2}$ layers. The results of applying the developed process to thin $\mathrm{KY}\left(\mathrm{WO}_{4}\right)_{2}$ substrates down to $<2 \mu \mathrm{m}$ thick layers are reported. Finally, the future challenges for the realization of integrated active optical devices in $\mathrm{KY}\left(\mathrm{WO}_{4}\right)_{2}$-on-glass are discussed.

\subsection{Preparation of $\mathrm{KY}\left(\mathrm{WO}_{4}\right)_{2}$-on-glass assemblies}

The following section details the preparation of $\mathrm{KY}\left(\mathrm{WO}_{4}\right)_{2}$ assemblies (i.e., $\mathrm{KY}\left(\mathrm{WO}_{4}\right)_{2}$ bonded onto a glass substrate) for the lapping and polishing process.

\subsubsection{Three-grade beveled $\mathrm{KY}\left(\mathrm{WO}_{4}\right)_{2}$ edges}

The $\mathrm{KY}\left(\mathrm{WO}_{4}\right)_{2}$ samples used in this study (Altechna, LT) are $10 \times 10 \times 1 \mathrm{~mm}^{3}$ slabs optically polished (i.e., root mean square (RMS) roughness $<1.5 \mathrm{~nm}$ ) on one side and low grade polished (i.e., RMS roughness $<30 \mathrm{~nm}$ ) on the other. The sides of the, as delivered, samples are rough and they have beveled facets of several tens of micrometers from the polishing process (Fig. 3.1(a)). The roughness on the side facets of the samples created chipped edges during the lapping process, which created defects on the sample surface. The existing beveled facets from the manufacturer are not favorable for the thinning procedure because they result in sharp vulnerable edges when the layer becomes thin, as illustrated in Fig. 3.1(b). A method is developed to create smooth three-grade beveled $\mathrm{KY}\left(\mathrm{WO}_{4}\right)_{2}$ facets with blunt corners (Fig. 3.1(b)). The blunt corners in combination with the different roughness will prevent the edges from chipping. 
(a)

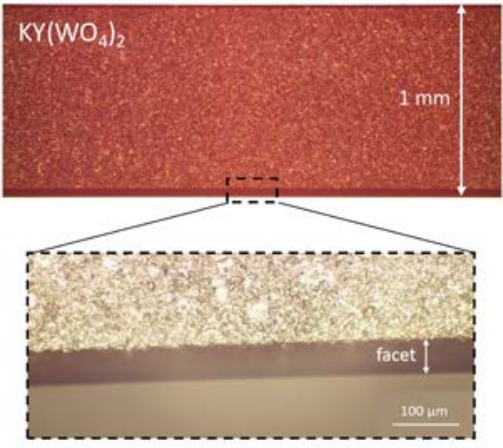

(b)

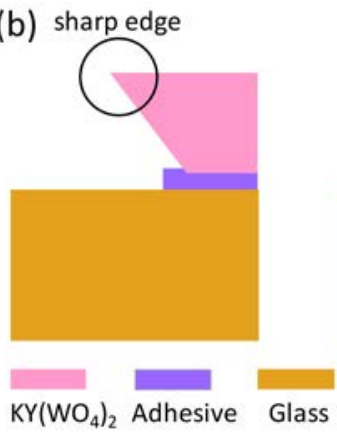

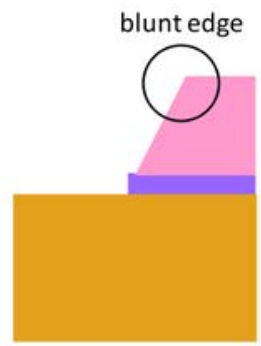

Fig. 3.1 (a) Front view, microscope image of the edge of an as delivered $\mathrm{KY}\left(\mathrm{WO}_{4}\right)_{2}$ sample from the manufacturer, showing the beveled facet and roughness. (b) Side view illustration of a sharp and a blunt edge of a roughly $50 \mu \mathrm{m}$ thick $\mathrm{KY}\left(\mathrm{WO}_{4}\right)_{2}$ sample. The sharp edge is vulnerable for chipping whereas the chance of chipping of the edge is limited for the blunt edge.

The corners of the samples are rounded, prior to beveling, again to prevent chipping. This is done by manually turning the corner of the sample over wet rotating sandpaper of consecutively $15 \mu \mathrm{m} \mathrm{SiC,} 3 \mu \mathrm{m} \mathrm{Al} \mathrm{O}_{3}$ and $0.3 \mu \mathrm{m} \mathrm{Al} \mathrm{O}_{3}$ (Struers, DE), as schematically shown in Fig. 3.2(a). The sample is held by thumb and index finger at the corner indicated with a green arrow. After the rounding step, the beveled facets are applied to the edges of the sample. To that aim, a special tool, inspired on traditional diamond polishing dop tool, was designed to handle the sample during the process (Fig. 3.2(b)). In the tool, a sample can easily be clamped by a spring mechanism (Fig. 3.2(b)). Dedicated base disks are made with a consecutively larger thickness to create the different contact angles between the sample and sandpaper as illustrated in Fig. 3.2(c, d). The head of the tool is held between the thumb and index finger and guides the sample in an inward-outward motion over the rotating plate, onto which sandpaper is mounted (Fig. 3.2(e)). At the same time, pressure is exerted on the center of the bar of the tool (orange arrow) to create the beveled facet.

The beveled facets are made in three sections as schematically shown in Fig. 3.2(f). Sections 1, 2 and 3 are roughly $800 \mu \mathrm{m}, 150 \mu \mathrm{m}$ and $50 \mu \mathrm{m}$ and are made with sandpaper of subsequently smaller grain size (i.e., $15 \mu \mathrm{m} \mathrm{SiC,} 3 \mu \mathrm{m} \mathrm{Al} \mathrm{A}_{2} \mathrm{O}_{3}$ and $0.3 \mu \mathrm{m} \mathrm{Al}_{2} \mathrm{O}_{3}$ ). The height of each segment in the facet correspond with the targeted layer thickness that will be removed during the different lapping stages (Section 3.4.1). The facets should have a smaller roughness than the lapping particles used to prevent them from clustering in the edge, which can cause chipping of the edge. This can be achieved using the mentioned type of sandpaper because fixed particles give a finer surface finish than rolling particles used for the lapping and polishing. A photograph of the corner of one sample is shown in Fig. 3.2(g) where the different grades of beveled facets are visible. 
(a)
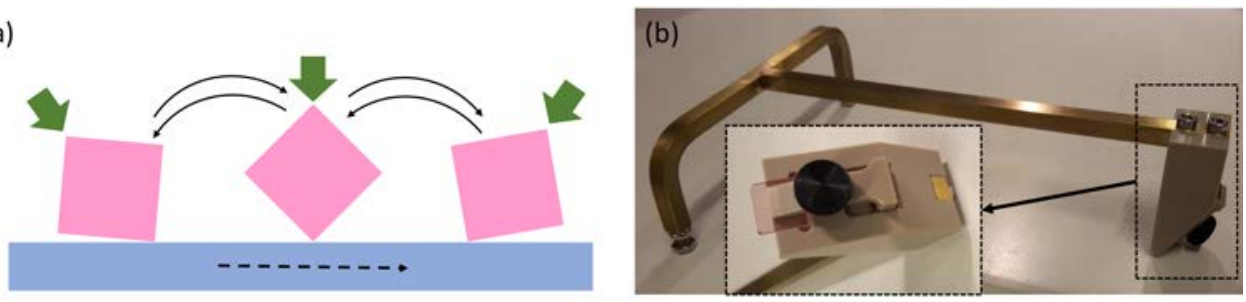

(c)
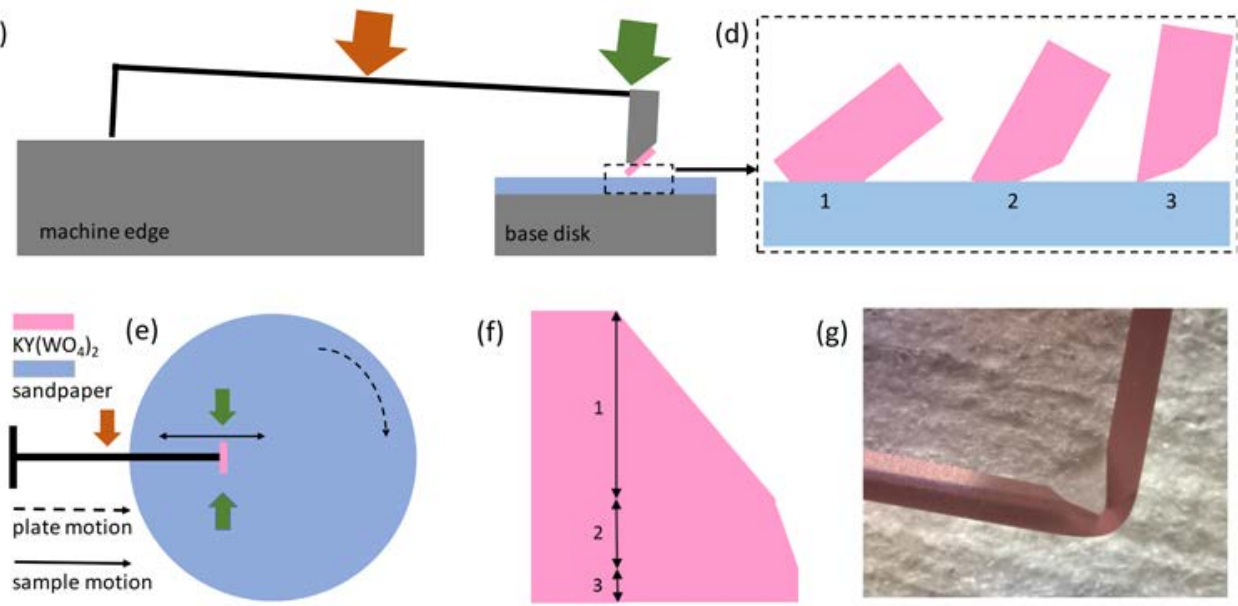

(f)

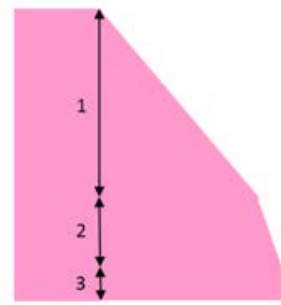

(g)

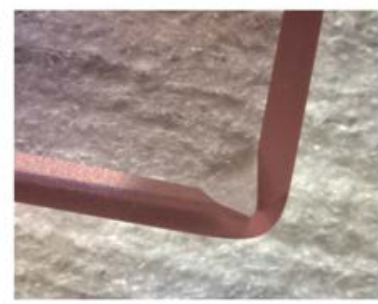

Fig. 3.2 (a) Side view schematic representation of the motion during the process of rounding of the corners. The sample is held between the thumb and index finger at the corner pointed out by the green arrow. (b) Photographs of the beveling tool and closeup (inset) of the top of the tool with a sample (transparent pink) mounted for beveling. (c) Schematic representation of the relative position of the tool on the machine. The height of the base disk is increased to vary the contact angle. (d) Schematic representation of how to achieve different bevel angles using the setup shown in (c). (e) Top view schematic of the manual linear in- and outward motion of the sample on the rotating sandpaper. The head of the tool is held between thumb and index finger to guide the sample. Pressure is exerted on the center of the bar of the tool with the index finger of the other hand (orange arrow). NOTE: During the process of rounding of the corners, the sample is held by hand instead of using the tool. (f) Schematic representation of the three areas of the beveled facets. The indicated areas, 1, 2, and 3, are consecutively made with $15 \mu \mathrm{m} \mathrm{SiC,} 3 \mu \mathrm{m} \mathrm{Al}{ }_{2} \mathrm{O}_{3}$ and $0.3 \mu \mathrm{m} \mathrm{Al}{ }_{2} \mathrm{O}_{3}$ sandpaper. (g) Close-up photograph of a beveled facets of a $\mathrm{KY}\left(\mathrm{WO}_{4}\right)_{2}$ sample with the mentioned grade of beveled facets, looking from the top of the crystal. 


\subsubsection{Preparation of $\mathrm{KY}\left(\mathrm{WO}_{4}\right)_{2}$ assemblies}

$\mathrm{KY}\left(\mathrm{WO}_{4}\right)_{2}$ stacks, consisting of a $\mathrm{KY}\left(\mathrm{WO}_{4}\right)_{2}$ sample and a glass substrate, are assembled and eventually mounted on an ultra-parallel glass plate for the lapping and polishing process. Typically, three $\mathrm{KY}\left(\mathrm{WO}_{4}\right)_{2}$ assemblies are mounted on the ultra-parallel plate in a triangular configuration (Fig. 3.3). This configuration provides a higher degree of stability of the samples on the lapping and polishing disk during the process compared to a single mounted assembly. It also permits controlling the load on the samples with a higher precision.

Details about the integration methods of $\mathrm{KY}\left(\mathrm{WO}_{4}\right)_{2}$ on glass substrates, using UV curable adhesive, are described in Chapter 2. The height of the individual assemblies is measured with a precision thickness measurement system (Milimar C1208, Mahr, GmbH, DE) including an inductive probe (Milimar P1300, Mahr, GmbH, DE) before mounting on a ultra-parallel plate ( $\varnothing 83 \mathrm{~mm}$, thickness $6 \mathrm{~mm}, 0 \mathrm{CON}-166$, Logitech). The assemblies are only used when the deviation between the assemblies is within the measurement accuracy of the system (i.e., $\pm 0.4 \mu \mathrm{m}$ including repeatability, hysteresis and error limit of the measurement system). The assemblies are mounted in a triangular configuration on the ultra-parallel glass plate using low temperature melting wax (Alcowax, NikkaSeiko, JP), as shown in Fig. 3.3. For the mounting, both the assemblies and ultra-parallel plate are heated to $65^{\circ} \mathrm{C}$ on a hotplate. The assemblies are then mounted onto the given positions by melting a thin layer of wax in the required location and positioning the samples. Another ultra-parallel plate combined with a load of $500 \mathrm{~g}$ is placed on top during the cooling process to ensure an equal height of the assemblies after mounting. The height of the assemblies is checked afterwards with the precision measurement system. The procedure is repeated when the assemblies deviate more than $\pm 0.4 \mu \mathrm{m}$ from each other.

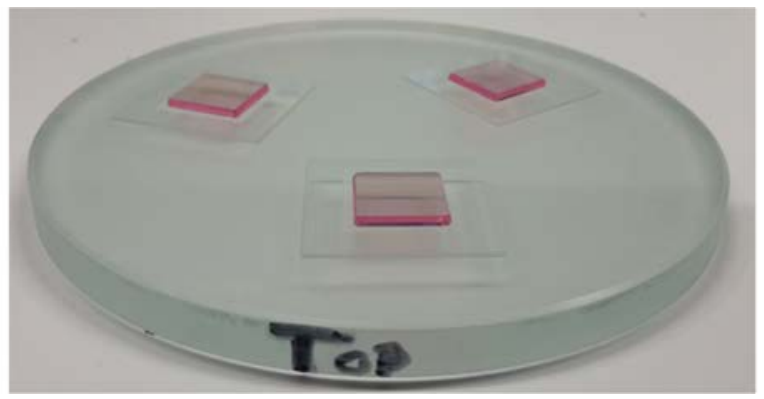

Fig. 3.3 Photographs of three assemblies each consisting of a $\mathrm{KY}\left(\mathrm{WO}_{4}\right)_{2}$ sample bonded with UV-curable adhesive onto a MEMpax substrate and wax mounted onto an ultraparallel supporting glass plate for thinning and polishing. 


\subsection{Lapping and polishing equipment and consumables}

High precision lapping and polishing equipment is required to enable the fabrication of optical high-index contrast $\mathrm{KY}\left(\mathrm{WO}_{4}\right)_{2}$ devices. The precision lapping and polishing machine is described in Section 3.3.1 followed by an explanation of the used lapping and polishing particles and disks (Section 3.3.2). The "conditioning of the disk" is the preparation of the disk to obtain the required planarity and surface finish before usage for the lapping and polishing steps, which will be described in Section 3.3.3. The general lapping and polishing process is detailed in Section 3.3.4.

\subsubsection{Lapping and polishing machine}

The lapping and polishing process is carried out with a PM5 precision lapping and polishing machine from Logitech (UK), shown in Fig. 3.4(a). The machine is positioned in a specially designed laminar flow cabinet, with an HEPA filter, which creates an environment with a reduced amount of large particles (i.e., 99.99862\% of particles $>0.3 \mu \mathrm{m}$ are filtered). The polishing jig (Fig. 3.4(b)) is held on the rotating disk by a positioning fork, which can be held static or can be swept in the desired range with the required speed. The disk rotation can be varied from 0 to $70 \mathrm{rpm}$. This range allows precise control of both low and high removal rates. Lapping particles are mixed with DI water in a dedicated cylinder. Prior to lapping, the lapping slurries have to be shaken to remove the sediment layer that typically forms at the bottom of the cylinder. The cylinder is rotated during the process to avoid sedimentation and ensure a homogeneous mixture. The slurry flow can be adjusted by opening/closing a screw (0-1-2) and the slurry is dispensed onto the disk via a slide (Fig. 3.4(a)). During the polishing step, the polishing suspension is held in a container and it is dispensed on the disk through a tap (Fig. 3.4(c)).

The ultra-parallel plate containing the three $\mathrm{KY}\left(\mathrm{WO}_{4}\right)_{2}$ assemblies is held by vacuum on the precision jig (PP5, Logitech, UK), as shown in Fig. 3.4(b). The load on the samples can be adjusted from 100 to $1500 \mathrm{~g}$ and the removed layer thickness of the samples can be monitored during the process with the digital gauge on the jig (precision of $1 \mu \mathrm{m})$. 


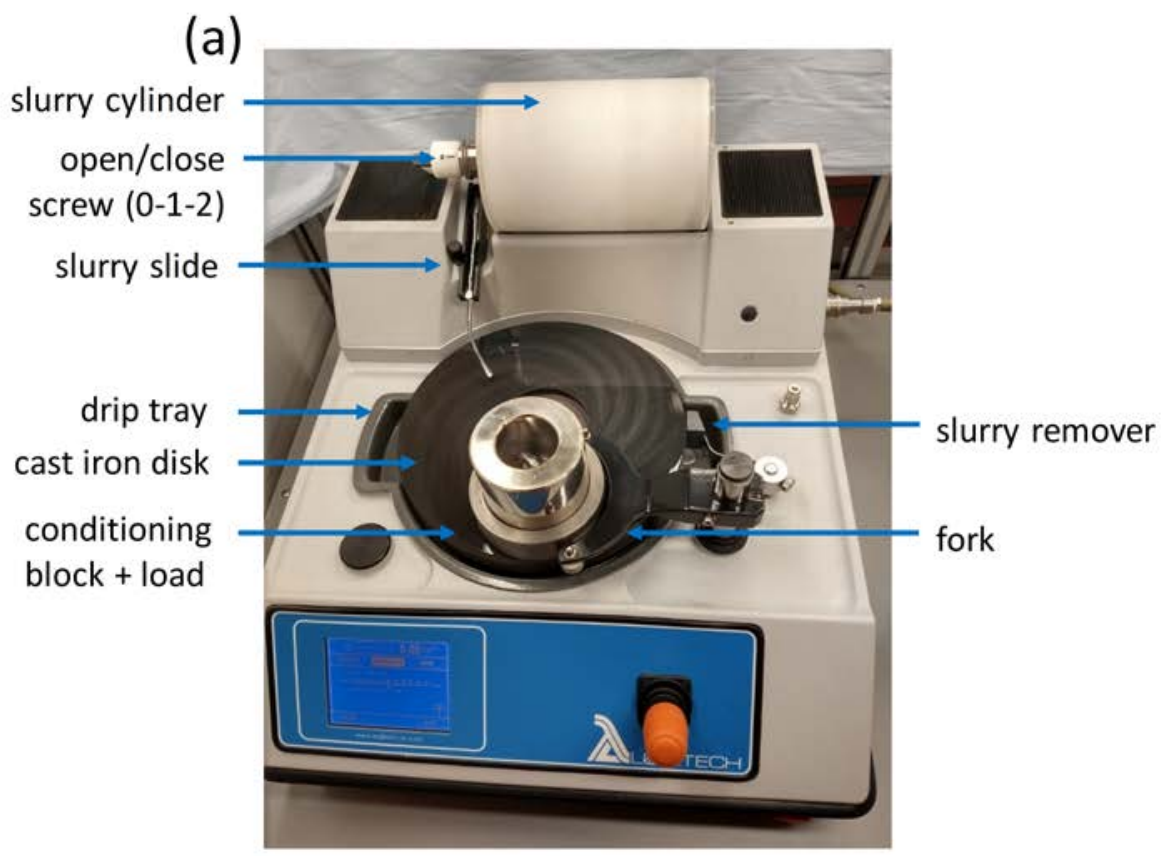

(b)

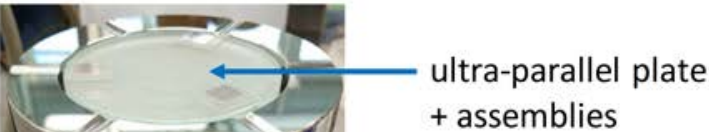

removal gauge

vacuum tube

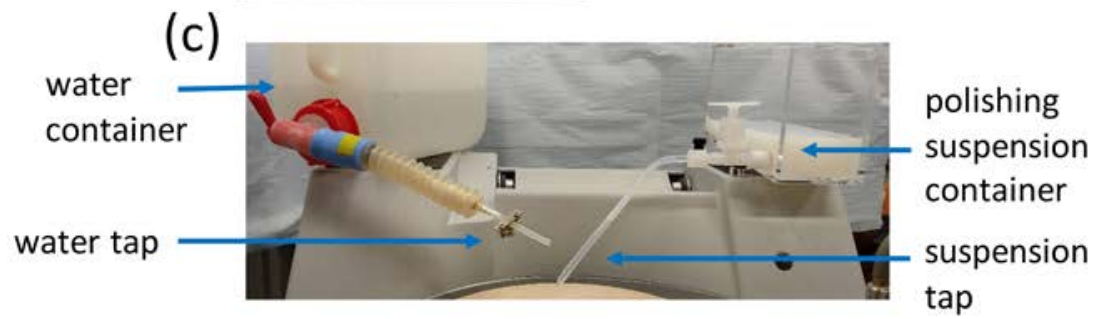

Fig. 3.4 (a) Lapping and polishing machine (PM5 from Logitech) with conditioning block and additional load on a dedicated cast iron disk. (b) Precision jig holding the ultra-parallel plate with vacuum. (c) Close up of water and polishing container and tap. 


\subsubsection{Lapping and polishing materials}

In this research, different types of disks are used for the lapping and polishing process of $\mathrm{KY}\left(\mathrm{WO}_{4}\right)_{2}$. They all have their own base disk, conditioning block, and slurry cylinder or suspension container to reduce the need for conditioning of the disk and minimize cross contamination between the different process steps.

A cast iron disk is chosen for lapping. The high hardness of the disk makes it suitable to achieve a high level of planarity when the disk is properly conditioned. Calcined aluminum oxide particles with grain sizes of 9,3 and $1 \mu \mathrm{m}$ mixed with DI water, are used to develop a so called coarse, medium and fine lapping process. The aluminum oxide particles are hard (Mohs hardness 9.0) enough to allow an high removal rate on the soft and brittle $\mathrm{KY}\left(\mathrm{WO}_{4}\right)_{2}$ (i.e., Mohs hardness of 4.0-5.0 [21]) but not too hard to make defined scratches, which is the case for lapping of $\mathrm{KY}\left(\mathrm{WO}_{4}\right)_{2}$ using diamond (Mohs hardness of 10.0) particles.

Pink (1LPE1-0600, Logitech) polyurethane disks with Shore A hardness of 94-97 are used for the development of the polishing process. This disk is selected because of it high hardness, which minimizes the rounding effect on the sample surface during long (i.e., several hours) polishing process compared to polishing on softer polishing cloths. Pre-polishing with $3 \mu \mathrm{m} \mathrm{CeO}_{2}$ slurry (0CON-023, Logitech, UK, $200 \mathrm{~g} / \mathrm{L}$, Mohs hardness 8.0) was investigated prior to polishing. Those particles have a higher hardness than the $40 \mathrm{~nm}$ colloidal $\mathrm{SiO}_{2}$ suspension (OP-U, Struers, DE, Mohs hardness 7.0) selected for polishing. It is expected that the roughness from lapping will be reduced more efficient with the pre-polishing step, due to the higher hardness of the particles, and therefore the final polishing time could be reduced.

\subsubsection{Conditioning of cast iron and polyurethane disks}

The lapping and polishing disks needs to be checked on planarity and defects before use. The planarity can be checked with a precision meter, referenced on a granite master flat block, at four points of the base disk (i.e., position of 3, 6, 9 and 12 o'clock) as shown in Fig. 3.5(a). The precision meter needs to measure the deviation from the reference value between two points. Therefore, the legs of the precision meter have to be placed as shown in Fig. 3.5(a) at the 9 o'clock position. An average value of the deviation will be measured when the legs are placed as shown at the 3 o'clock position (Fig. 3.5(a)). If the meter indicates a larger deviation than $2 \mu \mathrm{m}$ from the zero reference, the disk is concave (i.e., positive deviation from zero) or convex (i.e., negative deviation from zero) and should be conditioned. Conditioning of the disk is also necessary if defects, such as pits or scratches, are detected after a bare-eye inspection. The conditioning of the lapping and polishing disks is carried out with a special conditioning block with an additional 
load of $3.5 \mathrm{~kg}$. The conditioning block and load are placed at different locations of the disk depending on the type of defect that needs to be corrected. In the case of a defect (i.e., scratch or pit) the conditioning block and weight should be placed at the center of the rim of the disk. To correct for a concave disk, the conditioning block and weight should be placed towards the outer edge of the disk and to correct a convex disk, the conditioning block and weight needs to be placed towards the inner edge (Fig. 3.5(b)). It is important to ensure that the whole rim of the disk is covered by the conditioning block to avoid that a ridge is created.

(a)

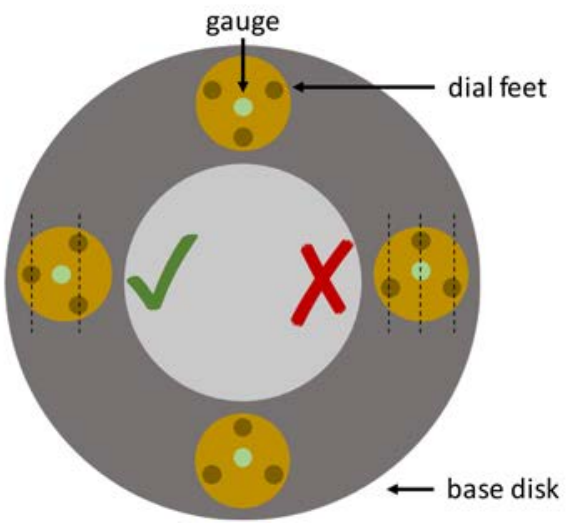

(b)

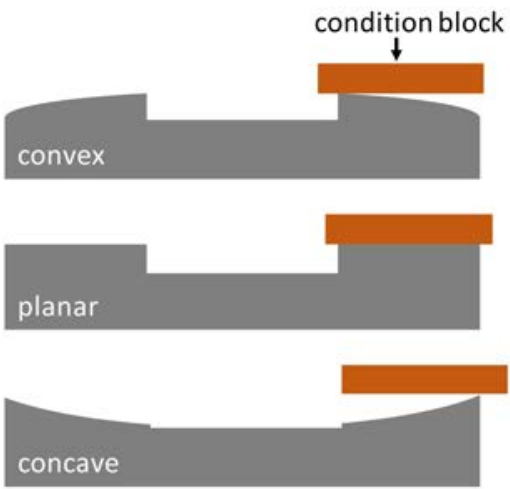

Fig. 3.5 (a) Schematic representation of the correct and incorrect positioning of the feet of the precision measurement tool and the 4 measurement positions for flatness/convexity/concavity on the base disk. (b) Indication of the positioning of the conditioning block in the case of inside, center and outside positioning for respectively convex, defects, and concave disk conditioning.

Both the lapping and polishing disk are conditioned using a dedicated conditioning block for the particular disk. The cast iron disk (Fig. 3.6(a)) is conditioned using a cast iron block with grooves (Fig. 3.6(b)). The grooves are wide and rounded such that they can easily be cleaned after the process. In the case of the polyurethane disk (Fig. 3.6(c)), a conditioning block with $200 \mu \mathrm{m}$ diamond pellets (Fig. 3.6(d)) is used. The diamonds will scratch over the surface of the polyurethane disk and remove the top surface effectively such that a fresh surface is exposed.

The conditioning block is positioned on the rim of the base disk at different positions depending on the curvature or defect that has to be corrected (i.e., center for defect or general condition, outer side for concave and towards the inner side for a convex disk conditioning). Both types of conditioning blocks have to be held steady while the curvature of the disk is corrected. 

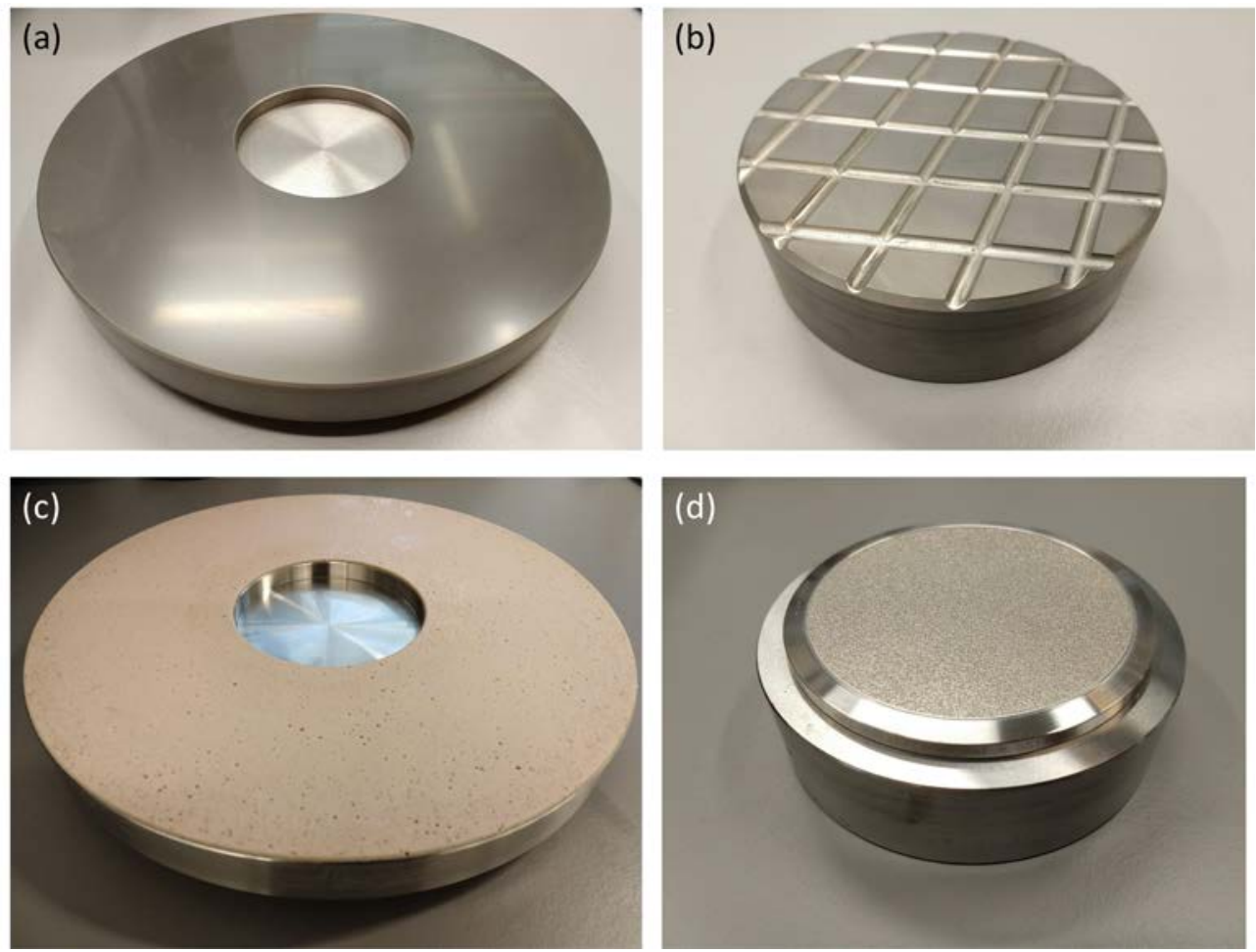

Fig. 3.6 (a) Cast iron disk $(\varnothing 30 \mathrm{~cm})$ and (b) cast iron conditioning block $(\varnothing 12.7 \mathrm{~cm})$ both dedicated for medium lapping. (c) Polyurethane disk $(\varnothing 30 \mathrm{~cm})$ and (d) diamond conditioning block (200 $\mu \mathrm{m}$ diamond pellets, $\varnothing 12.7 \mathrm{~cm}$ ) both dedicated for polishing with $40 \mathrm{~nm} \mathrm{SiO} 2$ suspension.

A process time of 20 minutes with a rotation speed of $40 \mathrm{rpm}$ and a load of $3.5 \mathrm{~kg}$ is typically sufficient to condition both the cast iron as well as the polyurethane disk. A calcined $\mathrm{Al}_{2} \mathrm{O}_{3}$ suspension with a particle size compatible to the disk (i.e., $3 \mu \mathrm{m} \mathrm{Al}_{2} \mathrm{O}_{3}$ slurry for the disk dedicated for medium lapping) is used with a flow rate of 10$12 \mathrm{drop} / \mathrm{min}$ during the process. Only water is used with a flow rate of $1 \mathrm{drop} / \mathrm{sec}$ during conditioning of the polyurethane disk.

The cast iron disk has to be cleaned with DI water and a soft tissue and the polyurethane disk has to be cleaned with DI water and a soft nylon brush to remove all residues after the process. Then, the planarity of the disk have to be re-checked and the process is repeated until the specifications are met. The polyurethane disk has to be surface conditioned after planarization to ensure an equal surface smoothness of the polyurethane layer. The diamond block is positioned at the center of the rim during surface conditioning and it is swept across the whole surface of the rim (i.e. 0-100 \% sweep), during this process. 
The cast iron disks are vulnerable to rust. Therefore, they need to be stored with an oil film (e.g., paraffin, liquid) to protect the disk. This oil layer can be removed with a soft tissue and isopropanol (IPA) before use. The polyurethane disk has to be cleaned thoroughly with water and a soft brush after a polishing process on $\mathrm{KY}\left(\mathrm{WO}_{4}\right)_{2}$ samples with polishing fluid. The polishing fluid will otherwise crystalize in the pores of the pad and those crystals can cause serious scratching problems on the $\mathrm{KY}\left(\mathrm{WO}_{4}\right)_{2}$ samples when the disk is re-used.

\subsubsection{Overall lapping and polishing process description}

Before a process can be started, the filter fan unit of the laminar flow cabinet has to be on for at least 2 hours to ensure a regulated environment. Firstly, the slurry is placed on a shaker to remove the sedimented layer at the bottom of the cylinder. During this time, the lapping/polishing machine is cleaned with IPA and a soft tissue to remove any residues and particles. Then, the dripping tray, base disk, jig and other modules are cleaned and mounted on the machine. Subsequently, the base disk is checked for planarity and defects as described in Section 3.3.3. Defects on the disk will cause defects on the samples due to clustering of lapping particles. A poor surface curvature of the samples is obtained when the disk is not planar because the sample surface will be a mirror image of the surface of the disk (e.g., the sample will have a convex curvature when the disk is concave). The rim of the jig should also be conditioned for an optimal grip of the jig on the base disk during the process, otherwise the jig can make sudden movements due to the friction difference (e.g., quick rotation), which can lead to defects on either sample or base disk. The conditioning can be done with the settings required for the particular process stage, described in Section 3.4.1, with the center of the jig elevated for at least 10 minutes.

The samples mounted onto the ultra-parallel plate are measured before and after each process with the precision measurement tool in order to obtain the most accurate removal rate of material from the samples. After each measurement, the ultra-parallel plate can be mounted on the jig with vacuum and the specified load on the samples can be set and measured with a sensitive lab scale. The process is then performed with the required settings (Section 3.4). A higher particle concentration than mentioned in Section 3.4 will lead to a higher removal rate, due to the fact that the sample is in contact with a larger fraction of lapping particles. Higher load or rotation speed give more friction between the sample surface and base disk and lead to defects due to increased stress.

The motion of the jig, flow rate of the slurry and the wetness of the disk need to be monitored carefully during the procedure. A constant flow rate is necessary to maintain the quality of the facets on the sample edges (i.e., without defects) during the process. A too low feed rate will lead to a too dry disk which will cause higher friction between the 
base disk and the samples. This will eventually lead to cracks that extend through the whole layer thickness. On the other hand, a too high feed rate will produce a wave of slurry bulging onto the samples, with the consequence of rounding and chipping of the edges. Typically, the process is interrupted and the samples and base disk cleaned and inspected as soon as something unexpected happens (i.e., sudden quick rotation of the jig, some unidentified particles on the base disk). All mounted components (base disk, positioning fork, dripping tray and jig) should be cleaned thoroughly when a defect (i.e., scratch or chipped edge) occurs on a sample.

A chipped edge has to be smoothened manually with consecutively, 5, 3, 1 and $0.3 \mu \mathrm{m} \mathrm{Al} \mathrm{O}_{3}$ sandpaper (Fig. 3.7(a, b)) and a scratch has to be removed by further lapping. An estimation has to be made on whether it is more efficient to remove a defect in for example a medium lapped surface with the same lapping slurry (i.e., $3 \mu \mathrm{m} \mathrm{Al}_{2} \mathrm{O}_{3}$ slurry) or remove it with coarse lapping slurry (i.e., $9 \mu \mathrm{m} \mathrm{Al}_{2} \mathrm{O}_{3}$ slurry) before continuing the process with the medium slurry. A lapped $\mathrm{KY}\left(\mathrm{WO}_{4}\right)_{2}$ surface has to be defect free before to proceed to the next lapping stage (i.e., coarse $\rightarrow$ medium $\rightarrow$ fine lapping $\rightarrow$ polishing). A $\mathrm{KY}\left(\mathrm{WO}_{4}\right)_{2}$ layer thinner than $50 \mu \mathrm{m}$ is too vulnerable for the reparation process because it has a high risk of cracking due to the stress in the layer. Therefore, the process has to be aborted when a defect occurs on this type of layers.
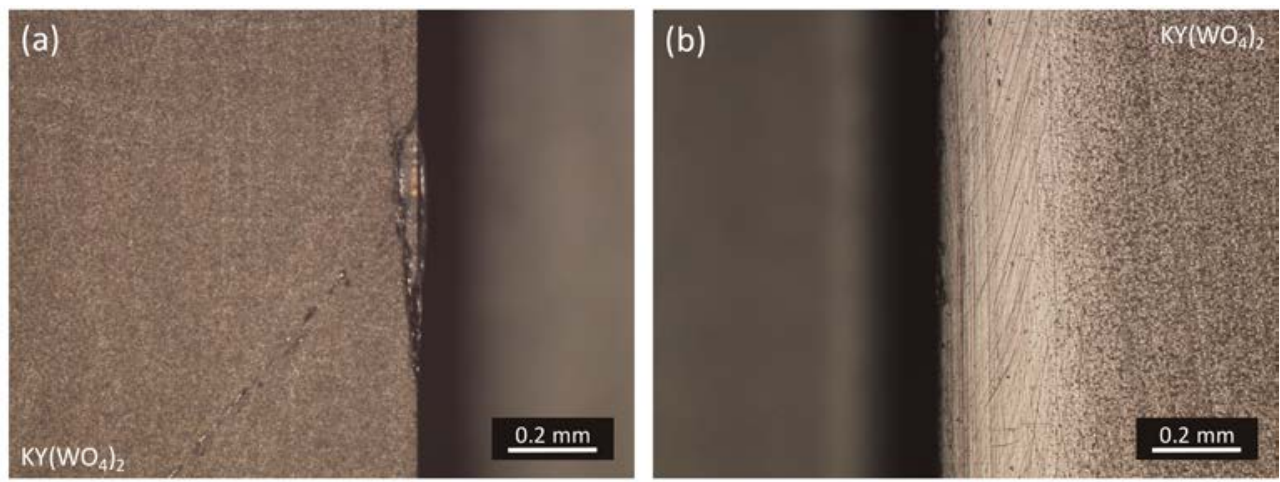

Fig. 3.7 Microscope image of a fine lapped KY(WO4)2 edges (a) with defect (b) after reparation.

The machine and mounted components are cleaned thoroughly with DI water and IPA when a particular process step is completed. The ultra-parallel plate assemblies mounted on it can be carefully cleaned with soap and a soft brush around the $\mathrm{KY}\left(\mathrm{WO}_{4}\right)_{2}$ samples. The surface of the samples needs to be cleaned with a soft tissue and IPA. It is important that no scrub motions are made during the cleaning of the sample because this can cause scratches or other defects. 


\subsection{Lapping and polishing process for $\mathrm{KY}\left(\mathrm{WO}_{4}\right)_{2}$}

The generic lapping and polishing process described in Section 3.3.4 was adapted to produce optical quality high-index contrast $\mathrm{KY}\left(\mathrm{WO}_{4}\right)_{2}$-on-glass devices, which requires the lapping of a $\mathrm{KY}\left(\mathrm{WO}_{4}\right)_{2}$ sample without defects from $1 \mathrm{~mm}$ down to roughly 1-2 $\mu \mathrm{m}$. After lapping, the sample is polished to an optical grade surface (i.e., RMS surface roughness $<2 \mathrm{~nm}$ [22]) with a high flatness (i.e., radius of curvature $>200 \mathrm{~m}$ to achieve a maximal deviation of $40 \mathrm{~nm}$ across $8 \mathrm{~mm}$ sample length). Both lapping and polishing processes (Section 3.4.1 and 3.4.2) have been developed first on thick (> $300 \mu \mathrm{m})$ $\mathrm{KY}\left(\mathrm{WO}_{4}\right)_{2}$ samples. The obtained process can then be used to produce high-index contrast $\mathrm{KY}\left(\mathrm{WO}_{4}\right)_{2}$-on-glass devices

\subsubsection{Lapping process for $\mathrm{KY}\left(\mathrm{WO}_{4}\right)_{2}$ layers}

The first stage, coarse lapping, is developed to enable a high material removal rate without surface defects. The majority $(\sim 800 \mu \mathrm{m})$ of the sample will be removed during this process step, during the final process. A slurry made from a mixture of DI water and $9 \mu \mathrm{m}$ calcined $\mathrm{Al}_{2} \mathrm{O}_{3}$ particles $(250.0 \mathrm{~g} / \mathrm{L})$ is made. A combination of a load on the samples of $200 \mathrm{~g} / \mathrm{cm}^{2}$, a rotation speed of the disk of $35 \mathrm{rpm}$ and a slurry flow of 10$12 \mathrm{drop} / \mathrm{min}$ resulted in a removal rate of $10-15 \mu \mathrm{m} / \mathrm{min}$ without defects on the $\mathrm{KY}\left(\mathrm{WO}_{4}\right)_{2}$ samples. The effective load on the sample reduces during this process stage due to the large thickness of material that is removed. The indicated load on the sample can be re-established midway the process to achieve the mentioned removal rate (Table 3.1).

The medium lapping stage is developed to obtain a balance between high removal rate and precise removal. For this stage, smaller lapping particles of $3 \mu \mathrm{m}$ calcined $\mathrm{Al}_{2} \mathrm{O}_{3}$ mixed with DI water $(208.3 \mathrm{~g} / \mathrm{L})$ were used with the same flow rate as in the previous stage. The load on the samples and rotation speed of the disk were reduced to $167 \mathrm{~g} / \mathrm{cm}^{2}$ and $30 \mathrm{rpm}$, respectively. The final settings resulted in a removal rate of 5-7 $\mu \mathrm{m} / \mathrm{min}$.

The last stage, fine lapping, has as goal to tune the layer thickness as close as possible to the 1-2 $\mu \mathrm{m}$ in the final process. A removal rate of $1-2 \mu \mathrm{m} / \mathrm{min}$ was achieved with $1 \mu \mathrm{m}$ calcined $\mathrm{Al}_{2} \mathrm{O}_{3}$ particles mixed in DI water $(187.5 \mathrm{~g} / \mathrm{L})$ in combination with slurry flow rate of 10-12 drop/min and a reduced load on the samples and reduced rotation speed of $133 \mathrm{~g} / \mathrm{cm}^{2}$ and $25 \mathrm{rpm}$, respectively.

Table 3 summarize the settings for the lapping process. The process was carried out on a thick (i.e., $>300 \mathrm{~mm}$ thick $\mathrm{KY}\left(\mathrm{WO}_{4}\right)_{2}$ layers) to verify whether this process leads to planar lapped layers with good surface quality. A microscope image of thick sample with a smooth medium and fine lapped surface finish is shown in Fig. 3.8(a) and (b) respectively. The flatness of this sample was measured using a profilometer (Dektak 8, 
Veeco), which resulted, after fitting with a quadratic function, in a surface curvature of $222 \mathrm{~m}$.
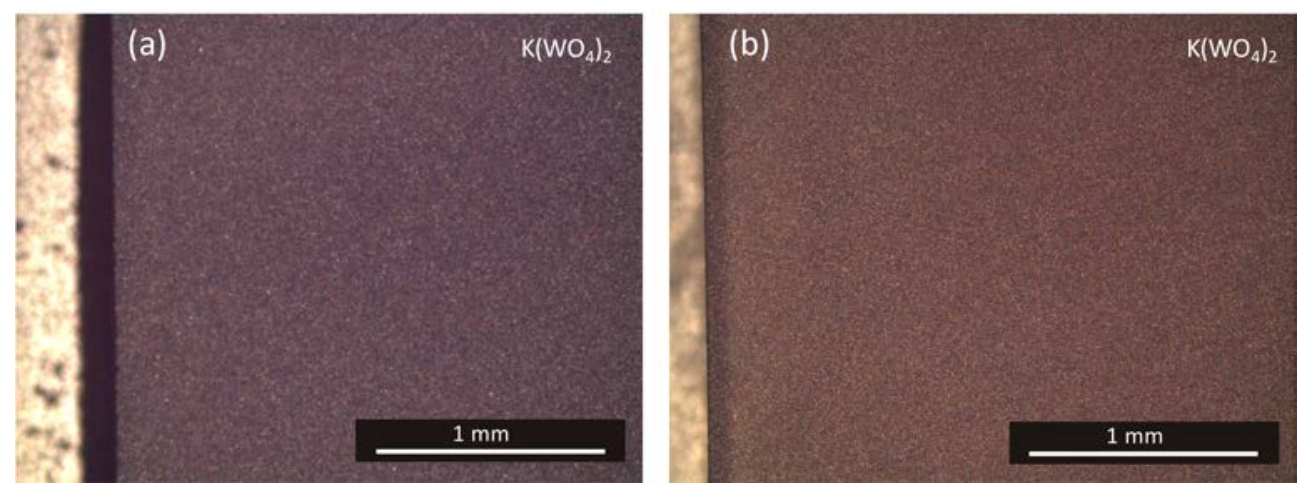

Fig. 3.8 Microscope image of a $\mathrm{KY}\left(\mathrm{WO}_{4}\right)_{2}$ samples with (a) a medium and (b) a fine lapped surface finish.

Table 3.1 Settings of for the different lapping stages of $\mathrm{KY}\left(\mathrm{WO}_{4}\right)_{2}$.

\begin{tabular}{|l|l|l|l|l|l|l|}
\hline $\begin{array}{l}\text { Lapping } \\
\text { stage }\end{array}$ & Particles & $\begin{array}{l}\text { Concentration } \\
(\mathbf{g} / \mathbf{L})\end{array}$ & $\begin{array}{l}\text { Load } \\
\left(\mathbf{g} / \mathbf{c m}^{2}\right)\end{array}$ & $\begin{array}{l}\text { Speed disk } \\
(\mathbf{r p m})\end{array}$ & $\begin{array}{l}\text { Removal rate } \\
(\boldsymbol{\mu m} / \mathbf{m i n})\end{array}$ & $\begin{array}{l}\text { Logitech, } \\
\text { UK product } \\
\text { nr. }\end{array}$ \\
\hline Coarse & $9 \mu \mathrm{m} \mathrm{Al}_{2} \mathrm{O}_{3}$ & 250.0 & 200 & 35 & $10-15$ & 0 CON-009 \\
\hline Medium & $3 \mu \mathrm{m} \mathrm{Al}_{2} \mathrm{O}_{3}$ & 208.3 & 167 & 30 & $5-7$ & 0 CON-008 \\
\hline Fine & $1 \mu \mathrm{m} \mathrm{Al}_{2} \mathrm{O}_{3}$ & 187.5 & 133 & 25 & $1-2$ & 0 CON-007 \\
\hline
\end{tabular}

The slurry rate was $10-12 \mathrm{drop} / \mathrm{min}$ in all stages

\subsubsection{Polishing process for $\mathrm{KY}\left(\mathrm{WO}_{4}\right)_{2}$ layers}

\subsubsection{Polishing with $\mathrm{SiO}_{2}$ suspension}

A polyurethane disk and $40 \mathrm{~nm}$ colloidal $\mathrm{SiO}_{2}$ suspension (OP-U, Struers, DE) is used to polish thick $\mathrm{KY}\left(\mathrm{WO}_{4}\right)_{2}$ samples with a fine lapped surface finish. A load of $290 \mathrm{~g} / \mathrm{cm}^{2}$ and a rotation speed of $25 \mathrm{rpm}$ where used to create enough friction to obtain a high polishing rate. The jig was set in a sweeping motion from 30-70 \% (were $50 \%$ equals the center of the rim of the base disk) to avoid trench forming in the disk for long (i.e., several hours) polishing time. The suspension was dispensed on the disk with a flow rate of 10-12 drop/min and additional water with a flow rate of 8-10 drop/min was used to avoid the disk from drying out.

The surface roughness and curvature were determined for a $\mathrm{KY}\left(\mathrm{WO}_{4}\right)_{2}$ surface polished for 2 hours (i.e., material removal rate of $\sim 3 \mu \mathrm{m} / \mathrm{h}$ ). The surface RMS roughness is measured with an atomic force microscope (AFM, Fast Scan, Bruker, DE) and resulted in an RMS roughness of $0.88 \mathrm{~nm}$ in a $0.5 \times 0.5 \mu \mathrm{m}^{2}$ area (Fig. 3.9(a)), which is an improvement in comparison with the as-delivered sample, which possesses an RMS 
roughness of $1.40 \mathrm{~nm}$ (Fig. 3.9(b)). To determine the curvature of the polished surface, a scan with a profilometer (Dektak 8, Veeco) was made as shown in Fig. 3.9(c). A curvature of 26.0 meters was obtained after fitting with a quadratic function. This curvature is bigger than the one obtained after the fine lapping step due to the reduced hardness of the polyurethane disk with respect to the cast iron disk. However, the planarity achieved in this work after the polishing step is better than the one reported in earlier work, in which a radius of 5.9 meters was obtained for a $\sim 1 \mathrm{~mm}$ thick $\mathrm{KY}\left(\mathrm{WO}_{4}\right)_{2}$ sample [23]. Although using the same polishing equipment and similar process parameters than in this work, the load utilized in the referred work was much higher, namely $400 \mathrm{~g} / \mathrm{cm}^{2}$. Such high load leads to a stronger pressure between the sample and the base disk, which produced more rounding given the softness of the polyurethane disk.

Figure 3.9(d) shows Newton rings created between the sample surface and an optical flat illuminated with monochromatic light ( $\lambda=589 \mathrm{~nm}$, KEMET, UK). The Newton rings reveal that the surface is convex and the smaller fringes at the circumference indicate the presence of the rounding of the edges. 

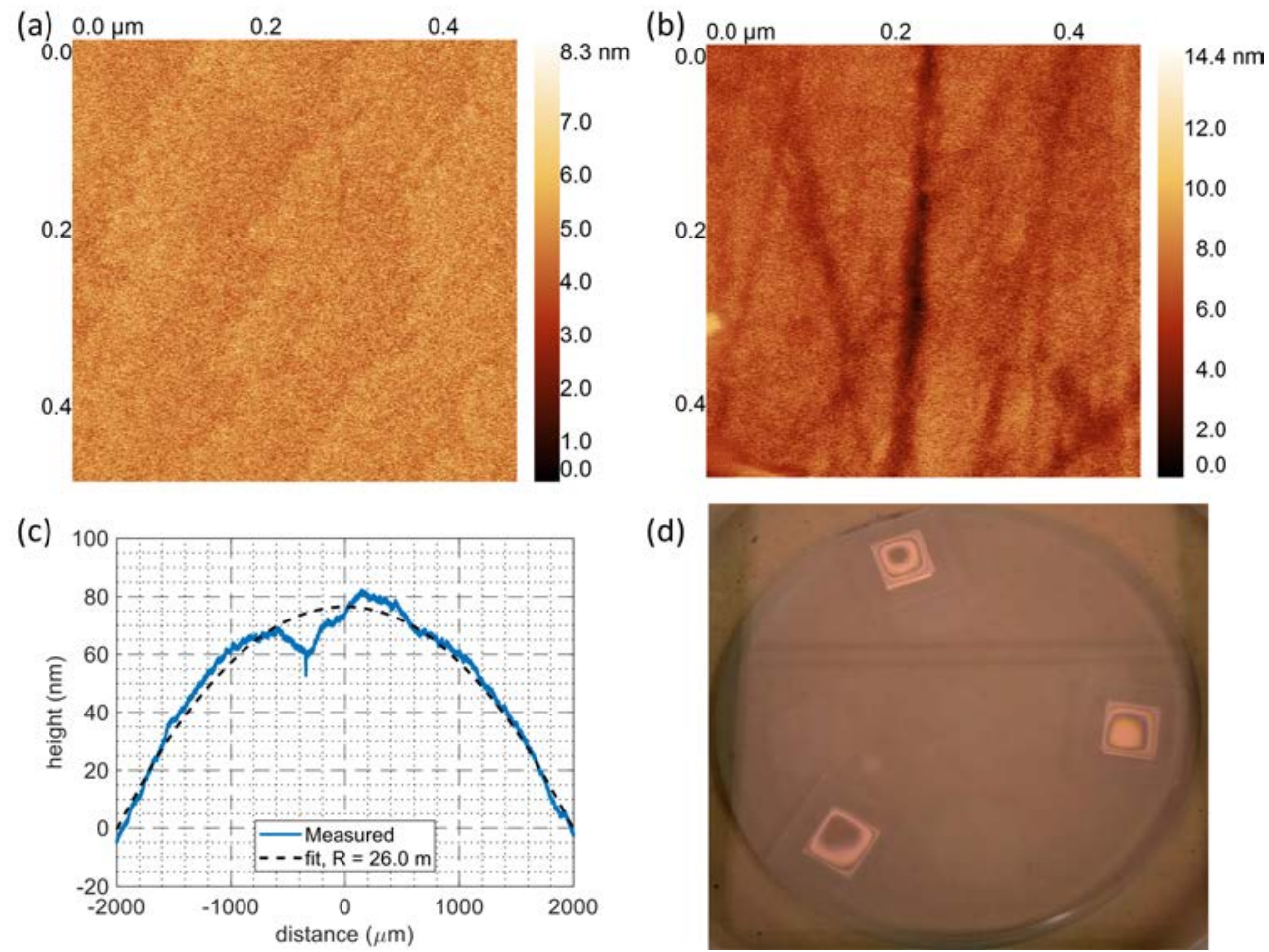

(d)

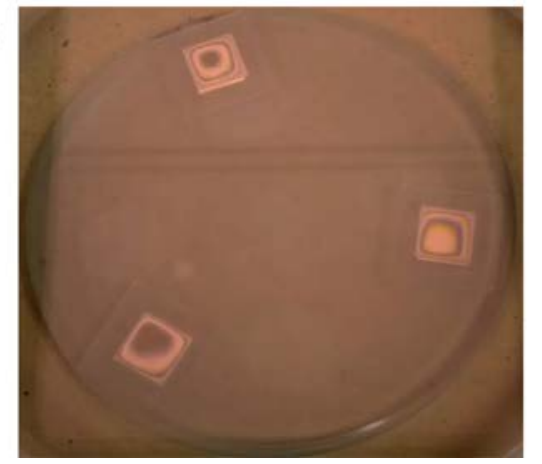

Fig. 3.9 AFM measurements on a $0.5 \times 0.5 \mu \mathrm{m}^{2}$ area (a) 2 hours polished $\mathrm{KY}\left(\mathrm{WO}_{4}\right)_{2}$ sample, RMS roughness of $0.88 \mathrm{~nm}$ and (b) an as-received sample with RMS roughness of $1.41 \mathrm{~nm}$. (c) Measured surface profile of a $\mathrm{KY}\left(\mathrm{WO}_{4}\right)_{2}$ sample after 2 hours of polishing (blue). The measurement was carried out using a Dektak profilometer. The dashed line shows the quadratic function fit with a radius of curvature of $26.0 \mathrm{~m}$. (d) Newton rings on the same polished samples, illuminated with a sodium lamp through an optical flat, demonstrating the high uniformity of the samples.

\subsubsection{Extended polishing time}

The RMS surface roughness after 2 hours of polishing is within the specifications given for an optical quality surface. However, not all features from the fine lapping stage were removed after 2 hours. It could be that the load on the samples was too high which caused that micro fractures caused by lapping propagated further into the layer [23]. The polishing was repeated on $\mathrm{KY}\left(\mathrm{WO}_{4}\right)_{2}$ samples with fine lapped surface finish with the same settings as before only with a load of $167 \mathrm{~g} / \mathrm{cm}^{2}$ and a process time of 5 hours. The roughness and potential defects of the fine lapped surface where still not completely removed after this polishing time. The RMS surface roughness between the defects was reduced to $0.28 \mathrm{~nm}$ in a $0.5 \times 0.5 \mu \mathrm{m}^{2}$ area. 


\subsubsection{Pre-polishing with $\mathrm{CeO}_{2}$ suspension}

A pre-polishing test with $\mathrm{CeO}_{2}$ particles was performed with the intention of reducing the polishing time and therefore also reducing the rounding of the edges. $\mathrm{CeO}_{2}$ particles are harder than the $\mathrm{SiO}_{2}$ particles and they should therefore be able to remove the roughness from the fine lapping step more efficiently. $\mathrm{CeO}_{2}$ particles of $3 \mu \mathrm{m}(0 \mathrm{CON}$ 023, Logitech, UK) mixed with DI water $(200 \mathrm{~g} / \mathrm{L})$ were used on a pink polyurethane disk. The $\mathrm{KY}\left(\mathrm{WO}_{4}\right)_{2}$ samples had a fine lapped surface finish at the start of the experiment. The same process settings where used as for the fine lapping to create enough friction to remove the surface roughness from the fine lapping. The sweeping motion of the jig (same settings as in Section 3.4.2.1) was used to avoid deformation of the polyurethane disk. The surface finish after 30 minutes of pre-polishing is shown in Fig. 3.10(a), which reveals an orange peel effect on the surface. The orange peel structure could not be removed with longer polishing time (up till 90 min, Fig. 3.10(b)) nor with the subsequent polishing step using $40 \mathrm{~nm} \mathrm{SiO}$ suspension, with the settings specified in Section 3.4.2.2, for 30 minutes. Similar surface finish was observed after prepolishing with a $0.5 \mu \mathrm{m} \mathrm{CeO}_{2}$ particle slurry (0CON-260, Logitech, UK) on a softer polyurethane disk (ILPE1-0100, Logitech) and a polishing cloth (MD-Dac. Struers, DE). This surface effect might occur due to a chemical reaction of $\mathrm{CeO}_{2}$ with the $\mathrm{KY}\left(\mathrm{WO}_{4}\right)_{2}[24,25]$. Therefore, $\mathrm{CeO}_{2}$ was not utilized in the final process as prepolishing suspension to achieve optically polished $\mathrm{KY}\left(\mathrm{WO}_{4}\right)_{2}$ layers.

Further research has to be carried out for the optimization of the polishing stage to achieve an optical quality layer with minimal surface rounding (i.e., RMS roughness $<2$ $\mathrm{nm}$ and an $\mathrm{R}>200 \mathrm{~m})$.
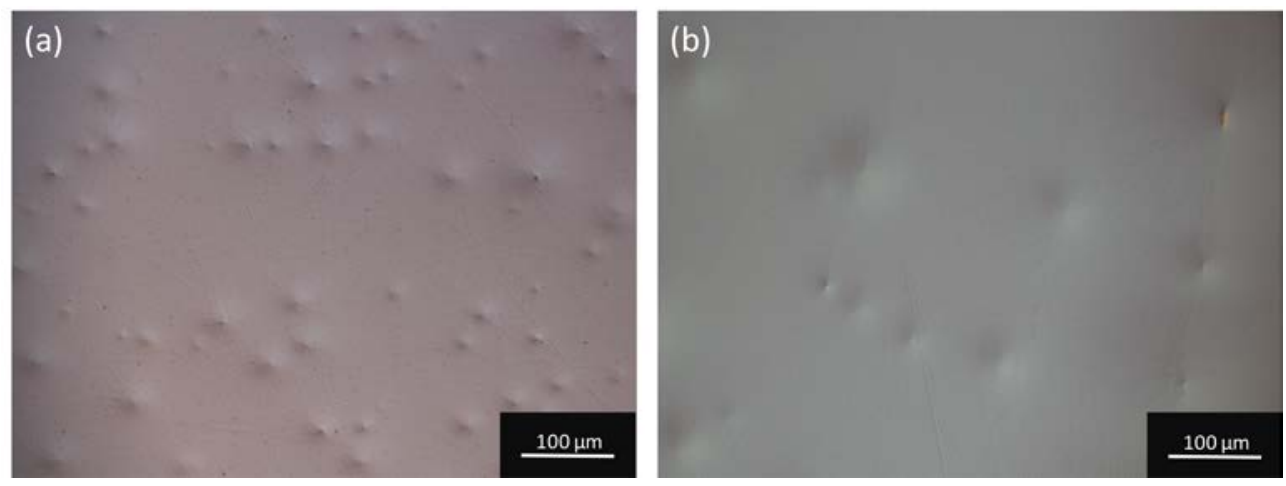

Figure 3.10 Optical microscope image in Normarski configuration of the $\mathrm{KY}\left(\mathrm{WO}_{4}\right)_{2}$ surface polished on a pink polyurethane disk with $3 \mu \mathrm{m} \mathrm{CeO}_{2}$ suspension for (a) 30 minutes (b) 90 minutes. 


\subsection{Lapping towards thin layers}

The lapping stages (coarse, medium and fine), as described in Section 3.4.1, are used to lap the $\mathrm{KY}\left(\mathrm{WO}_{4}\right)_{2}$ samples, with the intention to achieve a defect free layer with a thickness of 1-2 $\mu \mathrm{m}$.

Lapping of $\mathrm{KY}\left(\mathrm{WO}_{4}\right)_{2}$ samples bonded on flat glass substrates was tested. The samples are bonded using an optical curable adhesive and a flip-chip bonder as described in Chapter 2.

Layers of roughly $800 \mu \mathrm{m}$ were successfully removed during coarse lapping. No defects were observed on the surface or edges of the samples and the process could be continued with medium lapping. The $\mathrm{KY}\left(\mathrm{WO}_{4}\right)_{2}$ layers were thinned from $\sim 200 \mu \mathrm{m}$ to $\sim 55 \mu \mathrm{m}$ in the medium lapping stage. Two of the three sample surfaces had at least two scratches that occurred due to chipped edges. Those chipped edges (Fig. 3.11) are the outcome of too major resulting stress on the edges caused by the fact that the load applied on the thin samples is too large for such thin, brittle layers. The final lapping stage, to thin the layer to $\sim 2 \mu \mathrm{m}$, could not be validated because the thin layers where never defect free after the medium lapping stage and too thin to repair the defect, which implied that further processing had to be aborted.

Medium and fine lapping test with lower load (load at least below $150 \mathrm{~g} / \mathrm{cm}^{2}$ ) have to be performed on thin layers $(<300 \mu \mathrm{m})$. In our system, a load below $100 \mathrm{~g} / \mathrm{cm}^{2} \mathrm{can}$ only be reached when at least three assemblies are mounted on the ultra-parallel plate (i.e., is the most stable configuration compared to one assembly) since the spring system of the polishing jig cannot accurately maintain a weight lower than $100 \mathrm{~g}$, independent of the surface area (i.e., with three assemblies, of a square centimeter each, a total load of $\sim 110 \mathrm{~g}$ will result in a load as low as $\sim 35 \mathrm{~g} / \mathrm{cm}^{2}$ ).

Another way of improving the process could be protection of the edges of the samples from chipping, for example using glass, similar to what is done during end-facet polishing of $\mathrm{KY}\left(\mathrm{WO}_{4}\right)_{2}$ [23]. However, this is only possible if the lapping and polishing characteristics of glass are similar to those of $\mathrm{KY}\left(\mathrm{WO}_{4}\right)_{2}$ using the same process. A test was performed, with the same settings as used for $\mathrm{KY}\left(\mathrm{WO}_{4}\right)_{2}$, on three glass assemblies (sample and substrate) with the same dimensions as the $\mathrm{KY}\left(\mathrm{WO}_{4}\right)_{2}$ samples. We observed that the glass laps $\sim 1.5$ times slower than $\mathrm{KY}\left(\mathrm{WO}_{4}\right)_{2}$ and reaches an optical surface finish with shorter polishing time. The different lapping and polishing characteristics of $\mathrm{KY}\left(\mathrm{WO}_{4}\right)_{2}$ and glass will reduce the process speed and will not have additional value to the existing process. To protect the $\mathrm{KY}\left(\mathrm{WO}_{4}\right)_{2}$ a material with a similar hardness (Mohs hardness 4.0-5.0) to that of the crystal have to be used that can be cleaned with water and IPA. 


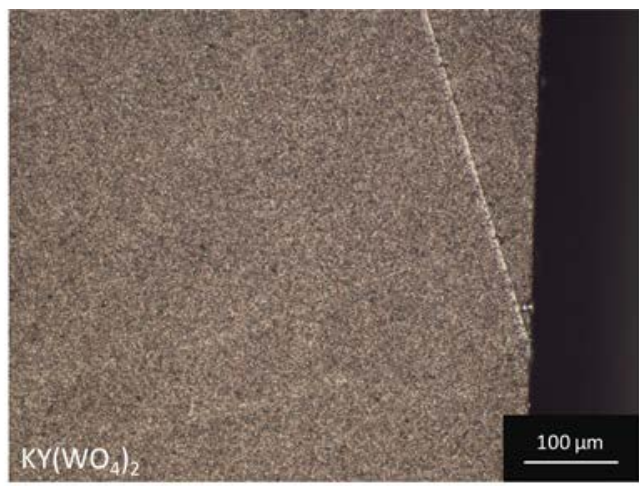

Fig. 3.11 Microscope image of a chipped edge on a $56 \mu \mathrm{m}$ thin $\mathrm{KY}\left(\mathrm{WO}_{4}\right)_{2}$ sample that caused a scratch on the sample surface.

\subsection{Conclusion}

A lapping process was developed on thick $\mathrm{KY}\left(\mathrm{WO}_{4}\right)_{2}$ samples $(>300 \mu \mathrm{m})$. A surface roughness of $0.88 \mathrm{~nm}$ with a radius of curvature of 26.0 meter was achieved after 2 hours of polishing with $40 \mathrm{~nm} \mathrm{SiO}_{2}$ suspension. Further work needs to be carried out to increase the planarity of the samples after the polishing step, probably by reducing the polishing time by the introduction of a pre-polishing step.

The developed lapping and polishing process was applied to the thinning of $\mathrm{KY}\left(\mathrm{WO}_{4}\right)_{2}$ samples from $1 \mathrm{~mm}$ down to a couple of micrometers. Unfortunately, scratches appeared during the medium lapping process. The scratches can contaminate the polishing material and other samples during further processing and the samples were too thin to repair the damage. Therefore, further processing had to be aborted. Further process development has to be done to enable the production of thin $\mathrm{KY}\left(\mathrm{WO}_{4}\right)_{2}$-on-glass samples in a reliable way. 


\section{References}

[1] F. Brunner, G. J. Spühler, J. Aus der Au, L. Krainer, F. Morier-Genoud, R. Paschotta, N.

Lichtenstein, S. Weiss, C. Harder, A. A. Lagatsky, A. Abdolvand, N. V Kuleshov, and U. Keller, "Diode-pumped femtosecond $\mathrm{Yb}: \mathrm{KGd}\left(\mathrm{WO}_{4}\right)_{2}$ laser with 1.1-W average power," Opt. Lett. 25, 1119 (2000)

[2] A. A. Kovalyov, V. V. Preobrazhenskii, M. A. Putyato, O. P. Pchelyakov, N. N. Rubtsova, B. R. Semyagin, V. E. Kisel', S. V. Kuril'chik, and N. V. Kuleshov, "115 fs pulses from $\mathrm{Yb}^{3+}: \mathrm{KY}\left(\mathrm{WO}_{4}\right)_{2}$ laser with low loss nanostructured saturable absorber," Laser Phys. Lett. 8, 431435 (2011)

[3] S. Erhard, J. Gao, A. Giesen, K. Contag, A. A. Lagatsky, A. Abdolvand, N. V. Kuleshov, J. Aus der Au, G. J. Spuhler, F. Brunner, R. Paschotta, and U. Keller, "High power Yb:KGW and $\mathrm{Yb}: \mathrm{KYW}$ thin disk laser operation," in Technical Digest. Summaries of Papers Presented at the Conference on Lasers and Electro-Optics. Postconference Technical Digest (IEEE Cat. No.01CH37170) (IEEE, 2001), pp. 333-334

[4] X. Mateos, P. Loiko, S. Lamrini, K. Scholle, P. Fuhrberg, S. Vatnik, I. Vedin, M. Aguiló, F. Díaz, U. Griebner, and V. Petrov, "Thermo-optic effects in Ho:KY $\left(\mathrm{WO}_{4}\right)_{2}$ thin-disk lasers," Opt. Mater. Express 8, 684 (2018)

[5] Z. Cong, Z. Liu, Z. Qin, X. Zhang, H. Zhang, J. Li, H. Yu, and W. Wang, "LD-pumped actively Q-switched Nd:KLu(WO$\left.)_{4}\right)_{2}$ self-Raman laser at 1185nm," Opt. Laser Technol. 73, 50-53 (2015)

[6] L. E. Batay, A. N. Kuzmin, A. S. Grabtchikov, V. A. Lisinetskii, V. A. Orlovich, A. A. Demidovich, A. N. Titov, V. V. Badikov, S. G. Sheina, V. L. Panyutin, M. Mond, and S. Kück, "Efficient diode-pumped passively Q-switched laser operation around $1.9 \mu \mathrm{m}$ and self-frequency Raman conversion of Tm-doped KY(WO $\left.{ }_{4}\right)_{2}$," Appl. Phys. Lett. 81, 2926-2928 (2002)

[7] M. T. Chang, W. Z. Zhuang, K. W. Su, Y. T. Yu, and Y. F. Chen, "Efficient continuous-wave self-Raman Yb:KGW laser with a shift of $89 \mathrm{~cm}^{-1}$," Opt. Express 21, 24590 (2013)

[8] I. M. Krygin, A. D. Prokhorov, V. P. D’yakonov, M. T. Borowiec, and H. Szymczak, "Spin-spin interaction of $\mathrm{Dy}^{3+}$ ions in $\mathrm{KY}\left(\mathrm{WO}_{4}\right)_{2}$," Phys. Solid State 44, 1587-1596 (2002)

[9] G. Dhanaraj, K. Byrappa, V. Prasad, and M. Dudley, Springer Handbook of Crystal Growth, Springer Handbook of Crystal Growth (Springer Berlin Heidelberg, 2010)

[10] D. Geskus, S. Aravazhi, S. M. García-Blanco, and M. Pollnau, "Giant optical gain in a rare-earthion-doped microstructure," Adv. Mater. 24, 22-25 (2012)

[11] Y.-S. Yong, S. Aravazhi, S. A. Vázquez-Córdova, J. J. Carjaval, F. Díaz, J. L. Herek, S. M. García-Blanco, and M. Pollnau, "Temperature-dependent absorption and emission of potassium double tungstates with high ytterbium content.," Opt. Express 24, 26825-26837 (2016)

[12] A. A. Kaminskii, A. F. Konstantinova, V. P. Orekhova, A. V Butashin, R. F. Klevtsova, and A. A. Pavlyuk, "Optical and nonlinear laser properties of the $\chi^{(3)}$-active monoclinic $\alpha-\mathrm{KY}\left(\mathrm{WO}_{4}\right)_{2}$ crystals," Crystallogr. Reports 46, 665-672 (2001)

[13] K. van Dalfsen, S. Aravazhi, C. Grivas, S. M. García-Blanco, and M. Pollnau, "Thulium channel waveguide laser with $1.6 \mathrm{~W}$ of output power and $\sim 80 \%$ slope efficiency," Opt. Lett. 39, 4380 (2014)

[14] D. Geskus, S. Aravazhi, K. Wörhoff, and M. Pollnau, "High-power, broadly tunable, and low-

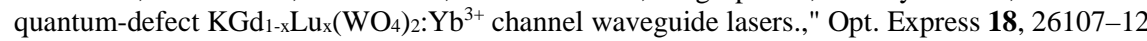
(2010)

[15] D. Geskus, S. Aravazhi, C. Grivas, K. Wörhoff, and M. Pollnau, "Microstructured $\mathrm{KY}\left(\mathrm{WO}_{4}\right)_{2}: \mathrm{Gd}^{3+}, \mathrm{Lu}^{3+}, \mathrm{Yb}^{3+}$ channel waveguide laser," Opt. Express 18, 22417-22422 (2010)

[16] Y. Romanyuk, "liquid-phase epitaxy of doped $\mathrm{KY}\left(\mathrm{WO}_{4}\right)_{2}$ layers for waveguide lasers," Fédérale de Lausanne (2005)

[17] S. Aravazhi, D. Geskus, K. van Dalfsen, S. A. Vázquez-Córdova, C. Grivas, U. Griebner, S. M. 
García-Blanco, and M. Pollnau, "Engineering lattice matching, doping level, and optical properties of $\mathrm{KY}\left(\mathrm{WO}_{4}\right)_{2}$ : $\mathrm{Gd}, \mathrm{Lu}, \mathrm{Yb}$ layers for a cladding-side-pumped channel waveguide laser," Appl. Phys. B 111, 433-446 (2013)

[18] Y.-S. Yong, S. Aravazhi, S. A. Vázquez-Córdova, J. L. Herek, S. M. García-Blanco, and M. Pollnau, "Gain dynamics in a highly ytterbium-doped potassium double tungstate epitaxial layer," J. Opt. Soc. Am. B 35, 2176 (2018)

[19] R. Frentrop, J. Olivares, V. Tormo-Márquez, and S. M. García-Blanco, "High-contrast slab waveguide fabrication in $\mathrm{KY}\left(\mathrm{WO}_{4}\right)_{2}$ by swift heavy ion irradiation," in Integrated Optics: Devices, Materials, and Technologies XXII (SPIE, 2018), Vol. 10535

[20] M. A. Sefunc, F. B. Segerink, and S. M. García-Blanco, "High index contrast passive potassium double tungstate waveguides," Opt. Mater. Express 8, 629 (2018)

[21] B. Denker and E. Shklovsky, Handbook of Solid-State Lasers : Materials, Systems and Applications (Woodhead Publishing, 2013)

[22] Edmund Optics, "Understanding Optical Specifications," https://www.edmundoptics.com/resources/application-notes/optics/understanding-opticalspecifications/

[23] D. Geskus, "Channel waveguide lasers and amplifiers in single-crystalline ytterbium-doped tungstates," (2011)

[24] L. M. Cook, "Chemical processes in glass polishing," J. Non. Cryst. Solids 120, 152-171 (1990)

[25] T. Hoshino, Y. Kurata, Y. Terasaki, and K. Susa, "Mechanism of polishing of $\mathrm{SiO}_{2}$ films by $\mathrm{CeO}_{2}$ particles," J. Non. Cryst. Solids 283, 129-136 (2001) 


\section{Chapter 4}

\section{The influence of oxygen flow on the optical and material characteristics of RF reactive co-sputtered $\mathrm{Al}_{2} \mathrm{O}_{3}$}

Amorphous $\mathrm{Al}_{2} \mathrm{O}_{3}$ is an attractive material for integrated photonics. Its low losses from the visible till the mid-IR together with the possibility of doping with different rare-earth ions permits the realization of active and passive functionalities in the same chip at wafer level. The influence of oxygen flow on the optical (i.e., refractive index and propagation losses) and material (i.e., structure of the layer) characteristics of the $R F$ reactive sputtered $\mathrm{Al}_{2} \mathrm{O}_{3}$ layers is investigated.

This chapter is based on:

C.I. van Emmerik, M.L. Stok, W.A.P.M Hendriks, M. de Goede, L. Chang, M. Dijkstra, F. Segerink, D. Post, E.G. Keim, M.J. Dikkers and S.M. García-Blanco, "Relative oxidation state of the target as guideline for depositing optical quality $\mathrm{RF}$ reactive magnetron sputtered $\mathrm{Al}_{2} \mathrm{O}_{3}$ ” (submitted) 


\subsection{Introduction}

Aluminum oxide $\left(\mathrm{Al}_{2} \mathrm{O}_{3}\right)$ is a dielectric material commonly used as coating for many applications due to its optical properties [1], high hardness [2,3], durability and wear [4]. $\mathrm{Al}_{2} \mathrm{O}_{3}$, both in its crystalline [5-7] as well as amorphous phases [8-14], is also an attractive material for integrated photonics. In particular, amorphous $\mathrm{Al}_{2} \mathrm{O}_{3}$. This material has a moderate refractive index ( $\mathrm{n} 1.65$ at $633 \mathrm{~nm}[15,16])$, a wide transparency window (150-5500 $\mathrm{nm}$ [17]) and low propagation losses (i.e., planar waveguide losses of $0.12 \pm 0.02 \mathrm{~dB} / \mathrm{cm}$ have been reported at $1523 \mathrm{~nm}[18,19])$. Amorphous $\mathrm{Al}_{2} \mathrm{O}_{3}$ exhibits high rare-earth ion solubility in comparison with other materials used in integrated photonics, such as $\mathrm{Si}$ and $\mathrm{Si}_{3} \mathrm{~N}_{4}$ [20,21], with moderate luminescence quenching [11,22]. Rare-earth ion doped amorphous aluminum oxide has been used for lasers emitting at different wavelengths, including $\sim 0.88, \sim 1.06$ and $\sim 1.330 \mu$ m (i.e., $\mathrm{Nd}^{3+}: \mathrm{Al}_{2} \mathrm{O}_{3}$ ) [23], $\sim 1.03 \mu \mathrm{m}$ (i.e., $\left.\mathrm{Yb}^{3+}: \mathrm{Al}_{2} \mathrm{O}_{3}\right)[24,25]$, $\sim 1.55 \mu \mathrm{m} \quad$ (i.e., $\left.\mathrm{Er}^{3+}: \mathrm{Al}_{2} \mathrm{O}_{3}\right) \quad$ [8,24,26,27], $\sim 1.8-1.9 \mu \mathrm{m} \quad\left(\mathrm{Tm}^{3+}: \mathrm{Al}_{2} \mathrm{O}_{3}\right)$ [28-30] and $\sim 2 \mu \mathrm{m}\left(\mathrm{Ho}^{3+}: \mathrm{Al}_{2} \mathrm{O}_{3}\right)[12]$ and amplifiers, operating in the C-band [11,31]. Given its ease of deposition at the wafer-level, $\mathrm{Al}_{2} \mathrm{O}_{3}$ is well-suited for integration as gain material with the well-established $\mathrm{Si}_{3} \mathrm{~N}_{4}[10,24,32-34]$ and $\mathrm{Si}$ [35-37] integrated photonic platforms.

$\mathrm{Al}_{2} \mathrm{O}_{3}$ can be deposited using different methods including the synthesis by the solgel method [38,39], chemical vapor deposition (CVD) [40], pulsed laser deposition (PLD) [41], atomic layer deposition (ALD) [42-46] and reactive co-sputtering $[15,16,19]$. The performances of the devices made by sol-gel and CVD method suffer from luminescence quenching due to $\mathrm{OH}^{-}$incorporation [47], whereas PLD and ALD are limited by their low growth rate for wafer scale $\mathrm{Al}_{2} \mathrm{O}_{3}$ layers $[45,48]$. Reactive magnetron sputtering is suitable for wafer scale deposition. DC-powered sputtering did not result in optical quality layers due to arcing [15], whereas RF-powered sputtering resulted in low $\mathrm{OH}^{-}$incorporation and low optical losses $[18,19]$. For this reason, $\mathrm{RF}$ reactive co-sputtering was selected in this work as fabrication technique for rare-earth ion doped $\mathrm{Al}_{2} \mathrm{O}_{3}$ layers.

The influence of both the hysteresis observed on the bias voltage [49-51], reactive gas partial pressure [52] and deposition rate [53] versus oxygen flow during reactive magnetron sputtering of $\mathrm{Al}_{2} \mathrm{O}_{3}$ coatings as well as the temperature during and after $[54,55]$ the deposition process have been studied and the mechanical characteristics of the deposited $\mathrm{Al}_{2} \mathrm{O}_{3}$ coatings have been reported. Published results show that the optimal process parameters are very dependent on the history of the process and erosion of the target. However, limited number of studies have been focused on understanding how the deposition parameters affect the optical properties (i.e., refractive index and propagation loss) of the $\mathrm{Al}_{2} \mathrm{O}_{3}$ layers $[15,45,56,57]$. Demirtas et al. investigated the 
influence of the deposition temperature on the optical losses of $\mathrm{Al}_{2} \mathrm{O}_{3}$ layers deposited by ALD [45] and Wörhoff et al. presented a comparative study between DC and RF reactive sputtering [15] and their influence on the optical characteristics of the layers. The effect of reactive gas (oxygen) flow during deposition on the optical properties of the sputtered layers has not yet been studied, although it is known to be a key parameter in reactive magnetron sputtering.

In this chapter, the influence of oxygen flow on the optical and material characteristics of $\mathrm{RF}$ reactive sputtered $\mathrm{Al}_{2} \mathrm{O}_{3}$ layers is studied. By proper choice of this parameter, the refractive index, propagation losses and crystallinity of the $\mathrm{Al}_{2} \mathrm{O}_{3}$ layers can be engineered. Transmission electron microscopy (TEM) and X-ray diffraction (XRD) are used to identify the crystallinity of the layer (i.e., amorphous vs (poly)crystalline). Prism coupling was used to determine the layer thickness and refractive index of the layers and to qualitatively evaluate their propagation losses. The results of this study permit understanding how to select the optimum set-point for the sputter deposition process to achieve the desired optical properties for the layers in a reproducible and stable manner.

\subsection{Hysteresis during reactive magnetron sputtering}

Reactive magnetron sputtering of $\mathrm{Al}_{2} \mathrm{O}_{3}$ is based on the sputtering of metallic aluminum, $\mathrm{Al}$, from the target that undergo a chemical reaction with the reactive $\mathrm{O}_{2}$ gas molecules on the substrate and walls of the reaction chamber deposit an $\mathrm{Al}_{2} \mathrm{O}_{3}$ layer. Inert energetic argon ions are used to sputter the aluminum atoms from the target. During the sputtering process not only aluminum atoms are released from the target but also secondary electrons. An electric potential between the target and the chamber wall, acting respectively as cathode and anode, cause the argon ions to be attracted to the target and the emitted electrons to be energized away from the target. Those energized electrons ionize the neutral argon gas. A strong bended magnetic field on the target surface traps the electrons along a trajectory, so called racetrack. The electrons in the racetrack enhance the sputtering yield in this area causing an actual erosion track along this racetrack with a certain depth (Fig. 4.1) further mentioned as racetrack [51,58]. 


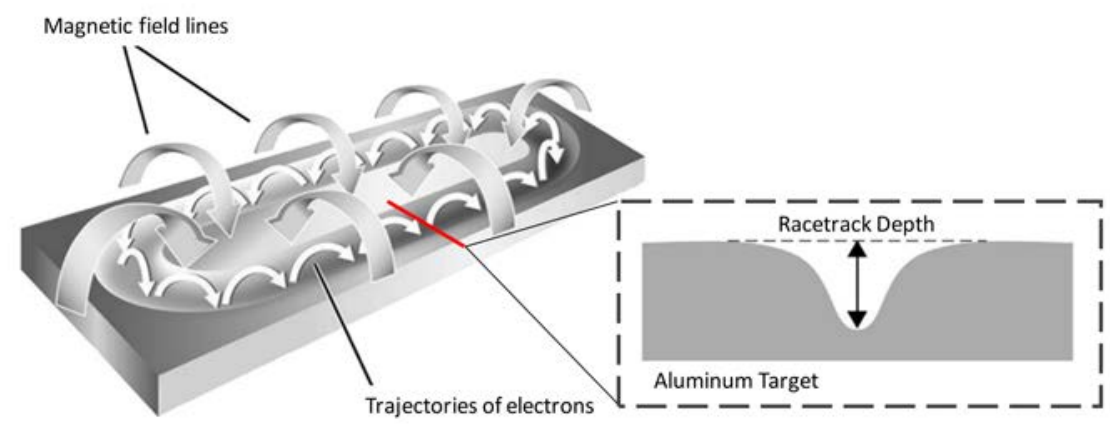

Fig. 4.1 Illustration of a planar magnetron target with the magnetic field lines and the electrons which follow the racetrack trajectory underneath this field [59]. The red line gives a cross-section of the racetrack demonstrating the depth after target erosion by bombardment of argon ions [51].

The operation conditions for the deposition of $\mathrm{Al}_{2} \mathrm{O}_{3}$ are not unique and depend on the operation history of the process. Hysteresis due to direct control of the oxygen flow is a well-known phenomenon [60,61]. When the oxygen flow is low, the substrate and chamber wall act as a sufficient getter pump for the oxygen molecules to form $\mathrm{Al}_{2} \mathrm{O}_{3}$ compound. $\mathrm{Al}_{2} \mathrm{O}_{3}$ will also be formed on the target, although the removal mechanism (by sputtering) is larger than the oxidation rate of the target and the target will stay predominantly in the so called metallic mode. The oxygen partial pressure, bias voltage (i.e., voltage between target and ground of the chamber) and the deposition rate of $\mathrm{Al}_{2} \mathrm{O}_{3}$ will stay almost constant, as shown in Fig 4.2. As the getter pump of the substrate and chamber wall saturates, a sudden increase of the oxygen partial pressure will occur. At this point, the removal rate of the oxidized layer on the target is lower than the formation of an oxide layer and the target will be completely oxidized. This is called the oxidized or poisoned mode. The deposition rate and the bias voltage decrease due to respectively the lower sputter yield and higher electron emission of the $\mathrm{Al}_{2} \mathrm{O}_{3}$ than for $\mathrm{Al}[61,62]$. The oxygen partial pressure increases rapidly with increasing oxygen flow in this mode due to full oxidation of all surfaces in the reaction chamber (i.e., target, substrate, walls of reaction chamber) and is controlled by the pump speed of the reactor. When the oxygen flow is decreased, the oxygen partial pressure first follows the same trajectory. At a certain point, $\mathrm{B}$, the removal rate of oxidized layer on the target dominates again over the formation of the compound layer and the target enters the metallic mode, which causes a sudden decrease in the oxygen partial pressure and an increase of the bias voltage and the deposition rate. This transition point does not always coincide with the transition for increasing oxygen flow and the region where hysteresis occur is the so called "transition region" (i.e., region between point B and A). 

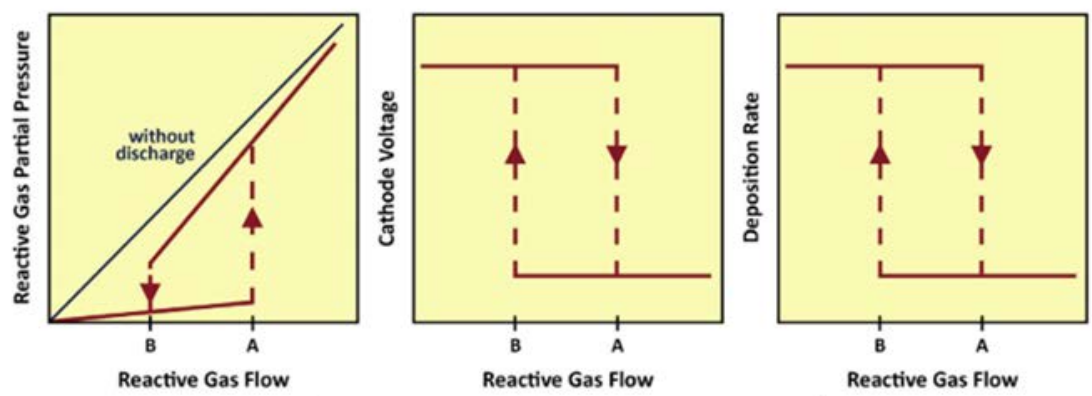

A: Transition metallic mode - reactive mode

B: Transition reactive mode - metallic mode

Fig. 4.2 Schematic of the hysteresis behavior of the oxygen partial pressure, voltage, and deposition rate as a function of reactive gas flow for reactive sputtering [59].

The formation of layers with the right stoichiometry and high deposition rate occur in the transition region. At this operation point, the consumption of reactive gas is maximal [53,63]. Numerical studies using the (advanced) Berg model $[60,64]$ and the reactive sputter deposition (RSD) model [61] have been performed in the literature to get more insight into the influence of the different process settings (i.e., non-reactive gas pressure, pumping speed and target area) to reduce or eliminate the hysteresis effect for DC reactive co-sputtering using a constant total ion current on at the target.

One way to reduce the hysteresis is by increasing the working pressure by an increased flow of inert argon gas. The stable operation point in the transition region shifts to higher oxygen flow mainly due to the lower supply of oxygen ions close to the surface of the target (Fig. 4.3(a)). Another approach is to increase the pumping speed such that the derivative of the total supply of reactive gas consumption stays positive [52,60]. However, this critical pumping speed is often unfeasible to realize (Fig. 4.3(b)). A small target area leads to an increased current density. Since it is easier to remove an oxidized layer on the target with a larger current density, smaller targets permit more stable operation at higher oxygen values (Fig. 4.3(c)) [65]. 

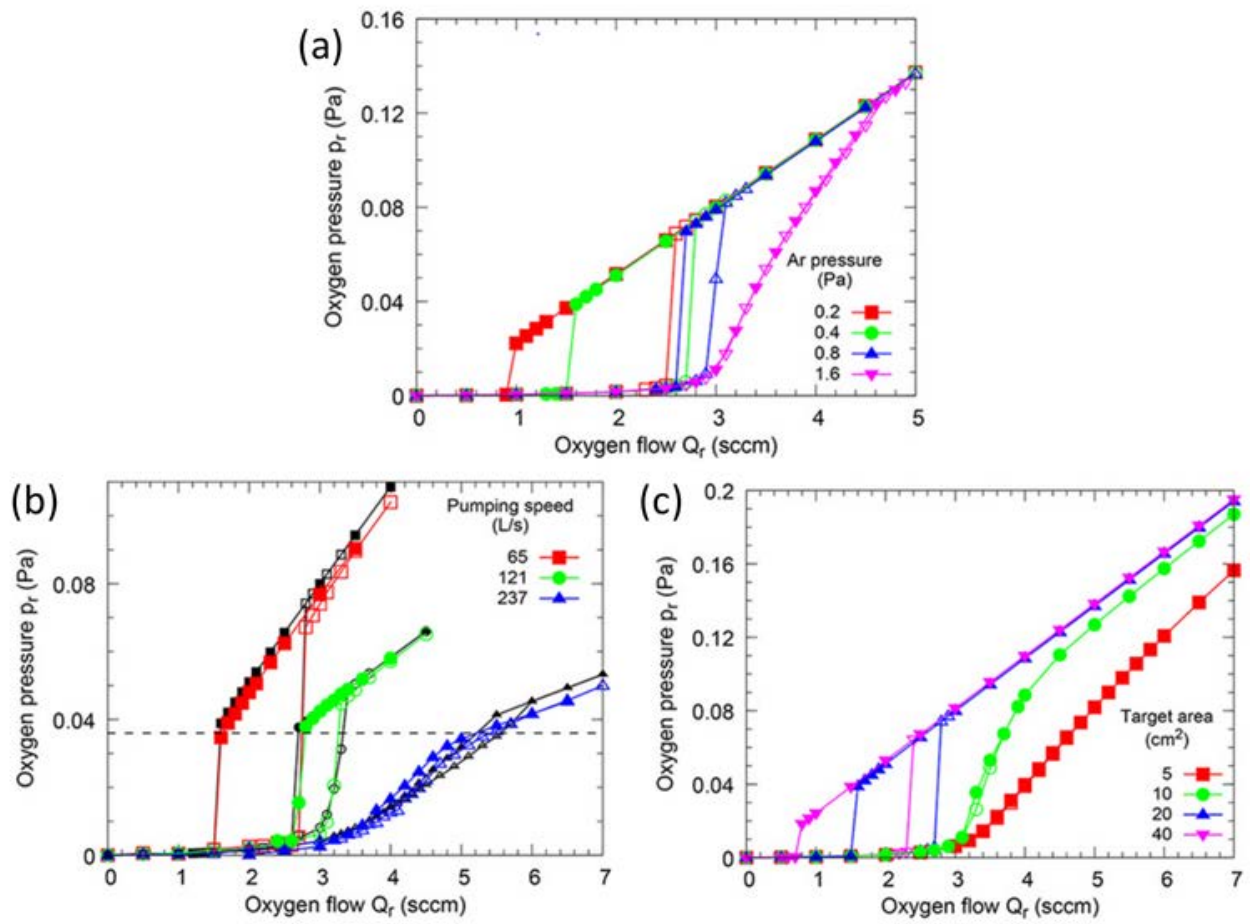

Fig. 4.3 Numerical results based on the RSD model for the influence of the (a) argon pressure, (b) pumping speed and (c) target area on the hysteresis of the oxygen partial pressure as function of oxygen flow [61].

\subsection{RF reactive co-sputtering of $\mathrm{Al}_{2} \mathrm{O}_{3}$ layers: general description}

An AJA ATC 15000 RF reactive co-sputtering system (Fig. 4.4(a)) [18] is used for the deposition of $\mathrm{Al}_{2} \mathrm{O}_{3}$ layers. A schematic of the sputtering chamber is shown in Fig. 4.4(b). A $10 \mathrm{~cm}$ in diameter silicon wafer with $8 \mu \mathrm{m}$ thick thermal oxide layer is introduced through a load-lock and is placed on a rotating heated holder in the main reaction chamber. Three sputtering guns, designed for 2 inch targets are present in the machine, and currently used for aluminum (Al, $99.9995 \%$ purity), erbium (Er, $99.95 \%$ purity) and ytterbium (Yb, $99.9 \%$ purity). Two targets can be ignited with their own RF power source at the same time. The main chamber is pre-evacuated to a base pressure of $0.1 \mu$ Torr (i.e., $13 \mu \mathrm{Pa}$ ), using a turbomolecular pump. Such a low base pressure is necessary to reduce the $\mathrm{OH}^{-}$level. $\mathrm{OH}^{-}$bonds incorporated into the material induce absorption losses around $1400 \mathrm{~nm}$ of wavelength [15] and a strong luminescence quenching when the layers are doped with rare-earth ions $[39,66]$. 
A power of $200 \mathrm{~W}$ is used on the Al-target while powers in the range $5-20 \mathrm{~W}$ for the Er-target and $10-35 \mathrm{~W}$ for the Yb-target are utilized to obtain various doping concentrations in the $\mathrm{Al}_{2} \mathrm{O}_{3}$ layer [67]. Argon flows of 25.0 and $5.0 \mathrm{sccm}$ are applied to respectively the $\mathrm{Al}$ and $\mathrm{Er}$ (or $\mathrm{Yb}$ ) targets. An oxygen flow is added to oxidize the aluminum ions to form an $\mathrm{Al}_{2} \mathrm{O}_{3}$ layer on the wafer. The oxygen flow needed for optically guiding layers depends on the status of the target (Section 4.4) and varies in the range of 2.0-2.8 sccm for undoped $\mathrm{Al}_{2} \mathrm{O}_{3}$ layers in this research. The distance between wafer and target can be adjusted in the range of 4 to 7 inches (i.e., 10.2 to $17.8 \mathrm{~cm}$ ), with increments of 0.25 inch (i.e., $0.64 \mathrm{~cm}$ ). A deposition height of 6.0 inch (i.e., $15.2 \mathrm{~cm}$ ) in combination with a rotation motion of the wafer during deposition were proven to produce the most uniform $\mathrm{Al}_{2} \mathrm{O}_{3}$ layers (Appendix $\mathrm{A}$ ) and they were the settings utilized in all the depositions. The wafer holder is heated by two, $1 \mathrm{~kW}$, halogen lamps to control the temperature on the wafer during deposition. A set temperature of $580^{\circ} \mathrm{C}$ (i.e., expected wafer temperature $\sim 335^{\circ} \mathrm{C}$ ) and a work pressure of $\sim 4 \mathrm{mTorr}$ (i.e., $0.53 \mathrm{~Pa}$ ) is used for all depositions.

The bias voltage between the target (cathode) and the chamber (anode) is monitored and it gives an indication of the degree of oxidation of the target. Prior to each deposition and with the substrate still in the load-lock chamber, the bias voltage as a function of oxygen flow is measured, using the same gas and power settings as during deposition and with the shutter of the target open, to determine the desired operating $\mathrm{O}_{2}$ flow (as it will be discussed in detail in following sections). The substrate is then introduced into the sputtering chamber and the Al-target is pre-sputtered for 10 minutes using the process settings (Table 4.1), with the shutter in front of the target closed. Pre-sputtering has as goal to ensure having always the same initial deposition conditions. When a new target is installed, it is pre-sputtered for 2 hours, with the proces settings shown in Table 4.1, and an oxygen flow of $2.5 \mathrm{sccm}$ to form the racetrack (Section 4.2).

Table 4.1 Settings for the deposition of optical guiding $\mathrm{Al}_{2} \mathrm{O}_{3}$ layers

\begin{tabular}{|l|l|l|l|}
\hline & Al-target & Er-target & Yb-target \\
\hline Power (W) & 200 & $5-20$ & $10-35$ \\
\hline Ar $(\mathbf{s c c m})$ & 25.0 & 5.0 & 5.0 \\
\hline $\mathbf{O}_{2}(\mathbf{s c c m})$ & $2.0-2.8$ \\
\hline Set temperature $\left({ }^{\circ} \mathbf{C}\right) *$ & 580 & \\
\hline Target-wafer distance (inch) & 6.0 \\
\hline
\end{tabular}


(a)

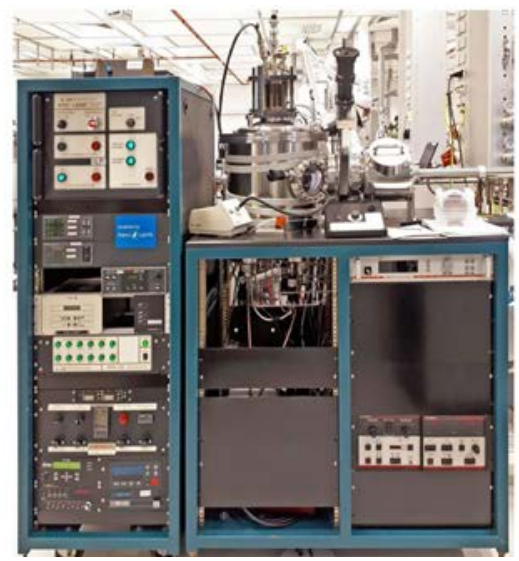

(b)

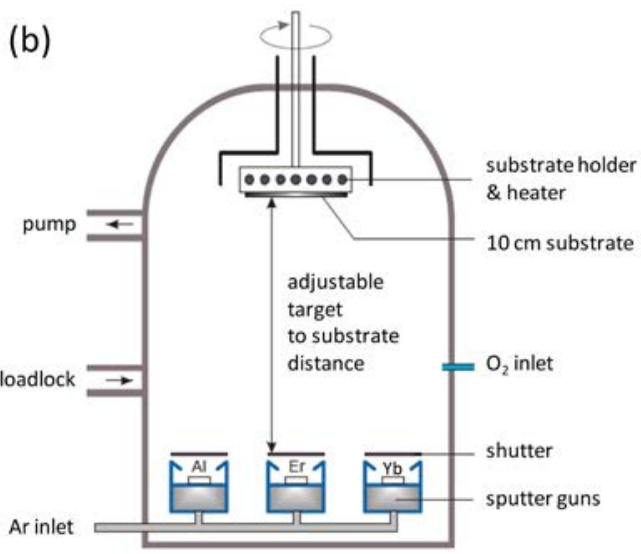

Fig. 4.4 (a) Photograph and (b) schematic representation of AJA ATC 1500 reactive cosputtering system, modified from [68].

\subsection{Influence of target erosion on process parameters}

The oxygen flow is a crucial parameter in reactive sputtering, influencing the stoichiometry, deposition rate and structure of $\mathrm{Al}_{2} \mathrm{O}_{3}$ layers [53,63]. This relationship is often very non-linear and highly complex and the process typically exhibits a hysteresis effect [59], as discussed in Section 4.2.

The bias voltage is measured with the settings described in Section 4.3 for an increasing and decreasing flow of oxygen, as shown in Fig. 4.5(a). No hysteresis is seen from this curve. The process is free from hysteresis due to the fact that the pump speed is large enough to mitigate the influence of the gettering of reactive gas [60]. This can be illustrated with the graph in Fig. 4.5(b) which shows the relationship between the partial pressure of oxygen as function of the total oxygen flow. The total flow is the sum of all sources for reactive gas consumption:

$$
Q_{t o t}=Q_{t}+Q_{c}+Q_{p}
$$

where, $Q_{t}$ and $Q_{c}$ are the gettering of $\mathrm{O}_{2}$ molecules at the target and additional area in the chamber (i.e., substrate and chamber walls) and $Q_{p}$ is the reactive gas pumped out of the system by the turbomolecular pump. No hysteresis occurs if $d Q_{\text {tot }} / d p>0$ over the whole process region. The positive linear slope of the curve (Fig. 4.5(b)) indicates that the pump speed is sufficient to fulfill this condition over the whole oxygen flow region presented in the figure, when the settings as mentioned in Table 4.1 are used $[61,64]$. 

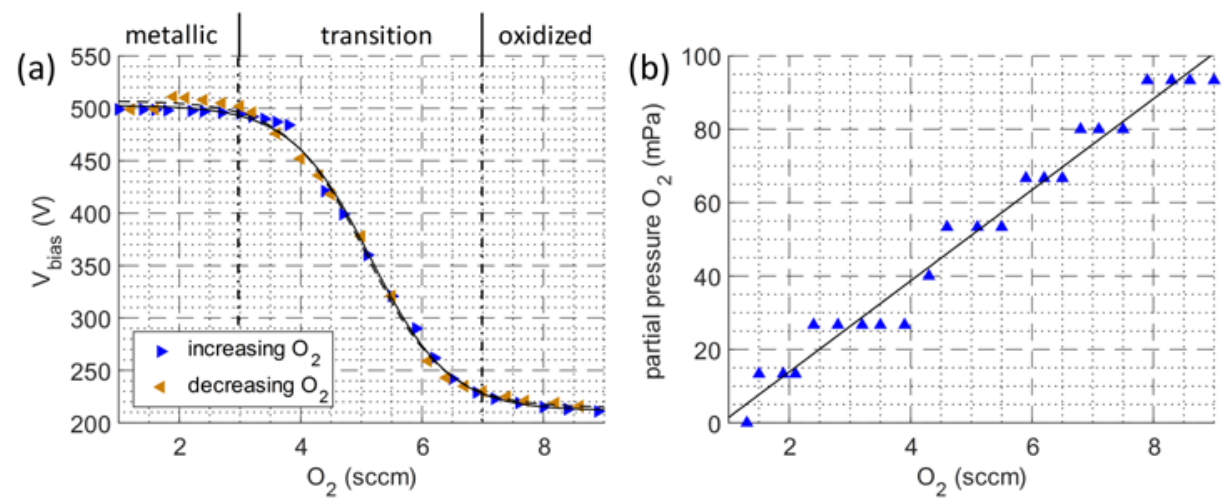

Fig. 4.5 (a) Bias voltage as function of oxygen flow in the chamber. Three regions are indicated: metallic, transition and oxidized. No hysteresis effect is observed. (b) Partial pressure of oxygen as function of the oxygen flow.

The bias voltage curve (Fig. 4.5(a)) is fitted with a sigmoid function to be able to follow the change of the bias voltage over the target lifetime (i.e., erosion of the target). The fitting is given by:

$$
V_{\text {bias }}=\frac{V_{m} e^{r c}+V_{o x} e^{r O_{2}}}{e^{r c}+e^{r O_{2}}}
$$

where $c$ and $r$ are respectively, the center and "slope" of the smooth step function and $O_{2}$ is the oxygen flow and $V_{m}$ and $V_{o x}$ represent the voltage at respectively the metallic and oxidized state of the target [69].

Figure 4.6 presents the metallic and oxide voltages extracted from the curve fitting as a function of number of hours of sputtering of the aluminum target. It can be seen that the bias voltage for the metallic target state reduce over time while the bias voltage at the oxidized target state has a much weaker reduction over the lifetime of the target. The reduction of the bias voltage in general can be explained by a stronger magnetic field in a deeper racetrack, due to the presence of the permanent magnets underneath the target. The stronger magnetic field gives rise to an increased ion bombardment on the target. The larger ion bombardment increases the sputtering rate of $\mathrm{Al}$ atoms which result in a larger emission of secondary electrons. The release of more electrons increases the current in the system which induces a lower bias voltage to maintain a constant power on the target. The decrease in bias voltage is much weaker in the oxidized mode due to an effective smaller increase in emitted electrons. This is due to fact that the secondary electron emission (SEE) coefficient is higher (i.e., SEE metal compound 0.091, SEE oxide compound $0.198[62,70]$ ) and the metal sputter yield is lower when sputtering from an oxidized target compared to a full metallic target [71]. 


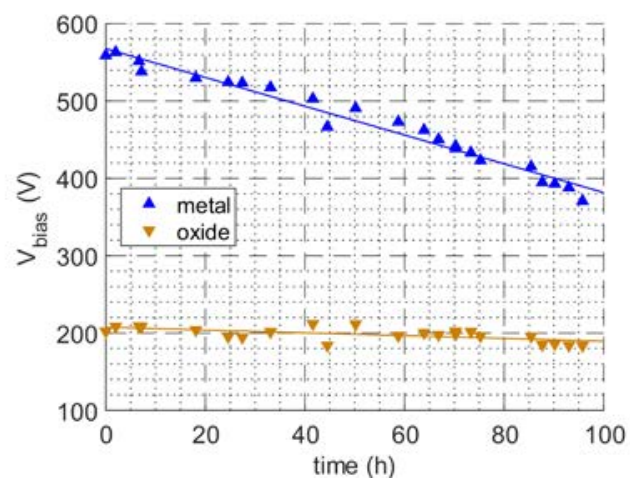

Fig. 4.6 (a) The evolution of the $V_{\text {met, }}$ and $V_{\text {ox }}$ extracted from the fitted sigmoid function over the lifetime of the target.

The fabrication of optical guiding $\mathrm{Al}_{2} \mathrm{O}_{3}$ layer with the highest possible deposition rate requires a bias voltage just outside the metallic mode of the target. We expect, therefore, that the right process point is related to a certain relative oxidation state of the target. The relative oxidation state of the target is defined as:

$$
\eta_{o x}=\frac{V_{m}-V_{O_{2}}}{V_{m}-V_{o x}}
$$

where $V_{m}$ and $V_{o x}$ represent the metallic and oxidized voltage, which can be extracted from Eq. 4.2 and $V_{O_{2}}$ defines the bias voltage for a given oxygen flow in the curve [51].

Figure 4.7(a) shows the relative oxidation of the target as function of oxygen flow with an indication of the three operational modes of the target (i.e., metallic, transition and oxidized). Figure 4.7(b) shows the evolution of the shift of the oxygen flow necessary to achieve a $\eta_{\text {ox }}$ of 5,50 and $95 \%$ as a function of number of hours of sputtering of the aluminum target. From this figure can be seen that oxygen flow necessary to achieve $\eta_{\mathrm{ox}}=5 \%$ shifts to a higher oxygen value whereas the oxygen flow necessary to achieve $\eta_{\mathrm{ox}}=95 \%$ shifts to lower oxygen flow. This means that the transition region in the $\mathrm{V}_{\text {bias }}\left(\mathrm{O}_{2}\right)$ or $\eta_{\text {ox }}\left(\mathrm{O}_{2}\right)$ curve becomes smaller. The width of the transition region is determined by the ratio between the removal rate of the oxide compound on the target and oxidation rate of the target. The total sputter yield of metallic atoms from either the metallic or oxidized region of the target depend on the ion bombardment at that particular position on the target [72]. The ion collection efficiency is larger inside the racetrack due to a stronger magnetic field due to the presence of the permanent magnets underneath the target. This causes an increased rate of ion bombardment inside the racetrack, resulting in a rise of the total sputter yield of metal atoms inside the racetrack. The relative lower ion bombardment outside the racetrack, due to the weaker magnetic field, results in oxidation of the target to develop from the perimeter of the target to the perimeter of the racetrack. The sputter yield of metallic 
atoms is lower from an oxidized target compared to a metallic target [71]. This makes it more difficult to remove the oxidized region from the target and the dominant fraction of sputtered atoms are from the metallic region inside the racetrack. This causes a larger erosion at the center of the track causing deepening of the racetrack. The geometry of the racetrack and the increased magnetic field causes re-deposition of aluminum inside the racetrack [51]. The deposition of aluminum atoms on another metallic area reduces the effective metallic yield which reduces the getter pump effect which eventually lead to a smaller transition region and a fully oxidized target at lower oxygen flow (Fig. 4.7(b)).
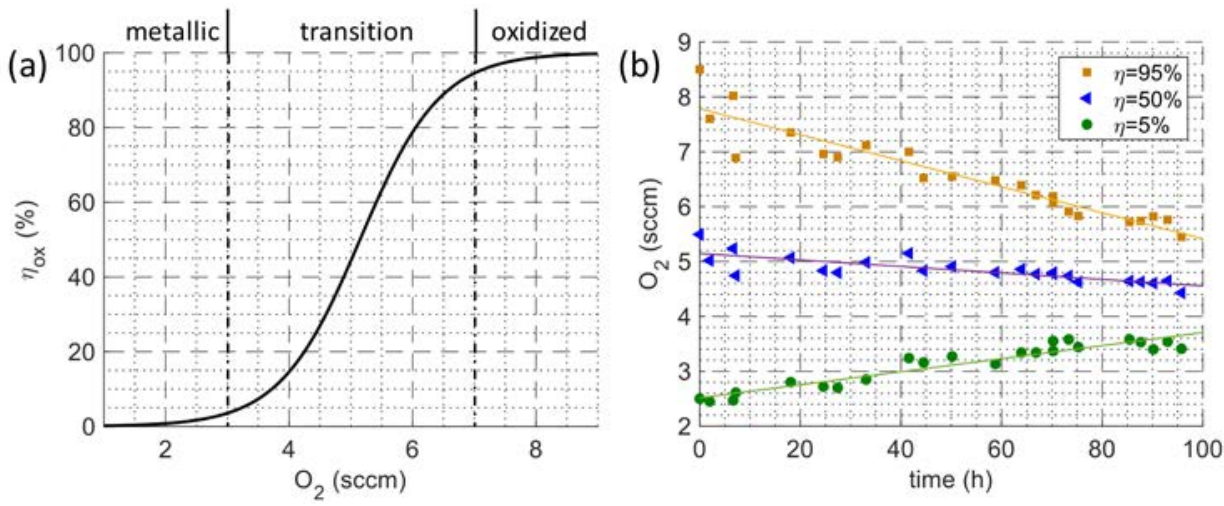

Fig. 4.7 (a) Relative oxidation state of the target as function of oxygen flow. Three regions are indicated: metallic, transition and oxidized. (b) The evolution of the corresponding $\mathrm{O}_{2}$ flow to achieve a $\eta_{\text {ox }}$ of 5,50 and $95 \%$ as function of lifetime of the target.

\subsection{Characterization of the sputtered $\mathrm{Al}_{2} \mathrm{O}_{3}$ films}

Both the optical properties (i.e., refractive index and propagation losses) as well as the material structure (i.e., crystallinity) of the deposited layers were characterized as a function of oxygen flow.

A prism coupling method (i.e., Metricon 2010) is employed to measure the refractive index and thickness of the deposited films using light of a wavelength of $632.8 \mathrm{~nm}$. The propagation losses are qualitatively determined, at the same wavelength, by looking at the streak of light travelling in the layers after coupling using the prism coupler. The losses are grouped in three categories: optical guiding, lossy guiding and no guiding. The light propagates for at least $5 \mathrm{~cm}$ without noticeable attenuation by eye for the classification 'guiding' (Fig. 4.8(a),(b)). The layer is classified as 'lossy' if the light streak diminish within $5 \mathrm{~cm}$ propagation length (Fig. 4.8 (b),(c)). If no light streak is observed the layer is classified as 'no guiding'. 
(a)

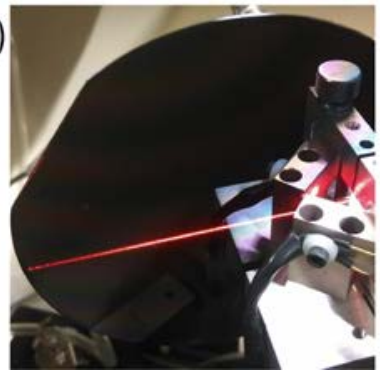

(b)

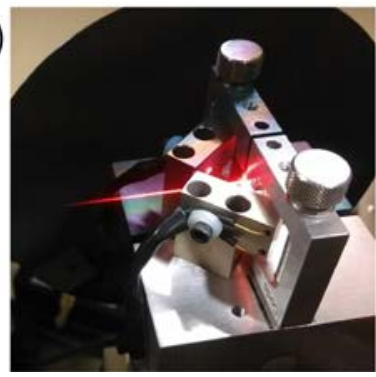

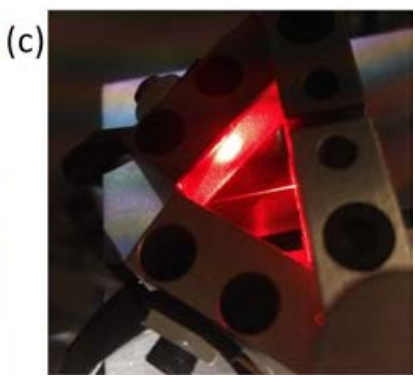

Fig. 4.8 Examples of the different qualitatively determined classes of guiding. (a) guiding, (b) on the edge between guiding and lossy guiding and (c) lossy guiding.

Transmission electron microscopy (TEM) is used to identify the crystalline nature of the layer (i.e., amorphous vs (poly)crystalline) and to estimate the mean crystal size [73,74]. The samples for TEM analysis are prepared with the in situ lift-out technique [75] using a focused ion beam (FIB) process (FEI Nova600 NanoLab Dualbeam-SEM/FIB system). The prepared samples are mounted on an Omniprobe molybdenum 3-post lift out grid (Fig. 4.9(a)). The sample facets have an amorphous surface layer due to the thinning procedure with the $\mathrm{Ga}^{+}$ions. This amorphous layer is reduced to a couple of nanometers during the last stage of the preparation process by milling with subsequently $5 \mathrm{keV}$ and $2 \mathrm{keV}$ acceleration voltage [75]. A small lamella with a thickness of $\sim 50 \mathrm{~nm}$ was prepared with this method (Fig. 4.9(b)). TEM images are made using a Philips CM3000ST-FEG $300 \mathrm{keV}$ TEM system with a Gatan Ultrascan1000 CCD camera with a resolution of $\sim 0.1 \mathrm{~nm}$. The software of the CCD camera is used to make the inverse fast fourier transform of the TEM image resulting in the diffraction pattern of the image. This diffraction pattern is used to determine the lattice constant of the (poly)crystalline planes [76].

(a)

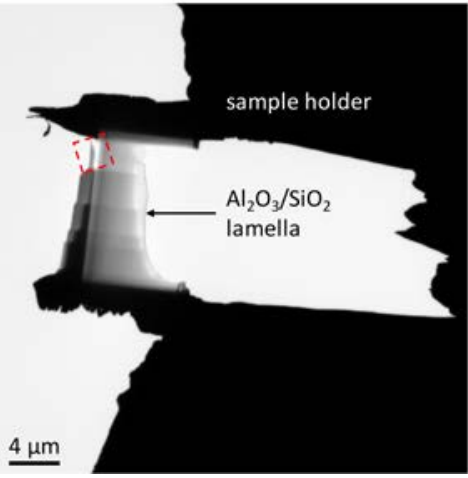

(b)

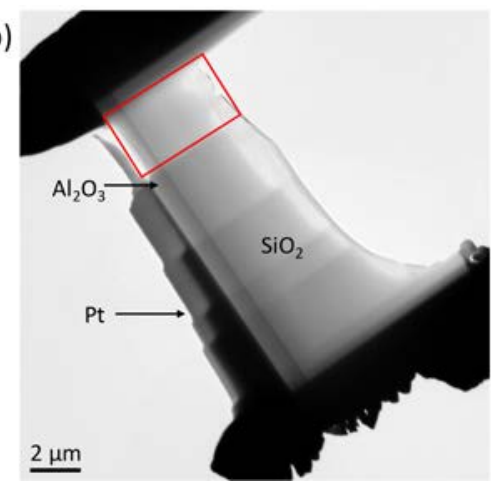

Fig. 4.9 (a) $\mathrm{Al}_{2} \mathrm{O}_{3} / \mathrm{SiO}_{2}$ lamella prepared by FIB milling in a molybdenum holder; (b) close-up of the $\mathrm{Al}_{2} \mathrm{O}_{3} / \mathrm{SiO}_{2}$ lamella, with Pt coating for FIB milling. Top side of the lamella (indicated by red square) is $\sim 50 \mathrm{~nm}$ thick. 
In an amorphous structure the electrons are elastically scattered in all directions, which results in a hazy circle in the center of the diffraction pattern. On the other hand, a regular array of spots appears on the diffraction pattern when a set of atomic planes in a single crystalline sample are oriented perpendicular to the electron beam (Fig. 4.10(a)). When the sample is polycrystalline, the diffraction pattern is formed by the sum of the diffraction patterns of the different crystals that form the material, each with a different orientation. The diffraction pattern consists of spots distributed along rings (Fig. 4.10(b)). The rings on the diffraction pattern become continuous (Fig. 4.10(c)) for a sample with many small crystallites due to the fact that diffraction occurs in all angles [73].
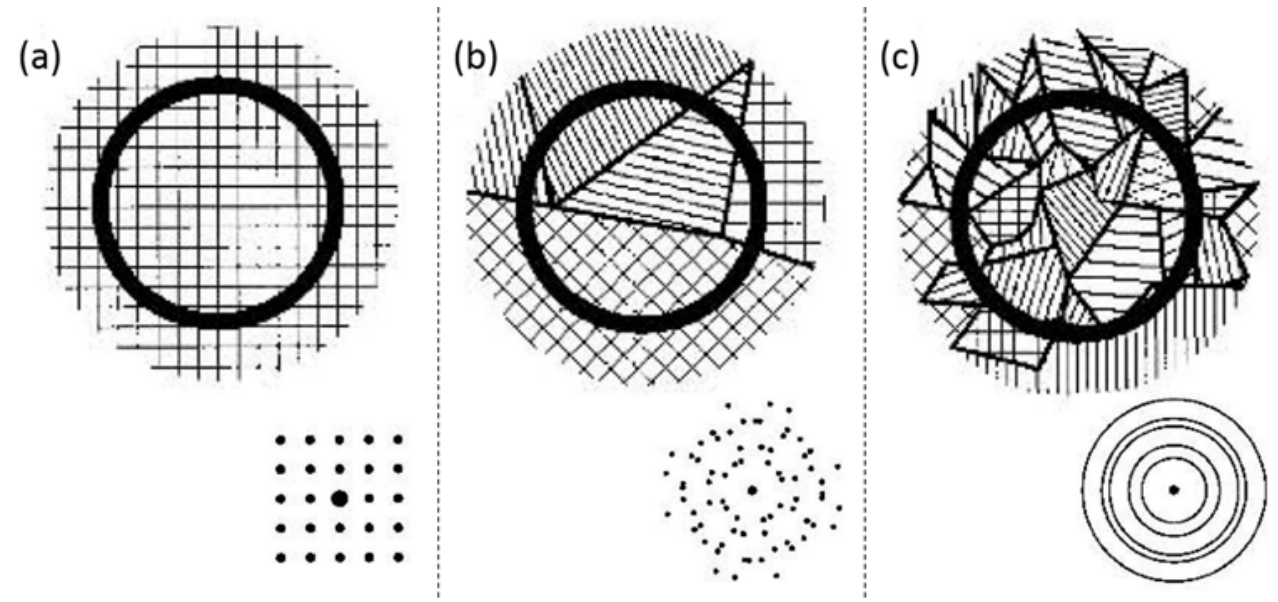

Fig. 4.10 Example of diffraction patterns (bottom) that arise from different micro structured samples (top) at the selected area within the black circle. (a) Crystalline sample, (b) polycrystalline sample with large grains, (c) polycrystalline sample with small grains. Image modified from [73].

X-Ray diffraction (XRD) permits to identify the crystalline phase, based on the diffraction footprint of the different phases of $\mathrm{Al}_{2} \mathrm{O}_{3}$ crystals [54]. The XRD analyses are performed with an X-Ray Powder Diffraction X'Pert-Pro (PANalytical B.V.) with two $\mathrm{Cu} \mathrm{K \alpha} \mathrm{X}$-ray sources $(\lambda=0.15405980 \AA$ and $\lambda=0.15444260 \AA)$. The measurements are done in the Bragg-Bretano $\theta: \theta$ configuration with a $2 \theta$ scan range from $5-100^{\circ}$ and a collection time of 48 minutes. 


\subsection{Effect of oxygen flow on the optical and morphological properties of the sputtered $\mathrm{Al}_{2} \mathrm{O}_{3}$ layers}

The relative oxidation state of the target has a large influence on the refractive index and propagation losses of the sputtered $\mathrm{Al}_{2} \mathrm{O}_{3}$ layers. To increase our understanding of this influence, a series of $\mathrm{Al}_{2} \mathrm{O}_{3}$ layers were deposited with various oxygen flows. The depositions were performed with the settings shown in Table 4.1 for a deposition time of 160 minutes. A bias voltage curve as function of oxygen flow was made, as described in Section 4.3, every other deposition to recalibrate the relative oxidation state of the target during the process.

Figure 4.11(a) shows a section of the bias voltage curves, for different target ages, as a function of oxygen where the oxygen settings and qualitative optical guiding properties as defined in Section 4.5 are indicated. From this graph it can be seen that the oxygen flow set point cannot be determined based on the bias voltage graph. On the other hand, the relative oxidation state seems to be a promising parameter to determine the set point for the oxygen flow, as shown in Fig. 4.11(b). All the optical guiding layers were obtained at a relative oxidation state of the target of $5 \pm 1.5 \%$.
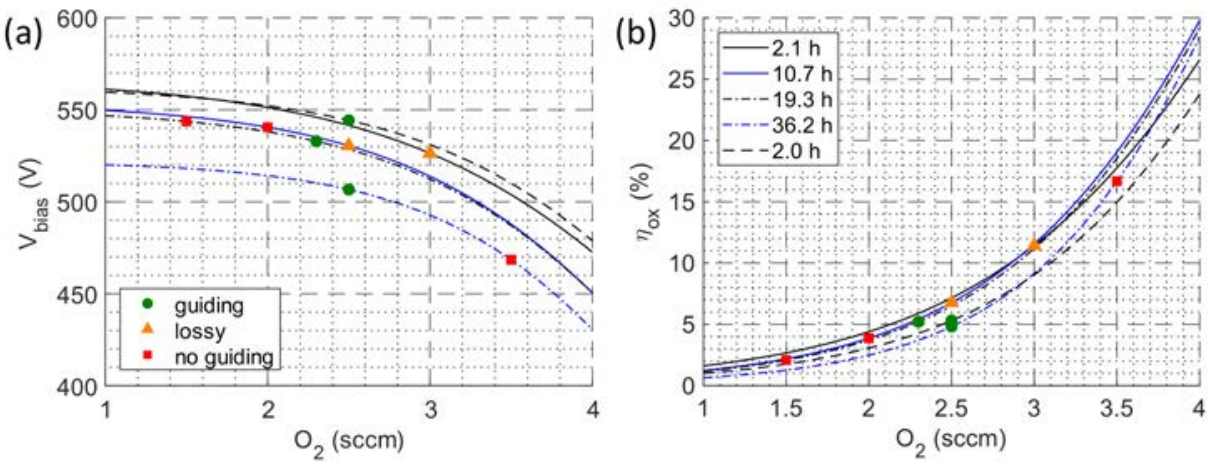

Fig 4.11 (a) Section of the bias voltage curve as function of oxygen flow and (b) relative oxidation state of the target as function of oxygen flow. In both graphs deposition parameters with their optical guiding properties are indicated.

Optical guidance was achieved for layers deposited with relative target oxidation states in the range of $5 \pm 1.5 \%$ for undoped $\mathrm{Al}_{2} \mathrm{O}_{3}$ layers. The refractive indices of the guiding layers varied in the range from 1.665 to 1.670 as shown in Fig. 4.12(a). The $\mathrm{Al}_{2} \mathrm{O}_{3}$ layers became lossy for $\mathrm{n} \sim 1.685$. Those losses can be caused by small $\mathrm{Al}_{2} \mathrm{O}_{3}$ crystals in the layer. Lack of guiding was observed for layers with a $\mathrm{n}<1.665$ $\left(\eta_{\text {ox }}\right.$ roughly $\left.<5 \%\right)$ or a $n>1.720\left(\eta_{\text {ox }}\right.$ roughly $\left.>15 \%\right)$. The losses in the low refractive index layers are caused by absorption due to aluminum ions, which are not oxidized. For 
layers deposited with a large oxidation state of the target, a refractive index close to that of sapphire ( $\mathrm{n} \approx 1.75$ [6]), the stable crystalline form of $\mathrm{Al}_{2} \mathrm{O}_{3}$, was obtained. This suggests a high degree of polycrystallinity in the layer, which causes high propagation losses.

The study was repeated with erbium doped layers to verify if a similar behavior occurs with rare-earth ions doped in $\mathrm{Al}_{2} \mathrm{O}_{3}$ layer (Fig. 4.12(b)). The same process settings were used for the $\mathrm{Er}^{3+}: \mathrm{Al}_{2} \mathrm{O}_{3}$ layers as for the undoped $\mathrm{Al}_{2} \mathrm{O}_{3}$ layers only now with a power of $20 \mathrm{~W}$ applied onto the Er-target, which resulted in a $\sim 0.3$ at.\% concentration of $\mathrm{Er}^{3+}$ in the layer. It can be seen from Fig. 4.12 (a) and (b) that the refractive index as function of the relative oxidation state of the target has a similar shape for the $\mathrm{Er}^{3+}: \mathrm{Al}_{2} \mathrm{O}_{3}$ layers compared to the undoped $\mathrm{Al}_{2} \mathrm{O}_{3}$ layers. The curve is shifted to lower $\eta_{\text {ox }}$ values. Loiko et al. demonstrated that $\mathrm{Tm}_{2} \mathrm{O}_{3}$ most likely is situated in the interstitial positions in the $\mathrm{Al}_{2} \mathrm{O}_{3}$ layer deposited with $\mathrm{RF}$ reactive co-sputtering [16] and Rönn et al. demonstrated the fabrication process of alternating of sub monolayers of $\mathrm{Er}_{2} \mathrm{O}_{3}$ and monolayers of $\mathrm{Al}_{2} \mathrm{O}_{3}$ to form optical $\mathrm{Er}^{3+}: \mathrm{Al}_{2} \mathrm{O}_{3}$ using ALD [46]. This, however, does not explain the lower $\eta_{\text {ox }}$ values needed for optically guiding $\mathrm{Er}^{3+}: \mathrm{Al}_{2} \mathrm{O}_{3}$ layers compared to the undoped $\mathrm{Al}_{2} \mathrm{O}_{3}$ layers because the same amount of oxygen is needed for to form $\mathrm{Al}_{2} \mathrm{O}_{3}$ or $\mathrm{Er}_{2} \mathrm{O}_{3}$. Further research with spectroscopic methods is therefore needed to identify the differences between both types of layers.
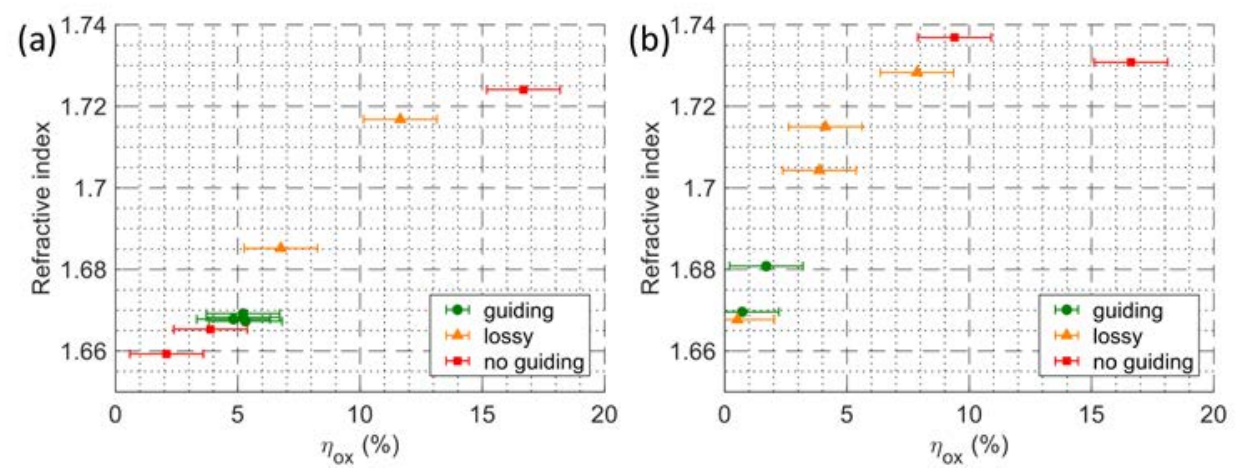

Fig. 4.12 Refractive index (measured at a wavelength of $632.8 \mathrm{~nm}$ using a prism coupler setup) as function of the target oxidation state (error margin of refractive index is 0.001) for (a) undoped $\mathrm{Al}_{2} \mathrm{O}_{3}$ and (b) $~ 0.3$ at. $\% \mathrm{Er}^{3+}: \mathrm{Al}_{2} \mathrm{O}_{3}$ layers.

Figure 4.12(a) shows that a large range of refractive indices can be obtained by varying the oxygen flow during the sputtering process. Refractive indices above 1.665 suggest the presence of some sort of crystalline (or polycrystalline) structure. A polycrystalline structure could be the origin of the higher propagation losses observed in those layers. To confirm this hypothesis, three samples were prepared, two with low refractive index and good propagation losses and the third one with a high refractive 
index and high propagation losses. The refractive index was varied by changing the oxygen flow with the aim of working at different relative target oxidation states of the target. Table 4.2 summarizes the deposition and optical characteristics of the undoped $\mathrm{Al}_{2} \mathrm{O}_{3}$ layers.

Table 4.2 Characteristics of undoped $\mathrm{Al}_{2} \mathrm{O}_{3}$ layers used for TEM and XRD

\begin{tabular}{|l|l|l|l|}
\hline Sample & $\boldsymbol{\eta}_{\mathbf{o x}} \mathbf{( \% )}$ & $\mathbf{n}(\boldsymbol{\lambda}=\mathbf{6 3 2 . 8} \mathbf{~ n m})$ & Guiding \\
\hline $\mathbf{1}$ & -- & 1.665 & Yes* \\
\hline $\mathbf{2}$ & 5.2 & 1.669 & Yes \\
\hline $\mathbf{3}$ & 11.6 & 1.717 & No \\
\hline \multicolumn{2}{|l}{ *waveguide losses of $0.60 \pm 0.04 \mathrm{~dB} / \mathrm{cm}$ at $1560 \mathrm{~nm}[14]$}
\end{tabular}

TEM and XRD measurements were performed in the three samples to determine their structure. Thin lamellas were prepared as described in Section 4.5. The TEM images of the samples 1-3 are shown in Fig. 4.13 (a-c) respectively, with their corresponding diffraction patterns. The predominantly amorphous nature of the $\mathrm{Al}_{2} \mathrm{O}_{3}$ layers is visible for all the samples in their diffraction pattern (i.e., hazy spot at the center of the diffraction pattern). Sample 2 (Fig 4.13(b)) and 3 (Fig 4.13(c)) show an additional polycrystalline nature, which is more prominent at a higher relative oxidation state of the target. The lattice spacing of the three rings present in samples 2 and 3 are inferred from the diffractogram. The spacings are $1.39 \AA, 1.97 \AA$ and $2.39 \AA$, indicated with respectively 1, 2 and 3 in Fig 4.7(c). They correspond with the (440), (400) and (311) orientations of $\gamma-\mathrm{Al}_{2} \mathrm{O}_{3}[77,78]$.
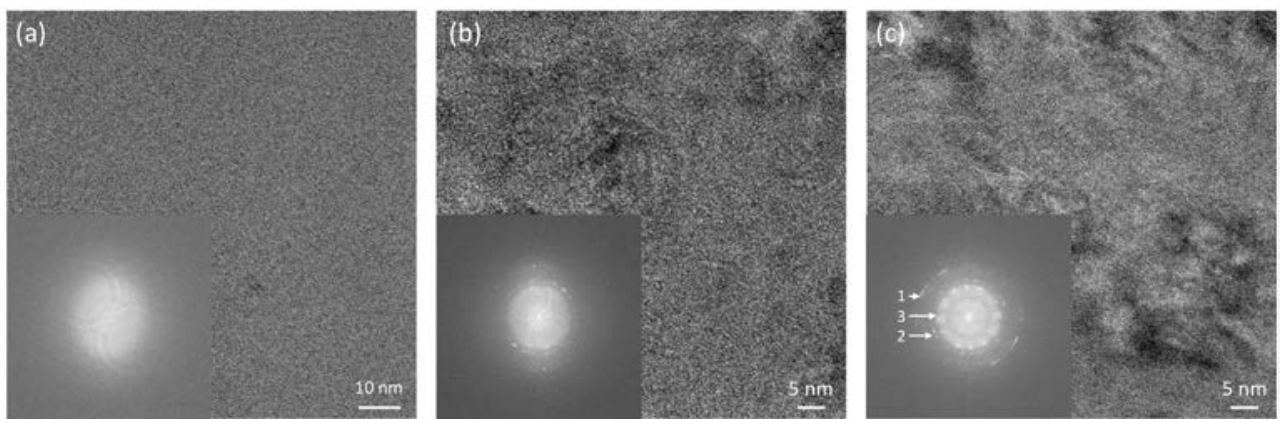

Fig. 4.13 TEM images and corresponding diffractograms of a (a) amorphous $\mathrm{Al}_{2} \mathrm{O}_{3}$ layer with low propagation losses [14]; (b) a polycrystalline $\mathrm{Al}_{2} \mathrm{O}_{3}$ layer with optical guiding; (c) a polycrystalline $\mathrm{Al}_{2} \mathrm{O}_{3}$ layer without optical guiding. 
The XRD results are shown in Fig. 4.14. The two sharp peaks at $2 \theta \sim 33^{\circ}$ and $69^{\circ}$ correspond to the (002) and (100) peaks of the silicon substrate, respectively. The amorphous network of both $\mathrm{Al}_{2} \mathrm{O}_{3}$ layers is characterized by the broad halo at the diffraction angles $2 \theta \sim 15-25^{\circ}$. The halo at $2 \theta \sim 45^{\circ}$ is associated to certain degree of polycrystallinity in the $\mathrm{Al}_{2} \mathrm{O}_{3}$ layer with a refractive index of 1.718 . The phase of the crystallization cannot be identified because $\gamma, \delta$ and $\alpha \mathrm{Al}_{2} \mathrm{O}_{3}$ all have a diffraction peak around $45^{\circ}$ [54] and no other halos or peaks have been measured to being able to associate the crystalline phase to the fingerprint peaks as defined in the JCPDS (Joint Committee on Powder Diffraction Standards) charts.

Both TEM and XRD analysis shows the dominant amorphous character of the $\mathrm{Al}_{2} \mathrm{O}_{3}$ network. A degree of polycrystallinity is observed for the high refractive $(n>1.70)$ index layers. The diffraction patterns obtained with TEM indicate, most likely, the presence of polycrystalline $\gamma-\mathrm{Al}_{2} \mathrm{O}_{3}$.

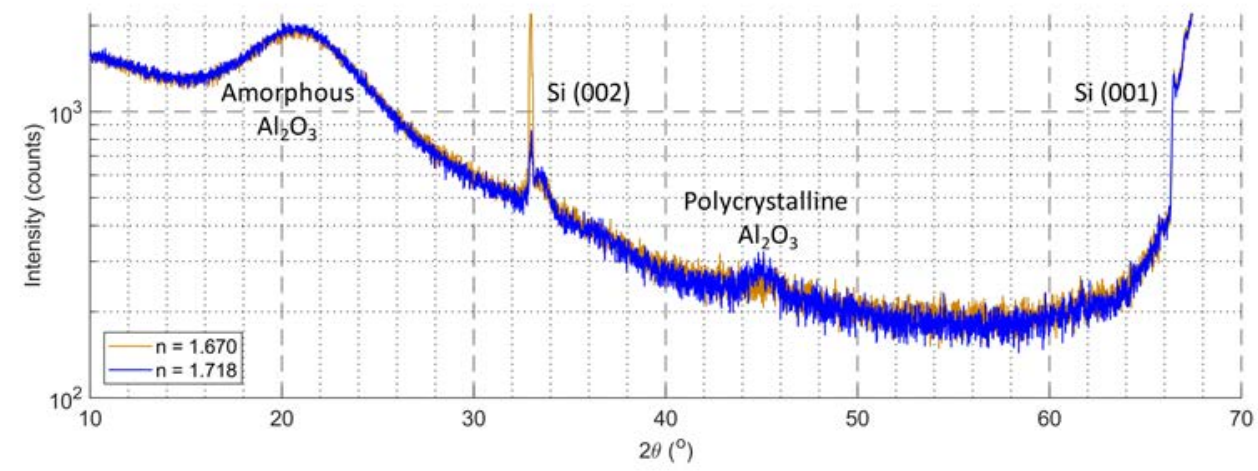

Fig. 4.14 XRD measurement of two $\mathrm{Al}_{2} \mathrm{O}_{3}$ layers made with different oxygen concentrations resulting in (a) a guiding layer with $\mathrm{n}=1.670$ (yellow) and (b) nonguiding layer with $n=1.718$ (blue) at $632.8 \mathrm{~nm}$.

The increase in crystallinity due to larger oxygen flow has also been seen for $\mathrm{Al}_{2} \mathrm{O}_{3}$ coatings $[2,49]$. The formation of crystalline structure is governed by the diffusion length of the deposited particles and their energetic contribution. The diffusion length is given by the relation $x \sim \sqrt{D_{s} / d}$ where, $d$, is the deposition rate and $D_{s} \sim e^{-1 / T_{w}}$ is the surface diffusion coefficient which depends on the wafer temperature, $T_{w}$ [49]. More research is needed to identify operational relative oxidation states of the target for different wafer temperatures to obtain optically guiding layers. 


\subsection{Conclusion}

The relative oxidation state of the target is introduced to identify the correct oxygen flow to grow optical guiding $\mathrm{Al}_{2} \mathrm{O}_{3}$ layers. Optical guidance for undoped $\mathrm{Al}_{2} \mathrm{O}_{3}$ layers with a refractive index of $\sim 1.665$ has been demonstrated for depositions made at a set temperature of $580^{\circ} \mathrm{C}$. The optical guiding was achieved with relative oxidation state of the target of $\eta_{\mathrm{ox}} \approx 1.5 \pm 1.5 \%$ for 0.3 at. $\% \mathrm{Er}^{3+}: \mathrm{Al}_{2} \mathrm{O}_{3}$ layers and $\eta_{\mathrm{ox}} \approx 5.0 \pm 1.5 \%$ for undoped $\mathrm{Al}_{2} \mathrm{O}_{3}$ layers. TEM measurements revealed a polycrystalline $\gamma$-phase in undoped $\mathrm{Al}_{2} \mathrm{O}_{3}$ layers, which became more pronounced with higher oxidation states of the target. 


\section{References}

[1] X. Tang, F. Luo, F. Ou, W. Zhou, D. Zhu, and Z. Huang, "Effects of negative substrate bias voltage on the structure and properties of aluminum oxide films prepared by DC reactive magnetron sputtering," Appl. Surf. Sci. 259, 448-453 (2012)

[2] R. Cremer, K. Reichert, D. Neuschütz, G. Erkens, and T. Leyendecker, "Sputter deposition of crystalline alumina coatings," Surf. Coatings Technol. 163-164, 157-163 (2003)

[3] M. Sridharan, M. Sillassen, J. Bøttiger, J. Chevallier, and H. Birkedal, "Pulsed DC magnetron sputtered $\mathrm{Al}_{2} \mathrm{O}_{3}$ films and their hardness," Surf. Coatings Technol. 202, 920-924 (2007)

[4] J. Wang, Y.-H. Yu, S. . Lee, and Y.-W. Chung, "Tribological and optical properties of crystalline and amorphous alumina thin films grown by low-temperature reactive magnetron sputterdeposition," Surf. Coatings Technol. 146-147, 189-194 (2001)

[5] C. Grivas, C. Corbari, G. Brambilla, and P. G. Lagoudakis, "Tunable, continuous-wave Ti:sapphire channel waveguide lasers written by femtosecond and picosecond laser pulses," Opt. Lett. 37, 4630 (2012)

[6] S. H. Waeselmann, S. Heinrich, C. Kränkel, and G. Huber, "Lasing of $\mathrm{Nd}^{3+}$ in sapphire," Laser Photon. Rev. 10, 510-516 (2016)

[7] S. H. Waeselmann, C. E. Rüter, D. Kip, C. Kränkel, and G. Huber, "Nd:sapphire channel waveguide laser," Opt. Mater. Express 7, 2361 (2017)

[8] J. D. Bradley, R. Stoffer, L. Agazzi, F. Ay, K. Wörhoff, and M. Pollnau, "Integrated $\mathrm{Al}_{2} \mathrm{O}_{3}: \mathrm{Er}^{3+}$ ring lasers on silicon with wide wavelength selectivity," Opt. Lett. 35, 73 (2010)

[9] M. Belt and D. J. Blumenthal, "Erbium-doped waveguide DBR and DFB laser arrays integrated within an ultra-low-loss $\mathrm{Si}_{3} \mathrm{~N}_{4}$ platform," Opt. Express 22, 10655 (2014)

[10] E. S. Hosseini, J. D. B. Bradley, J. Sun, G. Leake, T. N. Adam, D. D. Coolbaugh, and M. R. Watts, "CMOS-compatible 75 mW erbium-doped distributed feedback laser," Opt. Lett. 39, 3106 (2014)

[11] S. A. Vázquez-Córdova, M. Dijkstra, E. H. Bernhardi, F. Ay, K. Wörhoff, J. L. Herek, S. M. García-Blanco, and M. Pollnau, "Erbium-doped spiral amplifiers with $20 \mathrm{~dB}$ of net gain on silicon," Opt. Express 22, 25993 (2014)

[12] N. Li, E. S. Magden, Z. Su, N. Singh, A. Ruocco, M. Xin, M. Byrd, P. T. Callahan, J. D. B. Bradley, C. Baiocco, D. Vermeulen, and M. R. Watts, "Broadband 2- $\mu$ m emission on silicon chips: monolithically integrated Holmium lasers," Opt. Express 26, 2220 (2018)

[13] J. Mu, M. Dijkstra, and S. M. Garcia-Blanco, "Resonant Coupling for Active-passive Monolithic Integration of $\mathrm{Al}_{2} \mathrm{O}_{3}$ and $\mathrm{Si}_{3} \mathrm{~N}_{4}$," IEEE Photonics Technol. Lett. 1-1 (2019)

[14] M. de Goede, M. Dijkstra, R. Obregón, J. Ramón-Azcón, E. Martínez, L. Padilla, F. Mitjans, and S. M. Garcia-Blanco, " $\mathrm{Al}_{2} \mathrm{O}_{3}$ microring resonators for the detection of a cancer biomarker in undiluted urine," Opt. Express 27, 18508 (2019)

[15] K. Worhoff, F. Ay, and M. Pollnau, "Optimization of Low-Loss $\mathrm{Al}_{2} \mathrm{O}_{3}$ Waveguide Fabrication for Application in Active Integrated Optical Devices," in ECS Transactions (ECS, 2006), Vol. 3, pp. $17-26$

[16] P. Loiko, N. Ismail, J. D. B. Bradley, M. Götelid, and M. Pollnau, "Refractive-index variation with rare-earth incorporation in amorphous $\mathrm{Al}_{2} \mathrm{O}_{3}$ thin films," J. Non. Cryst. Solids 476, 95-99 (2017)

[17] E. R. Dobrovinskaya, L. A. Lytvynov, and V. Pishchik, Sapphire Material, Manufacturing, Applications (Springer, 2009)

[18] K. Wörhoff, J. D. B. Bradley, F. Ay, D. Geskus, T. P. Blauwendraat, and M. Pollnau, "Reliable Low-Cost Fabrication of Low-Loss $\mathrm{Al}_{2} \mathrm{O}_{3}: \mathrm{Er}^{3+}$ Waveguides With 5.4-dB Optical Gain," IEEE J. Quantum Electron. 45, 454-461 (2009) 
[19] J. D. B. Bradley, F. Ay, K. Wörhoff, and M. Pollnau, "Fabrication of low-loss channel waveguides in $\mathrm{Al}_{2} \mathrm{O}_{3}$ and $\mathrm{Y}_{2} \mathrm{O}_{3}$ layers by inductively coupled plasma reactive ion etching," Appl. Phys. B 89, 311-318 (2007)

[20] P. G. Kik and A. Polman, "Erbium-Doped Optical-Waveguide Amplifiers on Silicon," MRS Bull. 23, 48-54 (1998)

[21] P. Xing, G. F. R. Chen, X. Zhao, D. K. T. Ng, M. C. Tan, and D. T. H. Tan, "Silicon rich nitride ring resonators for rare - earth doped telecommunications-band amplifiers pumped at the O-band," Sci. Rep. 7, 9101 (2017)

[22] L. Agazzi, K. Wörhoff, and M. Pollnau, "Energy-Transfer-Upconversion Models, Their Applicability and Breakdown in the Presence of Spectroscopically Distinct Ion Classes: A Case Study in Amorphous $\mathrm{Al}_{2} \mathrm{O}_{3}: \mathrm{Er}^{3+}$," J. Phys. Chem. C 117, 6759-6776 (2013)

[23] J. Yang, K. van Dalfsen, K. Wörhoff, F. Ay, and M. Pollnau, "High-gain $\mathrm{Al}_{2} \mathrm{O}_{3}: \mathrm{Nd}^{3+}$ channel waveguide amplifiers at 880 nm, 1060 nm, and 1330 nm," Appl. Phys. B 101, 119-127 (2010)

[24] J. D. B. Bradley, E. S. Hosseini, Z. Su, T. N. Adam, G. Leake, D. Coolbaugh, and M. R. Watts, "Monolithic erbium- and ytterbium-doped microring lasers on silicon chips," Opt. Express 22, 12226 (2014)

[25] M. Goede, L. Chang, J. Mu, M. Dijkstra, R. Obregón, E. Martínez, L. Padilla, R. Mitjans, and S. M. Garcia-Blanco, " $\mathrm{Al}_{2} \mathrm{O}_{3}: \mathrm{Yb}^{3+}$ integrated microdisk laser label-free biosensor," Submiss. (n.d.)

[26] E. Salih Magden, G. Singh, N. Singh, A. Baldycheva, E. Shah Hosseini, J. Sun, M. Moresco, T. N. Adam, G. Leake, D. Coolbaugh, J. D. B Bradley, and M. R. Watts, "Ultra-narrow-linewidth $\mathrm{Al}_{2} \mathrm{O}_{3}: \mathrm{Er}^{3+}$ lasers with a wavelength-insensitive waveguide design on a wafer-scale silicon nitride platform "Silicon photonic hybrid ring-filter external cavity wavelength tunable lasers," Opt. Express 14014, 57-62 (2003)

[27] N. Li, D. Vermeulen, Z. Su, E. S. Magden, M. Xin, N. Singh, A. Ruocco, J. Notaros, C. V. Poulton, E. Timurdogan, C. Baiocco, and M. R. Watts, "Monolithically integrated erbium-doped tunable laser on a CMOS-compatible silicon photonics platform," Opt. Express 26, 16200 (2018)

[28] J. D. B. Bradley, Z. Su, E. S. Magden, N. Li, M. Byrd, P. Purnawirman, T. N. Adam, G. Leake, D. Coolbaugh, and M. R. Watts, "1.8- $\mu \mathrm{m}$ thulium microlasers integrated on silicon," in Proc. SPIE 9744, Optical Components and Materials XIII, S. Jiang and M. J. F. Digonnet, eds. (International Society for Optics and Photonics, 2016), Vol. 9744, p. 97440U

[29] Z. Su, N. Li, E. Salih Magden, M. Byrd, J. D. B. Purnawirman, T. N. Adam, G. Leake, D. Coolbaugh, J. D. B. Bradley, and M. R. Watts, "Ultra-compact and low-threshold thulium microcavity laser monolithically integrated on silicon," Opt. Lett. 41, 5708 (2016)

[30] N. Li, C. Purnawirman, Z. Su, E. Salih Magden, P. T. Callahan, K. Shtyrkova, M. Xin, A. Ruocco, C. Baiocco, E. P. Ippen, F. X. Kärtner, J. D. B. Bradley, D. Vermeulen, and M. R. Watts, "Highpower thulium lasers on a silicon photonics platform," Opt. Lett. 42, 1181 (2017)

[31] J. D. B. Bradley, R. Stoffer, A. Bakker, L. Agazzi, F. Ay, K. Worhoff, and M. Pollnau, "Integrated $\mathrm{Al}_{2} \mathrm{O}_{3}: \mathrm{Er}^{3+}$ Zero-Loss Optical Amplifier and Power Splitter With 40-nm Bandwidth," IEEE Photonics Technol. Lett. 22, 278-280 (2010)

[32] M. Belt and D. J. Blumenthal, "High Temperature Operation of an Integrated Erbium- Doped DBR Laser on an Ultra-Low-Loss $\mathrm{Si}_{3} \mathrm{~N}_{4}$ Platform," 79, 8-10 (2015)

[33] J. Mu, M. de Goede, M. Dijkstra, and S. M. García-Blanco, "Monolithic Integration of $\mathrm{Al}_{2} \mathrm{O}_{3}$ and $\mathrm{Si}_{3} \mathrm{~N}_{4}$ for Double-layer Integrated Photonic Chips," in Advanced Photonics 2018 (BGPP, IPR, NP, NOMA, Sensors, Networks, SPPCom, SOF) (OSA, 2018), p. ITh1I.1

[34] J. Mu, M. Dijkstra, Y. S. Yong, M. de Goede, L. Chang, and S. M. Garcia Blanco, "Monolithic Integration of and towards Double-layer Active-passive Platform," IEEE J. Sel. Top. Quantum Electron. 1-1 (2019)

[35] L. Agazzi, J. D. B. Bradley, M. Dijkstra, F. Ay, G. Roelkens, R. Baets, K. Wörhoff, and M. Pollnau, "Monolithic integration of erbium-doped amplifiers with silicon-on-insulator waveguides," Opt. Express 18, 27703 (2010) 
[36] P. F. Jarschel, M. C. M. M. Souza, R. B. Merlo, and N. C. Frateschi, "Loss Compensation in Microring-Based Si Photonics Devices via Er ${ }^{3+}$ Doped Claddings," IEEE Photonics J. 10, 1-12 (2018)

[37] P. F. Jarschel and N. C. Frateschi, "Resonant amplification via Er-doped clad Si photonic molecules: Towards compact low-loss/high-Q Si photonic devices," Solid. State. Electron. 155, 144-149 (2019)

[38] T. Ishizaka and Y. Kurokawa, "Optical properties of rare-earth ion $\left(\mathrm{Gd}^{3+}, \mathrm{Ho}^{3+}, \mathrm{Pr}^{3+}, \mathrm{Sm}^{3+}, \mathrm{Dy}^{3+}\right.$ and $\mathrm{Tm}^{3+}$ ) -doped alumina films prepared by the sol-gel method," J. Lumin. 92, 57-63 (2000)

[39] T. Ishizaka, R. Nozaki, and Y. Kurokawa, "Luminescence properties of $\mathrm{Tb}^{3+}$ and Eu ${ }^{3+}$-doped alumina films prepared by sol-gel method under various conditions and sensitized luminescence," J. Phys. Chem. Solids 63, 613-617 (2002)

[40] W. Koh, S.-J. Ku, and Y. Kim, "Chemical vapor deposition of $\mathrm{Al}_{2} \mathrm{O}_{3}$ films using highly volatile single sources," Thin Solid Films 304, 222-224 (1997)

[41] R. Serna, M. Jiménez de Castro, J. A. Chaos, A. Suárez-Garcia, C. N. Afonso, M. Fernández, and I. Vickridge, "Photoluminescence performance of pulsed-laser deposited $\mathrm{Al}_{2} \mathrm{O}_{3}$ thin films with large erbium concentrations," J. Appl. Phys. 90, 5120-5125 (2001)

[42] M. M. Aslan, N. A. Webster, C. L. Byard, M. B. Pereira, C. M. Hayes, R. S. Wiederkehr, and S. B. Mendes, "Low-Loss Optical Waveguides for the Near Ultra-Violet and Visible Spectral Regions with $\mathrm{Al}_{2} \mathrm{O}_{3}$ Thin Films from Atomic Layer Deposition.," Thin Solid Films 518, 49354940 (2010)

[43] J. Rönn, L. Karvonen, C. Kauppinen, A. P. Perros, N. Peyghambarian, H. Lipsanen, A. Säynätjoki, and Z. Sun, "Atomic Layer Engineering of Er-Ion Distribution in Highly Doped $\mathrm{Er}_{2} \mathrm{Al}_{2} \mathrm{O}_{3}$ for Photoluminescence Enhancement," ACS Photonics 3, 2040-2048 (2016)

[44] M. Demirtaş, A. Özden, E. Açikbaş, and F. Ay, "Extensive mode mapping and novel polarization filter design for ALD grown $\mathrm{Al}_{2} \mathrm{O}_{3}$ ridge waveguides," Opt. Quantum Electron. 48, 357 (2016)

[45] M. Demirtas, C. Odaci, N. K. Perkgoz, C. Sevik, and F. Ay, "Low Loss Atomic Layer Deposited $\mathrm{Al}_{2} \mathrm{O}_{3}$ Waveguides for Applications in On-Chip Optical Amplifiers," IEEE J. Sel. Top. Quantum Electron. 24, 1-8 (2018)

[46] J. Rönn, W. Zhang, A. Autere, X. Leroux, L. Pakarinen, C. Alonso-Ramos, A. Säynätjoki, H. Lipsanen, L. Vivien, E. Cassan, and Z. Sun, "Ultra-high on-chip optical gain in erbium-based hybrid slot waveguides," Nat. Commun. 10, 432 (2019)

[47] Chang Jin Kang, J. S. Chun, and Wong Jong Lee, "Properties of aluminium oxide films prepared by plasma-enhanced metal-organic chemical vapour deposition," Thin Solid Films 189, 161-173 (1990)

[48] A. Suárez-García, J. Gonzalo, and C. N. Afonso, "Low-loss $\mathrm{Al}_{2} \mathrm{O}_{3}$ waveguides produced by pulsed laser deposition at room temperature," Appl. Phys. A Mater. Sci. Process. 77, 779-783 (2003)

[49] K. Bobzin, E. Lugscheider, M. Maes, and C. Piñero, "Relation of hardness and oxygen flow of $\mathrm{Al}_{2} \mathrm{O}_{3}$ coatings deposited by reactive bipolar pulsed magnetron sputtering," Thin Solid Films 494, 255-262 (2006)

[50] A. Khanna and D. G. Bhat, "Nanocrystalline gamma alumina coatings by inverted cylindrical magnetron sputtering," Surf. Coatings Technol. 201, 168-173 (2006)

[51] N. D. Madsen, B. H. Christensen, S. Louring, A. N. Berthelsen, K. P. Almtoft, L. P. Nielsen, and J. Bøttiger, "Controlling the deposition rate during target erosion in reactive pulsed DC magnetron sputter deposition of alumina," Surf. Coatings Technol. 206, 4850-4854 (2012)

[52] P. Lei, W. Leroy, B. Dai, J. Zhu, X. Chen, J. Han, and D. Depla, "Study on reactive sputtering of yttrium oxide: Process and thin film properties," Surf. Coatings Technol. 276, 39-46 (2015)

[53] I. Safi, "Recent aspects concerning DC reactive magnetron sputtering of thin films: a review," Surf. Coatings Technol. 127, 203-218 (2000)

[54] V. Edlmayr, M. Moser, C. Walter, and C. Mitterer, "Thermal stability of sputtered $\mathrm{Al}_{2} \mathrm{O}_{3}$ 
coatings," Surf. Coatings Technol. 204, 1576-1581 (2010)

[55] X. Zhang, J. Zhu, L. Zhang, K. Kishimoto, S. Du, and X. Yin, "Crystallization of alumina films deposited by reactive magnetron sputtering with resputtering technique at low temperature," Surf. Coatings Technol. 228, S393-S396 (2013)

[56] M. K. Smit, G. A. Acket, and C. J. van der Laan, " $\mathrm{Al}_{2} \mathrm{O}_{3}$ films for integrated optics," Thin Solid Films 138, 171-181 (1986)

[57] M. Serényi, T. Lohner, G. Sáfrán, and J. Szívós, "Comparison in formation, optical properties and applicability of DC magnetron and RF sputtered aluminum oxide films," Vacuum 128, 213-218 (2016)

[58] T. Nakano, Y. Saitou, and K. Oya, "Transient evolution of the target erosion profile during magnetron sputtering: Dependence on gas pressure and magnetic configuration," Surf. Coatings Technol. 326, 436-442 (2017)

[59] G. Bräuer, "Magnetron Sputtering," in Comprehensive Materials Processing (Elsevier, 2014), Vol. 4, pp. 57-73

[60] S. Berg and T. Nyberg, "Fundamental understanding and modeling of reactive sputtering processes," Thin Solid Films 476, 215-230 (2005)

[61] K. Strijckmans, R. Schelfhout, and D. Depla, "Tutorial: Hysteresis during the reactive magnetron sputtering process," J. Appl. Phys. 124, 241101 (2018)

[62] D. Depla, S. Mahieu, and R. De Gryse, "Magnetron sputter deposition: Linking discharge voltage with target properties," Thin Solid Films 517, 2825-2839 (2009)

[63] A. G. Spencer, R. P. Howson, and R. W. Lewin, "Pressure stability in reactive magnetron sputtering," Thin Solid Films 158, 141-149 (1988)

[64] E. Särhammar, T. Nyberg, and S. Berg, "Applying "the upgraded Berg model” to predict hysteresis free reactive sputtering," Surf. Coatings Technol. 290, 34-38 (2016)

[65] T. Nyberg, S. Berg, U. Helmersson, and K. Hartig, "Eliminating the hysteresis effect for reactive sputtering processes," Appl. Phys. Lett. 86, 164106 (2005)

[66] S. Dai, C. Yu, G. Zhou, J. Zhang, G. Wang, and L. Hu, "Concentration quenching in erbiumdoped tellurite glasses," J. Lumin. 117, 39-45 (2006)

[67] L. Agazzi, "Spectroscopic excitation and quenching processes in rare-earth-ion-doped $\mathrm{Al}_{2} \mathrm{O}_{3}$ and their impact on amplifier and laser performance," (2012)

[68] J. Bradley, " $\mathrm{Al}_{2} \mathrm{O}_{3}: \mathrm{Er}^{3+}$ as gain platform for integrated optics," (2009)

[69] J. C. Polking, A. Boggess, and D. Arnold, Differential Equations, 2nd ed. (Pearson Prentice Hall, 2006)

[70] D. Depla, S. Heirwegh, S. Mahieu, J. Haemers, and R. De Gryse, "Understanding the discharge voltage behavior during reactive sputtering of oxides," J. Appl. Phys. 101, 013301 (2007)

[71] S. Kadlec, J. Musil, and J. Vyskočil, "Modeling of inhomogeneous film deposition and target erosion in reactive sputtering," J. Vac. Sci. Technol. A Vacuum, Surfaces, Film. 8, 1560-1565 (1990)

[72] S. Berg, H. Blom, T. Larsson, and C. Nender, "Modeling of reactive sputtering of compound materials," J. Vac. Sci. Technol. A Vacuum, Surfaces, Film. 5, 202-207 (1987)

[73] P. J. Goodhew and J. Humphreys, Electron Microscopy and Analysis, third edit (Taylor \& Francis, 2001)

[74] R. F. Egerton, Physical Principles of Electron Microscopy (Springer US, 2006)

[75] J. Mayer, L. A. Giannuzzi, T. Kamino, and J. Michael, "TEM Sample Preparation and FIBInduced Damage," MRS Bull. 32, 400-407 (2007)

[76] C. Kittel, Introduction to Solid State Physics, 8th ed. (John Wiley \& Sons, Ltd, 2005), Vol. 37

[77] R. S. Zhou and R. L. Snyder, "Structures and transformation mechanisms of the $\eta, \gamma$ and $\theta$ 
transition aluminas," Acta Crystallogr. Sect. B Struct. Sci. 47, 617-630 (1991)

[78] W. Engelhart, W. Dreher, O. Eibl, and V. Schier, "Deposition of alumina thin film by dual magnetron sputtering: Is it $\gamma-\mathrm{Al}_{2} \mathrm{O}_{3}$ ?," Acta Mater. 59, 7757-7767 (2011) 


\section{Chapter 5}

\section{Integration technologies for single-layer active-passive $\mathrm{Al}_{2} \mathrm{O}_{3}$}

Amorphous $\mathrm{Al}_{2} \mathrm{O}_{3}$ is an attractive platform for integrated photonics, providing active and passive functionalities. We have developed two integration schemes to create active and passive regions at the same level on one wafer. The first process is based on chemical mechanical planarization while the second one is based on deposition through two different shadow masks to create a planar active-passive $\mathrm{Al}_{2} \mathrm{O}_{3}$ layer. The proposed fabrication processes reduce the number of fabrication steps compared to the vertical integration of the two materials while, at the same time, minimize the misalignment intrinsic to the vertical integration schemes. All structures are defined within a single photolithography and etching step and they are therefore automatically aligned. As a proof of principle, we demonstrated the luminescence of ring resonator devices fabricated in the active region.

This chapter is based on:

C.I. van Emmerik, M. Dijkstra, M. de Goede, L. Chang, J. Mu and S.M. Garcia-Blanco, "Single-layer activepassive $\mathrm{Al}_{2} \mathrm{O}_{3}$ photonic integration platform”, Optical Material Express, 8(10),3049-3054 (2018) 


\subsection{Introduction}

Amorphous $\mathrm{Al}_{2} \mathrm{O}_{3}$ is an attractive material for integrated photonics, providing active and passive functionalities when doped with rare-earth ions. Whereas $\mathrm{Si}$ and $\mathrm{Si}_{3} \mathrm{~N}_{4}$ have a low solubility for rare-earth ions [1,2], amorphous $\mathrm{Al}_{2} \mathrm{O}_{3}$ can host high concentrations of those ions with moderate quenching of luminescence [3,4]. The ability to host high concentrations of rare-earth ions in combination with the wide transparency window (150-5500 nm [5]) and low propagation loss [6,7], makes amorphous $\mathrm{Al}_{2} \mathrm{O}_{3}$ an attractive material for UV, visible, near- and mid-IR on-chip active devices [8-10].

Many different lasers and amplifiers have been demonstrated in the last few years using amorphous rare-earth ion doped $\mathrm{Al}_{2} \mathrm{O}_{3}$ as gain material [4,11-13], as well as rareearth ion doped $\mathrm{Al}_{2} \mathrm{O}_{3}$ in combination with passive photonic platforms, such as $\mathrm{Si}_{3} \mathrm{~N}_{4}$ [14-16]. The realization of the active devices in a fully doped $\mathrm{Al}_{2} \mathrm{O}_{3}$ layer has two main limitations, namely a restriction in the dopant concentration that can be used and lack of integration with other optical functions on the chip. The current integration schemes rely on several photolithography steps, which introduce losses due to misalignment $[16,17]$.

In this work, we propose two single-layer monolithic integration schemes for the integration of active and passive regions on a wafer. The proposed methods are based on a photonics damascene method [18,19], derived from the process used in microelectronics [20,21]. Using this approach, only one lithography and etching step is required to fabricate all functionalities, leading to self-aligned transitions from the passive to the active sections. Since the difference of refractive index between doped and undoped $\mathrm{Al}_{2} \mathrm{O}_{3}$ is minimal [22], very low transition losses are expected. Furthermore, the low loss of the undoped $\mathrm{Al}_{2} \mathrm{O}_{3}$ waveguide will permit the realization of complex integrated photonic devices [23-25]. The developed processes can be extended to the integration of two optical materials that can be deposited at the wafer level, e.g., $\mathrm{Si}_{3} \mathrm{~N}_{4}$ and $\mathrm{Al}_{2} \mathrm{O}_{3}$, provided that the effective index of the waveguide mode is matched across the active-passive interface.

In the first section of this chapter, the fabrication process based on chemical mechanical planarization (CMP) is detailed and the experimental demonstration of luminescence in an active ring resonator coupled to a passive bus waveguide is given. This work is published in [26] and it is performed before the material study presented in chapter 4 , which means that the selection of the settings for the deposition of the active and passive materials are probably not at the optimal settings. In the second section of the chapter, the fabrication process based on deposition through two shadow masks is detailed and the demonstration of a disk resonator is given. 


\subsection{CMP assisted fabrication of single-layer active-passive $\mathrm{Al}_{2} \mathrm{O}_{3}$}

The main goal of this study is the demonstration of the integration of $\mathrm{Yb}^{3+}$-doped ring resonators with passive bus waveguides. The fabrication flow is shown schematically in Fig. 5.1. Firstly, active regions of $\mathrm{Yb}^{3+}: \mathrm{Al}_{2} \mathrm{O}_{3}(650 \mu \mathrm{m}$ wide and $1000-3550 \mu \mathrm{m}$ long) are deposited by $\mathrm{RF}$ reactive co-sputtering (Section 4.3) with a target $\mathrm{Al}_{2} \mathrm{O}_{3}$ layer height of $\sim 400 \mathrm{~nm}$ through a shadow mask. This thickness guarantees single mode operation at the pump and signal wavelengths $\left(\lambda_{\text {pump }}=976 \mathrm{~nm}, \lambda_{\text {signal }} \approx 1030 \mathrm{~nm}\right)$ in a ring resonator with a waveguide cross-section of $1.8 \times 0.4 \mu \mathrm{m}^{2}$ and a radius of $200 \mu \mathrm{m}$. Those regions are then overgrown with a roughly $200 \mathrm{~nm}$ thicker passive layer (i.e., $\sim 600 \mathrm{~nm}$ undoped $\mathrm{Al}_{2} \mathrm{O}_{3}$ ). A chemical mechanical planarization (CMP) step is performed to planarize the active-passive layer, producing a wafer with a planar layer of undoped $\mathrm{Al}_{2} \mathrm{O}_{3}$ with regions of active rare-earth ion doped material in it. Waveguides are then fabricated using standard lithography and inductively coupled reactive ion etching (Oxford Plasma Pro 100 Cobra) with $\mathrm{BCl}_{3} / \mathrm{HBr}$ gases optimized for $\mathrm{Al}_{2} \mathrm{O}_{3}$ etching [27]. Finally, the waveguides are protected with a thick oxide layer deposited by plasma enhanced chemical vapor deposition (PECVD) as cladding.

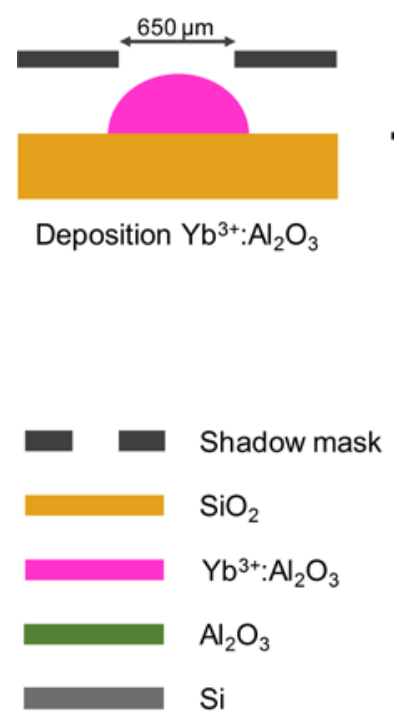

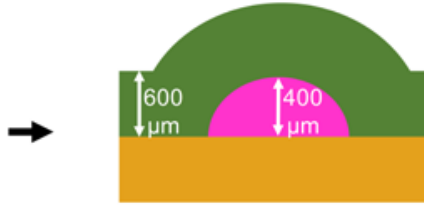

Deposition $\mathrm{Al}_{2} \mathrm{O}_{3}$

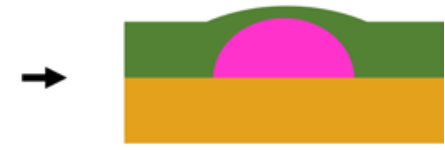

CMP

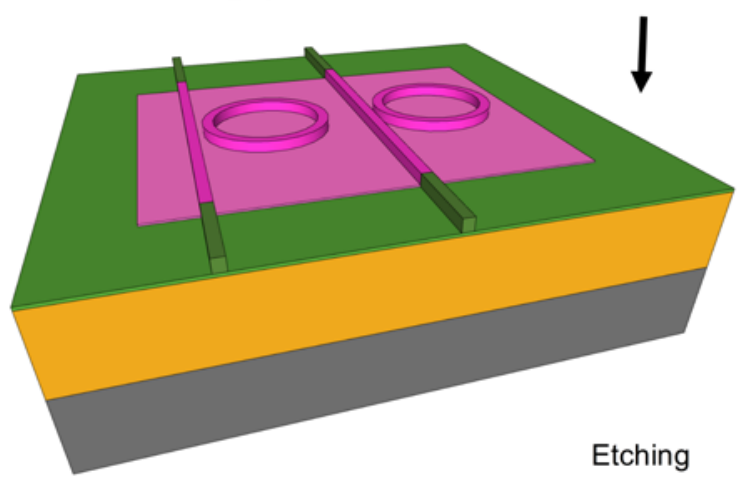

Fig. 5.1 Schematic representation of the fabrication process of active-passive $\mathrm{Al}_{2} \mathrm{O}_{3}$ devices, showing consecutively the deposition of $\mathrm{Yb}^{3+}: \mathrm{Al}_{2} \mathrm{O}_{3}$ through a shadow mask (target thickness of $400 \mathrm{~nm}$ ), the deposition of the undoped $\mathrm{Al}_{2} \mathrm{O}_{3}$ layer (target thickness of $600 \mathrm{~nm}$ ), planarization using CMP and waveguide fabrication by etching. 


\subsubsection{Reactive co-sputtering of $\mathrm{Al}_{2} \mathrm{O}_{3}$}

The $\mathrm{Al}_{2} \mathrm{O}_{3}$ layers are deposited by radio-frequency (RF) reactive co-sputtering using an AJA ATC 1500 instrument [6]. Argon flows of 25 and 5 sccm are applied to respectively the aluminum (Al, 99.9995\% purity) and ytterbium (Yb, 99.9\% purity) metallic targets and an oxygen flow of $4 \mathrm{sccm}$ is added to the process to ensure full oxidation of the layer. When depositing an undoped layer, an RF sputtering power of $200 \mathrm{~W}$ was applied to the Al-target and an additional RF sputtering power of $20 \mathrm{~W}$ was applied on the Yb-target when depositing the active regions. The reaction chamber was pre-evacuated to $0.1 \mu$ Torr (i.e., $13 \mu \mathrm{Pa}$ to reduce the $\mathrm{OH}^{-}$level, whereas the pressure was kept around $4 \mathrm{mT}$ Torr (i.e., $0.53 \mathrm{~Pa}$ ) during the deposition process. $\mathrm{OH}^{-}$free deposition is required for devices based on rare-earth ion transitions, because these bonds induce strong luminescence quenching and therefore, greatly diminish or hinder optical gain [28,29]. The wafer is positioned $17 \mathrm{~cm}$ from the target and the set temperature at the machine is $650{ }^{\circ} \mathrm{C}$ (i.e., expected wafer temperature $\sim 375^{\circ} \mathrm{C}$ ) ${ }^{*}$.

The active regions are deposited through a shadow mask. This mask is made from $200 \mu \mathrm{m}$ thick 301 stainless steel. The openings for the deposition of active regions are made by laser cutting (Rofin MPS). All regions have a width of $650 \mu \mathrm{m}$ and lengths varying from 1000 to $3550 \mu \mathrm{m}$. Those areas are made such that a consecutive row of 5 similar rings, with a radius ranging from 50 to $300 \mu \mathrm{m}$, can fit in this area, as shown in Fig. 5.2(a). The openings are placed in a line of six (for the 6 different ring radii) and the structure is repeated homogeneously over the wafer to ensure equal planarization.

First, the shadow mask is aligned with the wafer flat and clamped together in the holder. The deposition is then performed as described earlier. The deposition rate of the $\mathrm{Al}_{2} \mathrm{O}_{3}$ of the active regions through the openings in the shadow mask is reduced to $\sim 75 \%$ of the deposition rate without the shadow mask and the regions have a curved profile, as shown in the profilometer scan of Fig. 5.2(b). Both features are caused by the shielding effect of the shadow mask. There are three targets available for deposition (Al, Er, Yb), which are positioned in the reaction chamber under an angle, such that they all point in a similar way to the wafer. The sides of the open regions in the mask are $200 \mu \mathrm{m}$ high and, therefore, a part of the exposed region on the wafer is shielded from the plasma. To minimize this feature the wafer is rotating. There is also a small gap between the mask and wafer and due to the angle of incidence of the plasma, $\mathrm{Al}_{2} \mathrm{O}_{3}$ particles can deposit

\footnotetext{
* The deposition settings (i.e., oxygen flow, deposition height and wafer temperature) differ from the optimized settings as described in Chapter 4 . At this moment in time we were not aware of the importance of the influence of the relative oxidation state of the target in combination with the wafer temperature. Further study is needed to the influence of the effect of the deposition height, wafer temperature and doping concentration on the optical and material characteristics of the $\mathrm{Al}_{2} \mathrm{O}_{3}$ layers as function of oxygen.
} 
slightly underneath the mask, as shown in Fig. 5.2(c). The influence of the mask, for an opening width of $650 \mu \mathrm{m}$, is too big to achieve a uniform top layer in the deposited regions. The width of the regions should at least be doubled to obtain a plateau region of a couple of tens of micrometers in the deposited regions. The active regions on the edge of the shadow mask design were displaced by roughly $300 \mu \mathrm{m}$. This is most likely caused by the difference in thermal expansion coefficient between the stainless steel and silicon wafer $\left(\alpha_{\text {stainles-steel }} \approx 19.5 \mathrm{ppm} /{ }^{\circ} \mathrm{C}, \alpha_{\mathrm{Si}} \approx 3.5 \mathrm{ppm} /{ }^{\circ} \mathrm{C}\right.$ around $\left.400-600{ }^{\circ} \mathrm{C}\right)$. A new shadow mask should be made from a material that with an expansion coefficient that is more comparable to that of silicon. Molybdenum is a good candidate $\left(\alpha_{\text {molybdenum }} \approx 5.5 \mathrm{ppm} /{ }^{\circ} \mathrm{C}, 400-600{ }^{\circ} \mathrm{C}\right.$ ) it has a smaller deviation in thermal expansion coefficient compared to silicon and can withstand the high deposition temperatures [30].

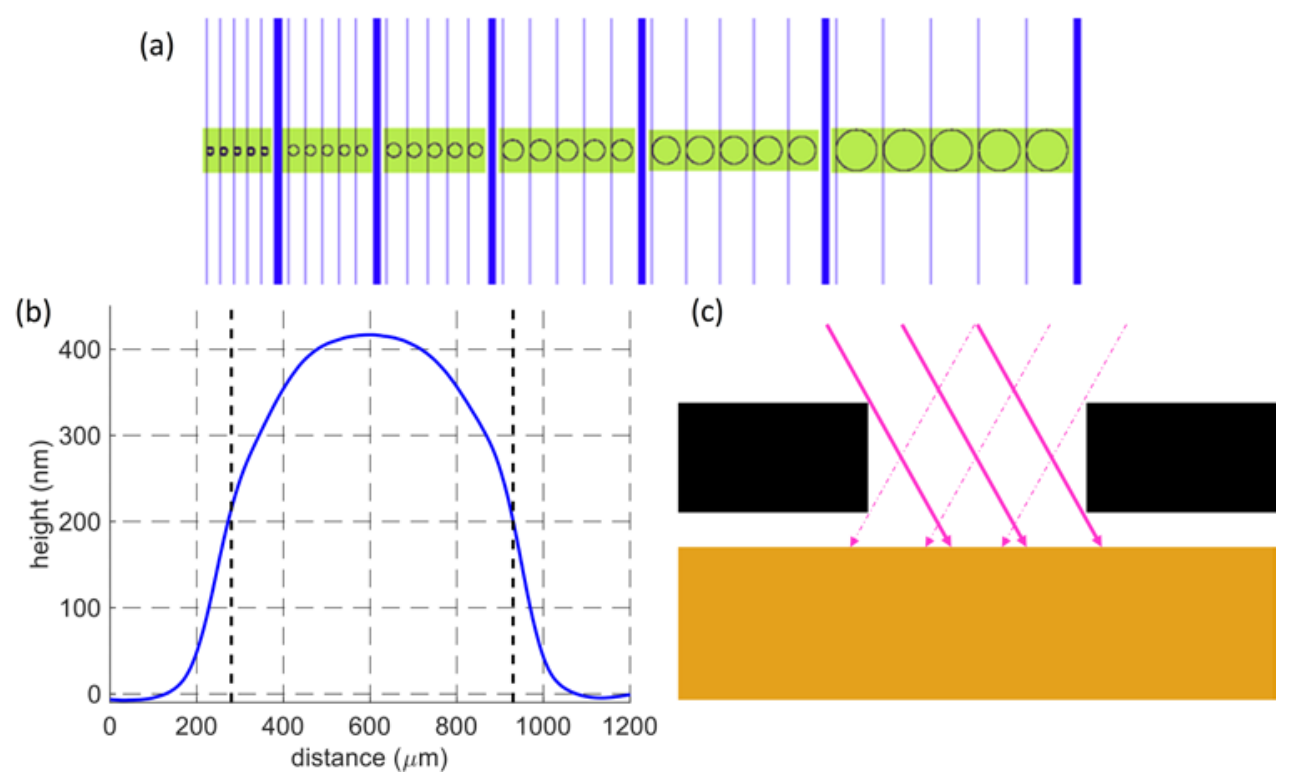

Fig. 5.2 (a) Representation of the chip layout with waveguides and ring resonators. The active regions are shown in green. (b) Profilometer scan along the width of a deposited $\mathrm{Yb}^{3+}: \mathrm{Al}_{2} \mathrm{O}_{3}$ region, the dashed vertical lines represent the sidewall of the shadow mask. (c) Schematic representation of the deposition of $\mathrm{Yb}^{3+}: \mathrm{Al}_{2} \mathrm{O}_{3}$ (pink arrows) with a shadow mask (black) on $\mathrm{SiO}_{2}$ (yellow). Continuous and dashed pink arrows represent the direction of the plasma during deposition. 


\subsubsection{Chemical mechanical planarization of $\mathrm{Al}_{2} \mathrm{O}_{3}$}

A wafer with active regions was fabricated with the above mentioned procedure. This resulted in an active region with a maximum height of $290 \mathrm{~nm}$ (target was $400 \mathrm{~nm}$ ). The height is lower than expected due to the lower deposition rate caused by small openings of the mask. The active regions were overgrown with a $480 \mathrm{~nm}$ (i.e., $200 \mathrm{~nm}$ thicker than the thickness of the active layer in the deposited regions) thick undoped $\mathrm{Al}_{2} \mathrm{O}_{3}$ to complete the layer, as shown in Fig. 5.3(a).

After the fabrication of the layer, there is a $290 \mathrm{~nm}$ high bump on top of the layer, as shown in Fig. 5.3(a). This bump needs to be planarized to enhance the quality of the lithography and etching process and to achieve the right waveguide dimensions. A chemical mechanical planarization (CMP) process was developed, using a Mecapol E460 CMP machine in combination with an IC1000 pad from DOW.

The main planarization was done using a solution of Semi Sperse 25 (SS25) slurry diluted in a ratio of 1 to 2 with DI water. The $\mathrm{pH}$ was adjusted with $2 \% \mathrm{HCl}$ solution to 7 , in order to obtain a more mechanical driven removal [31]. The optimal settings for the pressure on the wafer and rotation speed of table were deduced from a preliminary planarization tests on similar $\mathrm{Al}_{2} \mathrm{O}_{3}$ layers (Appendix B). During the first CMP step of 60 seconds the focus was to planarize the wafer, mainly reducing the height of the bumps. To ensure this, only the bumps had to be in contact with the pad and therefore a pressure of 0.50 bar was used on the wafer. To have a high removal rate the rotation speed of the table and head was set to $70 \mathrm{rpm}$. The focus for the second step of 60 seconds was to achieve the correct layer thickness and have further planarization. Therefore, the pressure on the wafer was increased to 0.75 bar to ensure that the whole wafer was in contact with the pad. The rotation speed of the table and head was set to $50 \mathrm{rpm}$ for a removal rate of $\sim 50 \mathrm{~nm} / \mathrm{min}$ for the main surface of the wafer. For the final smoothening step, a slurry with a ratio of 1 to 4 , SS25 to DI water with a pH of 8 was used, to have a chemical dominated removal. The same settings as in the second step were used for 120 seconds because the removal rate was much lower.

The final layer is shown in Fig. 5.3(b), where the layer of passive $\mathrm{Al}_{2} \mathrm{O}_{3}$ is $400 \mathrm{~nm}$ and there is still a bump of $120 \mathrm{~nm}$ on top of this layer. This is not beneficial for optimal performance of the waveguides because there will be a smaller optical overlap with the active region. Further optimization of the deposition through a shadow mask and planarization of the wafer is underway. 


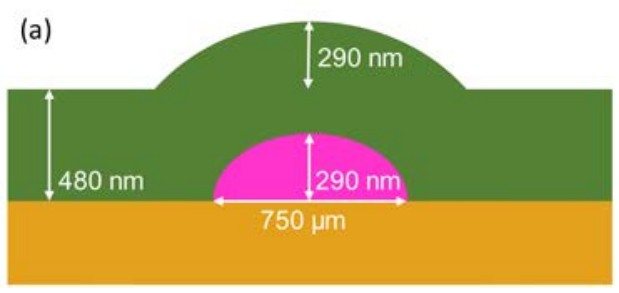

(b)

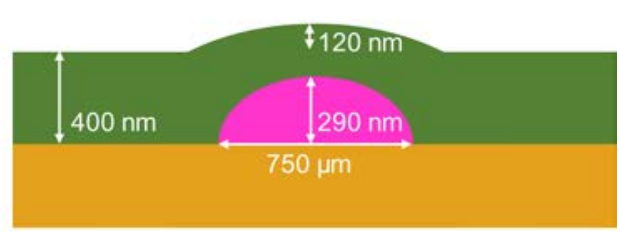

Fig. 5.3 Schematic representation of the layer thicknesses of active region, passive layer and bump (a) after deposition; (b) layer thicknesses after CMP. The height and width of a bump and the thickness of the undoped layer were measured in a central position of the wafer with respectively a profilometer (Veeco Dektak 150) and ellipsometer (Woollam M-2000UI).

\subsubsection{Demonstration of single-layer active-passive $\mathrm{Al}_{2} \mathrm{O}_{3}$}

Ring resonators with an input-output bus waveguide were fabricated with the fabrication procedure described above. The active layer $\left(\mathrm{Yb}^{3+}: \mathrm{Al}_{2} \mathrm{O}_{3}\right)$ thickness in this sample was $290 \mathrm{~nm}$ with an overall final layer thickness of $400 \mathrm{~nm}$ (Fig. 5.3(b)). Light was butt coupled into the input bus waveguide through a polarization maintaining fiber. To enhance the coupling efficiency to the chip, index matching fluid was utilized. The device was pumped at $976 \mathrm{~nm}$ to excite the $\mathrm{Yb}^{3+}$ ions in the doped region. A photo of the luminescence in the active region was taken with a standard photo camera through a microscope objective such that the rings of radii 100 and $150 \mu \mathrm{m}$ are clearly visible, as shown in Fig. 5.4. The luminescence in the visible regime is probably due to $\mathrm{Er}^{3+}$ or $\mathrm{Tm}^{3+}$ impurities in the active region. At the top of the ring a weaker, tilted, straight line is visible. This is caused by stray light from the incoupling light, which luminesces in the active region. Unfortunately, the dopant concentration utilized was too low, which, in combination with the relatively low overlap with the pump (i.e., $290 \mathrm{~nm}$ thick doped layer in a in total $400 \mathrm{~nm}$ thick $\mathrm{Al}_{2} \mathrm{O}_{3}$ layers is comparable with $43 \%$ of the power in the fundamental mode overlapping with the active region) prevented lasing from the device. In Fig. 5.4, a taper transition region is visible at both ends of the active part of the bus waveguide. Due to the deposition with the shadow mask, a vertical taper is naturally formed between the passive and active $\mathrm{Al}_{2} \mathrm{O}_{3}$ regions, which leads to an adiabatic transition. Since the fabrication is realized in a single lithography and etching step, no misalignment in that region occurs, further increasing the efficiency of the transition. Towards the center of the active region the fraction of doped layer slightly increases and therefore the luminescence becomes stronger.

This result is the first demonstration of the integration, in a single photonic layer, of active and passive dielectric materials. It paves the road towards on-chip lasers and 
amplifiers that can directly be integrated with passive building blocks on the same platform minimizing the need for accurate alignment procedures.
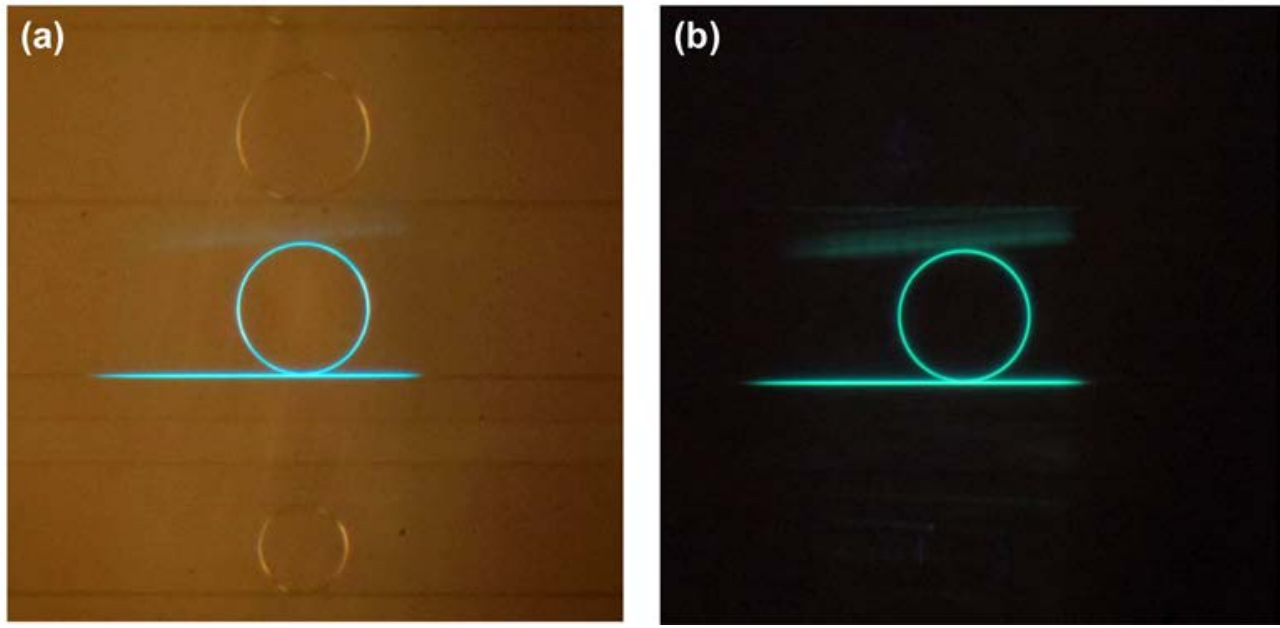

Fig. 5.4 Photograph of (a) Chip containing rings with a radius of 100 and $150 \mu \mathrm{m}$ showing the luminescence of the ytterbium doped active region in the center ring. (b) Same photograph without background light. Luminescent stray light can be observed on the top of the ring.

\subsection{Shadow mask assisted fabrication of single-layer active-passive $\mathrm{Al}_{2} \mathrm{O}_{3}$}

The first process relies on CMP, which is time consuming and the polishing characteristics (i.e., removal rate and rounding of the areas) depend on the surface area and configuration of the active regions [32]. A second fabrication process was developed to integrate active and passive areas in one layer in a more efficient and reliable manner by using two different shadow masks. The fabrication flow, shown in Fig. 5.5, consist of three steps: (1) deposition of active and passive regions, using shadow masks, (2) lithography and (3) etching of the devices. First, active regions of $\mathrm{Yb}^{3+}: \mathrm{Al}_{2} \mathrm{O}_{3}(2-5 \mathrm{~mm}$ wide and $14.7 \mathrm{~mm}$ long) are deposited by RF reactive co-sputtering through a shadow mask. The wider openings in the shadow mask were implemented to ensure reaching the target thickness during the depositions. A layer thickness of $\sim 500 \mathrm{~nm}$ is targeted. This thickness guarantees single mode operation at the pump and signal wavelengths (i.e., $\lambda_{\text {pump }}=976 \mathrm{~nm}, \lambda_{\text {signal }} \approx 1030 \mathrm{~nm}$ ) in ring resonators with a cross-section of $1.4 \times 0.5 \mu \mathrm{m}^{2}$ with a radius of $200 \mu \mathrm{m}$. The connective passive regions are then deposited, with the same technique and target height, through a second shadow mask, which is a negative of the first one. The waveguides are fabricated on the active-passive $\mathrm{Al}_{2} \mathrm{O}_{3}$ layer using standard lithography and inductively coupled reactive ion etching 
(Oxford Plasma Pro 100 Cobra) with $\mathrm{BCl}_{3} / \mathrm{HBr}$ gases optimized for $\mathrm{Al}_{2} \mathrm{O}_{3}$ etching [27]. A protective oxide layer is deposited by PECVD as cladding to protect the devices.

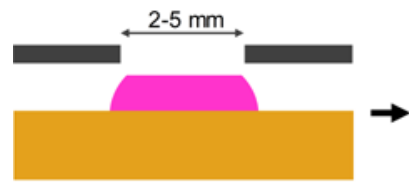

Deposition $\mathrm{Yb}^{3+}: \mathrm{Al}_{2} \mathrm{O}_{3}$

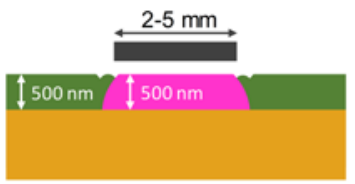

Deposition $\mathrm{Al}_{2} \mathrm{O}_{3}$

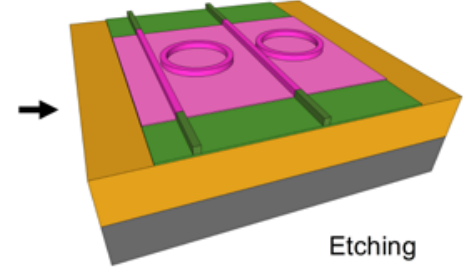

$\mathrm{Si}$

$$
\begin{array}{ll}
\text { Shadow mask } & \mathrm{Yb}^{3+}: \mathrm{Al}_{2} \mathrm{O}_{3} \\
\mathrm{SiO}_{2} & \mathrm{Al}_{2} \mathrm{O}_{3}
\end{array}
$$

Fig. 5.5 Schematic representation of the fabrication process of active-passive $\mathrm{Al}_{2} \mathrm{O}_{3}$ devices using two shadow masks. The deposition of $\mathrm{Yb}^{3+}: \mathrm{Al}_{2} \mathrm{O}_{3}$ and undoped $\mathrm{Al}_{2} \mathrm{O}_{3}$ areas through two different shadow masks (target thickness of $500 \mathrm{~nm}$ ) and waveguide fabricated by reactive ion etching are consecutively shown.

\subsubsection{Reactive co-sputtering using two shadow masks}

The deposition of both layers was performed with similar settings as described in Section 5.2.1. An alignment ring, dedicated for the wafer holder of the AJA ATC 1500, was used to align the wafer and mask before clamping. The optimum settings for the oxygen flow in the chamber and power on the Yb-target were respectively $3.0 \mathrm{sccm}^{*}$ and $25 \mathrm{~W}$, for that deposition. The height between the target and substrate was set to $15 \mathrm{~cm}$ to obtain the most planar layer as possible (Appendix A). A preliminary study of the influence of the temperature on the refractive index of $\mathrm{Yb}^{3+}: \mathrm{Al}_{2} \mathrm{O}_{3}$ layers was performed as described in Appendix C. A set temperature of $420^{\circ} \mathrm{C}$ was chosen to obtain a deposition temperature around $380{ }^{\circ} \mathrm{C}$ and to achieve a refractive index around $\sim 1.67$ at $1030 \mathrm{~nm}$ for both doped and undoped $\mathrm{Al}_{2} \mathrm{O}_{3}$ regions.

The masks are made with laser cutting (Rofin MPS) in $200 \mu \mathrm{m}$ thick molybdenum. This material has a similar thermal expansion coefficient, $\alpha$, compared to silicon ( $\alpha_{\text {molybdenum }} \approx 5.5 \mathrm{ppm} /{ }^{\circ} \mathrm{C}, \alpha_{\mathrm{Si}} \approx 3.5 \mathrm{ppm} /{ }^{\circ} \mathrm{C}$ around $400-600{ }^{\circ} \mathrm{C}$ ), which allows precise control over the location and size of the deposited regions on the wafer.

\footnotetext{
*Study is performed before the material study (Chapter 4). At this moment in time we were not aware of the importance of the influence of the relative oxidation state of the target on optical quality of the layers. Further research have to be done to identify the optimal oxidation state of the target as function of oxygen flow for different ytterbium concentrations and wafer temperatures.
} 
The minimum width of the openings was made $2 \mathrm{~mm}$ to ensure that a plateau region with the desired height could be reached as shown in Fig. 5.6(a). The mask openings are $14.7 \mathrm{~mm}$ long and cover all waveguide devices on a single chip. Various spacing between the active and passive masks, ranging from $-400 \mu \mathrm{m}$ (gap) to $+400 \mu \mathrm{m}$ (overlap) offset between the masks (Fig 5.6(b)), are defined to investigate the influence of this spacing on the planarity of the final layer.

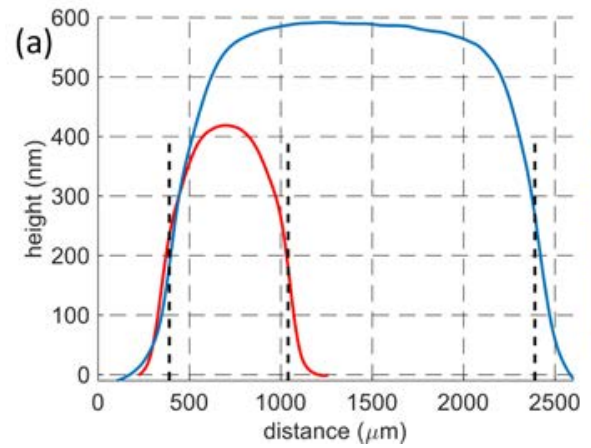

(b)

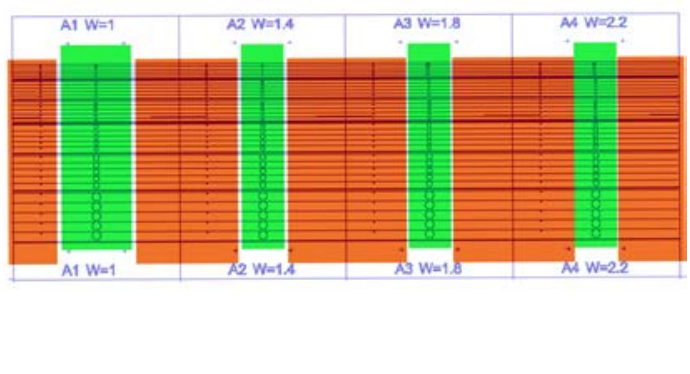

Fig. 5.6 (a) Profile scan of deposited $\mathrm{Yb}^{3+}: \mathrm{Al}_{2} \mathrm{O}_{3}$ areas for a mask width of $650 \mu \mathrm{m}$ (red), used for CMP assisted integration, and $2000 \mu \mathrm{m}$ (blue). Vertical dashed lines indicated the position of the side walls of the shadow mask. (b) Representation of the chip layouts with waveguides and ring resonators (blue), the active regions (green) and the passive regions (orange). Offset of the active and passive mask are from left to right: $-400,-300$, $-200,-100 \mu \mathrm{m}$.

\subsubsection{Demonstration of single-layer active-passive $\mathrm{Al}_{2} \mathrm{O}_{3}$}

A preliminary test with the two-shadow mask procedure was performed. The first mask was aligned manually to the optical flat present on the wafer and shadow mask. This due to the fact that two whole batch of wafers (i.e., 50 pieces) with a diameter $100.0 \pm 0.5 \mathrm{~mm}$ did not fit in the alignment ring with a diameter of $100.1 \mathrm{~mm}$. The second mask was aligned, after the first deposition, manually to the optical flats, of the mask and wafer. The alignment was adjusted to fit the overlap with the active deposited regions. This resulted in connected active-passive layer in the center of the wafer where an overlap between the two masks was defined. Figure 5.7(a) shows a profile scan of the transition from a passive region ( $\mathrm{h}_{\text {passive }} \approx 480 \mathrm{~nm}$ ) on the left to an active region ( $\mathrm{h}_{\text {active }} \approx 440 \mathrm{~nm}$ ) on the right side of the overlap. The height and width of the overlap region, respectively $\sim 390 \mathrm{~nm}$ and $\sim 460 \mu \mathrm{m}$, define a taper angle of $\sim 0.1^{\circ}$, which leads to an adiabatic transition of the fundamental mode.

The refractive index of the active and passive regions were determined with ellipsometry (Woollam-2000UI) at $1030 \mathrm{~nm}$. This resulted in a refractive index of 1.71 for the active and 1.67 for the passive regions. The refractive index of the active region 
is higher than expected at the chosen set temperature (i.e., $420^{\circ} \mathrm{C}$ ) compared to the results presented in Appendix C. It is possible that replacement of the heating lamp and deposition of $\mathrm{Al}_{2} \mathrm{O}_{3}$ on the quartz plate through which the set temperature is measured caused a higher wafer temperature than expected. It would be beneficial to measure the wafer temperature during deposition with, for example, an infrared camera to be able to adjust the set temperature accurately depending on the amount of open area on the mask. More research still needs to be done to achieve refractive index matched active-passive $\mathrm{Al}_{2} \mathrm{O}_{3}$ layers.

Waveguide devices are fabricated on this active-passive layer despite the fact that larger layer thickness and non-index matching in the transition might induce losses. Light was butt coupled into the input bus waveguide through a non-polarization maintaining fiber. Index matching fluid was utilized and the polarization of the fiber was controlled, using a fiber polarization controller, to optimize the coupling. The disk resonator was pumped at $976 \mathrm{~nm}$, to excite the $\mathrm{Yb}^{3+}$ ions in the doped region. The spontaneous emission of the signal wavelength, $\sim 1030 \mathrm{~nm}$, was captured through an objective with an infrared camera. The image of a $200 \mu \mathrm{m}$ radius disk resonator located in the active region is shown in Fig 5.7(b). The intensity of the pump light increases when it enters the active region. No major decay or scattering is observed in the transition region from active to passive, which indicates that the elevated, non-index matched transition region does not induce major losses. Either the available pump power was not sufficient or the $\mathrm{Yb}^{3+}$ concentration was not sufficiently high to obtain lasing in these devices. Too high internal losses in the active or passive $\mathrm{Al}_{2} \mathrm{O}_{3}$ layer of the fabricated device could also be a cause for not achieving lasing.

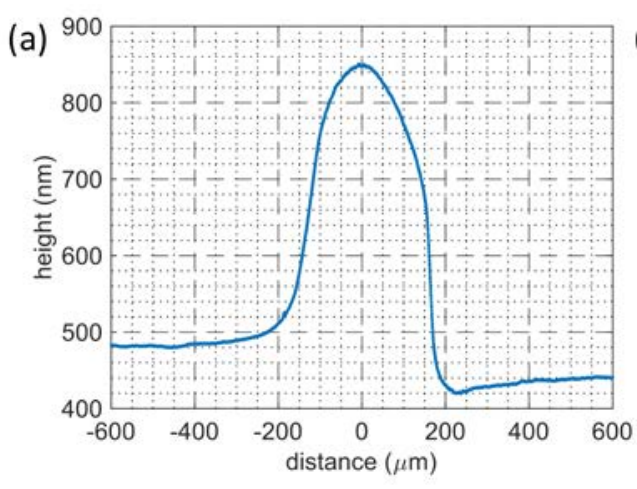

(b)

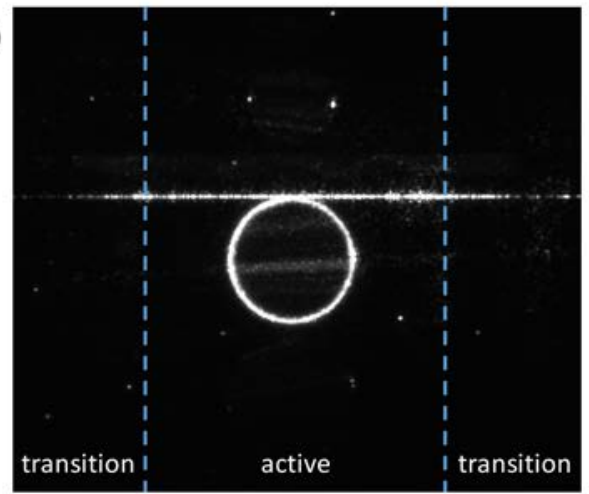

Fig. 5.7 (a) Profile scan from active (left) to passive (right) area. (b) Photograph made with infrared camera from a disk (radius of $200 \mu \mathrm{m}$ ) pumped with $976 \mathrm{~nm}$ to excite the $\mathrm{Yb}^{3+}$ ions with spontaneous stimulated emission at $1028 \mathrm{~nm}$ in the active region. Stray light illuminates contamination on top of the $\mathrm{SiO}_{2}$ cladding. 


\subsection{Conclusion}

This chapter describes the two methods to fabricate an active-passive $\mathrm{Al}_{2} \mathrm{O}_{3}$ layer. The first one is based on CMP to planarize the layer. This method relays on the deposition of the active regions through a shadow mask and chemical mechanical planarization of the active-passive layer. The second method is based on the deposition through two different shadow masks, which are negative of each other, to create a planar active-passive layer. Spontaneous stimulated emission in resonant structures fabricated in those layers have been demonstrated for both methods. Those fabrication methods pave the road towards on-chip lasers and amplifiers which can directly be integrated with passive building blocks on the same platform minimizing the need for accurate alignment waveguide procedures. 


\section{References}

[1] P. G. Kik and A. Polman, "Erbium-Doped Optical-Waveguide Amplifiers on Silicon," MRS Bull. 23, 48-54 (1998)

[2] P. Xing, G. F. R. Chen, X. Zhao, D. K. T. Ng, M. C. Tan, and D. T. H. Tan, "Silicon rich nitride ring resonators for rare - earth doped telecommunications-band amplifiers pumped at the O-band," Sci. Rep. 7, 9101 (2017)

[3] L. Agazzi, K. Wörhoff, and M. Pollnau, "Energy-Transfer-Upconversion Models, Their Applicability and Breakdown in the Presence of Spectroscopically Distinct Ion Classes: A Case Study in Amorphous $\mathrm{Al}_{2} \mathrm{O}_{3}: \mathrm{Er}^{3+}$," J. Phys. Chem. C 117, 6759-6776 (2013)

[4] S. A. Vázquez-Córdova, M. Dijkstra, E. H. Bernhardi, F. Ay, K. Wörhoff, J. L. Herek, S. M. García-Blanco, and M. Pollnau, "Erbium-doped spiral amplifiers with $20 \mathrm{~dB}$ of net gain on silicon," Opt. Express 22, 25993 (2014)

[5] E. R. Dobrovinskaya, L. A. Lytvynov, and V. Pishchik, Sapphire Material, Manufacturing, Applications (Springer, 2009)

[6] K. Wörhoff, J. D. B. Bradley, F. Ay, D. Geskus, T. P. Blauwendraat, and M. Pollnau, "Reliable Low-Cost Fabrication of Low-Loss $\mathrm{Al}_{2} \mathrm{O}_{3}: \mathrm{Er}^{3+}$ Waveguides With 5.4-dB Optical Gain," IEEE J. Quantum Electron. 45, 454-461 (2009)

[7] M. Demirtas, C. Odaci, N. K. Perkgoz, C. Sevik, and F. Ay, "Low Loss Atomic Layer Deposited $\mathrm{Al}_{2} \mathrm{O}_{3}$ Waveguides for Applications in On-Chip Optical Amplifiers," IEEE J. Sel. Top. Quantum Electron. 24, 1-8 (2018)

[8] T. Ishizaka and Y. Kurokawa, "Optical properties of rare-earth ion $\left(\mathrm{Gd}^{3+}, \mathrm{Ho}^{3+}, \mathrm{Pr}^{3+}, \mathrm{Sm}^{3+}, \mathrm{Dy}^{3+}\right.$ and $\mathrm{Tm}^{3+}$ ) -doped alumina films prepared by the sol-gel method," J. Lumin. 92, 57-63 (2000)

[9] J. Yang, K. van Dalfsen, K. Wörhoff, F. Ay, and M. Pollnau, "High-gain $\mathrm{Al}_{2} \mathrm{O}_{3}: \mathrm{Nd}^{3+}$ channel waveguide amplifiers at 880 nm, 1060 nm, and 1330 nm," Appl. Phys. B 101, 119-127 (2010)

[10] Purnawirman, N. Li, E. S. Magden, G. Singh, N. Singh, A. Baldycheva, E. S. Hosseini, J. Sun, M. Moresco, T. N. Adam, G. Leake, D. Coolbaugh, J. D. B. Bradley, and M. R. Watts, "Ultra-narrowlinewidth $\mathrm{Al}_{2} \mathrm{O}_{3}: \mathrm{Er}^{3+}$ lasers with a wavelength-insensitive waveguide design on a wafer-scale silicon nitride platform," Opt. Express 25, 13705 (2017)

[11] J. D. B. Bradley, L. Agazzi, D. Geskus, F. Ay, K. Wörhoff, and M. Pollnau, "Gain bandwidth of $80 \mathrm{~nm}$ and $2 \mathrm{~dB} / \mathrm{cm}$ peak gain in $\mathrm{Al}_{2} \mathrm{O}_{3}: \mathrm{Er}^{3+}$ optical amplifiers on silicon," J. Opt. Soc. Am. B 27, 187 (2010)

[12] G. Singh, P. Purnawirman, J. D. B. Bradley, N. Li, E. S. Magden, M. Moresco, T. N. Adam, G. Leake, D. Coolbaugh, and M. R. Watts, "Resonant pumped erbium-doped waveguide lasers using distributed Bragg reflector cavities.," Opt. Lett. 41, 1189-92 (2016)

[13] J. Rönn, L. Karvonen, C. Kauppinen, A. P. Perros, N. Peyghambarian, H. Lipsanen, A. Säynätjoki,

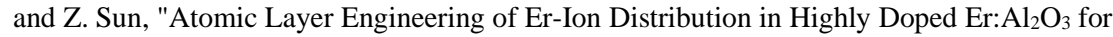
Photoluminescence Enhancement," ACS Photonics 3, 2040-2048 (2016)

[14] M. Belt and D. J. Blumenthal, "High Temperature Operation of an Integrated Erbium- Doped DBR Laser on an Ultra-Low-Loss $\mathrm{Si}_{3} \mathrm{~N}_{4}$ Platform," 79, 8-10 (2015)

[15] L. Agazzi, J. D. B. Bradley, M. Dijkstra, F. Ay, G. Roelkens, R. Baets, K. Wörhoff, and M. Pollnau, "Monolithic integration of erbium-doped amplifiers with silicon-on-insulator waveguides," Opt. Express 18, 27703 (2010)

[16] J. Mu, M. Dijkstra, Y.-S. Yong, F. B. Segerink, K. Wörhoff, M. Hoekman, A. Leinse, and S. M. García-Blanco, "Low-loss, broadband and high fabrication tolerant vertically tapered optical couplers for monolithic integration of $\mathrm{Si}_{3} \mathrm{~N}_{4}$ and polymer waveguides," Opt. Lett. 42, 3812 (2017)

[17] Z. Su, N. Li, H. C. Frankis, E. S. Magden, T. N. Adam, G. Leake, D. Coolbaugh, J. D. B. Bradley, and M. R. Watts, "High-Q-factor $\mathrm{Al}_{2} \mathrm{O}_{3}$ micro-trench cavities integrated with silicon nitride waveguides on silicon," Opt. Express 26, 11161 (2018) 
[18] J. P. Epping, M. Hoekman, R. Mateman, A. Leinse, R. G. Heideman, A. van Rees, P. J. M. van der Slot, C. J. Lee, and K.-J. Boller, "High confinement, high yield $\mathrm{Si}_{3} \mathrm{~N}_{4}$ waveguides for nonlinear optical applications," Opt. Express 23, 642 (2015)

[19] M. H. P. Pfeiffer, A. Kordts, V. Brasch, M. Zervas, M. Geiselmann, J. D. Jost, and T. J. Kippenberg, "Photonic Damascene process for integrated high-Q microresonator based nonlinear photonics," Optica 3, 20 (2016)

[20] S. Yew, T. Liu, M. Lur, W. Sun, "Dual damascene process," U.S. patent US5801094A (September 1, 1998)

[21] S. Deleonibus, B. Guillaumot, "Damascene architecture electronic storage and method for making same," U.S. patent US6955963B2 (2005)

[22] P. Loiko, N. Ismail, J. D. B. Bradley, M. Götelid, and M. Pollnau, "Refractive-index variation with rare-earth incorporation in amorphous $\mathrm{Al}_{2} \mathrm{O}_{3}$ thin films," J. Non. Cryst. Solids 476, 95-99 (2017)

[23] Y. Fan, R. M. Oldenbeuving, C. G. Roeloffzen, M. Hoekman, D. Geskus, R. G. Heideman, and K.-J. Boller, "290 Hz Intrinsic Linewidth from an Integrated Optical Chip-based Widely Tunable InP-Si ${ }_{3} \mathrm{~N}_{4}$ Hybrid Laser," in Conference on Lasers and Electro-Optics (OSA, 2017), p. JTh5C.9

[24] N. Li, D. Vermeulen, Z. Su, E. S. Magden, M. Xin, N. Singh, A. Ruocco, J. Notaros, C. V. Poulton, E. Timurdogan, C. Baiocco, and M. R. Watts, "Monolithically integrated erbium-doped tunable laser on a CMOS-compatible silicon photonics platform," Opt. Express 26, 16200 (2018)

[25] D. T. Spencer, T. Drake, T. C. Briles, J. Stone, L. C. Sinclair, C. Fredrick, Q. Li, D. Westly, B. R. Ilic, A. Bluestone, N. Volet, T. Komljenovic, L. Chang, S. H. Lee, D. Y. Oh, M.-G. Suh, K. Y. Yang, M. H. P. Pfeiffer, T. J. Kippenberg, E. Norberg, L. Theogarajan, K. Vahala, N. R. Newbury, K. Srinivasan, J. E. Bowers, S. A. Diddams, and S. B. Papp, "An optical-frequency synthesizer using integrated photonics," Nature 557, 81-85 (2018)

[26] C. I. van Emmerik, M. Dijkstra, M. de Goede, L. Chang, J. Mu, and S. M. Garcia-Blanco, "Singlelayer active-passive $\mathrm{Al}_{2} \mathrm{O}_{3}$ photonic integration platform," Opt. Mater. Express 8, 3049 (2018)

[27] J. D. B. Bradley, F. Ay, K. Wörhoff, and M. Pollnau, "Fabrication of low-loss channel waveguides in $\mathrm{Al}_{2} \mathrm{O}_{3}$ and $\mathrm{Y}_{2} \mathrm{O}_{3}$ layers by inductively coupled plasma reactive ion etching," Appl. Phys. B 89, 311-318 (2007)

[28] T. Ishizaka, R. Nozaki, and Y. Kurokawa, "Luminescence properties of $\mathrm{Tb}^{3+}$ and $\mathrm{Eu}^{3+}$-doped alumina films prepared by sol-gel method under various conditions and sensitized luminescence," J. Phys. Chem. Solids 63, 613-617 (2002)

[29] S. Dai, C. Yu, G. Zhou, J. Zhang, G. Wang, and L. Hu, "Concentration quenching in erbiumdoped tellurite glasses," J. Lumin. 117, 39-45 (2006)

[30] J. A. Shields, Applications of Molybdenum Metal and Its Alloys (2013)

[31] K. Wefers and C. Misra, Oxides and Hydroxides of Aluminum (1987), Vol. 19

[32] R. Ghodssi and P. Lin, MEMS Materials and Processing Handbook (Springer, 2011) 


\section{Chapter 6}

\section{Summary}

The integration of crystalline potassium yttrium double tungstate $\left(\mathrm{KY}\left(\mathrm{WO}_{4}\right)_{2}\right)$ and amorphous aluminum oxide $\left(\mathrm{Al}_{2} \mathrm{O}_{3}\right)$ - both host for rare-earth ions - on glass substrates has been demonstrated in this thesis. The work was performed with the aim to develop an integration process that allowed the fabrication of waveguide devices with standard lithography and etching procedures. In this chapter the main results of this work are summarized, conclusions are drawn, and an outlook for future work is given. 


\subsection{Integration of $\mathrm{KY}\left(\mathrm{WO}_{4}\right)_{2}$ on glass}

The first part of this thesis demonstrated the integration methods towards thin $\mathrm{KY}\left(\mathrm{WO}_{4}\right)_{2}$ layers on glass. A few specifications are set to increase the possibility for the fabrication of high-index contrast $\mathrm{KY}\left(\mathrm{WO}_{4}\right)_{2}$ waveguides in the future. These specifications are: a layer thickness of $0.90 \mu \mathrm{m}$ to $1.60 \mu \mathrm{m}$, depending on the application, with a maximum deviation of $\pm 0.02 \mu \mathrm{m}$ across the whole $10 \times 10 \mathrm{~mm}^{2}$ sample surface.

The findings of the bonding study performed for heterogeneous integration of $\mathrm{KY}\left(\mathrm{WO}_{4}\right)_{2}$-on-glass are presented in Chapter 2 and published in [1]. Different bonding methods are tested (i.e., manual, flip-chip assisted and wafer bonding) in combination with low temperature optical curable adhesive and high temperature $\left(\geq 150^{\circ} \mathrm{C}\right)$ curable adhesive as well as direct bonding. An ultimate planar bond between the $\mathrm{KY}\left(\mathrm{WO}_{4}\right)_{2}$ sample and the glass substrate was achieved with direct bonding. Flip-chip assisted bonding of the sample on a glass substrate with micropillars, which mimic a microbead filled epoxy, also resulted in a bond line without height deviations. Defects in the $\mathrm{KY}\left(\mathrm{WO}_{4}\right)_{2}$ layer bonded with a high temperature curable adhesive showed cracks through the whole layer, mainly along the $\mathbf{a}^{*}$-axis of the crystal, due to stress. High temperature adhesive is advantageous for future processing of the thin $\mathrm{KY}\left(\mathrm{WO}_{4}\right)_{2}$ layers (i.e., waveguide fabrication or integration with passive photonic materials). Therefore, a solution was found to guide the stress. This was done by dicing of trenches along the $\mathbf{a}^{*}$ axis that relieve the stress in the crystal resulting in a defect free interface between the $\mathrm{KY}\left(\mathrm{WO}_{4}\right)_{2}$ layer and the glass substrate.

The development of a lapping and polishing process of $\mathrm{KY}\left(\mathrm{WO}_{4}\right)_{2}$ towards high refractive index contrast slab waveguides is detailed in Chapter 3 . The lapping process is first developed on thick $(>300 \mu \mathrm{m}) \mathrm{KY}\left(\mathrm{WO}_{4}\right)_{2}$ layers and used thereafter with the intension to lap the samples from roughly $1 \mathrm{~mm}$ down to $1-2 \mu \mathrm{m}$. Unfortunately, the developed process did not work for this final lapping process to achieve micrometer thin layers. The polishing process was also developed on thick samples and where a layer with a root mean square surface roughness of $0.88 \mathrm{~nm}$ and a surface curvature of 26.0 meter was achieved after 2 hours of polishing. However, this curvature is not low enough to ensure the deviation of $\pm 0.02 \mu \mathrm{m}$ across the whole $10 \times 10 \mathrm{~mm}^{2}$ sample surface. Further, developments are needed for the realization of high refractive index contrast slab waveguides. The recommendations for future development will be given in Section 6.3. 


\subsection{Integration of single-layer active-passive $\mathrm{Al}_{2} \mathrm{O}_{3}$ on glass}

The second part of this thesis describes the integration of $\mathrm{Al}_{2} \mathrm{O}_{3}$ on glass at wafer level. Fabrication specifications were formulated to achieve single active-passive $\mathrm{Al}_{2} \mathrm{O}_{3}$ devices. First of all, the layer should be optically guiding and secondly the surface, created due to the deposition of both active and passive $\mathrm{Al}_{2} \mathrm{O}_{3}$ areas, should be as flat as possible such that light can be guided through the waveguides adiabatically.

The influence of oxygen flow during RF reactive co-sputtering on the optical properties of $\mathrm{Al}_{2} \mathrm{O}_{3}$ is described in Chapter 4. The relative oxidation state is introduced as parameter to identify the optimal process parameters. This description allows to identify an optimal relative target oxidation of $5.0 \pm 1.5 \%$ for low loss optical $\mathrm{Al}_{2} \mathrm{O}_{3}$ layer independent on the drift in the system. Transmission electron microscopy and $\mathrm{X}$-ray diffraction measurements revealed an increase of polycrystallinity with increasing oxygen flow.

Finally, two integration methods for single-layer active-passive $\mathrm{Al}_{2} \mathrm{O}_{3}$ are described in Chapter 5. Both methods use a shadow mask for the deposition of active $\mathrm{Al}_{2} \mathrm{O}_{3}$ areas. The first method is further based on planarization of the full layer after deposition of the undoped $\mathrm{Al}_{2} \mathrm{O}_{3}$ layer that covers the whole wafer including the active areas using chemical mechanical polishing. The findings of this method are published in [2]. For the second method, another shadow mask is used to deposit the passive regions on the wafer as well. The ease of fabrication is improved for this second method. The luminescence in the active $\mathrm{Yb}^{3}: \mathrm{Al}_{2} \mathrm{O}_{3}$ ring or disk resonator have been demonstrated as proof of principle for both methods.

\subsection{Recommendations for the heterogeneous integration of $\mathrm{KY}\left(\mathrm{WO}_{4}\right)_{2}$ on glass}

It has been shown that the heterogeneous integration of $\mathrm{KY}\left(\mathrm{WO}_{4}\right)_{2}$ on glass still has many challenges to overcome to finally be able to integrate high refractive index contrast waveguides in a reliable and reproducible manner. Some recommendations can be made concerning the integration scheme.

There is a high constraint on the maximal deviation of the height of the $\mathrm{KY}\left(\mathrm{WO}_{4}\right)_{2}$ layer of $\pm 0.02 \mu \mathrm{m}$ across the $10 \times 10 \mathrm{~mm}^{2}$ surface area. Deviation in the crystal layer can be produced during integration of the sample on the glass substrate (i.e., adhesive layer and height deviation in sample and or substrate), mounting of the $\mathrm{KY}\left(\mathrm{WO}_{4}\right)_{2}$ assemblies on the ultra-parallel glass plate for lapping and polishing (i.e., deviation in total height of the assemblies and wax layer) and further deviation can be caused if the 
vacuum holder of the lapping and polishing jig or lapping and polishing plate are not perfectly planar.

The deviation in the equipment (i.e., lapping and polishing jig and disks) should be minimized with careful maintenance and conditioning as described in Chapter 3 . The number of layers of the total stack used during polishing can be reduced to two when the $\mathrm{KY}\left(\mathrm{WO}_{4}\right)_{2}$ samples are bonded using direct bonding on a rigid glass plate that can be handled by the lapping and polishing jig as substrate.

The lapping and polishing process should be further optimized for the realization of thin defect free $\mathrm{KY}\left(\mathrm{WO}_{4}\right)_{2}$ slabs. The results presented in Chapter 3 showed that the load on the samples should be reduced during the medium lapping to reduce the chance of cracks on the thin samples when a scratch occur. It is further recommended to use an oil-based slurry during the fine lapping stage to reduce the interaction of the lapping particles with the $\mathrm{KY}\left(\mathrm{WO}_{4}\right)_{2}$ surface. Oil-based solution has a higher viscosity than water-based solution, which will leave a thicker film between the sample and lapping disk when the same process parameters are used. For this reason an oil-based slurry reduces the chance that the sample comes in direct contact with the plate.

The polishing time is still several hours and inherently induces rounding on the $\mathrm{KY}\left(\mathrm{WO}_{4}\right)_{2}$ surfaces. This is a disadvantage for the realization of the high refractive index contrast waveguides over the whole sample surface. Therefore, further investigation has into be done to pre-polishing with polishing particles that are only one order of magnitude smaller than the finest lapping particles to shorten the complete polishing time and minimize the rounding of the $\mathrm{KY}\left(\mathrm{WO}_{4}\right)_{2}$ surface.

\subsection{Recommendations for the integration of single-layer active-passive $\mathrm{Al}_{2} \mathrm{O}_{3}$ on glass}

The influence of oxygen flow to the optical properties during RF reactive co-sputtering have been investigated. It is recommended to also investigate the influence of the deposition temperature in the same process as both parameters have influence on each other.

It is further recommended to investigate the influence of the amount of open area in the shadow mask on the deposition temperature and study the influence on the optical and material properties of doped and undoped $\mathrm{Al}_{2} \mathrm{O}_{3}$ layers. This knowledge is needed to be able to fabricate refractive index matched single-layer active-passive devices. 
Processes and knowledge gained in this research can be transferred to develop a heterogeneous integration process for other laser crystals on glass substrates (e.g., YAG, diamond, sapphire) or fabrication of other amorphous layers used for optical applications that are produced by $\mathrm{RF}$ reactive co-sputtering (e.g., $\mathrm{TeO}_{2}$ [3,4], $\mathrm{TiO}_{2}$ [5], $\mathrm{Ta}_{2} \mathrm{O}_{5}$ [6]). The integration methods presented in this work are the first step towards the integration of multiple materials on a single wafer level which can then be processed with a single lithography and etching step.

\section{References}

[1] C. I. van Emmerik, R. Frentrop, M. Dijkstra, F. Segerink, R. Kooijman, M. Muneeb, G. Roelkens, E. Ghibaudo, J.-E. Broquin, and S. M. Garcia-Blanco, "Heterogeneous integration of KY(WO 4$)_{2}-$ on-glass: a bonding study," OSA Contin. 2, 2065-2076 (2019)

[2] C. I. van Emmerik, M. Dijkstra, M. de Goede, L. Chang, J. Mu, and S. M. Garcia-Blanco, "Singlelayer active-passive $\mathrm{Al}_{2} \mathrm{O}_{3}$ photonic integration platform," Opt. Mater. Express 8, 3049 (2018)

[3] H. Frankis, D. Su, D. Bonneville, J. Bradley, H. C. Frankis, D. Su, D. B. Bonneville, and J. D. B. Bradley, "A Tellurium Oxide Microcavity Resonator Sensor Integrated On-Chip with a Silicon Waveguide," Sensors 18, 4061 (2018)

[4] H. C. Frankis, K. M. Kiani, D. B. Bonneville, C. Zhang, S. Norris, R. Mateman, A. Leinse, N. D. Bassim, A. P. Knights, and J. D. B. Bradley, "Low-loss $\mathrm{TeO}_{2}$-coated $\mathrm{Si}_{3} \mathrm{~N}_{4}$ waveguides for application in photonic integrated circuits," Opt. Express 27, 12529 (2019)

[5] C. C. Evans, C. Liu, and J. Suntivich, "Low-loss titanium dioxide waveguides and resonators using a dielectric lift-off fabrication process," Opt. Express 23, 11160 (2015)

[6] C.-Y. Tai, J. S. Wilkinson, N. M. B. Perney, M. C. Netti, F. Cattaneo, C. E. Finlayson, and J. J. Baumberg, "Determination of nonlinear refractive index in a $\mathrm{Ta}_{2} \mathrm{O}_{5}$ rib waveguide using self-phase modulation," Opt. Express 12, 5110 (2004) 


\section{Hoofdstuk 7}

\section{Samenvatting}

In dit proefschrift is de integratie van kristallijn kalium yttrium dubbel wolframaat $\left(\mathrm{KY}\left(\mathrm{WO}_{4}\right)_{2}\right)$ en amorf aluminiumoxide $\left(\mathrm{Al}_{2} \mathrm{O}_{3}\right)$ - beiden gastheer voor zeldzame-aarde ionen - op glassubstraten beschreven. Het doel van dit onderzoek was om de integratieprocessen zo te ontwikkelen dat het mogelijk is om golfgeleiders te produceren door gebruik te maken van standaard lithografie en etsprocedures. In dit hoofdstuk zijn de belangrijkste resultaten samengevat. 


\subsection{Integratie van $\mathrm{KY}\left(\mathrm{WO}_{4}\right)_{2}$ op glas}

In het eerste deel van dit proefschrift zijn de integratiemethodes voor dunne $\mathrm{KY}\left(\mathrm{WO}_{4}\right)_{2}$-lagen op glas gedemonstreerd. Enkele specificaties zijn opgesteld om de realisatie van $\mathrm{KY}\left(\mathrm{WO}_{4}\right)_{2}$ golfgeleiders met hoog indexcontrast in de toekomst te waarborgen. Deze specificaties zijn: een laagdikte van $0.90 \mu \mathrm{m}$ tot $1.60 \mu \mathrm{m}$, afhankelijk van de toepassing, met een maximale afwijking van $\pm 0.02 \mu \mathrm{m}$ over het gehele $10 \times 10 \mathrm{~mm}^{2}$ kristaloppervlak.

De bevindingen van de bindingsstudie voor de heterogene integratie van $\mathrm{KY}\left(\mathrm{WO}_{4}\right)_{2}$ op glas zijn beschreven in Hoofdstuk 2 en gepubliceerd in [1]. Voor deze studie zijn verschillende bindingsmethoden getest (d.w.z., handmatig, flip-chip geassisteerd en direct wafer binding) in combinatie met lijm die uithardt op lage temperatuur en onder invloed van UV-licht, een lijm die op hoge temperatuur $\left(\geq 150^{\circ} \mathrm{C}\right)$ uithardt, en met directe bindingstechniek. Een ultiem homogene binding tussen het $\mathrm{KY}\left(\mathrm{WO}_{4}\right)_{2}$ kristal en het glassubstraat werd met directe binding bereikt. Een $\mathrm{KY}\left(\mathrm{WO}_{4}\right)_{2}$-kristal verlijmd met behulp van een flip-chip binder op een glassubstraat met micropilaren, die een lijm gevuld met microballetjes nabootsen, resulteerde ook in een lijmlaag zonder hoogteverschillen. De $\mathrm{KY}\left(\mathrm{WO}_{4}\right)_{2}$ kristallen verlijmd met lijm die op hoge temperatuur uithardt, vertoonde scheuren door de hele laag. Deze scheuren liepen voornamelijk langs de $\mathbf{a}^{*}$-as van het kristal en zijn het gevolg van spanning in de materialen. Lijm die op hoge temperatuur uithardt heeft als voordeel dat deze gebruikt kan worden bij de integratie van dunne $\mathrm{KY}\left(\mathrm{WO}_{4}\right)_{2}$-lagen met andere passief fotonische materialen. Om die reden is er gezocht naar een manier om de spanning door het kristal te begeleiden. De spanning in het kristal kon geleid worden door in het kristal lijnen langs de $\mathbf{a}^{*}$-as van het kristal te zagen. Deze aanpassing resulteerde in een defectvrije grenslaag tussen het $\mathrm{KY}\left(\mathrm{WO}_{4}\right)_{2}$-kristal en het glassubstraat.

De ontwikkeling van een lep- en polijstproces om vlakke, hoog brekingsindexcontrast golfgeleiders te realiseren in $\mathrm{KY}\left(\mathrm{WO}_{4}\right)_{2}$ is beschreven in Hoofdstuk 3. Het lepproces is eerst ontwikkeld op dikke (> $300 \mu \mathrm{m}) \mathrm{KY}\left(\mathrm{WO}_{4}\right)_{2}$-lagen en het proces is daarna gebruikt met de intentie om de dikte van de kristallen van $1 \mathrm{~mm}$ terug te brengen tot 1-2 $\mu \mathrm{m}$. Helaas was het ontwikkelde lepproces niet geschikt voor dit laatstgenoemde proces.

Het polijstproces is ook ontwikkeld op dikke $\mathrm{KY}\left(\mathrm{WO}_{4}\right)_{2}$ lagen wat, na 2 uur polijsten, in een gemiddelde oppervlakteruwheid van $0.88 \mathrm{~nm}$ en een oppervlaktekromming van 26.0 meter resulteerde. Deze oppervlaktekromming is echter niet klein genoeg om de afwijking van $\pm 0.02 \mu \mathrm{m}$ over het hele $10 \times 10 \mathrm{~mm}^{2}$ kristaloppervlak te garanderen. Vervolgonderzoek is nodig om de realisatie van vlakke, hoge brekingsindexcontrast, $\mathrm{KY}\left(\mathrm{WO}_{4}\right)_{2}$ golfgeleiders te realiseren. 


\subsection{Integratie van enkele-laag actief-passief $\mathrm{Al}_{2} \mathrm{O}_{3}$ op glas}

In het tweede deel van dit proefschrift wordt de integratie van $\mathrm{Al}_{2} \mathrm{O}_{3}$ op en glas op wafer niveau beschreven. Specificaties zijn opgesteld voor het bereiken van enkele laag actiefpassief $\mathrm{Al}_{2} \mathrm{O}_{3}$ structuren. Ten eerste moet de laag optisch geleidend zijn en ten tweede moet het oppervlak, ontstaan als gevolg van de depositie van zowel actieve als passieve $\mathrm{Al}_{2} \mathrm{O}_{3}$ gebieden, zo vlak mogelijk zijn, zodat het licht adiabatisch door de golfgeleiders kan worden geleid.

De invloed van de zuurstoftoevoer, tijdens radiofrequent $(\mathrm{RF})$ reactief co-sputteren, op de optische eigenschappen van $\mathrm{Al}_{2} \mathrm{O}_{3}$ is beschreven in Hoofdstuk 4. De relatieve oxidatietoestand van het Al-substraat is geïntroduceerd als parameter om de optimale procesparameters te identificeren. Deze beschrijving maakt het mogelijk om een relatieve oxidatiestaat van het $\mathrm{Al}$-substraat van $5.0 \pm 1.5 \%$ te identificeren als optimale instelling om $\mathrm{Al}_{2} \mathrm{O}_{3}$-lagen te realiseren met lage optische verliezen. Transmissieelektronenmicroscopie en röntgendiffractiemetingen lieten een toename in de hoeveelheid polykristallijne deeltjes in de lagen zien bij een toenemende toevoer van zuurstof.

Ten slotte zijn in Hoofdstuk 5 twee integratiemethodes voor de realisatie van enkele laag actief-passief $\mathrm{Al}_{2} \mathrm{O}_{3}$ beschreven. Voor beide methodes is een schaduwmasker gebruikt tijdens de depositie van actieve $\mathrm{Al}_{2} \mathrm{O}_{3}$-gebieden. De eerst methode is gebaseerd op het vlak maken van de volledig laag na depositie van de ongedoteerde $\mathrm{Al}_{2} \mathrm{O}_{3}$-laag die de hele wafer bedekt, inclusief de afgezette actieve gebieden, met behulp van chemisch-mechanisch polijsten. De bevindingen van deze integratiemethode zijn gepubliceerd in [2]. Voor de tweede methode is een ander schaduwmasker gebruikt om de passieve gebieden op de wafer te deponeren. Deze methode vergemakkelijkt de fabricage van de actieve-passieve lagen. De luminescentie in de actieve $\mathrm{Yb}^{3+}: \mathrm{Al}_{2} \mathrm{O}_{3}$ ring of disk resonator is gedemonstreerd om de potentie van deze integratie methodes te laten zien.

\subsection{Aanbevelingen voor de heterogene integratie van $\mathrm{KY}\left(\mathrm{WO}_{4}\right)_{2}$ op glas}

In dit werk is aangetoond dat er nog steeds veel uitdagingen te overwinnen zijn om $\mathrm{KY}\left(\mathrm{WO}_{4}\right)_{2}$ op een heterogene manier te integreren op glas, om uiteindelijk de integratie van golfgeleiders met hoog brekingsindex contrast op een reproduceerbare mogelijk te maken. Hieronder zijn enkele aanbevelingen gemaakt met betrekking tot dit integratieschema. 
Er is sterke beperking op de maximale afwijking van de hoogte van $\pm 0.02 \mu \mathrm{m}$ over het gehele $10 \times 10 \mathrm{~mm}^{2}$ oppervlakte van de $\mathrm{KY}\left(\mathrm{WO}_{4}\right)_{2}$ laag gesteld. De afwijking in de kristal laag kan worden veroorzaakt tijdens de integratie van het kristal op het glas substraat (d.w.z., verschil in de hoogte van de lijm laag, het kristal of het substraat), tijdens de montage van de $\mathrm{KY}\left(\mathrm{WO}_{4}\right)_{2}$ assemblages op de ultra parallelle glasplaat die gebruikt wordt tijdens het leppen en polijsten (d.w.z., afwinging in de totale hoogte van de assemblages en was laag) en de afwijking kan ook worden veroorzaakt door hoogte afwijkingen in de vacuüm houder van de lep en polijst houder of omdat de lep en polijst plaat niet perfect vlak zijn.

De afwijking in de gebruikte apparatuur (d.w.z., lep en polijst houder en de schijven) kan worden geminimaliseerd door zorgvuldig onderhoud en conditionering van apparatuur zoals beschreven in Hoofdstuk 3. Het aantal lagen van de assemblages kan worden teug gebracht tot twee wanneer de $\mathrm{KY}\left(\mathrm{WO}_{4}\right)_{2}$ kristallen met behulp van directe bindings techniek op een stevige glasplaat, die ook als substraat gebruikt kan worden in de vacuum houder tijdens het lep en polijst proces, gebonden worden.

Het lep en polijst proces mot verder geoptimaliseerd worden om de realisatie van dunne defect vrije $\mathrm{KY}\left(\mathrm{WO}_{4}\right)_{2}$ lagen mogelijk te maken. Uit de in Hoofdstuk 3 gepresenteerde resultaten in gebleken dat de belasting op de kristallen verminderd moet worden tijdens de gemiddelde lep fase om zo de kans op scheuren in de dunne laag te verkleinen wanneer er krassen zijn ontstaan. Verder is het aan te bevelen om een lep oplossing gebaseerd op olie te gebruiken tijdens de fijne lep fase om zo de directe interactie van de lep deeltjes met het $\mathrm{KY}\left(\mathrm{WO}_{4}\right)_{2}$ oppervlak te verminderen. Een oplossing gebaseerd op olie heeft een hogere viscositeit dan een oplossing gebaseerd op water, wat zorgt voor een dikkere vloeistof laag tussen het kristal en de lepschijf wanneer dezelfde procesparameters worden gebruikt. Om deze reden zal een op olie gebaseerde oplossing de kans op direct contact tussen de schijf en het kristal verminderen.

De polijst tijd is nog steeds enkele uren wat sowieso voor ronding in het $\mathrm{KY}\left(\mathrm{WO}_{4}\right)_{2}$ oppervlak zorgt. Dit is een nadeel voor de realisatie van golfgeleiders met een hoge brekingsindex over het gehele oppervlak. Daarom moet er vervolgonderzoek worden gedaan naar de mogelijkheid van een voor-polijst stap waarbij polijst deeltjes gebruikt worden die slechts een order kleiner zijn dan de fijne lep deeltjes om zo de volledige polijst tijd te verkorten en de afronding van het $\mathrm{KY}\left(\mathrm{WO}_{4}\right)_{2}$ oppervlak te minimaliseren.

\subsection{Aanbevelingen voor de integratie van enkele-laag actief-passief $\mathrm{Al}_{2} \mathrm{O}_{3}$ op glas}

De invloed van zuurstof toevoer op de optische eigenschappen van RF-reactief gesputterde lagen is onderzocht. Het is aan te bevelen om ook de invloed van de depositie 
temperatuur te onderzoeken in hetzelfde proces, aangezien beide parameters elkaar beïnvloeden.

Het is verder aan te bevelen om de invloed van het percentage open gebied in een schaduwmasker op de depositie temperatuur te onderzoeken en de optische en materiaal eigenschappen van gedoteerd en ongedoteerde $\mathrm{Al}_{2} \mathrm{O}_{3}$ lagen die op deze manier gemaakt zijn te bestuderen. Deze kennis is noodzakelijk om uiteindelijk enkele laag actievepassieve $\mathrm{Al}_{2} \mathrm{O}_{3}$ lagen met een overeenkomend brekingsindex te maken.

De opgedane kennis en ontwikkelde processen kunnen gebruikt worden om heterogene integratie processen voor ander laser kristallen (bijv. YAG, Diamand, Saffier) op glas te ontwikkelen of de fabricatie van andere (bijv. $\mathrm{TeO}_{2}$ [3,4], $\mathrm{TiO}_{2}$ [5], $\left.\mathrm{Ta}_{2} \mathrm{O}_{5}[6]\right)$ amorf RF-reactief gesputterde optische lagen te verbeteren. De integratie methodes die in dit werk zijn gepresenteerd, vormen de stap naar de integratie van meerdere optische materialen op één enkel wafer niveau die vervolgens verwerkt kunnen worden door middel van één enkele lithografie en ets stap.

\section{Referenties}

[1] C. I. van Emmerik, R. Frentrop, M. Dijkstra, F. Segerink, R. Kooijman, M. Muneeb, G. Roelkens, E. Ghibaudo, J.-E. Broquin, and S. M. Garcia-Blanco, "Heterogeneous integration of KY(WO 4$)_{2}-$ on-glass: a bonding study," OSA Contin. 2, 2065-2076 (2019)

[2] C. I. van Emmerik, M. Dijkstra, M. de Goede, L. Chang, J. Mu, and S. M. Garcia-Blanco, "Singlelayer active-passive $\mathrm{Al}_{2} \mathrm{O}_{3}$ photonic integration platform," Opt. Mater. Express 8, 3049 (2018)

[3] H. Frankis, D. Su, D. Bonneville, J. Bradley, H. C. Frankis, D. Su, D. B. Bonneville, and J. D. B. Bradley, "A Tellurium Oxide Microcavity Resonator Sensor Integrated On-Chip with a Silicon Waveguide," Sensors 18, 4061 (2018)

[4] H. C. Frankis, K. M. Kiani, D. B. Bonneville, C. Zhang, S. Norris, R. Mateman, A. Leinse, N. D. Bassim, A. P. Knights, and J. D. B. Bradley, "Low-loss $\mathrm{TeO}_{2}$-coated $\mathrm{Si}_{3} \mathrm{~N}_{4}$ waveguides for application in photonic integrated circuits," Opt. Express 27, 12529 (2019)

[5] C. C. Evans, C. Liu, and J. Suntivich, "Low-loss titanium dioxide waveguides and resonators using a dielectric lift-off fabrication process," Opt. Express 23, 11160 (2015)

[6] C.-Y. Tai, J. S. Wilkinson, N. M. B. Perney, M. C. Netti, F. Cattaneo, C. E. Finlayson, and J. J. Baumberg, "Determination of nonlinear refractive index in a $\mathrm{Ta}_{2} \mathrm{O}_{5}$ rib waveguide using self-phase modulation," Opt. Express 12, 5110 (2004) 
Appendix 


\section{A. Influence of the deposition height on the uniformity of the $\mathrm{Al}_{2} \mathrm{O}_{3}$ layer}

The uniformity of the deposited $\mathrm{Al}_{2} \mathrm{O}_{3}$ layer is important for a high yield in the performance of the fabricated optical devices. The sputtered layer uniformity varies as function of the distance between the target and the wafer. To study this effect, a thin $\mathrm{Al}_{2} \mathrm{O}_{3}$ layer (i.e., $\sim 50 \mathrm{~nm}$ thick) was deposited on a silicon wafer at room temperature, with the settings setting as mentioned in Table 4.1 (Chapter 4) with an oxygen flow of $2.5 \mathrm{sccm}$. A line scan of the layer thickness across the center of the wafer was measured by ellipsometry (Woollam M-2000UI). Figure A.1(a) shows the relative thickness of the deposited layers as function of radial position with respect to the thickness at the center of the wafer, for different target-wafer distances. As the distance increases, the layer varies from concave (i.e., the thickness of the edge of the layer is thicker than the thickness at the center) to convex. The change in the uniformity of the layer is caused by the distance and angle between target and substrate and can be explained using geometry rules [1,2]. A uniformity of $96 \%$ at a distance of $4.5 \mathrm{~cm}$ away from the center was obtained for a target-wafer distance of 6 inch (i.e., $15.2 \mathrm{~cm}$ ). To check whether the layers deposited at this target-wafer distance had good optical quality, a $890 \mathrm{~nm}$ thick $\mathrm{Al}_{2} \mathrm{O}_{3}$ layer was deposited with the settings as mentioned in Table 4.1 with an oxygen flow of $2.5 \mathrm{sccm}$ and set temperature of $650{ }^{\circ} \mathrm{C}$ (i.e., expected wafer temperature $\sim 375^{\circ} \mathrm{C}$ ). Light with a wavelength of $632.8 \mathrm{~nm}$ was coupled into the layer using prism coupling (Metricon 2010/M) and showed light propagation over the whole length of the layer (Fig. A.1(b)).

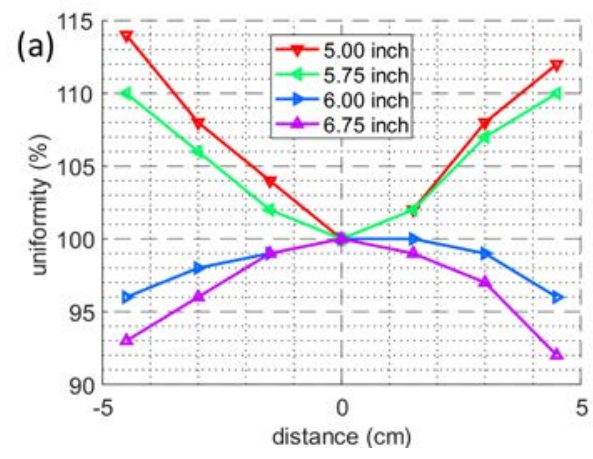

(b)

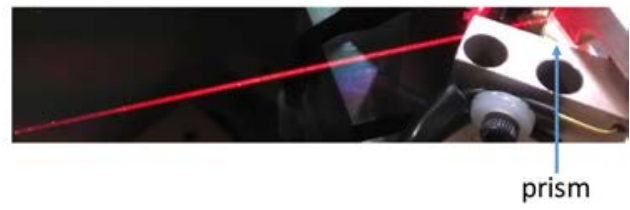

Fig. A.1 (a) Uniformity of the wafer thickness over the wafer for different deposition heights. (b) Photograph of $632.8 \mathrm{~nm}$ light coupled with a prism into an $\mathrm{Al}_{2} \mathrm{O}_{3}$ layer deposited at a height of 6 inch. 


\section{B. Planarization efficiency of $\mathrm{Al}_{2} \mathrm{O}_{3}$ regions for single-layer active-passive $\mathrm{Al}_{2} \mathrm{O}_{3}$ integration}

The CMP assisted integration method for single-layer active-passive $\mathrm{Al}_{2} \mathrm{O}_{3}$ (Section 5.2) leads to a topology comparable with the position and height of the active regions, so called bumps. This topology has to be removed before devices can be made with a single lithography and etching step.

The planarity of the $\mathrm{Al}_{2} \mathrm{O}_{3}$ layer is an important parameter to produce devices with similar performances. The planarization efficiency (PE) is therefore an important parameter during CMP. Material will be removed from the whole wafer surface (i.e., elevated regions and the rest of the wafer surface) during the CMP process. The planarization efficiency is given by:

$$
P E=\left(1-\frac{\Delta \text { down }}{\Delta u p}\right) \cdot 100 \%
$$

where, $\Delta$ up is the material removed at the top of the bumps, $\Delta$ down is the material removed at the additional surface of the wafer at any instant during the planarization process, as illustrated in Fig. B.1 [3]. The PE should be $\sim 1$ to achieve an optimal planarization process, which means that the height of the bumps is reduced much more than the additional surface area of the wafer. The height of the bumps is measured before and after the CMP process with a line scan using a profilometer (Veeco Dektak 8) and the height of the additional surface of the wafer is measured with ellipsometry (Woollam M-2000UI).

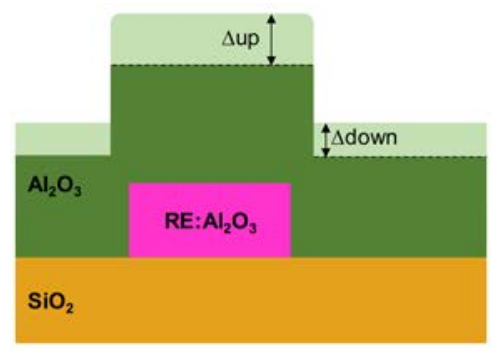

Fig. B.1 Illustration of the removed area on the top of the bump, $\Delta$ up, and at the wafer surface, $\Delta$ down, during a CMP process.

A preliminary study was performed to investigate the planarization efficiency as function of rotation speed of the wafer and table and as function of the pressure exerted on the wafer. The elevated regions, caused by the active $\mathrm{Al}_{2} \mathrm{O}_{3}$ in the real active-passive layers, were etched in etched in two $\sim 1.1 \mu \mathrm{m}$ thick $\mathrm{Al}_{2} \mathrm{O}_{3}$ layers to mimic this areas and had a height of $\sim 0.5 \mu \mathrm{m}$. The CMP procedure was performed on a Mecapol E460 machine in combination with a DOW-IC1000 grooved SUBA pad. A polishing slurry of 
Carbot Semi Sperse 25 (SS25) mixed with DI water in a ratio of SS25 : DI = 1:2 was used and the $\mathrm{pH}$ of the slurry was adjusted to 7 by adding $2 \% \mathrm{HCl}$ solution to obtain a more mechanical driven removal [4].

A slurry flow of $240 \mathrm{ml} / \mathrm{min}$ was used during all the procedures of 30 seconds and the polishing pad was conditioned with 2 sweeps with a diamond disk at the start of every run to establish the same surface roughness of the pad. A back pressure of 0.2 bar was used to hold the wafer into place and the speed of the head was always 1 rpm less than that of the table.

For the first experiment, the PE was studied as function of the velocity of the table while the pressure was kept constant at 0.75 bar. From the results shown in Fig. B.1(a), it can be seen that the PE decreases linearly with rotation speed. For the second experiment, the $\mathrm{PE}$ was studied as function of the pressure on the wafer while the rotation speed of the table was kept at $50 \mathrm{rpm}$. Also, here the PE decreases linearly with higher pressure on the wafer, as shown in Fig. B.2(b). The data point at 0.5 bar did not follow the trend and no clear explanation could be found to explain this point.

The experiments made at a rotation speed of $50 \mathrm{rpm}$ and a pressure of $0.75 \mathrm{bar}$ are slightly different for both experiments (Fig. B.2(a) PE $=48 \%$, Fig. B.2(b) PE=76\%). This difference can be caused by the fact that the mechanical properties of both wafers are slightly different. The process is performed in a multi-user cleanroom and it could be that the operation conditions during deposition and CMP of the layers change due to different processes that are performed by other useres, which also influence the process. Therefore, the presented results can only be used as guideline.

The PE does not say anything about the removal rate during the process. For a high removal rate of the upper part ( $80 \mathrm{~nm}$ in $30 \mathrm{sec}$ ) a pressure of 0.75 bar with an rotation speed between 30-50 rpm is optimal. While for the final smoothening and high precision removal a low pressure or rotation speeds is beneficial.
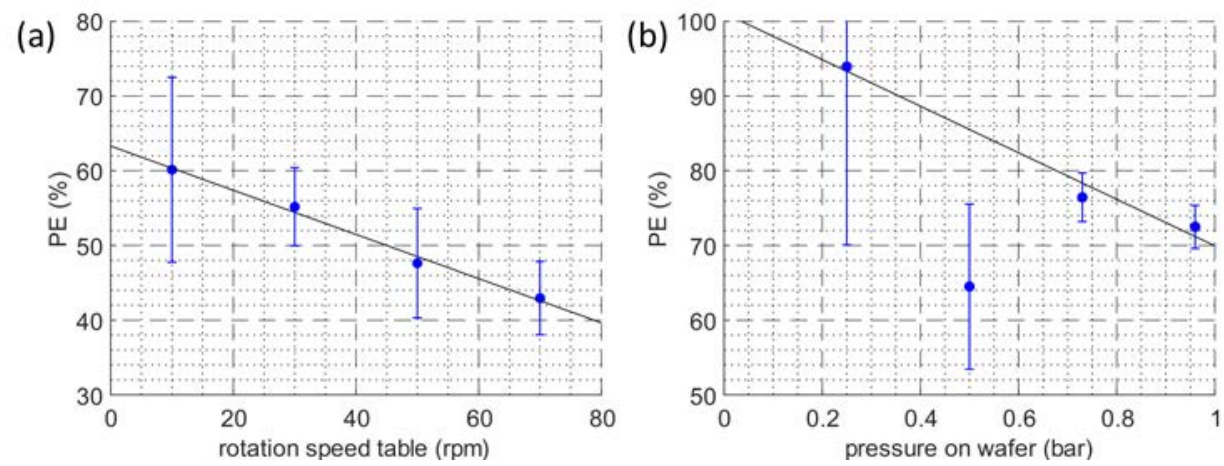

Fig. B.2 Planarization efficiency as function of (a) rotation speed of the table and (b) pressure on the wafer. 


\section{Effect of wafer temperature on the optical properties of reactive co-sputtered $\mathrm{Al}_{2} \mathrm{O}_{3}$ layers}

The influence of the deposition temperature on the optical properties of $\mathrm{Al}_{2} \mathrm{O}_{3}$ films has been studied using ALD [5] and RF reactive sputtering [6,7]. The first study showed that a $\mathrm{Al}_{2} \mathrm{O}_{3}$ layers deposited at $300{ }^{\circ} \mathrm{C}$ had minor $\mathrm{OH}^{-}$bonds, an amorphous structure and the highest refractive index (i.e., $1.639 \pm 0.001$ at $\lambda=1550 \mathrm{~nm}$ ) compared to the layers deposited at lower temperatures (i.e., 150, 200 and $250{ }^{\circ} \mathrm{C}$ ). Slab losses as low as $0.04 \pm 0.02 \mathrm{~dB} / \mathrm{cm}$ have been demonstrated at $1549 \mathrm{~nm}$ with this fabrication method. The second study showed a minor decrease in refractive index with increased temperature (i.e., temperature range between $350-500{ }^{\circ} \mathrm{C}$ ). The optical losses of the $\mathrm{Al}_{2} \mathrm{O}_{3}$ films reduced from $5 \mathrm{~dB} / \mathrm{cm}$ to $\sim 0.3 \mathrm{~dB} / \mathrm{cm}$ at $633 \mathrm{~nm}$ for deposition temperatures of $350{ }^{\circ} \mathrm{C}$ and $550{ }^{\circ} \mathrm{C}$, respectively.

A preliminary study was done to investigate the influence of temperature on the refractive index of rare-earth ion doped $\mathrm{Al}_{2} \mathrm{O}_{3}$ when deposited through a molybdenum mask and undoped $\mathrm{Al}_{2} \mathrm{O}_{3}$ layers deposited without a mask. The first represents the deposition of the active regions in single-layer active-passive $\mathrm{Al}_{2} \mathrm{O}_{3}$ areas and the latter the overgrown passive $\mathrm{Al}_{2} \mathrm{O}_{3}$ layer in the CMP assisted integration scheme. The undoped $\mathrm{Al}_{2} \mathrm{O}_{3}$ layers, deposited without mask, are made with a relative oxidation state of the target of $\eta_{\mathrm{ox}} \approx 5.0 \pm 2.0 \%$. The active $\mathrm{Yb}^{3+}: \mathrm{Al}_{2} \mathrm{O}_{3}$ regions are made with a power of $35 \mathrm{~W}$ on the Yb-target and with an oxygen flow of 2.5-3.0 $\mathrm{sccm}^{*}$ through a mask with $13 \%$ open surface. The set temperature was varied between $480{ }^{\circ} \mathrm{C}$ and $611^{\circ} \mathrm{C}$. All process settings are summarized in Table C.1. The refractive index is determined using an ellipsometer (Woollam M2000UI) and a qualitative measure of the guiding of light was performed with the prism coupling setup at a wavelength of $632.8 \mathrm{~nm}$.

Table C.1: Settings for deposition of $\mathrm{Al}_{2} \mathrm{O}_{3}$ layers

\begin{tabular}{|c|c|c|}
\hline & Al - target & Yb - target \\
\hline Power (W) & 200 & 35 \\
\hline Ar (sccm) & 25.0 & 5.0 \\
\hline $\mathrm{O}_{2}(\mathrm{sccm})$ for $\mathrm{Yb}^{3+}: \mathrm{Al}_{2} \mathrm{O}_{3}$ & \multicolumn{2}{|l|}{$2.5-3.0$} \\
\hline$\eta_{\mathrm{ox}}(\%)$ for $\mathrm{Al}_{2} \mathrm{O}_{3}$ & \multicolumn{2}{|l|}{$4.5-7.2$} \\
\hline Set temperature $\left({ }^{\circ} \mathrm{C}\right)$ & \multicolumn{2}{|l|}{$450-611$} \\
\hline Target-wafer distance (inch) & \multicolumn{2}{|l|}{6.0} \\
\hline
\end{tabular}

*Study performed before material study (Chapter 4). More research has to be done to identify the optimal oxidation state of the target as function of oxygen flow for different ytterbium concentrations and wafer temperatures. 
The refractive indices, for both series, are shown as a function of the set wafer temperature in Fig. C.1. It can be seen that there is a slightly increase for the undoped $\mathrm{Al}_{2} \mathrm{O}_{3}$ layers deposited without mask. A step like increase from $\sim 1.69$ to $\sim 1.72$ is observed for the $\mathrm{Yb}^{3+}: \mathrm{Al}_{2} \mathrm{O}_{3}$ layers deposited trough the mask. The refractive index of $\sim 1.72$ becomes close to the refractive index of sapphire $(\mathrm{n} \approx 1.75$ [8]), the crystalline form of $\mathrm{Al}_{2} \mathrm{O}_{3}$. It is likely that the energy is sufficiently high to form a polycrystalline phase in the amorphous $\mathrm{Al}_{2} \mathrm{O}_{3}$ layer, which can also be achieved by ion source assisted magnetron sputtering [9] and with post processing of deposited layers by annealing [10,11] or re-sputtering [12]. The undoped $\mathrm{Al}_{2} \mathrm{O}_{3}$ layers deposited at a set temperature $<550^{\circ} \mathrm{C}$ had propagation over at least $5 \mathrm{~cm}$ at a wavelength of $632.8 \mathrm{~nm}$ while the layers above this temperature were lossy (propagation $<1 \mathrm{~cm}$ ). All layers deposited through the mask did guide light over the full length of the regions (i.e., total length of $14.7 \mathrm{~mm}$ ) without observable losses.

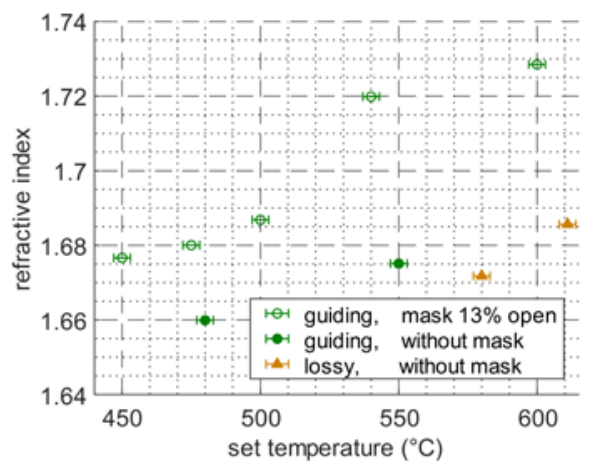

Fig. C.1 Refractive index as function of set temperature for $\mathrm{Yb}^{3+}: \mathrm{Al}_{2} \mathrm{O}_{3}$ layers deposited through a molybdenum mask with $13 \%$ opening and undoped $\mathrm{Al}_{2} \mathrm{O}_{3}$ layers (error margin in refractive index of 0.001).

A higher deposition temperature is expected when depositing through a molybdenum mask due to the fact that molybdenum has a low emissivity compared to silicon (emissivity molybdenum $\sim 0.1$ [13] and silicon $~ 0.7$ [14]) and it will therefore reflect thermal radiation from the wafer backwards causing an increase in wafer temperature. The set temperature is measured through a quartz window on the backside of the wafer holder in the AJA ATC 1500. The actual wafer temperature cannot be monitored during the deposition and therefore a calibration curve is made. A thermocouple is mounted on a silicon wafer with $8 \mu \mathrm{m}$ thick $\mathrm{SiO}_{2}$ with a silver past (PELCO ${ }^{\circledR}$ high performance silver paste) to measure the wafer temperature. Another mask, with $28 \%$ open area, was used during the calibration because the openings on the mask with $13 \%$ open area, where not sufficiently large in the center of the wafer to mount the thermocouple. The wafer is mounted, with or without mask, in the holder of the machine. The holder cannot rotate 
during the calibration due to the connecting wires. This will lead to an estimated deviation of $\pm 10^{\circ} \mathrm{C}$ in temperature compared to the wafer temperature during deposition. The calibration is done under normal process settings (i.e., work pressure $\sim 4$ mTorr, oxygen flow of $2.5 \mathrm{sccm}$ and argon flow of $25 \mathrm{sccm}$ and $5 \mathrm{sccm}$ on $\mathrm{Al}$ and Yb-target, respectively) without power on the targets. The set and wafer temperature are measured after 15 minutes when both temperatures are stabilized. The calibration curves (Fig C.2(a)) show that the wafer temperature is higher with mask than without mask. An estimation for the wafer temperature with a mask with $13 \%$ open area is made based on those calibration curves. Figure C.2(b) show the refractive indices for both undoped $\mathrm{Al}_{2} \mathrm{O}_{3}$ layer and $\mathrm{Yb}^{3+}: \mathrm{Al}_{2} \mathrm{O}_{3}$ regions as function of wafer temperature. Form this graph can be seen that the temperature for layers deposited without mask are not sufficient to reach the higher (i.e. $~ 1.72$ ) refractive index. The maximum set temperature is $611^{\circ} \mathrm{C}$ on the AJA ATC 1500 and therefore no high refractive index layers can be fabricated based on temperature increase without mask. This is valuable information for the fabrication of refractive index matched single-layer active-passive $\mathrm{Al}_{2} \mathrm{O}_{3}$ layers.
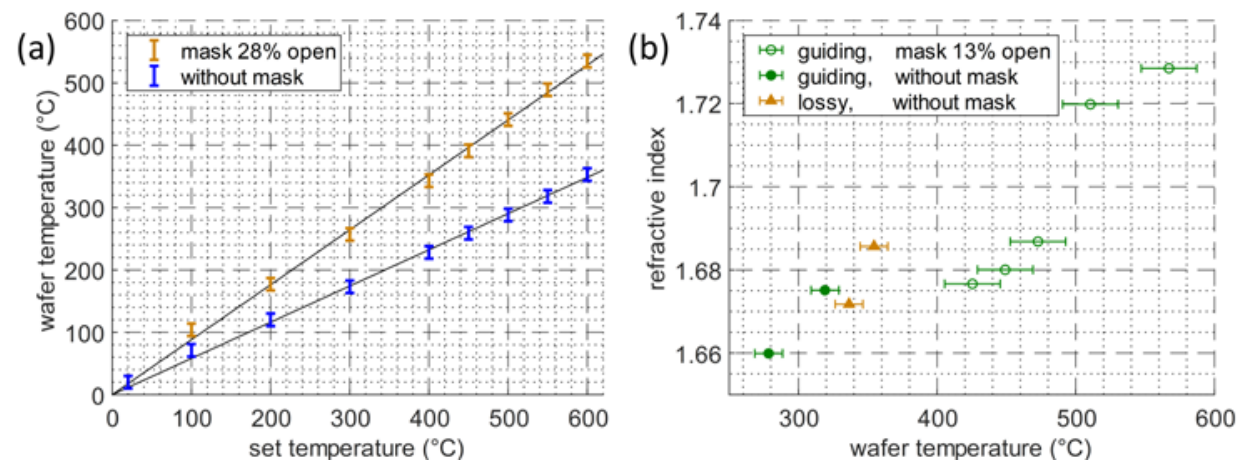

Fig C.2 (a) Temperature measured at the wafer interface with and without shadow mask as function of set temperature. (b) Refractive index at $1030 \mathrm{~nm}$ measured with ellipsometer for undoped $\mathrm{Al}_{2} \mathrm{O}_{3}$ layers deposited without mask and $\mathrm{Yb}^{3+}: \mathrm{Al}_{2} \mathrm{O}_{3}$ regions deposited through a mask with $13 \%$ area. 


\section{References}

[1] S. Swann, "Film thickness distribution in magnetron sputtering," Vacuum 38, 791-794 (1988)

[2] T. Fujimoto, B. Li, I. Kojima, S. Yokoyama, and S. Murakami, "An ultrahigh vacuum sputtering system with offset incidence magnetron sources onto a rotating substrate," Rev. Sci. Instrum. 70, 4362-4365 (1999)

[3] Y. Hong, V. K. Devarapalli, D. Roy, and S. V. Babu, "Synergistic Roles of Dodecyl Sulfate and Benzotriazole in Enhancing the Efficiency of CMP of Copper," J. Electrochem. Soc. 154, H444 (2007)

[4] K. Wefers and C. Misra, Oxides and Hydroxides of Aluminum (1987), Vol. 19

[5] M. Demirtas, C. Odaci, N. K. Perkgoz, C. Sevik, and F. Ay, "Low Loss Atomic Layer Deposited $\mathrm{Al}_{2} \mathrm{O}_{3}$ Waveguides for Applications in On-Chip Optical Amplifiers," IEEE J. Sel. Top. Quantum Electron. 24, 1-8 (2018)

[6] K. Worhoff, F. Ay, and M. Pollnau, "Optimization of Low-Loss $\mathrm{Al}_{2} \mathrm{O}_{3}$ Waveguide Fabrication for Application in Active Integrated Optical Devices," in ECS Transactions (ECS, 2006), Vol. 3, pp. $17-26$

[7] J. Bradley, "Al $\mathrm{A}_{2} \mathrm{O}_{3}: \mathrm{Er}^{3+}$ as gain platform for integrated optics," University of Twente (2009)

[8] S. H. Waeselmann, S. Heinrich, C. Kränkel, and G. Huber, "Lasing of $\mathrm{Nd}^{3+}$ in sapphire," Laser Photon. Rev. 10, 510-516 (2016)

[9] J. C. Ding, T. F. Zhang, R. S. Mane, K.-H. Kim, M. C. Kang, C. W. Zou, and Q. M. Wang, "Lowtemperature deposition of nanocrystalline $\mathrm{Al}_{2} \mathrm{O}_{3}$ films by ion source-assisted magnetron sputtering," Vacuum 149, 284-290 (2018)

[10] V. Edlmayr, M. Moser, C. Walter, and C. Mitterer, "Thermal stability of sputtered $\mathrm{Al}_{2} \mathrm{O}_{3}$ coatings," Surf. Coatings Technol. 204, 1576-1581 (2010)

[11] E. O. Filatova and A. S. Konashuk, "Interpretation of the Changing the Band $\mathrm{Gap}_{\text {of }} \mathrm{Al}_{2} \mathrm{O}_{3}$ Depending on Its Crystalline Form: Connection with Different Local Symmetries," J. Phys. Chem. C 119, 20755-20761 (2015)

[12] X. Zhang, J. Zhu, L. Zhang, K. Kishimoto, S. Du, and X. Yin, "Crystallization of alumina films deposited by reactive magnetron sputtering with resputtering technique at low temperature," Surf. Coatings Technol. 228, S393-S396 (2013)

[13] Plansee, "Molybdenum," https://www.plansee.com/en/materials/molybdenum.html

[14] T. Satō, "Spectral Emissivity of Silicon," Jpn. J. Appl. Phys. 6, 339-347 (1967) 
List of publications 


\section{Journal articles}

- W.A.P.M Hendriks, M. Dijkstra, I. Hegeman, M.L. Stok, C.I. van Emmerik, M.J. Dikkers, S.M. García-Blanco, "Effect of temperature on the morphology and optical and optical properties of $\mathrm{Al}_{2} \mathrm{O}_{3}$ films" (in preparation)

- $\quad$ C.I. van Emmerik, J. Mu, W.A.P.M. Hendriks, L. Chang, M. de Goede, M. Dijkstra, S.M. García-Blanco, "Rare-earth ion doped $\mathrm{Al}_{2} \mathrm{O}_{3}$ for active integrated photonics" (submitted)

- $\quad$ C.I. van Emmerik, M.L. Stok, W.A.P.M. Hendriks, M. de Goede, L. Chang, M. Dijkstra, F. Segerink, D. Post, E.G. Keim, M.J. Dikkers and S.M. García-Blanco, "Relative oxidation state of the target as guideline for depositing optical quality $\mathrm{RF}$ reactive magnetron sputtered $\mathrm{Al}_{2} \mathrm{O}_{3}$ " (submitted)

- $\quad$ C.I. van Emmerik, R. Kooijman, M. Dijkstra and S.M. García-Blanco, "Lapping and polishing of crystalline $\mathrm{KY}\left(\mathrm{WO}_{4}\right)_{2}$ : toward high refractive index contrast slab waveguides” Micromachines, 10(10), 674 (2019)

- $\quad$ C.I. van Emmerik, R. Frentrop, F. Segerink, R. Kooijman, M. Muneeb, G. Roelkens, E. Ghibaudo, J-E. Broquin, and S.M. García-Blanco, "Heterogeneous integration of $\mathrm{KY}\left(\mathrm{WO}_{4}\right)_{2}-$ on-glass: a bonding study”, OSA Continuum, 2(6), 2065-2076 (2019)

- $\quad$ C.I. van Emmerik, M. Dijkstra, M. de Goede, L. Chang, J. Mu and S.M. García-Blanco, "Singlelayer active-passive $\mathrm{Al}_{2} \mathrm{O}_{3}$ photonic integration platform”, Optical Material Express, 8(10), 30493054 (2018)

\section{Conference proceedings}

- $\quad$ M.L. Stok, C.I. van Emmerik, W.A.P.M. Hendriks, M. de Goede, L. Chang, J. Mu, M. Dijkstra, S.M. García-Blanco, "RF sputtering deposition parameters influence on the optical properties of rare-earth ion doped $\mathrm{Al}_{2} \mathrm{O}_{3}$ layers for integrated photonics” Proc. SPIE OPTO, PW20O-OE11, San Francisco, (2020), Oral Presentation

- $\quad$ M. de Goede, L. Chang, J. Mu, C. van Emmerik, M. Dijkstra, and S.M. García-Blanco, "Rareearth ion doped $\mathrm{Al}_{2} \mathrm{O}_{3}$ on $\mathrm{Si}_{3} \mathrm{~N}_{4}$ platform for on-chip amplifiers and lasers," Proc. ICTON, Angers, France, (2019) Invited

- J. Mu, M. de Goede, C. van Emmerik, L. Chang, M. Dijkstra, S. M. García-Blanco, “On-chip amplifiers and lasers in the $\mathrm{Al}_{2} \mathrm{O}_{3}$ oxide platform,” Proc. PIERS, Rome, Italy (2019), Invited

- $\quad$ S.M. García-Blanco, C.I. van Emmerik, J. Mu, M. de Goede, M. Dijkstra, and L. Chang, "Onchip amplifiers and lasers on the $\mathrm{Al}_{2} \mathrm{O}_{3}$ integrated photonics platform", Proc. SPIE OPTO, 109230, San Francisco, (2019), Oral Presentation

- $\quad$ C.I. van Emmerik, M. Dijkstra, L. Chang, M. de Goede, J. Mu and Sonia M. Garcia-Blanco "Single-layer active-passive $\mathrm{Al}_{2} \mathrm{O}_{3}$ at the wafer level: optimization study" Proc. $23^{\text {th }}$ Ann. Symp. IEEE Phot. Soc. Benelux Chapter, Brussels, Belgium, (2018), Poster presentation

- $\quad$ C.I. van Emmerik, S.M. Martinussen, M. Dijkstra, J. Mu, R. Kooijman and S.M. García-Blanco, "A novel polishing stop for accurate integration of potassium yttrium double tungstate on silicon dioxide”, Proc. SPIE OPTO, 10535, San Francisco, USA, (2018), Oral presentation 
- $\quad$ C.I. van Emmerik, S.M. Martinussen, J. Mu, M. Dijkstra, S.M. García Blanco, “A novel polishing stop for accurate integration of potassium yttrium double tungstate on silicon dioxide," Proc.22 ${ }^{\text {th }}$ Ann. Symp. IEEE Phot. Soc. Benelux Chapter, Delft, The Netherlands, p184-187, (2017), Poster presentation

- $\quad$ C.I. van Emmerik, S.M. Martinussen, J. Mu, M.A. Sefünç, M. Dijkstra, S.M. García-Blanco, "Toward highly confined potassium double tungstate waveguides for laser applications", Proc. $21^{\text {th }}$ Ann. Symp. IEEE Phot. Soc. Benelux Chapter, Ghent, Belgium, p163-166, (2016), Poster presentation

- $\quad$ C.I. van Emmerik, S.M. Martinussen, J. Mu, M. Sefünç, M. Dijkstra and S.M. García-Blanco, “Towards, high contrast potassium double tungstate rib waveguides for laser applications," presented at the Physics@FOM, Veldhoven, The Netherlands, (2016), Poster presentation

\section{Other Contributions}

- $\quad$ Y-S Yong, J. Mu, M. de Goede, C. van Emmerik and S.M. García-Blanco, "Monolithic/heterogeneous integration of active materials in $\mathrm{Si}_{3} \mathrm{~N}_{4} / \mathrm{SiO}_{2}$ photonic platform" PhotonicNL Magazine (2018) 
Acknowledgements 
My $\mathrm{PhD}$ trajectory was an amazing journey where I was able to develop myself on personal, professional and scientific level. I would not have been able to finish this journey without the help and presence of numerous people.

Therefore, I want to thank first my supervisor Sonia García-Blanco for the opportunity to join the integrated Optical Sciences (iOS) subgroup as the first $\mathrm{PhD}$ student in the RENOS project. You have introduced me in a whole new world of optical engineering. Thank you for your support, the great discussions we had and the opportunities you gave me to develop myself.

I would also like to express my gratitude to Herman Offerhaus and Jennifer Herek for leading the Optical Sciences (OS) group and bringing the supportive, harmonic and colorful atmosphere in the group.

In the RENOS project I worked closely together with Raimond and Simon. Thank you, guys, for the discussions and 'crazy' ideas on how we could realize integrated $\mathrm{KY}\left(\mathrm{WO}_{4}\right)_{2}$ waveguide devices. Thank you too to Mustafa, Sergio, Yean-Sheng and Dimitri for all the knowledge you transferred to me about polishing of $\mathrm{KY}\left(\mathrm{WO}_{4}\right)_{2}$ and the optical set-up to measure devices.

Next, this list cannot be complete without the whole 'reactive sputtering team' (Sergio, Lantian, Jinfeng, Ward, Michiel, Ivo). It was a great team effort to develop and improve the fabrication of $\mathrm{Al}_{2} \mathrm{O}_{3}$ layers and novel active-passive integration schemas.

All the work would have been much harder without the great assistance of the support staff of OS (Karen, Jeroen, Frans and Meindert). I want to especially thank, Frans, for all the FIB sessions and to TEM preparations you have done and Meindert for great expertise and assistance in the cleanroom processes.

Then I want to extend thanks to my office mates Wooje and Pablo for the nice conversations and discussions. I want to especially thank, Martijn, for the great work you did during your Master assignment and it was a great pleasure to be your supervisor during this period. Further, I want to thank all Post-docs, summer students from Lorentz University and bachelor and master students that have visited the group.

Next, I want to sincerely show appreciation to multiple technicians from the university. Especially Roy Kooijman who helped me with the development of the lapping and polishing process. It was a great pleasure to work with you and to learn some of the tricks needed to be a good polisher. Further I want to thank all other members of TCO who worked on the development and realization of the customized laminar flow cabinet and shadow masks. I am also grateful for the opportunity to work in the MESA+ Cleanroom at the University of Twente and with the personalized help of all the cleanroom staff. Thanks to you all.

Then I want to thank Muhammad Muneeb from the University of Gent to invite me to visit your lab to learn more about bonding with BCB. Also thank you Jean-Emmanuel 
Broquin and Elise Ghibaudo for the direct bonding test you performed with $\mathrm{KY}\left(\mathrm{WO}_{4}\right)_{2}$ on glass.

I also want to express my gratitude to my committee members Prof. Jean-Emmanuel Broquin, Prof. Delphine Marris-Morini, Prof. Lis Nanver, Prof. Guus Rijnders, Assoc. Prof. Alexey Kovalgin and Assoc. Prof. Herman Offerhaus for their time to review my thesis.

Further, I want to thank Koen and Ido Middelkamp, from “All it Takes” personal training for the personal approach to get me fit and to 'become who you want to be' and all other trainers for the challenging and inspiring training sessions. I also want to thank Ben and Ria Middelkamp for the mental coaching training sessions to learn about 'GEWOON DOEN'. I also want to thank my French horn, piano and clarinet teachers (Rianne, Wouter and Rieke) for all the inspiring lessons. I am also thankful that I have learned how to draw mandalas from my grandmother Lydia when I was young. Further, I want to thank Anne for the friendship and support during our $\mathrm{PhD}$ and study time. The sports, music and drawing activities made me able to relax and recharge from the sometimes hectic PhD live.

Last but not least, I want to thank my grandparents (Lieuwe en Gé) for their support and interesting stories from my grandfather about the early years of the UT. And finally, I want to thank my father, mother and brother (Pieter, Korrie and Lourens) for their support and guidance during this journey. 
